Florida International University FIU Digital Commons

$11-8-2016$

\title{
Mercury Sulfide Dissolution in Environmental Conditions: Thermodynamic and Kinetic Approaches
}

Ping Jiang

Department of Chemistry \& Biochemistry, pjian002@fiu.edu

DOI: $10.25148 /$ etd.FIDC001206

Follow this and additional works at: https:// digitalcommons.fiu.edu/etd

Part of the Analytical Chemistry Commons, and the Environmental Chemistry Commons

\section{Recommended Citation}

Jiang, Ping, "Mercury Sulfide Dissolution in Environmental Conditions: Thermodynamic and Kinetic Approaches" (2016). FIU

Electronic Theses and Dissertations. 3027.

https://digitalcommons.fiu.edu/etd/3027

This work is brought to you for free and open access by the University Graduate School at FIU Digital Commons. It has been accepted for inclusion in FIU Electronic Theses and Dissertations by an authorized administrator of FIU Digital Commons. For more information, please contact dcc@fiu.edu. 


\title{
FLORIDA INTERNATIONAL UNIVERSITY
}

Miami, Florida

\section{MERCURY SULFIDE DISSOLUTION IN ENVIRONMENTAL CONDITIONS:}

THERMODYNAMIC AND KINETIC APPROACHES

\author{
A dissertation submitted in partial fulfillment of \\ the requirements for the degree of \\ DOCTOR OF PHILOSOPHY \\ in \\ CHEMISTRY
}

by

Ping Jiang

2016 
To: Dean Michael R. Heithaus

College of Arts, Sciences and Education

This dissertation, written by Ping Jiang, and entitled Mercury Sulfide Dissolution in Environmental Conditions: Thermodynamic and Kinetic Approaches, having been approved in respect to style and intellectual content, is referred to you for judgment.

We have read this dissertation and recommend that it be approved.

Rudolf Jaffé

Bruce McCord

Martin Quirke

Georgio Tachiev

Yong Cai, Major Professor

Date of Defense: November 8, 2016

The dissertation of Ping Jiang is approved.

Dean Michael R. Heithaus

College of Arts, Sciences and Education

Andrés G. Gil

Vice President for Research and Economic Development

And Dean of the University Graduate School

Florida International University, 2016 
(C) Copyright 2016 by Ping Jiang

All rights reserved. 


\section{DEDICATION}

I dedicate this work to my husband Changjun Fan, my son Aaron Fan, my parents, and my grandma. Without their understanding, encouragement, support and love, the completion of this work would not have been possible. 


\section{ACKNOWLEDGMENTS}

In the past over five years of graduate study at FIU, I am so grateful for the valuable assistance from many people. First of all, I would like to thank my major professor, Dr. Yong Cai, for his incredible supervision, guidance and endless encouragement.

I am very grateful to Dr. Rudolf Jaffé, Dr. Bruce McCord, Dr. Martin Quirke, and Dr. Georgio Tachiev for their willingness to serve as my committee members. I appreciate their valuable time, insightful advices, and precious suggestions to my research. I would like to thank Dr. Guangliang Liu, Dr. Yanbin Li, and Dr. Guidi Yang for all helpful suggestion and discussion.

I would like to express my sincere thanks to Department of Chemistry \& Biochemistry at Florida International University for the Teaching Assistant Fellowship during the five and half years.

I would like to thank my lab mates for their support and patience. My five and half years are full of great memories because of you. I also would like to thank my family for their endless support and love.

Finally, I wish to express my appreciation to those who have helped me in any respect during my study at FIU, as well as expressing my apology that I could not mention personally one by one. 


\title{
ABSTRACT OF THE DISSERTATION \\ MERCURY SULFIDE DISSOLUTION IN ENVIRONMENTAL CONDITIONS: \\ THERMODYNAMIC AND KINETIC APPROACHES
}

\author{
by \\ Ping Jiang \\ Florida International University, 2016 \\ Miami, Florida \\ Professor Yong Cai, Major Professor
}

Mercury $(\mathrm{Hg})$ is a global contaminant of ecosystems and human health risk, with complicated biogeochemical processes. Mercury sulfide $(\mathrm{HgS})$ dissolution has been suggested as a key process in $\mathrm{Hg}$ cycling, as it could potentially increase the pool of inorganic $\mathrm{Hg}$ (iHg) for the production of methylmercury $(\mathrm{MeHg})$. Despite previous sporadic observations of enhanced $\mathrm{HgS}$ dissolution under certain conditions, much remains unclear on mechanisms of $\mathrm{HgS}$ dissolution. The objective of my research was to advance the mechanistic understanding of $\mathrm{HgS}$ dissolution, concerning re-adsorption of released $\mathrm{Hg}$, effects of thiol-ligands, and $\mathrm{Hg}$ speciation.

Considering the lack of feasible techniques to differentiate dissolution and readsorption processes, I first developed an efficient method using isotope tracer and isotope dilution techniques to investigate the re-adsorption of released $\mathrm{Hg}$ during $\mathrm{HgS}$ dissolution. The HgS dissolution rate with consideration of re-adsorption was two times the rate calculated from detecting $\mathrm{Hg}$ alone in the presence of $\mathrm{O}_{2}$, indicating the importance of $\mathrm{Hg}$ re-adsorption during $\mathrm{HgS}$ dissolution. I further examined the role of $\mathrm{Hg}$-ligand complexation in $\mathrm{HgS}$ dissolution and $\mathrm{Hg}(\mathrm{II})$ re-adsorption using a thermodynamic 
adsorption method, selecting L-cysteine (Cys) as a model compound for low molecular weight ligands and Waskish fulvic acid (FA) for natural dissolved organic matter (DOM). My results suggest that the presence of Cys enhanced $\mathrm{HgS}$ dissolution through the decreased re-adsorption of $\mathrm{Hg}$-Cys complex, whereas Waskish FA inhibited $\mathrm{HgS}$ dissolution, possibly because of the adsorption of FA on $\mathrm{HgS}$ surface that covered dissolution sites.

I further employed a geochemical modeling method to study $\mathrm{Hg}$ speciation and the relation of $\mathrm{iHg}$ speciation to $\mathrm{MeHg}$, aiming to provide a methodological example for potentially evaluating the implications of $\mathrm{Hg}$ species distribution during $\mathrm{HgS}$ dissolution on MeHg production. I applied geochemical model PHREEQC to the Florida Everglades, a well-studied wetland with model input parameters available, to determine the distribution of iHg in surface water at different sites. The modeling results suggest that sulfide and DOM govern iHg speciation, and the $\mathrm{Hg}$-sulfide and $\mathrm{Hg}$-DOM species are related to $\mathrm{MeHg}$ in environmental media but not fish, suggesting the importance of $\mathrm{iHg}$ speciation in $\mathrm{MeHg}$ production and the complexity of $\mathrm{Hg}$ bioaccumulation. 


\section{TABLE OF CONTENTS}

CHAPTER

PAGE

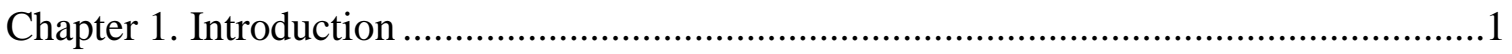

1.1 Source, exposure and toxicity of mercury …………......................................... 1

1.2 Mercury biogeochemical cycling in the environment ........................................... 3

1.2.1 Mercury in the air ........................................................................... 3

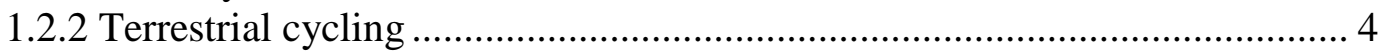

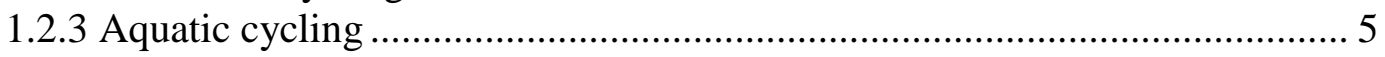

1.3 Mercury sulfide ( $\mathrm{HgS})$ as a sink for $\mathrm{Hg}$ cycling in the environment ...................... 6

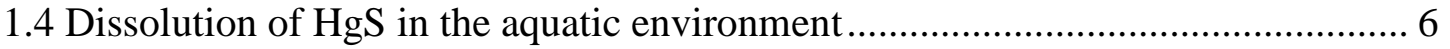

1.4.1 Enhanced $\mathrm{HgS}$ dissolution in the environment............................................ 7

1.4.2 Re-adsorption of dissolved $\mathrm{Hg}$ on $\mathrm{HgS}$ surface ...................................... 8

1.4.3 Isotope tracer technique and its potential applications in $\mathrm{HgS}$ dissolution

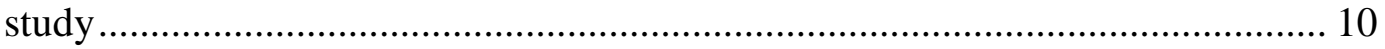

1.4.4 Release of $\mathrm{Hg}$ from $\mathrm{HgS}$ dissolution and its implications on $\mathrm{Hg}$ cycling ... 11

1.5 Geochemical modeling on $\mathrm{Hg}$ speciation and cycling ......................................... 12

1.5.1 Determination of $\mathrm{Hg}$ species in aquatic systems ...................................... 12

1.5.2 Geochemical modeling methods for $\mathrm{Hg}$ studies ......................................... 13

1.5.3 Geochemical modeling of $\mathrm{Hg}$ speciation in the Florida Everglades............ 15

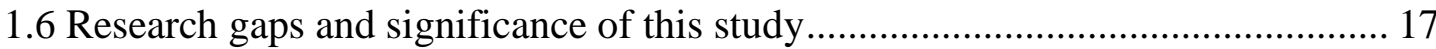

1.7 Objectives, hypotheses, and approaches ........................................................... 18

Chapter 2. Evaluating the Role of Re-adsorption of Dissolved $\mathrm{Hg}^{2+}$ during Cinnabar Dissolution Using Isotope Tracer Technique …………................................................21

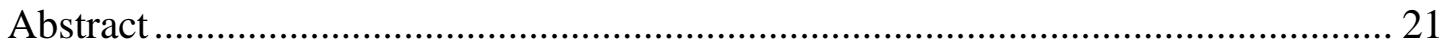

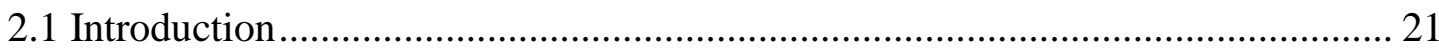

2.2 Experimental methods .............................................................................. 25

2.2.1 Pretreatment of cinnabar and selection of filters ....................................... 25

2.2.2 Simultaneous determination of cinnabar dissolution and $\mathrm{Hg}^{2+}$

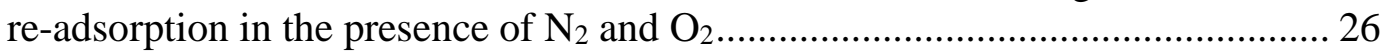

2.2.3 Thermodynamics of $\mathrm{Hg}$ adsorption on cinnabar........................................ 27

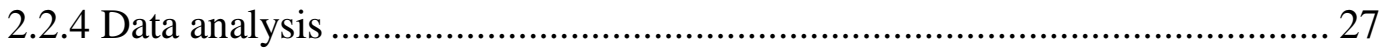

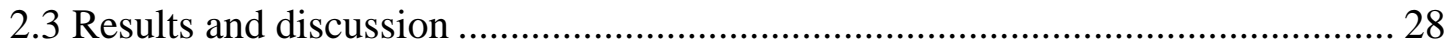

2.3.1 Developing a method for simultaneously monitoring $\mathrm{Hg}$ adsorption and dissolution using isotope dilution and isotope tracer technique ............................ 28 2.3.2 Applying the developed technique to study cinnabar dissolution and $\mathrm{Hg}^{2+}$

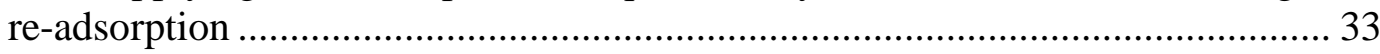

2.3.3 Thermodynamics of $\mathrm{Hg}$ adsorption on cinnabar and validation of the

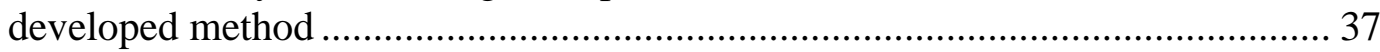

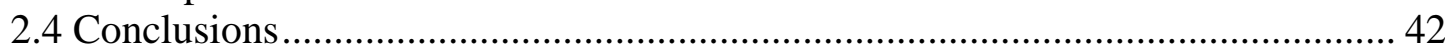

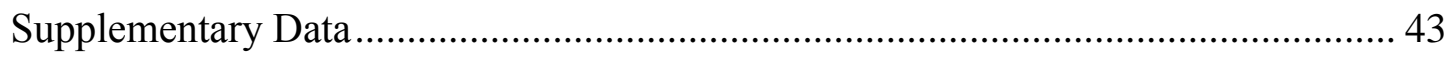


Chapter 3. Effects of Thiol-containing Ligands on Cinnabar Dissolution and Re-

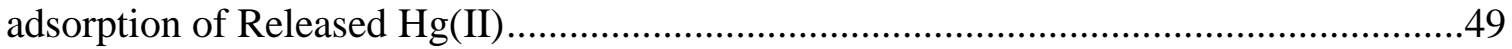

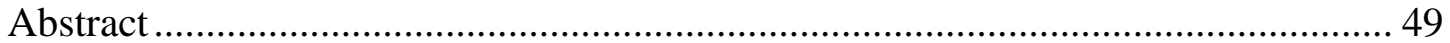

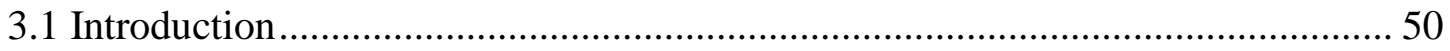

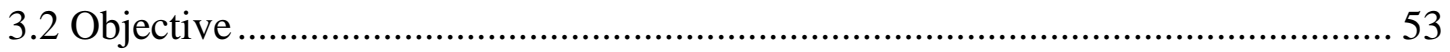

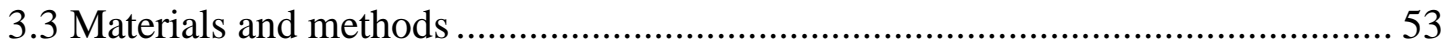

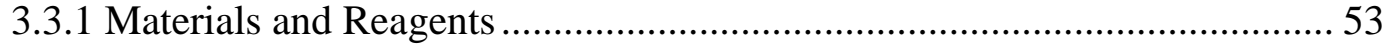

3.3.2 Derivatization of L-cysteine with SBD-F ............................................ 54

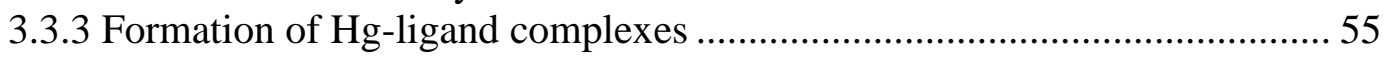

3.3.4 Adsorption of Hg-cysteine complex on cinnabar surface ......................... 56

3.3.5 The role of Hg-FA complexes in cinnabar dissolution ............................. 57

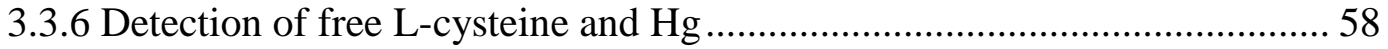

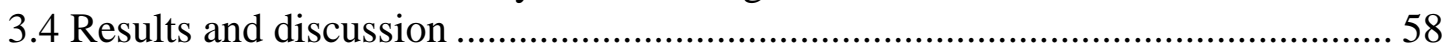

3.4.1 Derivatization of L-cysteine with SBD-F ........................................... 58

3.4.2 Determination of $\mathrm{Hg}$ and $\mathrm{L}$-cysteine complexing ratio ............................ 59

3.4.3 Adsorption of $\mathrm{Hg}$-cysteine complexes on cinnabar surface .......................62 62

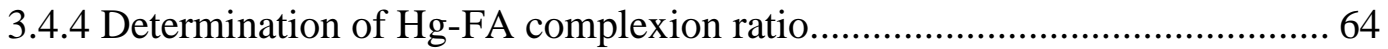

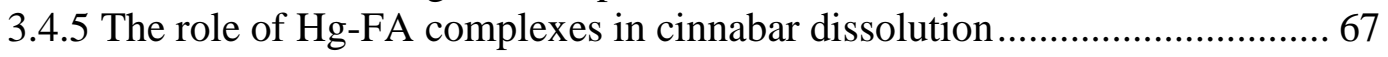

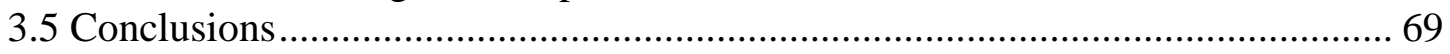

Chapter 4. Geochemical Modeling of Mercury Speciation in Surface Water and Implications on Mercury Cycling in the Florida Everglades ........................................71

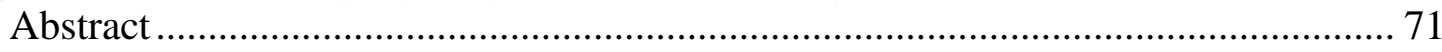

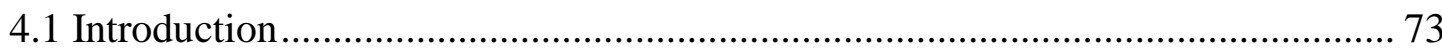

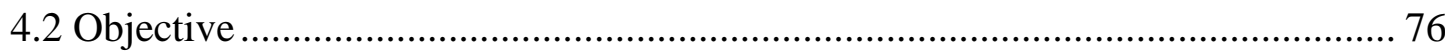

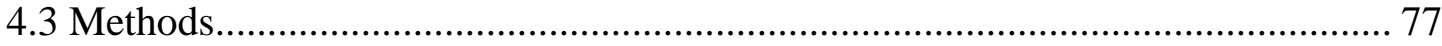

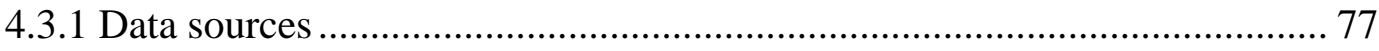

4.3.2 Determination of $\mathrm{THg}, \mathrm{MeHg}$, and other ancillary parameters ................... 80

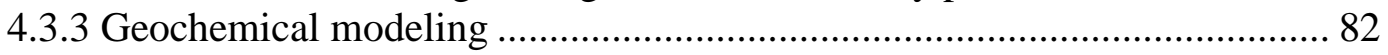

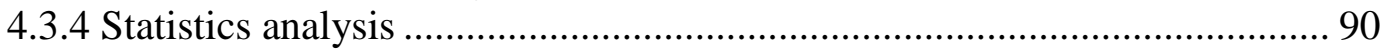

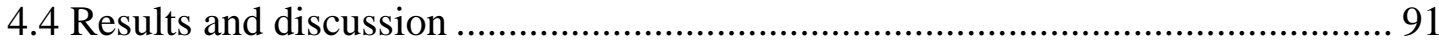

4.4.1 Distribution of inorganic $\mathrm{Hg}$ species in surface water............................. 91

4.4.2 Inorganic $\mathrm{Hg}$ species in surface water and $\mathrm{MeHg}$ in different media........ 102

4.4.3 The influences of $\mathrm{Hg}$ species on bioavailability and bioaccumulation...... 110

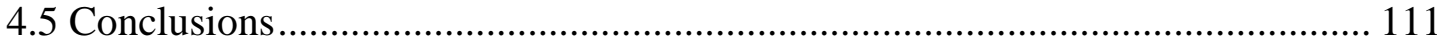

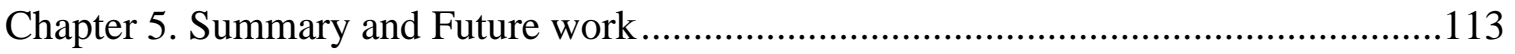

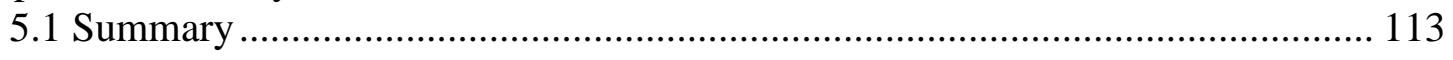

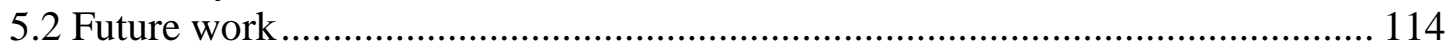

References................................................................ 116

Appendices.............................................................. 132

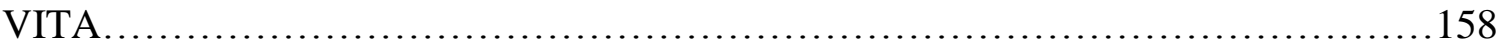




\section{LIST OF TABLES}

TABLE

PAGE

Table 2.1 Parameters of adsorption kinetics and isotherms of $\mathrm{Hg}$ on cinnabar using different models (in the absence of $\mathrm{O}_{2}$ ) and dissolution (in the present of $\mathrm{O}_{2}$ ) 38

Table 3.1 Comparisons of parameters of adsorption isotherm between $\mathrm{Hg}$ and $\mathrm{Hg}$-Cys on cinnabar.

Table 4.1 List of biogeochemical parameters used in the modeling and the concentration ranges found in the Everglades surface water.

Table 4.2 The reactions and equilibrium constants of Hg available in PHREEQC (200). 87

Table 4.3 Spearman's correlation matrix - coefficients between concentrations of $\mathrm{Hg}$ species and methylmercury in various ecosystem compartments in dry and wet seasons with measurable sulfide.

Table 4.4 Spearman's correlation matrix - coefficients and sample numbers between concentrations of $\mathrm{Hg}$ species in surface water and $\mathrm{MeHg}$ in various ecosystem compartments in both seasons $\left(\left[\mathrm{S}^{2-}\right]=3.2 \times 10^{-7} \mathrm{mg} / \mathrm{L}\right)$.

Table 4.5 Spearman's correlation matrix - coefficients and sample numbers between concentrations of $\mathrm{Hg}$ species and $\mathrm{MeHg}$ in various ecosystem compartments in both seasons $\left(\left[\mathrm{S}^{2-}\right]<<3.2 \times 10^{-7} \mathrm{mg} / \mathrm{L}\right)$

Table 4.6 Spearman's correlation matrix - coefficients and sample numbers between concentrations of $\mathrm{Hg}$ species in surface water and $\mathrm{MeHg}$ in fish in both seasons. 


\section{LIST OF FIGURES}

FIGURE

PAGE

Figure 1.1 Conceptual biogeochemical cycling of mercury in the environment.

Figure 2.1 A schematic showing the procedure of simultaneously monitoring the dissolution of cinnabar and re-adsorption of released $\mathrm{Hg}$ using isotope tracer and isotope dilution techniques. 25

Figure 2.2 Variations of spiked ${ }^{202} \mathrm{Hg}^{2+}$ in aqueous phase (CXaq), $\mathrm{Hg}$ dissolved from cinnabar in aqueous phase (Cdaq), and the total $\mathrm{Hg}$ dissolved from cinnabar (Cdtot). $A$ and $\mathrm{C}$, purged with $\mathrm{N}_{2} ; \mathrm{B}$ and $\mathrm{D}$, purged with $\mathrm{O}_{2}$. Since Cdaq at time 0 was likely resulted from the isotopic replacement of natural $\mathrm{Hg}$ adsorbed on cinnabar by the spiked ${ }^{202} \mathrm{Hg}^{2+}$, rather than the cinnabar dissolution, this $\mathrm{Hg}$ was deducted from the measured Cdaq when calculating the total released $\mathrm{Hg}$ from cinnabar (Cdtot).

Figure 2.3 Nonlinear regressions of spiked ${ }^{202} \mathrm{Hg}(\mathrm{A})$, total dissolved $\mathrm{Hg}(\mathrm{B})$, and dissolved $\mathrm{Hg}$ in the aqueous phase $(\mathrm{C})$ against time.

Figure 2.4 The thermodynamic of ${ }^{202} \mathrm{Hg}^{2+}$ adsorption on cinnabar. A, variation of equilibrium concentrations of ${ }^{202} \mathrm{Hg}\left(\mu \mathrm{g} \mathrm{L}^{-1}\right)$ at $24 \mathrm{~h}$ with different initial ${ }^{202} \mathrm{Hg}^{2+}$ concentrations $\left(0,10,20,50,100,200,400 \mu \mathrm{g} \mathrm{L}^{-1}\right)$. B, non-linear regression of $\mathrm{q}_{\mathrm{e}}$ against $\mathrm{C}_{\mathrm{e}}$ using Langmuir and Freundlich models $\left(\mathrm{T}=20^{\circ} \mathrm{C}\right)$. 41

Figure 2.5 Comparisons of total dissolved $\mathrm{Hg}$ estimated by the thermodynamic equilibrium using Langmur model (Eq.2.12) and by the new method developed in this study (Eq. 2.7). A, without $\mathrm{O}_{2}$ (purging with $\mathrm{N}_{2}$ ); B, with $\mathrm{O}_{2}$ (purging with $\mathrm{O}_{2}$ )..... 41

Figure 3.1 Possible reactions involved in cinnabar dissolution in the presence of DOM. 51

Figure 3.2 The effect of concentration of SBD-F on fluorescence response of the derivative of L-cysteine.

Figure 3.3 The effect of $\mathrm{HgNO}_{3}$ and cysteine molar ratio on the SBD-Cys fluorescent response of L-Cysteine.

Figure 3.4 Adsorption isotherm of $\mathrm{Hg}\left(\mathrm{HgNO}_{3}\right)$ and $\mathrm{Hg}$-cysteine complex on cinnabar in $\mathrm{NaH}_{2} \mathrm{PO}_{4} / \mathrm{Na}_{2} \mathrm{HPO}_{4}$ buffer $(0.005 \mathrm{M}, \mathrm{pH} 8), \mathrm{t}=20{ }^{\circ} \mathrm{C}$.

Figure 3.5 The percentage of $\mathrm{Hg}$ bound with $\mathrm{FA}$ with different mass ratios of $\mathrm{Hg}$ to FA at 1,24 and 72 hours. 
Figure 3.6 Concentrations of released $\mathrm{Hg}$ as unbound $\mathrm{Hg}$, bound $\mathrm{Hg}$, and total $\mathrm{Hg}$ from

cinnabar dissolution at $24 \mathrm{~h}$ in the presence of $1,2.5,5,10$, and $20 \mathrm{mg} / \mathrm{L}$ of FA. 69

Figure 4.1 A map showing sampling sites in the Florida Everglades during the dry (spring) and wet season (fall) in 2005.

Figure 4.2 The percentages of $\mathrm{Hg}$ species in surface water of Florida Everglades in dry and wet seasons of 2005 at stations where sulfide concentrations were $>0.02 \mathrm{mg} / \mathrm{L} \ldots \ldots . .92$

Figure 4.3 Variations of percentages of $\mathrm{Hg}$ species in surface water of Florida Everglades in dry and wet seasons of 2005 at stations where sulfide concentrations were $>0.02 \mathrm{mg} / \mathrm{L}$

Figure 4.4 Sulfide concentrations $(\mathrm{mg} / \mathrm{L})$ in pore water and surface water from the Florida Everglades during both seasons (please note that the detection limit is 0.02 $\mathrm{mg} / \mathrm{L})$.......

Figure 4.5 Sulfate concentrations $(\mathrm{mg} / \mathrm{L})$ in pore water and surface water from the Florida Everglades during both seasons.

Figure 4.6 DOC concentrations (mg/L) in surface water from the Florida Everglades in dry season and wet season.

Figure 4.7 The percentages of $\mathrm{Hg}$ species in surface water of Florida Everglades in dry and wet seasons of 2005 at stations where sulfide concentrations were $<0.02 \mathrm{mg} / \mathrm{L}$ and assigned $3.2 \times 10^{-7} \mathrm{mg} / \mathrm{L}$ 


\section{ABBREVIATIONS AND ACRONYMS}

Cys Cysteine

CVAFS Cold vapor atomic fluorescence spectrometry

DOM Dissolved organic matter

DOC Dissolved organic carbon

Eh Redox potential

EDTA Ethylenediaminetetraacetic acid

EPA/USEPA The United States Environmental Protection Agency

FA Fulvic acid

FDEP Florida Department of Environmental Protection

HA Humic acid

$\mathrm{Hg} \quad$ Mercury

$\mathrm{Hg}(\mathrm{I}) \quad$ Monovalent $\mathrm{Hg}$

$\operatorname{Hg}(0) \quad$ Elemental mercury

$\mathrm{Hg}(\mathrm{II}) \quad$ Inorganic divalent mercury

$\mathrm{HgS} \quad$ Mercury sulfide

IRB Iron reducing bacteria

LMW Low molecular weight

$\mathrm{MeHg} \quad$ Methylmercury

$\mathrm{Me}_{2} \mathrm{Hg} \quad$ Dimethylmercury

$\mathrm{pHg} \quad$ Particulate mercury

$\mathrm{pH}_{\mathrm{pzc}} \quad \mathrm{pH}$ at the point of zero charge

R-EMAP Regional Environmental Monitoring and Assessment Program 


$\begin{array}{ll}\text { RGM } & \text { Reactive gaseous mercury } \\ \text { SBD-F } & \text { Ammonium 7-fluorobenzo-2-oxa-1, 3-diazole-4-sulphonate } \\ \text { SRB } & \text { Sulfate reducing bacteria } \\ \text { SOPs } & \text { Standard operating procedures } \\ \text { SESD } & \text { Science and Ecosystem Support Division } \\ \text { THg } & \text { Total concentration of mercury } \\ \text { UNEP } & \text { United Nations Environment Program } \\ \text { USGS } & \text { The U.S. Geological Survey } \\ \alpha-H g S \text { (red) } & \text { Cinnabar } \\ \beta-H g S \text { (black) } & \text { Metacinnabar }\end{array}$




\section{Chapter 1. Introduction}

\subsection{Source, exposure and toxicity of mercury}

Mercury (Hg) is one of the most important global contaminants (1). Both natural (e.g., volcanic activity, weathering of geologically $\mathrm{Hg}$-enriched soil, and forest fires) and anthropogenic (e.g., the burning of fossil fuels and incinerating of municipal or medical waste) processes can lead to mercury contamination (2-6). Mercury can exist in three oxidation states $(0,+1,+2)$ in the natural environment. The only stable monovalent $\mathrm{Hg}$ $(\mathrm{Hg}(\mathrm{I}))$ is in the form of dimer $\left(\mathrm{Hg}_{2}{ }^{2+}\right)$, which can disproportionate to $\mathrm{Hg}(0)$ and $\mathrm{Hg}(\mathrm{II})$ readily (7). The dominant chemical forms of $\mathrm{Hg}$ in general in the environment are elemental mercury $(\mathrm{Hg}(0))$, inorganic divalent mercury $(\mathrm{Hg}(\mathrm{II}))$, and organic $\mathrm{Hg}$, mainly methylmercury $\left(\mathrm{MeHg}\right.$ or $\left.\left[\mathrm{CH}_{3} \mathrm{Hg}\right]^{+}\right)$and dimethylmercury $\left(\mathrm{Me}_{2} \mathrm{Hg}\right.$ or $\left.\left(\mathrm{CH}_{3}\right)_{2} \mathrm{Hg}\right)$. More than $95 \%$ of mercury in the atmosphere is $\operatorname{Hg}(0)$ because of its relatively low deposition velocity and high vapor pressure (8). Inorganic $\mathrm{Hg}(\mathrm{II})$ is the dominant form of mercury in water, soil, and sediment and can be methylated to the toxic MeHg through microbemediated (e.g., sulfate reducing bacteria, SRB or iron reducing bacteria, IRB) and abiotic processes $(7,9,10)$. Because of its lipophilic and protein-binding properties, $\mathrm{MeHg}$ is then easily accumulated by aquatic biota through the food web (7).

All $\mathrm{Hg}$ forms, in particular the organomercury species, are highly toxic substances (11). Acute $\mathrm{Hg}$ exposure can produce permanent damage to the nervous and other systems to cause a range of symptoms such as paresthesia, ataxia, sensory disturbances, tremors, renal toxicity, myocardial infarction, and even death (12). Chronic $\mathrm{Hg}$ exposure was considered to mainly occur from the consumption of contaminated fish and other aquatic organisms $(13,14)$. Rice is another important pathway for human exposure to $\mathrm{MeHg}$ in recent years. 
This was first discovered in Guizhou province, China, and it potentially exists elsewhere (15-17). The toxicity of $\mathrm{Hg}$ depends on the chemical form and the sources of exposure (11). The most dangerous mercury species is $\mathrm{MeHg}$, which is obtained mainly from the diet and can be almost completely absorbed into blood and then be distributed to other organs in the human body, such as brain, kidney, liver, hair, and other tissues within a few days (18). The biological half-life of $\mathrm{MeHg}$ in blood was estimated to be 80.2 days (19), much longer than that of inorganic $\mathrm{Hg}$ in blood (20). Methylmercury can readily cross the placenta and blood-brain barrier to cause irreversible damage to the developing central nervous systems of the fetus (21).

To control $\mathrm{Hg}$ releases and limit its use and exposures, efforts involving new legislation has been enacted in the United States and other countries. Reductions of $\mathrm{Hg}$ releases from industry were achieved based on this work (11). Successful control of $\mathrm{Hg}$ pollution requires global action because $\mathrm{Hg}$ can move through air and water(1). Therefore, domestic efforts might not be sufficient to address the adverse effects of $\mathrm{Hg}$ pollution (11). The United Nations Environment Program (UNEP) called for the establishment of a Global Mercury Partnership to protect human health and global environment from $\mathrm{Hg}$ pollution since 2005 . Under assistance of the partnership and after five negotiating sessions of the intergovernmental negotiating committee from 2010 to 2013, an historic agreement called 'The Minamata Convention on Mercury' was reached and signed by 92 governments to help reduce the risks from toxic effects of $\mathrm{Hg}$ to hundreds of millions of people worldwide (22). 


\subsection{Mercury biogeochemical cycling in the environment}

The atmospheric, aquatic and terrestrial environments are all recipients of $\mathrm{Hg}$ releasing to the environment (11). The input of $\mathrm{Hg}$ from natural and anthropogenic activities can redistribute $\mathrm{Hg}$ in the atmosphere, terrestrial, and aquatic systems through complex $\mathrm{Hg}$ transport and transformation processes (11). Once entering the environment, $\mathrm{Hg}$ can undergo long-range transport in the atmosphere and widely spread in aquatic and terrestrial ecosystems. A variety of processes occur with $\mathrm{Hg}$ transport (e.g., evaporation, dissolution, precipitation, and uptake by organisms) and transformation (e.g., methylation/demethylation, oxidation/reduction). The $\mathrm{Hg}$ movements can be conceptualized as a mercury cycle (Figure 1.1) (23).

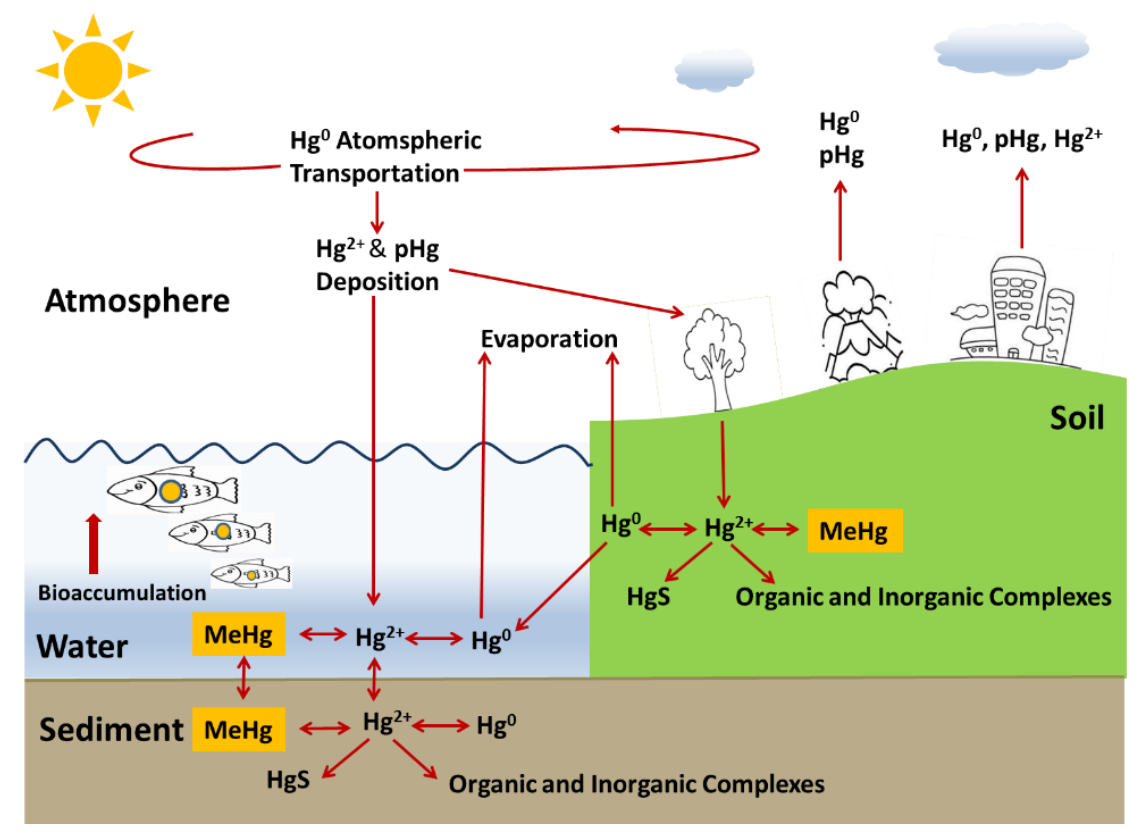

Figure 1.1 Conceptual biogeochemical cycling of mercury in the environment.

\subsubsection{Mercury in the air}

The atmosphere is the most important media for the global transport and dispersion of $\mathrm{Hg}$ (24). Atmosphere Hg exists primarily as three inorganic forms: gaseous elemental 
mercury $(\mathrm{Hg}(0))$; reactive gaseous mercury (RGM) (e.g., $\mathrm{HgCl}_{2}, \mathrm{Hg}(\mathrm{OH})_{2}$, or compounds of the other halides); and particulate mercury (pHg) (25). Elemental $\mathrm{Hg}$, the dominant form in the atmosphere, is slowly oxidized to the mercuric state. Most of this oxidation occurs in the aqueous phase of the atmosphere (e.g., water droplets in clouds) by reaction with ozone $\left(\mathrm{O}_{3}\right)$, hydroxyl radicals $(\mathrm{OH})$, or hydrogen peroxide $\left(\mathrm{H}_{2} \mathrm{O}_{2}\right)$. Gas-phase oxidation reactions of $\mathrm{Hg}(0)$ to $\mathrm{Hg}(\mathrm{II})$ by $\mathrm{O}_{3}, \mathrm{Cl}_{2}$, and $\mathrm{H}_{2} \mathrm{O}_{2}$ may also be important. Some of the $\mathrm{Hg}(\mathrm{II})$ produced in the atmosphere is re-reduced by mechanisms involving $\mathrm{SO}_{2}(\mathrm{~g})(26)$. Once released to the atmosphere, $\operatorname{Hg}(0)$ is subject to long-distance air transport over a global scale with a long atmosphere life time of about 0.5-1.5 years (27). Mercury(II) is a highly surface reactive species and deposits much faster than $\mathrm{Hg}(0)$ through both dry and wet processes on the earth's surface with shorter atmosphere lifetimes, typically from minutes to weeks (26).

\subsubsection{Terrestrial cycling}

Wet and dry depositions are major pathways to transfer $\mathrm{Hg}$ and its compounds from the atmosphere to terrestrial and aquatic environments (11). Both RGM and $\mathrm{pHg}$ can be deposited by dry and wet deposition at significant rates $\mathrm{Hg}(0)$ dry deposition, while RGM can be removed more rapidly than $\mathrm{pHg}$ and $\mathrm{Hg}(0)$ because of its characteristics of reactivity and water solubility (28). Upon deposition, a portion of $\mathrm{Hg}$ on the surface of land can rapidly volatilize back to the atmosphere, while the rest is incorporated into the soil pool with long retention time (29). In the long periods of time, up to hundreds of years are required for $\mathrm{Hg}$ to release from soil to surface water and other media (11). In the terrestrial system, the majority of $\mathrm{Hg}$ is bound to soils and associated with minerals and organic matter, in particular thiol-containing organic matter (30). Mercury can return back to the 
atmosphere by forming volatile $\mathrm{Hg}(0)$ through reduction of $\mathrm{Hg}(\mathrm{II})$ in soil, subsequent diffusion or mass transport. Other pathways of $\mathrm{Hg}$ returning to the atmosphere from soil can also be involved, e.g., burning of organic matter (29).

\subsubsection{Aquatic cycling}

The predominant form of $\mathrm{Hg}$ resulting from wet and dry deposition to watersheds, lake surfaces, or oceans is $\operatorname{Hg}(\mathrm{II})$ as it is in terrestrial systems (31), with a minor portion consisting of $\mathrm{Hg}(0)$ and organic mercury (9). Once in aquatic ecosystems, $\mathrm{Hg}(\mathrm{II})$ exists in dissolved and/or particulate forms, and can undergo various chemical and physical transformations $(18,23)$. The reduction of $\mathrm{Hg}(\mathrm{II})$ to $\mathrm{Hg}(0)$ can be initiated by aquatic microorganisms (32) or by abiotic processes facilitated by light and/or humic substance (33). Then the formed $\mathrm{Hg}(0)$ is easily volatilized into the atmosphere (25). In addition to redox transformations, methylation can convert $\mathrm{Hg}(\mathrm{II})$ to $\mathrm{MeHg}$, subsequently demethylation of $\mathrm{MeHg}$ can also occurs (7). Once $\mathrm{Hg}$ is converted into $\mathrm{MeHg}$, which is more toxic, it can be readily taken up by aquatic organisms and bioaccumulated through the aquatic food chain (18). As MeHg can accumulate in fish tissue to high levels, it poses high risk to human beings through fish consumption. It is widely accepted that the methylation of $\mathrm{Hg}(\mathrm{II})$ is mainly driven by microbially mediated processes near sediments. Sulfate reducing bacteria (SRB) have long been considered as the primary methylators $(34$, 35). Redox potential (Eh), $\mathrm{pH}$ condition, as well as the concentration of inorganic and organic complexing ligands strongly influence the physical and chemical forms of $\mathrm{Hg}(\mathrm{II})$ $(7,36)$ and therefore the rate and efficiency of methylation. In addition to the methylation mediated by microorganisms, abiotic processes may also be involved in the conversion of $\mathrm{Hg}$ (II) to $\mathrm{MeHg}$ (37-39). The reverse process of methylation, demethylation usually occurs 
simultaneously with methylation (10). Similar to methylation process, both biotic $(40,41)$ and abiotic (42-44) pathways can convert $\mathrm{MeHg}$ to $\mathrm{Hg}(\mathrm{II})$ with the former one dominant. Methanogens and SRB could be involved as the primary microorganisms in the demethylation process $(41,45,46)$. In aquatic systems, mercury sulfide $(\mathrm{HgS})$ is the main insoluble inorganic $\mathrm{Hg}$ compound. The reduction of sulfate to sulfide has been suggested as the cause of $\mathrm{HgS}$ formation (47) This process limits the bioavailability of $\mathrm{Hg}$ in anaerobic sediments, which could reduce methylation efficiency.

\subsection{Mercury sulfide (HgS) as a sink for $\mathrm{Hg}$ cycling in the environment}

There are two polymorphs for $\mathrm{HgS}$ : cinnabar (red $\mathrm{HgS}$, hexagonal) and metacinnabar (black $\mathrm{HgS}$, cubic). Cinnabar is the principal ore of mercury $(48,49)$, and metacinnabar is one of the largest sinks for $\mathrm{Hg}$ in the environment in sulfidic waters, $\mathrm{Hg}$-contaminated floodplain soils and sediments $(47,50)$. Cinnabar is the thermodynamically stable form at low temperature (51). The mobility, reactivity, and potential bioavailability of $\mathrm{Hg}$ are determined by its speciation in $\mathrm{Hg}$ contaminated regions (49). Mercury sulfide has been considered as the most insoluble and least leachable $\mathrm{Hg}$ species because of its low solubility product constant $\left(\mathrm{k}_{\mathrm{sp}}=10^{-55.9 \sim-50.9}\right)(52)$. Formation of mercury sulfide is an important step in the geochemical cycle of $\mathrm{Hg}$, inhibiting $\mathrm{Hg}(\mathrm{II})$ methylation and bioaccumulation (53), and immobilizing mercury $\mathrm{Hg}(\mathrm{II})$ in sediments. Therefore, it is traditionally believed that mercury sulfide is formed as a sink for $\mathrm{Hg}$ cycling in the environment $(47,54,55)$.

\subsection{Dissolution of HgS in the aquatic environment}

The assumption that $\mathrm{HgS}$ is a permanent sink of $\mathrm{Hg}$ in the aquatic environment has been challenged over the last two decades (56-59). Instead of being the sink, recent studies 
showed that cinnabar can also serve as a continuous source of inorganic $\mathrm{Hg}$ in the natural environment because a variety of environmental factors can facilitate the solubility of cinnabar. These factors include the presence of iron(III) (60), sulfide (61), dissolved organic matter $(\mathrm{DOM})(59,62,63)$, and aquatic microorganisms $(64,65)$. The enhanced dissolution of cinnabar facilitated by these environmental factors could be an important process controlling $\mathrm{Hg}$ cycling in the aquatic environment. Dissolution of cinnabar would make the originally stable and immobile $\mathrm{Hg}$ species more reactive and bioavailable, increasing the possibility of $\mathrm{Hg}$ transport, methylation and bioaccumulation, posing great risks to humans and wildlife. In areas where soils and sediments are heavily contaminated with $\mathrm{Hg}$, the effect of dissolution of cinnabar will be significant in the aquatic cycling of $\mathrm{Hg}$, since even the release of a small fraction of sequestered $\mathrm{Hg}$ would remarkably increase the amount of $\mathrm{Hg}$ available in the aquatic environment (66).

\subsubsection{Enhanced HgS dissolution in the environment}

In consideration of the significance of enhanced release of $\mathrm{Hg}$ under certain environmental conditions, the factors and processes facilitating $\mathrm{HgS}$ dissolution were studied in recent years, and the dissolution rates were estimated in previous studies (54, 56-63). Several possible mechanisms have been proposed for the enhanced dissolution of cinnabar in the environment. The most common one is that cinnabar dissolution is enhanced via the formation of $\mathrm{HgL}_{\mathrm{x}}$ complexes, especially the formation of $\mathrm{Hg}$-thiol complexes $(59,62,63,67,68)$. The coordination between dissolved $\mathrm{Hg}^{2+}$ and ligands would reduce the concentration of free $\mathrm{Hg}^{2+}$ and thus promote the dissolution of cinnabar. Another proposed mechanism is that the oxidation of $\mathrm{S}^{2-}$ in the presence of $\mathrm{O}_{2}$ or other

oxidants would decrease the concentration of $\mathrm{S}^{2-}$ and thus promote the dissolution of 
cinnabar $(56,60)$. The latter pathway is associated with iron-oxidizing bacteria. $\mathrm{The}^{\mathrm{F}} \mathrm{Fe}^{3+}$ is reduced after oxidizing $\mathrm{S}^{2-}$ and regenerated $\mathrm{Fe}^{3+}$ in the presence of the bacteria, as a result, more $\mathrm{S}^{2-}$ can be oxidized and the iron-oxidizing bacteria promotes the dissolution of cinnabar $(64,65)$.

The re-adsorption of $\mathrm{Hg}$ on cinnabar has been observed and experimentally demonstrated by directly and indirectly evidence $(56,63,69,70)$. In a pure $\mathrm{HgS}$ dissolution system, concentration of sulfate (which is the oxidation product of dissolved sulfide) should equal to that of the released $\mathrm{Hg}$. However, it was found that the concentration of sulfate was much higher than that of the dissolved $\mathrm{Hg}$, suggesting possible re-adsorption of released $\mathrm{Hg}$ (63). Adsorption experiments also showed that added $\mathrm{Hg}$ (II) into a metacinnabar suspension could be quickly absorbed on metacinnabar surface (56). In addition, contrary results were sometimes observed regarding the effects of organic ligands on cinnabar dissolution. For instance, minor changes in cinnabar dissolution were observed in the presence and absence of organic ligands (e.g., salicylic acid, acetic acid, EDTA, or cysteine) $(59,62,63,68)$. These inconsistent results were speculated to be attributed to the difference in binding strength between those ligands and $\mathrm{Hg}$ and the possible re-adsorption of dissolved $\mathrm{Hg}$ on cinnabar (63). The co-occurrence of re-adsorption should be evaluated since it may be the reason to underestimate the dissolution of $\mathrm{Hg}$, thus the adverse effect of this process in $\mathrm{Hg}$ cycling.

\subsubsection{Re-adsorption of dissolved $\mathrm{Hg}$ on $\mathrm{HgS}$ surface}

Inorganic divalent $\mathrm{Hg}$ ions can be adsorbed on a variety of solid phases in natural environments, e.g., particulate particles in water (71), soil (72), sediment (73) and minerals (74). The adsorption process may involve one or several possible mechanisms, including 
physisorption (Van der Waals interaction) and chemisorptions (ion exchange or surface complexation). Surface complexation was considered by most researchers to be the possible mechanism of $\mathrm{Hg}^{2+}$ ions adsorption on $\mathrm{HgS}(56,75)$. The surface of cinnabar with a $\mathrm{pH}_{\mathrm{pzc}} 3-4$ ( $\mathrm{pH}$ at the point of zero charge) is expected to be negatively charged in natural aquatic environments with a $\mathrm{pH}$ of 6-8 because of the deprotonation of exposed sulfhydryl groups $(63,76)$. In natural fresh water, uncharged $\mathrm{Hg}$ complexes $\mathrm{Hg}(\mathrm{OH})_{2}, \mathrm{HgOHCl}$, and $\mathrm{HgCl}_{2}$ are considered the dominant species of inorganic $\mathrm{Hg}$ in the absence or very low concentration of sulfide (7). Therefore, the mechanism of $\mathrm{Hg}$ adsorption on cinnabar should be surface complexation rather than ion exchange (77). The adsorption process could be described as:

$$
2 \equiv \mathrm{S}-\mathrm{H}+\mathrm{Hg}(\mathrm{OH})_{2} \leftrightarrow(\equiv \mathrm{S})_{2} \mathrm{Hg}+2 \mathrm{H}_{2} \mathrm{O}
$$

Of which the surface sulfhydryl group is represented by $\equiv \mathrm{S}-\mathrm{H}$. In addition to these theoretical deductions, experiments have also provided both direct and indirect evidence for the occurrence of $\mathrm{Hg}$ re-adsorption on cinnabar surface (56, 63, 69, 70). For instance, the amount of $\mathrm{Hg}$ released was found to be much lower than that of S (normally represented by $\mathrm{SO}_{4}{ }^{2-}$ ), in strong disagreement with the stoichiometric estimation, indicating the readsorption of released $\mathrm{Hg}$ back on cinnabar particles (63). Inorganic divalent $\mathrm{Hg}$ ions added into cinnabar suspension was observed to decrease quickly, further proving the occurrence of this process (56). Because of the re-adsorption of released $\mathrm{Hg}$ following $\mathrm{HgS}$ dissolution, the dissolution rates of $\mathrm{HgS}$ that consider the re-adsorption process have been estimated using an indirect method, based on the increase in the concentration of $\mathrm{SO}_{4}{ }^{2-}$ in the solution. However, it should be noted that the calculation of $\mathrm{Hg}$ dissolution rates from changes in $\mathrm{SO}_{4}{ }^{2-}$ concentration was underestimate the dissolution rate since sulfide oxidation 
intermediates (e.g., $\mathrm{S}_{2} \mathrm{O}_{3}{ }^{2-}$ ) that also exist in the solution or on the $\mathrm{HgS}$ surfaces (69). In addition, this method cannot quantitatively measure $\mathrm{HgS}$ dissolution rates under natural conditions, where a variety of factors (e.g., Eh, DOM, pH) can affect the transformations of sulfur, resulting in a large variation in the ratio of released $\mathrm{Hg}$ to $\mathrm{SO}_{4}{ }^{2-}$. Therefore, though it has been speculated that dissolved $\mathrm{Hg}$ from $\mathrm{HgS}$ surface could be re-adsorbed back onto $\mathrm{HgS}$ surfaces $(56,57,69)$, re-adsorption process has not yet been taken into account when measuring $\mathrm{HgS}$ dissolution rate in previous studies $(56,59,63,69,78)$ mainly to the result of the lack of a feasible technique that can differentiate the dissolution and re-adsorption processes. It is almost impossible to determine the re-adsorption rate of released $\mathrm{Hg}$ on $\mathrm{HgS}$ using traditional $\mathrm{Hg}$ addition methods due to the simultaneous dissolution of $\mathrm{Hg}$ from $\mathrm{HgS}$. As the adsorption process of $\mathrm{Hg}$ on $\mathrm{HgS}$ is expected to have a very different environmental behavior than $\mathrm{HgS}$, this drawback could result in the insufficient evaluation of the importance of $\mathrm{HgS}$ dissolution in environment.

\subsubsection{Isotope tracer technique and its potential applications in $\mathrm{HgS}$ dissolution study}

Mercury isotope tracer techniques have been widely applied in studying the transport and transformation of $\mathrm{Hg}$ (e.g., methylation/demethylation, oxidation/reduction, and adsorption/desorption) $(73,79-84)$ in recent years mainly because of its high precision, short incubation time, and its ability to simultaneously determine the rates of multiple processes (10). Using this technique, stable isotope labeled $\mathrm{Hg}^{2+}$ (e.g., ${ }^{199} \mathrm{Hg}^{2+}$ ) and/or $\mathrm{MeHg}$ (e.g., $\mathrm{Me}^{201} \mathrm{Hg}$ ) have been added into samples to monitor one or more processes respectively. For example, the methylation rates of geochemically relevant inorganic $\mathrm{Hg}$ (II) species, including isotopically labeled cinnabar, metacinnabar, adsorbed $\mathrm{Hg}(\mathrm{II})$, and complexed $\mathrm{Hg}(\mathrm{II})$ have been investigated (84). Isotope tracer techniques have been 
successfully used to quantify the kinetics of adsorption of $\mathrm{Hg}$ and $\mathrm{MeHg}$ onto freshwater lake sediments and the subsequent rate of desorption by adding ${ }^{200} \mathrm{Hg}(\mathrm{II})$ and $\mathrm{Me}{ }^{199} \mathrm{Hg}$ to sediment suspensions (73). Adsorption/desorption processes were also investigated between inorganically or organically complexed $\mathrm{Hg}$ (II) and solid bound $\mathrm{Hg}$ by evaluating the isotope exchange processes after spiking naturally abundant $\mathrm{Hg}(\mathrm{II})$ and enriched

${ }^{198} \mathrm{Hg}$ (II) successively into solid substrates (carboxyl-, thiol-resin or goethite) (83). Despite the aforementioned advantages of using isotope tracer technique in revealing some key environmental processes and rates, a methodology utilizing this technique has not been developed and applied to the study of re-adsorption of re-leased $\mathrm{Hg}^{2+}$ and the effects of dissolution and re-adsorption processes.

\subsubsection{Release of $\mathrm{Hg}$ from $\mathrm{HgS}$ dissolution and its implications on $\mathrm{Hg}$ cycling}

Mercury deposits are distributed in 26 mercury mineral belts globally with three types: Almaden type, silica-carbonate, and hot-spring type. Cinnabar is the main ore mineral at these abundant $\mathrm{Hg}$ deposits as well as a by-product from quartz-alunite gold-silver and antimony deposits $(48,85)$. Mine waste and $\mathrm{Hg}$-enriched soils are a potential source of soluble $\mathrm{Hg}$ that can be transported and methylated in downstream aquatic environments (48). Elevated concentrations of $\mathrm{Hg}$ have been measured in the ground water and surface water down-gradient of the tailings in some $\mathrm{Hg}$ contaminated areas (85-88). However, it is $\mathrm{Hg}$ speciation that controls $\mathrm{Hg}$ mobility, and bioavailability through $\mathrm{MeHg}$ production and then bioaccumulation of $\mathrm{Hg}(49,89)$. Therefore, it is critical to know the distribution patterns of $\mathrm{Hg}$ species (e.g., what species are present at what percentages) for a better understanding of aquatic $\mathrm{Hg}$ cycling in $\mathrm{HgS}$ contaminated areas. 


\subsection{Geochemical modeling on Hg speciation and cycling}

Dissolved $\mathrm{Hg}$ exists mainly as $\mathrm{Hg}(0)$, inorganic $\mathrm{Hg}(\mathrm{II})$, and organic $\mathrm{Hg}$ forms (mostly $\mathrm{MeHg}$ and $\mathrm{Me}_{2} \mathrm{Hg}$ ) in aquatic systems. Generally, $\mathrm{Hg}(\mathrm{II})$ does not exist as free ions but complexes formed with inorganic and organic ligands, including hydroxide, chloride, sulfide, and DOM in aquatic systems (8). Inorganic $\mathrm{Hg}(\mathrm{II})$ complexes play an important role in the aquatic cycling of $\mathrm{Hg}$ because the complexes are closely associated with the uptake of SRB and IRB during methylation process. The pathway of $\mathrm{Hg}(\mathrm{II})$ uptake could be passive involving neutral forms of $\mathrm{Hg}$ through cell membranes, or active involvesand the formation of complexes of $\mathrm{Hg}$ and low molecular weight thiol ligands by bacteria. This can also be a facilitated uptake involving negative charged $\mathrm{Hg}$ species on the basis of cell physiology (90-93). Since inorganic $\mathrm{Hg}(\mathrm{II})$ speciation is believed to be a primary factor in the control of $\mathrm{Hg}$ bioavailability for methylating microorganisms $(7,52)$, speciation analysis of $\mathrm{Hg}(\mathrm{II})$ is crucial to predict the methylation potential and biogeochemical cycling in $\mathrm{Hg}$ contaminated areas.

\subsubsection{Determination of $\mathrm{Hg}$ species in aquatic systems}

Tremendous efforts have been made to develop $\mathrm{Hg}$ speciation analysis methods including chromatographic separation and non-chromatographic separation techniques (94-96). The chromatographic separation techniques are generally combined with an element specific detector to separate and analyze inorganic $\mathrm{Hg}(\mathrm{II})$ and organic $\mathrm{Hg}$ species or different organic $\mathrm{Hg}$ species (94). Cold vapor generation approaches are involved in non-chromatographic separation methods in many cases. So-called "reactive" $\mathrm{Hg}$ can be measured directly by stannous chloride $\left(\mathrm{SnCl}_{2}\right)$ reduction, while DOM bound $\mathrm{Hg}$ can't be measured in this moment. Extra steps such as UV irradiation, chemical oxidation, or 
ultrasonic treatment are required to convert $\mathrm{DOM}$ bound $\mathrm{Hg}$ to reactive $\mathrm{Hg}$ prior to $\mathrm{SnCl}_{2}$ reduction to determine total $\mathrm{Hg}(94)$.

Despite the very useful information on $\mathrm{Hg}$ speciation provided by using the above techniques, many significant $\mathrm{Hg}$ species cannot be analytically determined. For example, complexes of $\mathrm{Hg}$ and inorganic or organic ligands are difficult to determine (85-88). Because of the difficulty of direct analysis, the concentration of $\mathrm{Hg}$ (II) complexes in aquatic systems are obtained indirectly by thermodynamic calculation on the basis of stability constants (97). The dominant species include $\mathrm{Hg}$ hydroxides such as $\mathrm{Hg}(\mathrm{OH})^{+}$, $\mathrm{Hg}(\mathrm{OH})_{2}, \mathrm{Hg}(\mathrm{OH})^{3-}$ in fresh water and complexes of $\mathrm{Hg}$-chloride $\mathrm{HgCl}^{+}, \mathrm{HgClOH}_{,} \mathrm{HgCl}_{2}$, $\mathrm{HgCl}_{3}{ }^{-}, \mathrm{HgCl}_{4}{ }^{2-}$ in freshwater, estuarine and seawater under oxic condition $(98,99)$. Under anoxic conditions, sulfide may be combined with $\mathrm{Hg}$ to form $\mathrm{HgS}$ or soluble complexes such as $\mathrm{Hg}(\mathrm{SH})_{2}, \mathrm{HgS}_{2} \mathrm{H}^{-}$and $\mathrm{HgS}_{2}{ }^{2-}$ in natural water (100). However, many studies suggest that the majority of $\mathrm{Hg}$ species in natural water are the complexes of $\mathrm{Hg}$ and DOM. Thiol containing organic ligands are particularly important as a result of the high concentration of DOM and strong interactions between $\mathrm{Hg}$ and organic matter, in aqueous systems, particularly those with thiol moieties (101-104). Some geochemical models have been developed and applied to simulate $\mathrm{Hg}$ speciation by calculating speciation, sorption, and precipitation of aquatic chemical components on the basis of thermodynamic equilibrium constants $(105,106)$.

\subsubsection{Geochemical modeling methods for Hg studies}

Geochemical models have been widely applied to study $\mathrm{Hg}$ speciation and mobility in contaminated areas in previous work $(85,87)$. Frequently used programs are WATEQ4F, MINTEQA2, EQ 3/6, and PHREEQC(106). Data processing is very convenient in 
WATEQ4F using standard Excel files, however, calculations of analytical error, speciation and saturation index are limited. Using MINTEQA2, it is also possible to calculate the distribution of dissolved and adsorbed species (on solid phases). The capabilities of PHREEQC and EQ 3/6 are far greater than other models. While PHREEQC is public domain software, EQ 3/6 has to be purchased from the Lawrence Livermore National Laboratories (107). Species distribution of mercury in contaminated and natural environment can vary depending on environmental conditions. For example, mercury speciation calculations using PHREEQC suggest that $\mathrm{Hg}$ is predominantly in the form of $\mathrm{Hg}-\mathrm{CN}$ complexes in ground water and surface water down-gradient of the tailings in the Murray Brook gold deposit (northern New Brunswick, Canada) (87). Using both PHREEQC and MINTEQ modeling, the dominant species in Bayarque mining waste leaching was found to be $\mathrm{Hg}(0)$ and $\mathrm{Hg}(\mathrm{OH})_{2}$, while $\mathrm{HgCl}_{2}, \mathrm{HgCl}_{3}{ }^{-}$, and $\mathrm{HgClOH}$ were major species in the mining wastes leachates of the Valle del Azogue mine (Almería, Andalusia, Se Spain) along with the presence of high concentrations of $\mathrm{Hg}$ and chloride (85). Among all mercury species present in aqueous solutions, mercury complexes formed through interactions with sulfide and dissolved organic matter (DOM) dominate in many scenarios, such as that observed in the stratified water column of Offatts Bayou (Galveston Bay, Texas) where $\mathrm{HOHgHS}^{0}, \mathrm{HOHgHS}(\mathrm{DOM}), \mathrm{HgSHS}^{2-}$, and $\mathrm{HgS}_{2}{ }^{2-}$ may be major species of mercury (86).

In these contaminated aqueous systems, dissolved $\mathrm{Hg}$ occured due to the leaching of sediment or soil. Since the majority of $\mathrm{Hg}$ is present as $\mathrm{HgS}$ ether cinnabar or metacinnabar, $\mathrm{Hg}$ should be released into water through $\mathrm{HgS}$ dissolution. Knowing the $\mathrm{Hg}$ species released during cinnabar dissolution would be helpful in understanding the role of cinnabar 
dissolution in aquatic $\mathrm{Hg}$ cycling. However, much remains unclear about how inorganic $\mathrm{Hg}$ species are distributed in aqueous phase and how their varying bioavailability influence the uptake by methylating bacteria for production of $\mathrm{MeHg}$.

Geochemical modeling of $\mathrm{Hg}$ speciation requires a clear understanding of major $\mathrm{Hg}$ transport and transformation processes in a given system, in particular types and concentrations of inorganic and organic ligands present in the system and the stability constants of the complexes of these ligands with Hg. Therefore, applying a geochemical modeling approach to a relatively well-studied system with ancillary environmental parameters (e.g., concentrations of inorganic and organic ligands) to examine $\mathrm{Hg}$ speciation would be beneficial to improve understanding towards how $\mathrm{Hg}$ species distribution affects $\mathrm{MeHg}$ production and the overall $\mathrm{Hg}$ cycling in the aquatic environment.

\subsubsection{Geochemical modeling of $\mathrm{Hg}$ speciation in the Florida Everglades}

The Florida Everglades, a subtropical wetland ecosystem located in South Florida, provides significant ecological, water storage, flood control and recreational benefits to the region and important habitat for wildlife including endangered species. However, elevated levels of $\mathrm{Hg}$, especially $\mathrm{MeHg}$, a potent neurotoxin, have been measured in fish and wildlife e.g., wading birds, alligators, and Florida panthers in the Everglades over the last few decades (108-111). This not only is an issue for human consumption of fish, but also threatens fish-eating wildlife species and the biological diversity of the ecosystem (112114). To address this issues, efforts have been made to investigate source, transport, transformation (in particular methylation/demethylation), and bioaccumulation of $\mathrm{Hg}$ in 
fish and wildlife in the Florida Everglades $(45,115-118)$. Spatial patterns in mercury cycling and bioaccumulation in the Everglades have also been investigated (119-122).

In the Florida Everglades, atmospheric deposition was identified as the primary source of $\mathrm{Hg}$ mainly inorganic $\mathrm{Hg}(121,123)$. Unlike the elevated levels of $\mathrm{Hg}$ in Everglades wildlife, concentrations of total $\mathrm{Hg}(\mathrm{THg})$ in surface water and soil both were within background levels $(108,110,111,123,124)$. However, the concentrations of MeHg were found correlated with methylation rates $(89,125)$. The high levels of MeHg in fish and other biota could be produced by $\mathrm{MeHg}$ in situ production and subsequently bioaccumulation through the food web $(89,124)$. The production of MeHg is predominantly by SRB in soil, floc, and water $(89,116)$. Soil was identified as the largest source of MeHg, while methylation in periphyton could play significant role in the northern Everglades (79). Concentrations of sulfide, DOM, and other geochemical factors were found to influence the production of $\mathrm{MeHg}(91,126)$. These essential constituents could control speciation of $\mathrm{Hg}$ and then the bioavailability of $\mathrm{Hg}$ by SRM in aquatic systems (9093). The speciation of $\mathrm{Hg}$ in Everglades surface water was modeled using WHAM and PHREEQC by Reddy (127). The complexes of $\mathrm{Hg}$ and sulfide dominate with measurable sulfide concentrations, while $\mathrm{Hg}$ and fulvic acid complexes play a major role in the surface water with low sulfide ion concentrations. However, the mechanism by which $\mathrm{Hg}$ speciation regulates the production of $\mathrm{MeHg}$ was not determined. Speciation calculations were also applied using $\mathrm{MINEQL}^{+}$program to sulfidic pore waters in the Florida Everglades with the consideration of the adsorption of $\mathrm{Hg}$ on solid phase thiols (with or without $\mathrm{Hg}$ ) by Benoit (52). Neutral species $\mathrm{HgS}^{0}$ was considered the major species of $\mathrm{Hg}$ which controls $\mathrm{Hg}$ methylation by the passive diffusion of $\mathrm{Hg}$ uptake by SRB. This result 
is consistent with previous hypothesis proposed by same the researcher (92). However, some important geochemical factors such as $\mathrm{pH}$, Eh, DOM were not considered in the modeling.

\subsection{Research gaps and significance of this study}

The re-adsorption of released $\mathrm{Hg}$ from cinnabar dissolution in natural environment, as evidenced from previous discussions, is one of the key steps that will determine how the released mercury affects the cycling of mercury. However, this process has not yet been taken into account when measuring cinnabar dissolution rate in previous studies $(56,59$, $63,68,69)$, mainly because there is no feasible technique that can differentiate the dissolution and re-adsorption processes. It is almost impossible to determine the readsorption rate of released $\mathrm{Hg}$ on cinnabar using traditional $\mathrm{Hg}$ addition method in consideration of the simultaneous dissolution of $\mathrm{Hg}$ from cinnabar. Mercury adsorbed on cinnabar is expected to be very different in comparison with that of $\mathrm{HgS}$ in their environmental behavior, therefore, resulting in insufficient evaluation of the importance of cinnabar dissolution in the environment.

Various organic ligands exist extensively in natural aquatic systems, and mercury could bind with these ligands, in particular thiol-containing moieties in dissolved organic matter (DOM), which could have important effects on cinnabar dissolution and re-adsorption of $\mathrm{Hg}(63,67,128)$. The presence of DOM fractions was found to enhance the release of mercury from cinnabar under aerobic and anaerobic conditions $(58,59,63)$. However, whether the Hg-DOM complex could be re-adsorbed on cinnabar and, if the re-adsorption happens, the amount of $\mathrm{Hg}-\mathrm{DOM}$ complex that can be absorbed remain unknown. The missing adsorption information is important for an improved understanding of the role 
DOM plays during cinnabar dissolution and re-adsorption of the released $\mathrm{Hg}$ in the presence of DOM.

Efforts have been made to investigate source, transport, transformation (reduction/oxidation and in particular methylation/demethylation), and bioaccumulation of $\mathrm{Hg}$ in fish and wildlife in the Florida Everglades $(45,115-118)$. Spatial patterns in $\mathrm{Hg}$ cycling and bioaccumulation in the Everglades have been investigated. However, much remains unclear about how elevated levels of $\mathrm{Hg}$ in fish and wildlife are accumulated and the biogeochemical cycling of mercury in this system $(109,129)$. One of the particular concerns is the lack of study deals with the speciation of inorganic $\mathrm{Hg}$, whether being dissolved $\mathrm{Hg}$ ions (or neutral species) or bound to particles and organic matter, and the effect of these $\mathrm{Hg}$ species on $\mathrm{Hg}$ transformation (e.g., methylation and photochemical reactions) and bioaccumulation.

\subsection{Objectives, hypotheses, and approaches}

The first objective of this study was to decipher the role of re-adsorption of dissolved $\mathrm{Hg}$ in cinnabar dissolution and to quantitatively estimate the dissolution rates with the consideration of re-adsorption. The hypothesis behind this work is that the re-adsorption of the released $\mathrm{Hg}$ indeed happens and can't be neglected in the study of cinnabar dissolution. An isotope tracer technique was used to simultaneously differentiate the dissolution and re-adsorption processes. An experimental approach, using both isotope tracing and isotope dilution techniques, was developed to monitor $\mathrm{Hg}$ released into the solution as well as $\mathrm{Hg}$ re-adsorbed on cinnabar during the course of cinnabar dissolution. Equations were then derived to calculate the rates of cinnabar dissolution and $\mathrm{Hg}$ readsorption. The major virtue of the developed method is the ability to decipher the re- 
adsorption of released $\mathrm{Hg}$ on cinnabar during cinnabar dissolution. The method was then applied to investigate the dissolution of cinnabar and re-adsorption of released $\mathrm{Hg}$ under both aerobic and anaerobic conditions.

The second objective was to understand the role played by thiol-containing organic ligands during cinnabar dissolution and re-adsorption of the released $\mathrm{Hg}$, particularly through complexation with $\mathrm{Hg}$. It was hypothesized that the Hg-thiol complex could not be adsorbed or be adsorbed less than $\mathrm{Hg}$ species without thiols on cinnabar surface, reflecting higher concentration of released $\mathrm{Hg}$ in presence of thiols. L-cysteine (Cys) was selected as a model compound of low molecular weight (LMW) thiol-containing ligand and fulvic acid to represent DOM. Following investigation of the complexation of these organic ligands with $\mathrm{Hg}$, thermodynamic adsorption experiments of $\mathrm{Hg}$-cysteine complex and cinnabar dissolution in the presence of fulvic acid were conducted to evaluate the role of $\mathrm{Hg}$-thiol complexation in cinnabar dissolution and re-adsorption of $\mathrm{Hg}$.

The last objective was to understand how geochemical factors such as $\mathrm{pH}$, dissolved ions, and organic matter affect inorganic $\mathrm{Hg}$ species and subsequently control $\mathrm{Hg}$ methylation in the Florida Everglades. The hypothesis driving this study is that the formation of $\mathrm{MeHg}$ is controlled by complexes of inorganic $\mathrm{Hg}$ and ligands such as $\mathrm{Hg}$ DOM, $\mathrm{Hg}-\mathrm{S}$, and other species. Geochemical models are used to model the distribution of inorganic $\mathrm{Hg}$ species in this work. The distribution of inorganic $\mathrm{Hg}$ species in surface water throughout the entire Everglades is determined by applying geochemical models to different sampling sites provided by the Everglades Regional Environmental Monitoring and Assessment Program (R-EMAP). The patterns of inorganic Hg species distribution are related to $\mathrm{MeHg}$ levels in environmental matrices, inorganic $\mathrm{Hg}$ species potentially affect 
the production and fate of $\mathrm{MeHg}$, and can be further related to fish $\mathrm{Hg}$ levels to explore the relationship between inorganic $\mathrm{Hg}$ speciation, $\mathrm{MeHg}$ production, and $\mathrm{Hg}$ bioaccumulation. The implications of the inorganic $\mathrm{Hg}$ species distribution on important $\mathrm{Hg}$ transformation processes and the overall $\mathrm{Hg}$ cycling in the Florida Everglades are discussed. 


\title{
Chapter 2. Evaluating the Role of Re-adsorption of Dissolved $\mathrm{Hg}^{2+}$ during Cinnabar Dissolution Using Isotope Tracer Technique
}

\begin{abstract}
Cinnabar dissolution is an important factor controlling mercury $(\mathrm{Hg})$ cycling. Recent studies have suggested the co-occurrence of re-adsorption of the released $\mathrm{Hg}$ during the course of cinnabar dissolution. However, there is a lack of feasible techniques that can quantitatively assess the amount of $\mathrm{Hg}$ re-adsorbed on cinnabar when investigating cinnabar dissolution. In this study, a new method, based on isotope tracing and dilution techniques, was developed to study the role of $\mathrm{Hg}$ re-adsorption in cinnabar dissolution. The developed method includes two key components: 1) accurate measurement of both released and spiked $\mathrm{Hg}$ in aqueous phase and 2) estimation of re-adsorbed $\mathrm{Hg}$ on cinnabar surface via the reduction in spiked ${ }^{202} \mathrm{Hg}^{2+}$. By adopting the developed method, it was found that the released $\mathrm{Hg}$ for trials purged with oxygen could reach several hundred $\mu \mathrm{g} \mathrm{L}^{-1}$, while no significant cinnabar dissolution was detected under anaerobic condition. Cinnabar dissolution rate when considering $\mathrm{Hg}$ re-adsorption was approximately 2 times the value calculated solely with the $\mathrm{Hg}$ detected in the aqueous phase. These results suggest that ignoring the $\mathrm{Hg}$ re-adsorption process can significantly underestimate the importance of cinnabar dissolution, highlighting the necessity of applying the developed method in future cinnabar dissolution studies.
\end{abstract}

\subsection{Introduction}

Mercury sulfide (cinnabar and metacinnabar), a major ore mineral, is one of the largest mercury ( $\mathrm{Hg}$ ) sinks in contaminated sediments and soils (47). It has been considered as the most insoluble and least leachable $\mathrm{Hg}$ species due to its low solubility product constant $\left(\mathrm{k}_{\mathrm{sp}}\right.$ 
$=10^{-55.9 \sim-50.9}$ for the reaction $\left.\mathrm{HgS}(\mathrm{s})=\mathrm{Hg}^{2+}+\mathrm{S}^{2-}\right)(52,130)$. The formation of mercury sulfide in the environment plays a major role in restraining $\mathrm{Hg}$ biogeochemical cycling. However, previous studies showed that dissolution of mercury sulfide (e.g., cinnabar) can also serve as a continuous source of inorganic $\mathrm{Hg}$ in natural environment due to the fact that a variety of environmental factors can facilitate its dissolution. These factors include the presence of iron(III) in acidic water (60), sulfide in water (100), and dissolved organic matter (DOM) $(59,62,63)$. The enhanced dissolution of cinnabar could be an important process controlling $\mathrm{Hg}$ cycling in aquatic environments as this process would make the originally stable $\mathrm{Hg}$ more reactive and bioavailable, increasing the possibility of $\mathrm{Hg}$ transport, methylation and bioaccumulation, posing a great risk to humans and wildlife. This process is particularly important at areas where soils and sediments are heavily contaminated with $\mathrm{Hg}$ since even the release of a small fraction of sequestered $\mathrm{Hg}$ would remarkably increase the amount of $\mathrm{Hg}$ available in aquatic environment (66).

Dissolution of cinnabar in aquatic environment is very complex and the process could be conceptually simplified in two steps, 1) elimination of dissolution products $\left(\mathrm{S}^{2-}\right.$ and $\mathrm{Hg}^{2+}$ ) in the aqueous phase and 2) the subsequent dissolution of cinnabar (Table S1, Fig. S1) $(52,56,67)$. A variety of environmental factors are expected to enhance or inhibit cinnabar dissolution via affecting the fate of cinnabar dissolution products. These factors include $\mathrm{pH}$, redox potential (Eh), and $\mathrm{Hg}$ binding ligands $(57,60,63,69)$. Sulfide $\left(\mathrm{S}^{2-}\right)$, one of the cinnabar dissolution products, could be eliminated from the system via oxidation to $\mathrm{SO}_{4}{ }^{2-}$ at $\mathrm{pH} 5-8$ under aerobic condition $(56,57,60,68,70)$ or conversion to $\mathrm{HS}^{-}$and $\mathrm{H}_{2} \mathrm{~S}$ under anaerobic condition (52). The former pathway may play a more important role as quicker dissolution of cinnabar was observed in the presence of $\mathrm{O}_{2}(56,60,69) . \mathrm{Hg}^{2+}$, 
the other product, could bind with organic ligands, in particular thiol-containing moieties in dissolved organic matter $(\mathrm{DOM})(63,67,128)$. The binding process is expected to reduce the amount of free $\mathrm{Hg}^{2+}$ in aqueous phase and thus enhance cinnabar dissolution. Contrary results were sometimes observed regarding the effects of organic ligands on cinnabar dissolution. For instance, while organic ligands may enhance cinnabar dissolution, minor changes in cinnabar dissolution were observed in the presence and absence of organic ligands (salicylic acid, acetic acid, EDTA, or cysteine) $(59,62,63,68)$. These inconsistent results were speculated to be attributed to the differences in binding strength between those ligands and $\mathrm{Hg}$ and the possible re-adsorption of released $\mathrm{Hg}$ on cinnabar (63).

$\mathrm{Hg}^{2+}$ ion can be adsorbed on a variety of solid phases in natural environments, e.g., particles in water (71), soil (72), sediment (73) and minerals (74). The adsorption process may involve one or several possible mechanisms, including physisorption (Van der Waals interaction) and chemisorptions (ion exchange or surface complexation). Surface complexation was considered to be the possible mechanism of $\mathrm{Hg}^{2+}$ ions adsorption on $\mathrm{HgS}$ in most studies $(56,75)$. Surface of cinnabar (with a $\mathrm{pH}_{\mathrm{pzc}}$ of 3-4) is expected to be negatively charged in natural aquatic environments with a $\mathrm{pH}$ of $6-8$ due to the deprotonation of exposed sulfhydryl groups $(63,76)$. Since the dominant dissolved $\mathrm{Hg}^{2+}$ species in aquatic environments are often uncharged complexes, inorganic or organic complex formation, ion exchange should not be the major mechanism of $\mathrm{Hg}$ adsorption on cinnabar (77). Experimental results have provided both direct and indirect evidences for the occurrence of $\mathrm{Hg}$ re-adsorption on cinnabar surface $(56,63,69,70,131)$. For instance, the amount of $\mathrm{Hg}$ released was found to be much lower than that of S (normally represented by $\mathrm{SO}_{4}{ }^{2-}$ ), in strong disagreement with the stoichiometric estimation, indicating the 
adsorption of released $\mathrm{Hg}$ back on cinnabar particles $(56,63,69,70) . \mathrm{Hg}^{2+}$ added into cinnabar suspension was observed to decrease quickly, further proving the occurrence of this process (56). Nevertheless, this process has not yet been taken into account when measuring cinnabar dissolution rate in previous studies $(56,59,63,68,69)$, mainly due to the lack of a feasible technique that can differentiate the dissolution and re-adsorption processes. It is almost impossible to determine the re-adsorption rate of released $\mathrm{Hg}$ on cinnabar using traditional $\mathrm{Hg}$ addition method due to the simultaneous dissolution of $\mathrm{Hg}$ from cinnabar. The Hg re-adsorbed on cinnabar surface is expected to behavior differently in the environment than $\mathrm{HgS}$ itself, and therefore measuring cinnabar dissolution without considering $\mathrm{Hg}$ re-adsorption could result in underestimation of the importance of cinnabar dissolution in the environment.

Mercury isotope tracer technique has been widely applied in studying transport and transformation of $\mathrm{Hg}$, e.g., methylation/demethylation and oxidation/reduction $(79-81,132)$ in recent years mainly due to its high precision and ability of simultaneously determining the rates of multiple processes. It has also been successfully used to quantify the adsorption and desorption of $\mathrm{Hg}$ in sediments and particles $(73,83)$. The objective of this study was to decipher the role of re-adsorption of the released $\mathrm{Hg}$ in cinnabar dissolution. It is expected that the application of isotope tracer technique would make it feasible to simultaneously differentiate the dissolution and re-adsorption processes. An experimental approach, using both isotope tracing and isotope dilution techniques, was developed to monitor $\mathrm{Hg}$ released into the solution as well as $\mathrm{Hg}$ re-adsorbed on cinnabar during the course of cinnabar dissolution. Equations were then derived to calculate the rates of cinnabar dissolution and $\mathrm{Hg}$ re-adsorption. The major virtue of the developed method is its 
ability to quantify the re-adsorption of released $\mathrm{Hg}$ on cinnabar during cinnabar dissolution.

This method was then applied to investigate the dissolution of cinnabar and re-adsorption of released $\mathrm{Hg}$ under both aerobic and anaerobic conditions.

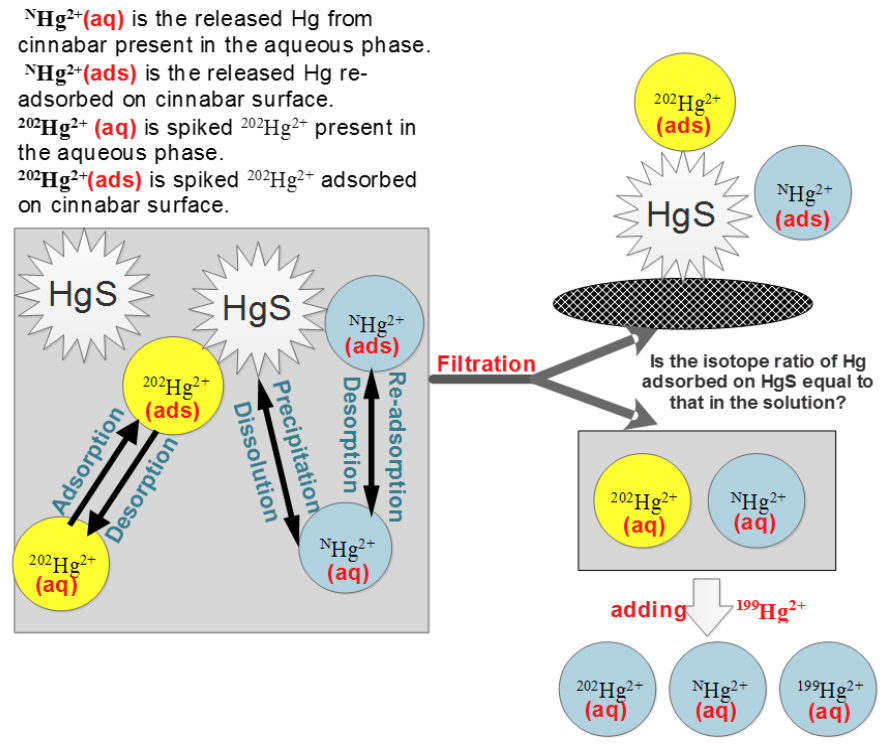

Figure 2.1 A schematic showing the procedure of simultaneously monitoring the dissolution of cinnabar and re-adsorption of released $\mathrm{Hg}$ using isotope tracer and isotope dilution techniques.

\subsection{Experimental methods}

\subsubsection{Pretreatment of cinnabar and selection of filters}

The surface of cinnabar was cleaned prior to use by soaking and shaking the cinnabar powder $(0.02 \mathrm{~g})$ in $1 \mathrm{~mol} \mathrm{~L}^{-1} \mathrm{HNO}_{3}$ at $150 \mathrm{rpm}$ (Orbital shaker, Henry Troemner LLC) for 3 days and subsequently filtering through a $0.45 \mu \mathrm{m}$ PVDF membrane (Millipore) (59). Cinnabar on the filter membrane was washed until the filtrate reaching neutral using approximately 2.5 L DI (de-ionized) water (>18.2 M 2$)$ and then transferred to a $250 \mathrm{~mL}$ Teflon bottle containing $200 \mathrm{~mL} \mathrm{NaNO} 3 / \mathrm{NaOH}$ solution $(\mathrm{pH}$ 8.0). The final concentration of cinnabar in the suspension was approximately $100 \mathrm{mg} \mathrm{L}^{-1}$ as $\mathrm{HgS}$. The average size of cinnabar was approximately 3,272 $\mathrm{nm}$ determined by dynamic light scattering (DLS) 
(Malvern Zetasizer Nano-ZS, Westborough, MA) (Supplementary Data Fig. S2). DI water and $\mathrm{NaNO}_{3} / \mathrm{NaOH}$ solution used were purged overnight with $\mathrm{N}_{2}$ to eliminate $\mathrm{O}_{2}$. All procedures were performed in a $\mathrm{N}_{2}$ glove box to avoid the exposure to air. Experiments were conducted to examine the adsorption of $\mathrm{Hg}$ on four types of filters $(0.22 \mu \mathrm{m}$ PTFE, $0.45 \mu \mathrm{m}$ PTFE, $0.22 \mu \mathrm{m}$ PVDF, and $0.45 \mu \mathrm{m}$ PVDF), and $0.22 \mu \mathrm{m}$ PTFE filter was chosen in this study since it had the best recovery for $\mathrm{Hg}$ with minimum adsorption on the filter (Supplementary Data, Table S2).

\subsubsection{Simultaneous determination of cinnabar dissolution and $\mathrm{Hg}^{2+}$ re-adsorption in the presence of $\mathrm{N}_{2}$ and $\mathrm{O}_{2}$}

Experiments using isotope tracer were designed to monitor the adsorption of $\mathrm{Hg}^{2+}$ on cinnabar during the course of cinnabar dissolution experiments. ${ }^{202} \mathrm{HgNO}_{3}(215 \mu \mathrm{L}, 46.6$ mg L $\mathrm{L}^{-1}$ as $\mathrm{Hg}$ ) was spiked into a $250 \mathrm{~mL}$ Teflon bottle with $180 \mathrm{~mL}$ of $\mathrm{NaNO}_{3} / \mathrm{NaOH}$ solution. Pretreated cinnabar (0.02 g wt.) was then added into the solution. The volume of the suspension solution was adjusted to $200 \mathrm{~mL}$ by adding $\mathrm{NaNO}_{3} / \mathrm{NaOH}$ solution. The final concentrations of ${ }^{202} \mathrm{Hg}^{2+}$ and cinnabar were $50 \mu \mathrm{g} \mathrm{L}^{-1}$ as $\mathrm{Hg}$ and $100 \mathrm{mg} \mathrm{L}^{-1}$ as $\mathrm{HgS}$, respectively. After shaking vigorously, $2.5 \mathrm{~mL}$ suspension was immediately sampled from each bottle using a $2.5 \mathrm{~mL}$ syringe and filtered through a $0.22 \mu \mathrm{m}$ PTFE membrane (representing time 0 ). Bottles with the remaining suspensions were then shaken at $125 \mathrm{rpm}$ with the purging of $\mathrm{N}_{2}\left(\sim 55 \mathrm{~mL} \mathrm{~min}{ }^{-1}\right.$, treatment 1$)$ or $\mathrm{O}_{2}\left(\sim 55 \mathrm{~mL} \mathrm{~min}^{-1}\right.$, treatment 2$)$. Triplicates (three independent Teflon bottles) were prepared for each treatment. An aliquot of suspension $(2.5 \mathrm{~mL})$ was sampled from each bottle at 1, 2, 4, 6, 8, 10, 23, 30, 47, and 54 $\mathrm{h}$, respectively, then filtered and preserved in a $4{ }^{\circ} \mathrm{C}$ refrigerator prior to analysis. Dissolved

${ }^{201} \mathrm{Hg}$ and ${ }^{202} \mathrm{Hg}$ in the filtrates were analyzed using an isotope dilution method. Upon 
analysis, $44.2 \mu \mathrm{L}{ }^{199} \mathrm{HgCl}_{2}\left(453 \mu \mathrm{g} \mathrm{L}^{-1}\right.$ as $\left.\mathrm{Hg}\right)$ was spiked into $2 \mathrm{~mL}$ filtrate, mixed thoroughly, diluted to $20 \mathrm{~mL}$ and then stabilized for 1 hour. ${ }^{199} \mathrm{Hg}^{2+},{ }^{201} \mathrm{Hg}^{2+}$ and ${ }^{202} \mathrm{Hg}^{2+}$ in the solutions were detected by a flow injection mercury analysis system (FIAS, from PerkinElmer) coupled with inductively coupled plasma mass spectrometry (ICP-MS, Elan DRC-e from PerkinElmer) following the method of isotope dilution technique (133). Details can be found in the Supplementary Data. Concentrations of spiked ${ }^{202} \mathrm{Hg}^{2+}$ and $\mathrm{Hg}^{2+}$ released from the $\mathrm{HgS}$ in the aqueous phase were calculated, as detailed below in Results section.

\subsubsection{Thermodynamics of $\mathrm{Hg}$ adsorption on cinnabar}

Thermodynamic experiments were further conducted to evaluate the adsorption capacity of $\mathrm{Hg}^{2+}$ on cinnabar. Adsorption of spiked ${ }^{202} \mathrm{Hg}^{2+}$ on cinnabar was observed to achieve equilibrium after 6 hours according to the results of preliminary experiments. The procedures for the adsorption experiments used here were identical to treatment 1 of the above experiment (purging with $\mathrm{N}_{2}$ ). ${ }^{202} \mathrm{Hg}^{2+}$ was spiked into the cinnabar suspension at the final concentrations of $0,10,20,50,100,200$, and $400 \mu \mathrm{g} \mathrm{L}^{-1}$. After shaking the bottles at $125 \mathrm{rpm}$ for 6 hours, $2.5 \mathrm{~mL}$ sample was collected from each bottle, filtered through a $0.22 \mu \mathrm{m}$ PTFE membrane, and stored at $4^{\circ} \mathrm{C}$ for analysis. Concentrations of the spiked ${ }^{202} \mathrm{Hg}^{2+}$ were then analyzed using the aforementioned isotope dilution method.

\subsubsection{Data analysis}

Two most commonly used adsorption isotherm equations (134-140), Langmuir and Freundlich isotherms, were adopted here to calculate the thermodynamic parameters of $\mathrm{Hg}$ adsorption on cinnabar. The kinetic adsorption of $\mathrm{Hg}^{2+}$ on cinnabar can be described as a pseudo-second order reaction (141) while first order reaction (142) was used to describe 
cinnabar dissolution. Details about these models can be found in the Supplementary Data (Eqs. (S1) - (S6)).

\subsection{Results and discussion}

\subsubsection{Developing a method for simultaneously monitoring $\mathrm{Hg}$ adsorption and dissolution using isotope dilution and isotope tracer technique}

A portion of the released $\mathrm{Hg}$ can be re-adsorbed on cinnabar surface after dissolving from cinnabar particles, resulting in the coexistence of two forms of $\mathrm{Hg}$ in the cinnabar suspension, the released $\mathrm{Hg}$ present in the aqueous phase and the released $\mathrm{Hg}$ re-adsorbed on cinnabar surface (Fig. 2.1). Concentration of the released Hg present in the aqueous phase can be determined readily, whereas it is still a challenge to directly measure the fraction of released $\mathrm{Hg}$ that is re-adsorbed on cinnabar surface. Without considering $\mathrm{Hg}$ readsorption, the direct measurement of solution $\mathrm{Hg}$ can only account for the portion of released $\mathrm{Hg}$ from $\mathrm{HgS}$ dissolution that is present in the aqueous phase, leaving out the fraction re-adsorbed on cinnabar surface, and thus resulting in underestimation of $\mathrm{Hg}$ dissolution rate. To quantify the sum of $\mathrm{Hg}$ released from cinnabar (in the aqueous phase and re-adsorbed on cinnabar surface), a new method based on isotope tracer technique was developed. The rationale is that re-adsorbed $\mathrm{Hg}$ on cinnabar surface $\left({ }^{\mathrm{N}} \mathrm{Hg}^{2+}(\mathrm{ads})\right)(\mathrm{N}$ represents $\mathrm{Hg}$ natural isotopic numbers) can be estimated by the decrease in the spiked isotope-enriched $\mathrm{Hg}\left({ }^{202} \mathrm{Hg}^{2+}(\mathrm{aq})\right)$ in aqueous phase. Developing such a method includes two key steps: 1) measuring both released $\mathrm{Hg}$ in the aqueous phase $\left({ }^{\mathrm{N}} \mathrm{Hg}^{2+}(\mathrm{aq})\right)$ and the residual ${ }^{202} \mathrm{Hg}^{2+}$ in the aqueous phase $\left({ }^{202} \mathrm{Hg}^{2+}(\mathrm{aq})\right)$, and 2) developing a method that can be used to estimate re-adsorbed $\mathrm{Hg}$ on cinnabar surface $\left({ }^{\mathrm{N}} \mathrm{Hg}^{2+}(\mathrm{ads})\right)$ by the reducing amount of spiked ${ }^{202} \mathrm{Hg}^{2+}$ in the aqueous phase $\left({ }^{202} \mathrm{Hg}^{2+}(\mathrm{aq})\right)$. 
$\mathrm{Hg}$ isotopes in the filtrate were analyzed using an isotope dilution technique. Prior to sample analysis, a known amount of ${ }^{199} \mathrm{Hg}^{2+}$ was spiked into the filtrate to serve as an internal standard. Abundances of ${ }^{202} \mathrm{Hg}^{2+},{ }^{199} \mathrm{Hg}^{2+}$, and ${ }^{201} \mathrm{Hg}^{2+}\left(N_{202}, N_{199}, N_{201}\right)$ in the solution were analyzed and the ratios of ${ }^{201} \mathrm{Hg} /{ }^{199} \mathrm{Hg}\left(R_{199}^{201}\right)$ and ${ }^{202} \mathrm{Hg} /{ }^{199} \mathrm{Hg}\left(R_{199}^{202}\right)$ were determined. $\mathrm{Hg}$ isotope ratios in the filtrates were different from the natural abundance of $\mathrm{Hg}$ because of the addition of ${ }^{202} \mathrm{Hg}^{2+}$ at time zero. These isotope ratios also changed over time accompanying with $\mathrm{Hg}$ dissolution from cinnabar and adsorption of the spiked ${ }^{202} \mathrm{Hg}^{2+}$. Therefore, the traditional isotope dilution method for analyzing samples with the natural abundance of $\mathrm{Hg}$ isotopes (143-147) is not applicable here for calculating $\mathrm{Hg}$ concentrations in the filtrates. A new method was developed in order to simultaneously calculate $\mathrm{Hg}$ originated from cinnabar dissolution and residual spiked ${ }^{202} \mathrm{Hg}^{2+}$ in the filtrates.

Since all 7 natural $\mathrm{Hg}$ isotopes were present in the used isotope-enriched $\mathrm{Hg}\left({ }^{202} \mathrm{Hg}^{2+}\right.$ and ${ }^{199} \mathrm{Hg}^{2+}$ ) because of the impurities in the standards, $\mathrm{Hg}$ isotopes in the filtrates originated from three sources, including cinnabar dissolution (with natural abundance of $\mathrm{Hg}$ isotopes, $\left.C_{\mathrm{d}}(\mathrm{aq})\right)$, spiked ${ }^{202} \mathrm{Hg}^{2+}\left(C_{\mathrm{x}}(\mathrm{aq})\right)$, and added ${ }^{199} \mathrm{Hg}^{2+}\left(C_{\mathrm{y}}(\mathrm{aq})\right)$. In consideration of all these sources, the ratios of ${ }^{201} \mathrm{Hg} /{ }^{199} \mathrm{Hg}\left(R_{199}^{201}\right)$ and ${ }^{202} \mathrm{Hg} /{ }^{199} \mathrm{Hg}\left(R_{199}^{202}\right)$ can be described using the following functions (Eq. (2.1) - (2.2)):

$$
\begin{aligned}
& R_{1}=R_{199}^{201}=\frac{N_{201}}{N_{199}}=\frac{C_{\mathrm{d}}(\mathrm{aq}) \mathrm{V} A_{\mathrm{n}}^{201}+C_{\mathrm{x}}(\mathrm{aq}) \mathrm{V} A_{202}^{201}+C_{\mathrm{y}}(\mathrm{aq}) \mathrm{V} A_{199}^{201}}{C_{\mathrm{d}}(\mathrm{aq}) \mathrm{V} A_{\mathrm{n}}^{199}+C_{\mathrm{X}}(\mathrm{aq}) \mathrm{V} A_{202}^{199}+C_{\mathrm{y}}(\mathrm{aq}) \mathrm{V} A_{199}^{199}} \\
& =\frac{C_{\mathrm{d}}(\mathrm{aq}) A_{\mathrm{n}}^{201}+C_{\mathrm{X}}(\mathrm{aq}) A_{202}^{201}+C_{\mathrm{y}}(\mathrm{aq}) A_{199}^{201}}{C_{\mathrm{d}}(\mathrm{aq}) A_{\mathrm{n}}^{199}+C_{\mathrm{X}}(\mathrm{aq}) A_{202}^{199}+C_{\mathrm{y}}(\mathrm{aq}) A_{199}^{199}}
\end{aligned}
$$




$$
\begin{aligned}
& R_{2}=R_{199}^{202}=\frac{N_{202}}{N_{199}}=\frac{C_{\mathrm{d}}(\mathrm{aq}) \mathrm{V} A_{\mathrm{n}}^{202}+C_{\mathrm{x}}(\mathrm{aq}) \mathrm{V} A_{202}^{202}+C_{\mathrm{y}}(\mathrm{aq}) \mathrm{V} A_{199}^{202}}{C_{\mathrm{d}}(\mathrm{aq}) \mathrm{V} A_{\mathrm{n}}^{199}+C_{\mathrm{x}}(\mathrm{aq}) \mathrm{V} A_{202}^{109}+C_{\mathrm{y}}(\mathrm{aq}) \mathrm{V} A_{199}^{199}} \\
& =\frac{C_{\mathrm{d}}(\mathrm{aq}) A_{\mathrm{n}}^{202}+C_{\mathrm{x}}(\mathrm{aq}) A_{202}^{202}+C_{\mathrm{y}}(\mathrm{aq}) A_{199}^{202}}{C_{\mathrm{d}}(\mathrm{aq}) A_{\mathrm{n}}^{199}+C_{\mathrm{x}}(\mathrm{aq}) A_{202}^{199}+C_{\mathrm{y}}(\mathrm{aq}) A_{199}^{199}}
\end{aligned}
$$

where $R_{199}^{201}$ represents the ratio of ${ }^{201} \mathrm{Hg}$ to ${ }^{199} \mathrm{Hg}$ in the filtrates; $R_{199}^{202}$ represents the ratio of ${ }^{202} \mathrm{Hg}$ to ${ }^{199} \mathrm{Hg}$ in the filtrates; $C_{\mathrm{d}}(\mathrm{aq})\left(\mu \mathrm{g} \mathrm{L} \mathrm{L}^{-1}\right)$ represents the concentration of natural $\mathrm{Hg}$ (from $\mathrm{HgS}$ dissolution) in the filtrates; $C_{\mathrm{x}}(\mathrm{aq})\left(\mu \mathrm{g} \mathrm{\textrm {L } ^ { - 1 }}\right)$ represents the residual concentration of spiked ${ }^{202} \mathrm{Hg}$ in the filtrates; $C_{\mathrm{y}}(\mathrm{aq})\left(\mu \mathrm{g} \mathrm{L} \mathrm{L}^{-1}\right)$ represents the concentration of added ${ }^{199} \mathrm{Hg}$ in the filtrates; $A_{n}^{\mathrm{i}}$ represents the abundance of $\mathrm{Hg}$ isotope $\mathrm{i}$ in natural $\mathrm{Hg} ; A_{202}^{\mathrm{i}}$ represents the abundance of $\mathrm{Hg}$ isotope $\mathrm{i}$ in the spiked ${ }^{202} \mathrm{Hg}$-enriched $\mathrm{Hg} ; A_{199}^{i}$ represents the abundance of $\mathrm{Hg}$ isotope $\mathrm{i}$ in the used ${ }^{199} \mathrm{Hg}$-enriched $\mathrm{Hg}$; V represents the volume of filtrates.

By solving Eq. (2.1) and Eq. (2.2), the concentrations of released $\mathrm{Hg}$ present in the aqueous phase $C_{\mathrm{d}}(\mathrm{aq})$ and residual spiked ${ }^{202} \mathrm{Hg} C_{\mathrm{x}}(\mathrm{aq})$ in the solution can be calculated by Eqs. (2.3) and (2.4), respectively. This isotope dilution method provides a precise tool to determine the concentrations of both released $\mathrm{Hg}$ and residual spiked ${ }^{202} \mathrm{Hg}^{2+}$ in the filtrates $\left(C_{\mathrm{d}}(\mathrm{aq})\right.$ and $\left.C_{\mathrm{x}}(\mathrm{aq})\right)$ at each sampling time of the dissolution experiment. Both $C_{\mathrm{d}}(\mathrm{aq})$ and $C_{\mathrm{x}}(\mathrm{aq})$ are necessary for the later calculation of cinnabar dissolution rate and re-adsorption rate of the released $\mathrm{Hg}$.

$$
\begin{aligned}
& C_{\mathrm{x}}(a q)=\frac{R_{1} C_{\mathrm{y}}(\mathrm{aq})\left(A_{\mathrm{n}}^{199} A_{199}^{202}-A_{\mathrm{n}}^{202} A_{199}^{199}\right)+R_{2} C_{\mathrm{y}}(\mathrm{aq})\left(A_{\mathrm{n}}^{201} A_{199}^{199}-A_{\mathrm{n}}^{199} A_{199}^{202}\right)+C_{\mathrm{y}}(\mathrm{aq})\left(A_{\mathrm{n}}^{202} A_{199}^{201}-A_{\mathrm{n}}^{201} A_{199}^{202}\right)}{R_{1}\left(A_{\mathrm{n}}^{202} A_{202}^{199}-A_{\mathrm{n}}^{199} A_{202}^{202}\right)+R_{2}\left(A_{\mathrm{n}}^{199} A_{202}^{201}-A_{\mathrm{n}}^{201} A_{202}^{199}\right)+\left(A_{\mathrm{n}}^{201} A_{202}^{202}-A_{\mathrm{n}}^{202} A_{202}^{201}\right)} \\
& C_{\mathrm{d}}(a q)=\frac{R_{1} C_{\mathrm{y}}(\mathrm{aq})\left(A_{199}^{199} A_{202}^{202}-A_{202}^{199} A_{199}^{202}\right)+R_{2} C_{\mathrm{y}}(\mathrm{aq})\left(A_{199}^{201} A_{202}^{199}-A_{202}^{201} A_{199}^{199}\right)+C_{\mathrm{y}}(\mathrm{aq})\left(A_{199}^{202} A_{202}^{201}-A_{199}^{201} A_{202}^{202}\right)}{R_{1}\left(A_{\mathrm{n}}^{202} A_{202}^{199}-A_{\mathrm{n}}^{199} A_{202}^{202}\right)+R_{2}\left(A_{\mathrm{n}}^{201} A_{202}^{201}-A_{\mathrm{n}}^{201} A_{202}^{202}\right)+\left(A_{\mathrm{n}}^{199} A_{202}^{202}-A_{\mathrm{n}}^{202} A_{202}^{199}\right)}
\end{aligned}
$$


$C_{\mathrm{y}}(\mathrm{aq})$ is known and it can be calculated as follows:

$$
C_{\mathrm{y}}(\mathrm{aq})=\frac{C_{199 \mathrm{Hg}}^{\mathrm{spiked}} \mathrm{v}_{1}}{\mathrm{~V}}
$$

where $C_{199 \mathrm{Hg}}^{\text {spiked }}$ is the concentration of ${ }^{199} \mathrm{Hg}$ spiked into the filtrates as internal standard; $\mathrm{V}_{1}$ is the volume of ${ }^{199} \mathrm{HgCl}_{2}$ spiked into the filtrates; $C_{\mathrm{d}}($ ads $)\left(\mu \mathrm{g} \mathrm{L}^{-1}\right)$ represents the concentration of natural $\mathrm{Hg}$ (from $\mathrm{HgS}$ dissolution) adsorbed on cinnabarin the filtrates; $C_{\mathrm{x}}(\mathrm{aq})\left(\mu \mathrm{g} \mathrm{L} \mathrm{L}^{-1}\right)$ represents the residual concentration of spiked ${ }^{202} \mathrm{Hg}$ in the filtrates.

The second key step of the proposed method is to calculate the amount of released $\mathrm{Hg}$ re-adsorbed on cinnabar $\left(C_{\mathrm{d}}\right.$ (ads)). Since the total amount of spiked ${ }^{202} \mathrm{Hg}$ $\left(c_{202 \mathrm{Hg}}^{\text {spiked }} \mathrm{V}_{2}\right.$, represented by $M_{\mathrm{x}}\left(\right.$ tot)) is known (Eq. (2.6)), the amount of spiked ${ }^{202} \mathrm{Hg}$ adsorbed on cinnabar $\left(M_{\mathrm{x}}(\mathrm{ads})\right)$ at each sampling time can be obtained by subtracting $M_{\mathrm{x}}(\mathrm{aq})$ from $M_{\mathrm{x}}(\mathrm{tot})$. If $M_{\mathrm{d}}(\mathrm{ads})$ can be related to $M_{\mathrm{x}}(\mathrm{ads})$, it would be feasible to calculate $M_{\mathrm{d}}(\mathrm{ads})$ by $M_{\mathrm{x}}(\mathrm{ads})$ and $C_{\mathrm{d}}(\mathrm{aq})$. Isotope ratios of $\mathrm{Hg}$ adsorbed on cinnabar surface are controlled by the adsorption/desorption process, while both adsorption/desorption and dissolution processes determine the ratios of $\mathrm{Hg}$ in the aqueous phase. As adsorption/desorption of $\mathrm{Hg}$ on cinnabar is expected to be much faster than cinnabar dissolution (72), it is reasonable to assume that the isotope ratios of $\mathrm{Hg}$ in the aqueous phase approximately equal to those of adsorbed $\mathrm{Hg}$ on cinnabar (Eq. (2.7)) due to the quick exchange of $\mathrm{Hg}$ isotopes between the aqueous and the particulate phases. This assumption was verified by the experiments described later.

$$
\begin{aligned}
& M_{\mathrm{X}}(\mathrm{tot})=c_{202 \mathrm{Hg}}^{\text {spiked }} \mathrm{V}_{2} \\
& \frac{M_{\mathrm{d}}(\mathrm{ads})}{M_{\mathrm{X}}(\mathrm{ads})}=\frac{M_{\mathrm{d}}(\mathrm{aq})}{M_{\mathrm{X}}(\mathrm{aq})}
\end{aligned}
$$


where $c_{202 \mathrm{Hg}}^{\text {spiked }}$ is the concentration of ${ }^{202} \mathrm{Hg}$ spiked into the cinnabar suspension solution; $\mathrm{V}_{2}$ is the volume of ${ }^{202} \mathrm{Hg}$ spiked; $\mathrm{V}_{3}$ is the volume of the cinnabar suspension solution; $M_{\mathrm{x}}$ (tot) $(\mu \mathrm{g})$ is the amount of ${ }^{202} \mathrm{Hg}$ spiked into the cinnabar suspension; $M_{\mathrm{d}}(\mathrm{ads})$, $M_{\mathrm{d}}(\mathrm{aq}), M_{\mathrm{x}}(\mathrm{ads})$, and $M_{\mathrm{x}}(\mathrm{aq})(\mu \mathrm{g})$ represent the amount of natural $\mathrm{Hg}$ (from $\mathrm{HgS}$ dissolution) on adsorbed on cinnabar surface and in the solution, and the amount of spiked ${ }^{202} \mathrm{Hg}$ adsorbed on cinnabar surface and in the solution, respectively.

By resolving Eq. (2.7), the amount of released $\mathrm{Hg}^{2+}$ that was re-adsorbed on cinnabar surface can be calculated from the released $\mathrm{Hg}$ in the aqueous phase and the distribution of spiked ${ }^{202} \mathrm{Hg}$ between the aqueous phase and cinnabar adsorbed phase using Eq. (2.8).

$$
\begin{aligned}
& M_{\mathrm{d}}(\mathrm{ads})=\frac{M_{\mathrm{x}}(\mathrm{tot})-M_{\mathrm{x}}(\mathrm{aq})}{M_{\mathrm{x}}(\mathrm{aq})} M_{\mathrm{d}}(\mathrm{aq})=\frac{C_{202 \mathrm{Hg}}^{\text {spiked }} \mathrm{V}_{2}-C_{\mathrm{x}}(\mathrm{aq}) \mathrm{V}_{3}}{C_{\mathrm{x}}(\mathrm{aq}) \mathrm{V}_{3}} C_{\mathrm{d}}(\mathrm{aq}) \mathrm{V}_{3} \\
& =\frac{C_{202 \mathrm{Hg}}^{\mathrm{spiked}} \mathrm{V}_{2}-C_{\mathrm{X}}(\mathrm{aq}) \mathrm{V}_{3}}{C_{\mathrm{x}}(\mathrm{aq})} C_{\mathrm{d}}(\mathrm{aq})
\end{aligned}
$$

Accordingly, the total amount of $\mathrm{Hg}$ released from cinnabar $\left(M_{\mathrm{d}}(\mathrm{tot})\right)$ can be calculated by summing the measured dissolved $\mathrm{Hg}$ in the aqueous phase $\left(C_{\mathrm{d}}(\mathrm{aq}) \mathrm{V}_{3}\right)$ and the estimated $\mathrm{Hg}$ adsorbed on cinnabar surface $\left(M_{\mathrm{d}}(\mathrm{ads})\right)$.

$$
M_{\mathrm{d}}(\mathrm{tot})=C_{\mathrm{d}}(\mathrm{aq}) \mathrm{V}_{3}+M_{\mathrm{d}}(\mathrm{ads})=C_{\mathrm{d}}(\mathrm{aq}) \mathrm{V}_{3}+\frac{C_{202 \mathrm{Hg}}^{\text {spiked }} \mathrm{V}_{2}-C_{\mathrm{x}}(\mathrm{aq}) \mathrm{V}_{3}}{C_{\mathrm{x}}(\mathrm{aq})} C_{\mathrm{d}}(\mathrm{aq})
$$

Then, the total concentration of $\mathrm{Hg}$ released from cinnabar $\left(C_{\mathrm{d}}(\mathrm{tot})\right)$ can be calculated by the division of $M_{\mathrm{d}}$ (tot) by $\mathrm{V}_{3}$ (Eq. 2.10).

$$
C_{\mathrm{d}}(\text { tot })=\frac{M_{\mathrm{d}}(\mathrm{tot})}{\mathrm{V}_{3}}=\frac{C_{\mathrm{d}}(\mathrm{aq}) \mathrm{V}_{3}+\frac{C_{202 \mathrm{Hg}}^{\text {spiked }} \mathrm{V}_{2}-C_{\mathrm{x}}(\mathrm{aq}) \mathrm{V}_{3}}{C_{\mathrm{x}}(\mathrm{aq})} C_{\mathrm{d}}(\mathrm{aq})}{\mathrm{V}_{3}}
$$


$=C_{\mathrm{d}}(\mathrm{aq})+\frac{\frac{C_{202 \mathrm{Hg}}^{\text {spiked }}}{\mathrm{v}_{3}}-C_{\mathrm{x}}(\mathrm{aq})}{C_{\mathrm{x}}(\mathrm{aq})} C_{\mathrm{d}}(\mathrm{aq})$

The equation can be simplified to Eq. (2.11) by defining $\frac{C_{202 \mathrm{Hg}}^{\text {spiked }} \mathrm{V}_{2}}{\mathrm{~V}_{3}}$ as $C_{\mathrm{x}}$ (tot).

$$
C_{\mathrm{d}}(\mathrm{tot})=C_{\mathrm{d}}(\mathrm{aq})+C_{\mathrm{d}}(\mathrm{ads})=C_{\mathrm{d}}(\mathrm{aq})+\frac{C_{\mathrm{X}}(\mathrm{tot})-C_{\mathrm{x}}(\mathrm{aq})}{C_{\mathrm{x}}(\mathrm{aq})} C_{\mathrm{d}}(\mathrm{aq})
$$

where $C_{\mathrm{d}}$ (tot) and $C_{\mathrm{x}}$ (tot) represent the total concentrations of natural $\mathrm{Hg}$ (from $\mathrm{HgS}$ dissolution) and spiked ${ }^{202} \mathrm{Hg}$ in the suspension solution (referring to the volume of cinnabar suspension solution).

\subsubsection{Applying the developed technique to study cinnabar dissolution and $\mathrm{Hg}^{2+}$ re- adsorption}

The developed technique was applied to determine the concentrations of $\mathrm{Hg}$ readsorbed on cinnabar surface $\left(C_{\mathrm{d}}(\mathrm{ads})\right)$ and the total amount of $\mathrm{Hg}$ released from cinnabar $\left(C_{\mathrm{d}}\right.$ (tot) $)$. The results showed that the spiked ${ }^{202} \mathrm{Hg}^{2+}$ adsorbed on the cinnabar surface quickly under both oxic and anoxic conditions, as illustrated by the rapid decrease in the dissolved ${ }^{202} \mathrm{Hg}^{2+}$ concentrations in the first 6 hours (Fig. 2.2A and 2.2B). For the treatment purged with $\mathrm{N}_{2}$, the variations in both the released $\mathrm{Hg}$ present in the aqueous phase and the total amount of released $\mathrm{Hg}$ were observed to be insignificant ( $p>0.1$, one-way ANOVA) during the course of experiment (54 hours), indicating that dissolution of $\mathrm{Hg}$ from cinnabar was negligible under anaerobic condition. In the presence of $\mathrm{O}_{2}$, detectable amount of $\mathrm{Hg}$ was dissolved from cinnabar, indicated by the continuous increase of both $C_{\mathrm{d}}(\mathrm{aq})$ and $C_{\mathrm{d}}$ (tot) with time (Fig. 2.2D). The concentration of total released $\mathrm{Hg}$ was estimated to be more than $300 \mu \mathrm{g} \mathrm{L}^{-1}$ after 54 hours. The results suggest that $\mathrm{O}_{2}$ can enhance the dissolution of cinnabar, in agreement with most previous studies $(56,57,69,70)$. Oxygen is expected 
to oxidize $\mathrm{S}^{2-}$ (one product of cinnabar dissolution) to $\mathrm{SO}_{4}{ }^{2-}$, and thus facilitating the dissolution of cinnabar. The dissolution product, $\mathrm{S}^{2-}$, could also be converted to $\mathrm{HS}^{-}$and $\mathrm{H}_{2} \mathrm{~S}$ under anaerobic condition and subsequently facilitate cinnabar dissolution (52). Results of this study support the notion that oxidization of $\mathrm{S}^{2-}$ to $\mathrm{SO}_{4}{ }^{2-}$ may play a more important role in cinnabar dissolution.

The importance of $\mathrm{Hg}$ re-adsorption in assessing cinnabar dissolution was evaluated by comparing the amount of released $\mathrm{Hg}$ from cinnabar with and without the consideration of the re-adsorption of the released $\mathrm{Hg}$ on cinnabar. As shown in Fig. 2.2D, the concentrations of total released $\mathrm{Hg}$ were found to be much higher than that in the solution ( 2 times), suggesting that a large proportion of the released $\mathrm{Hg}$ from cinnabar was re-adsorbed on cinnabar surface. To further evaluate the importance of $\mathrm{Hg}$ re-adsorption on cinnabar dissolution, parameters relevant to the adsorption of $\mathrm{Hg}$ and the dissolution of cinnabar were calculated using equations in table 2.1. Variations of the spiked ${ }^{202} \mathrm{Hg}$ fitted well with the pseudo-second order model, as indicated by the high value of $\mathrm{R}^{2}$ (0.9999) (Fig. 2.3A). Dissolution of cinnabar could be well predicted by the first order reaction equation $\left(\mathrm{R}^{2}=\right.$ 0.9898, Fig. 2.3B). Cinnabar dissolution rate constant was estimated to be $0.0208 \mathrm{~h}^{-1}$ when considering the re-adsorption of $\mathrm{Hg}$ on cinnabar surface by using the new method developed in this study (Table 2.1). If only the released $\mathrm{Hg}$ in the aqueous phase $\left(C_{\mathrm{d}}(\mathrm{aq})\right)$ was taken into account, this rate constant would decrease to $0.0109 \mathrm{~h}^{-1}$ (Fig. 2.3C), indicating that ignoring the re-adsorption of $\mathrm{Hg}$ on cinnabar surface would significantly underestimate the dissolution rate of cinnabar. 

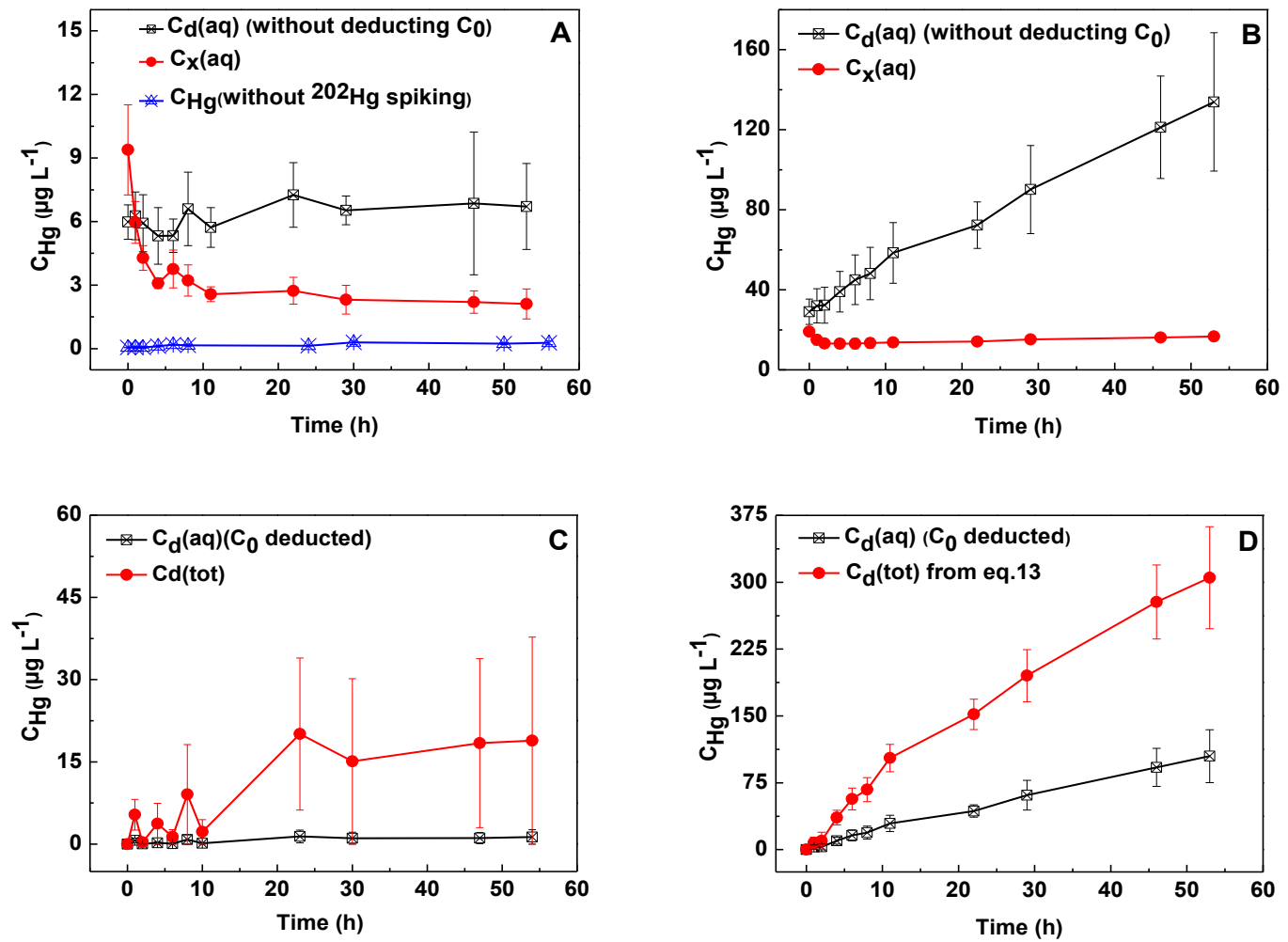

Figure 2.2 Variations of spiked ${ }^{202} \mathrm{Hg}^{2+}$ in aqueous phase $\left(\mathrm{C}_{\mathrm{X}}(\mathrm{aq})\right), \mathrm{Hg}$ dissolved from cinnabar in aqueous phase $\left(\mathrm{C}_{\mathrm{d}}(\mathrm{aq})\right)$, and the total $\mathrm{Hg}$ dissolved from cinnabar $\left(\mathrm{C}_{\mathrm{d}}(\right.$ tot $\left.)\right)$. A and $\mathrm{C}$, purged with $\mathrm{N}_{2} ; \mathrm{B}$ and $\mathrm{D}$, purged with $\mathrm{O}_{2}$. Since $\mathrm{C}_{\mathrm{d}}(\mathrm{aq})$ at time 0 was likely resulted from the isotopic replacement of natural $\mathrm{Hg}$ adsorbed on cinnabar by the spiked ${ }^{202} \mathrm{Hg}^{2+}$, rather than the cinnabar dissolution, this $\mathrm{Hg}$ was deducted from the measured $\mathrm{C}_{\mathrm{d}}(\mathrm{aq})$ when calculating the total released $\mathrm{Hg}$ from cinnabar $\left(\mathrm{C}_{\mathrm{d}}(\right.$ tot $\left.)\right)$.

As shown in Fig. 2.2A, natural $\mathrm{Hg}^{2+}$ in the solution was approximately $6 \mu \mathrm{g} \mathrm{L}^{-1}$ at the beginning of the experiment $(0 \mathrm{~h})$, while the concentration for the control treatment (without the addition of ${ }^{202} \mathrm{Hg}^{2+}$ ) was less than $1 \mu \mathrm{g} \mathrm{\textrm {L } ^ { - 1 }}$. The high concentration of natural $\mathrm{Hg}$ occurred in the solution after the addition of ${ }^{202} \mathrm{Hg}^{2+}$ could be caused by the instant adsorption of spiked ${ }^{202} \mathrm{Hg}^{2+}$ on cinnabar and the subsequent replacement of natural $\mathrm{Hg}$ from cinnabar surface. Although cinnabar particles were cleaned for several times with 1 mol $\mathrm{L}^{-1}$ nitric acid and DI water prior to the experiment, there could be still some $\mathrm{Hg}$ ions adsorbed loosely on the surface. This assumption was further tested by measuring the 
amount of replaced $\mathrm{Hg}$ with different initial concentrations of ${ }^{201} \mathrm{Hg}^{2+}$ spiked (Fig. S3). As shown in Fig. S3, the concentrations of $\mathrm{Hg}$ were less than $1 \mu \mathrm{g} \mathrm{L} \mathrm{L}^{-1}$ before ${ }^{201} \mathrm{Hg}^{2+}$ was spiked. An instant increase in $\mathrm{Hg}^{2+}$ was observed after spiking ${ }^{201} \mathrm{Hg}^{2+}$ for all treatments. In addition, the concentrations of natural $\mathrm{Hg}^{2+}$ increased gradually with the increasing concentration of spiked ${ }^{201} \mathrm{Hg}^{2+}$ (more ${ }^{201} \mathrm{Hg}^{2+}$ was instantly adsorbed on cinnabar). These results indicate that the initial increase in $\mathrm{Hg}$ concentration may be due to the isotopic replacement of the residual adsorbed $\mathrm{Hg}$ on cinnabar with the spiked isotope-enriched $\mathrm{Hg}$, rather than the cinnabar dissolution. Therefore, this $\mathrm{Hg}$ was deducted from the measured $C_{\mathrm{d}}(\mathrm{aq})$ when calculating the total released $\mathrm{Hg}$ from cinnabar dissolution $\left(C_{\mathrm{d}}(\right.$ tot $\left.)\right)$.

For traditional isotope dilution methods, $\mathrm{Hg}$ isotope ratios in the solution are expected to be a known constant (natural abundance of $\mathrm{Hg}$ in most cases) (143-147). However, $\mathrm{Hg}$ isotope ratios would change with time when investigating dynamic processes in which isotope tracers were spiked. For example, isotope ratios in the filtrates changed over time (Fig. 2.2) accompanying $\mathrm{Hg}$ dissolution from cinnabar and adsorption of the spiked ${ }^{202} \mathrm{Hg}^{2+}$ in this study. If traditional isotope dilution approaches are adopted, $\mathrm{Hg}$ isotope ratios in the filtrates before the addition of ${ }^{199} \mathrm{Hg}^{2+}$ should also be analyzed as well as that in the filtrates after spiking ${ }^{199} \mathrm{Hg}^{2+}$. However, this would make the analysis more tedious and may introduce extra errors. In this study, we developed a new isotope dilution method to determine both $\mathrm{Hg}$ released from cinnabar and residual spiked enriched $\mathrm{Hg}$ in the aqueous phase according to the detected $\mathrm{Hg}$ ratios in only the filtrates after spiking ${ }^{199} \mathrm{Hg}^{2+}$ at each sampling time. This method may also be applicable in studying other dynamic processes of $\mathrm{Hg}$ using isotope tracer techniques. 

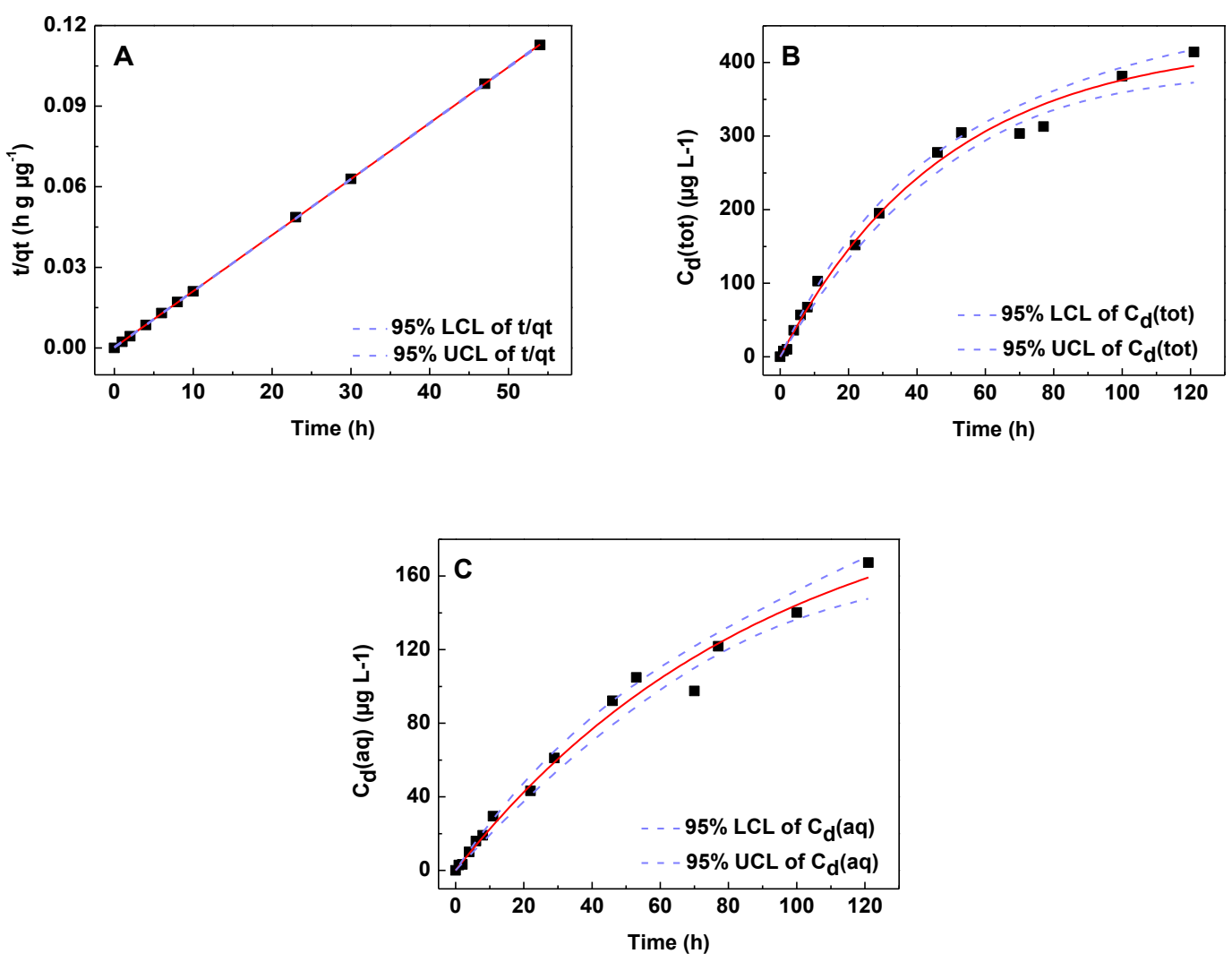

Figure 2.3 Nonlinear regressions of spiked ${ }^{202} \mathrm{Hg}(\mathrm{A})$, total dissolved $\mathrm{Hg}(\mathrm{B})$, and dissolved $\mathrm{Hg}$ in the aqueous phase $(\mathrm{C})$ against time.

\subsubsection{Thermodynamics of $\mathrm{Hg}$ adsorption on cinnabar and validation of the developed method}

Thermodynamics of $\mathrm{Hg}$ adsorption on cinnabar were investigated by using the isotopetracer method. As shown in Fig. 2.4A, percentage of ${ }^{202} \mathrm{Hg}$ adsorbed on cinnabar decreased from 94 to $48 \%$ with the increase of initial ${ }^{202} \mathrm{Hg}^{2+}$ concentration from 0 to $400 \mu \mathrm{g} \mathrm{L} \mathrm{L}^{-1}$, while the equilibrium adsorption capacity increased from 94 to $1930 \mu \mathrm{g} \mathrm{g}^{-1}$. At higher concentrations of initial $\mathrm{Hg}$, adsorption sites on cinnabar may be over occupied which could explain the negative relation of $\mathrm{Hg}$ removal efficiency with initial $\mathrm{Hg}$ concentration (148). The increasing equilibrium adsorption capacity at higher $\mathrm{Hg}$ concentrations could 
be attributed to higher adsorption rate at higher concentration and occupation of more available active sites (140). Nonlinear regression of the equilibrium adsorption capacity $q_{\mathrm{e}}$ $\left(\mu \mathrm{g} \mathrm{g}^{-1}\right)$ against the equilibrium concentration of ${ }^{202} \mathrm{Hg}^{2+} C_{\mathrm{e}}\left(\mu \mathrm{g} \mathrm{L}^{-1}\right)$ using both Langmuir and Freundlich models was performed to estimate parameters of isotherms. Langmuir model predicted the experimental data better than Freundlich model, indicated by its higher $\mathrm{R}^{2}$ (Table 2.1, and Fig. 2.4B).

Table 2.1 Parameters of adsorption kinetics and isotherms of $\mathrm{Hg}$ on cinnabar using different models (in the absence of $\mathrm{O}_{2}$ ) and dissolution (in the present of $\mathrm{O}_{2}$ )

\begin{tabular}{|c|c|c|c|}
\hline Kinetic models & Parameters & Values & $\overline{\mathbf{R}^{2}}$ \\
\hline The pseudo-second order rate equation & $q_{\mathrm{e}}\left(\mu \mathrm{g} \mathrm{g}^{-1}\right)$ & 485.4 & \multirow[b]{2}{*}{0.9999} \\
\hline$\frac{d q_{\mathrm{t}}}{d \mathrm{t}}=k_{1}\left(q_{\mathrm{e}}-q_{\mathrm{t}}\right)^{2} \quad \frac{t}{q_{\mathrm{t}}}=\frac{1}{K_{2} q_{\mathrm{e}}^{2}}+\frac{1}{q_{\mathrm{e}}} t$ & $K_{2}\left(\mathrm{~g} \mathrm{\mu g}^{-1} \mathrm{~h}^{-1}\right)$ & 0.00663 & \\
\hline Dissolution kinetic model & $\mathrm{C}_{0}(\mathrm{tot})\left(\mu \mathrm{g} \mathrm{\textrm {L } ^ { - 1 }}\right)$ & 430.26 & \multirow{2}{*}{0.9898} \\
\hline$C=C_{0} \cdot\left(1-e^{-k \mathrm{t}}\right)$ & $K($ tot $)\left(\right.$ hour $\left.^{-1}\right)$ & 0.0208 & \\
\hline & $C_{0}(\mathrm{aq})\left(\mu \mathrm{g} \mathrm{L}^{-1}\right)$ & 217.55 & \multirow{2}{*}{0.9851} \\
\hline & $K(\mathrm{aq})\left(\right.$ hour $\left.^{-1}\right)$ & 0.0109 & \\
\hline Langmuir model & $q_{\mathrm{m}}\left(\mu \mathrm{g} \mathrm{g}^{-1}\right)$ & 2137.1 & \multirow[b]{2}{*}{0.9952} \\
\hline$q_{\mathrm{e}}=\frac{q_{\mathrm{m}} k_{\mathrm{L}} C_{\mathrm{e}}}{1+k_{\mathrm{L}} C_{\mathrm{e}}}$ & $K_{\mathrm{L}}\left(\mathrm{L} \mu \mathrm{g}^{-1}\right)$ & 0.0450 & \\
\hline Freundlich model & $K_{\mathrm{F}}$ & 275.89 & \multirow{2}{*}{0.9390} \\
\hline$q_{\mathrm{e}}=K_{\mathrm{F}} C_{\mathrm{e}}^{1 / \mathrm{n}}$ & $1 / \mathrm{n}$ & 0.375 & \\
\hline
\end{tabular}

In order to derive the equation for calculating the total released $\mathrm{Hg}\left(C_{\mathrm{d}}(\right.$ tot $\left.)\right)$, it was assumed that the isotope ratios of $\mathrm{Hg}$ in the solution were identical with that adsorbed on cinnabar (Eq. (2.7)). This assumption was formulated based partially on that the rates of $\mathrm{Hg}$ adsorption/desorption were much higher than cinnabar dissolution. As shown in Fig. 2.2B and 2.2D, the dissolution of cinnabar has not achieved equilibrium at the end of the 
experiments (54 hours), while the equilibrium time for $\mathrm{Hg}$ adsorption was determined to be less than 6 hours, supporting this assumption. In order to further verify the hypothesis, the concentrations of dissolved $\mathrm{Hg}$ in the solution $C_{\mathrm{d}}$ (tot) were also calculated based on the thermodynamic model (Langmuir model). Total Hg detected at $\mathrm{t}$ time can be considered as $C_{\mathrm{e}}$ (i.e. $\left.C_{\mathrm{d}}(\mathrm{aq})+C_{\mathrm{x}}(\mathrm{aq})\right)$. Parameters $\left(K_{\mathrm{L}}\right.$ and $\left.q_{\mathrm{m}}\right)$ obtained from the thermodynamic experiments in the presence of $\mathrm{N}_{2}$ were adopted. By using Langmuir model, total adsorbed $\mathrm{Hg}$ on cinnabar can be calculated as (Eq. (S1)) $C_{\mathrm{d}+\mathrm{x}}$ (ads). Then, the total amount of dissolved $\mathrm{Hg}$ can be estimated as:

$$
C_{\mathrm{d}}(\text { tot })=C_{\mathrm{d}}(\mathrm{aq})+C_{\mathrm{d}}(\mathrm{ads})=C_{\mathrm{d}}(\mathrm{aq})+\left(C_{\mathrm{d}+\mathrm{x}}(\mathrm{ads})-C_{\mathrm{x}}(\mathrm{ads})\right)
$$

The comparisons of total released Hg calculated by both methods (Eqs. 2.7 and 2.12) were shown in Fig. 2.5. In the present of $\mathrm{O}_{2}$, the total dissolved $\mathrm{Hg}$ estimated by Langmuir model (Eq. (2.12)) was observed to be higher than that estimated using the newly developed method for the first 6 hours, and then became very close with time (Fig. 2.5B). This is reasonable since the adsorption of spiked $\mathrm{Hg}$ had not achieved equilibrium at the beginning of the experiment, which was expected to result in the overestimation of $\mathrm{Hg}$ adsorbed on cinnabar if Langmuir model was adopted. Dissolved $\mathrm{Hg}$ estimated using both methods were observed to be similar ( $p>0.05$, two-way ANOVA), especially after 6 hours ( $p>0.1$, two-way ANOVA, with an average RSD of 9.9\% (2.4-16.6\%) when $\mathrm{Hg}$ in the aqueous phase and cinnabar surface was expected to be equilibrated. These results further support the hypothesis that the isotope ratio of $\mathrm{Hg}$ in the solution is approximately identical with that adsorbed on cinnabar, suggesting the reliability of the proposed method in estimating the real dissolution of cinnabar. On the basis of these validations, the proposed method is expected to be a reliable technique in studying the dissolution of cinnabar. 
Isotope tracers have been already used for determining adsorption and desorption processes $(73,83)$. It has also been applied in investigating the methylation rates of geochemically relevant inorganic $\mathrm{Hg}$ (II) species, including isotopically labeled cinnabar, metacinnabar, adsorbed $\mathrm{Hg}(\mathrm{II})$, and complexed $\mathrm{Hg}(\mathrm{II})$ (84). The application of the newly developed isotope tracer techniques in this study provides new insights on how $\mathrm{Hg}$ dissolution occurs, evidencing the importance of re-adsorption process. The estimated dissolution rate without considering the re-adsorption is much lower than that with the consideration of re-adsorption on cinnabar surface. The cinnabar dissolution rates with the consideration of the $\mathrm{Hg}$ adsorbed on cinnabar surface have been previously estimated using an indirect method, from the increase in the concentration of $\mathrm{SO}_{4}{ }^{2-}$ in the solution. However, it should be noted that the calculation of $\mathrm{Hg}$ dissolution rates from changes in $\mathrm{SO}_{4}{ }^{2-}$ concentration could underestimate the dissolution rate since sulfide oxidation intermediates (e.g., $\mathrm{S}_{2} \mathrm{O}_{3}{ }^{2-}$ ) also exist in the solution or on the cinnabar surface (69). In addition, this method cannot be applied in quantitatively measuring cinnabar dissolution rates under natural conditions, where a variety of factors (e.g., Eh, DOM, pH) can affect the transformations of sulfur, resulting in a large variation in the ratio of released $\mathrm{Hg}$ to $\mathrm{SO}_{4}{ }^{2-}$. In de-ionized water, the dissolution rates within $48 \mathrm{~h}$ were determined to be 0.71 to $0.82 \mu \mathrm{mol}\left(\mathrm{SO}_{4}{ }^{2-}\right) \mathrm{m}^{-2}$ day $^{-1}$ for cinnabar (69). This rate (within $48 \mathrm{~h}$ ) was calculated to be $3.63 \mu \mathrm{mol} \mathrm{m}{ }^{-2}$ day $^{-1}$ using the new method developed in this study, larger than that determined by the generated $\mathrm{SO}_{4}{ }^{2-}$, which is supposed to underestimate the dissolution rate. The thermodynamic parameters of $\mathrm{Hg}^{2+}$ adsorption on cinnabar, i.e., $q_{\mathrm{m}}$ (the maximum monolayer adsorption capacity) and $K_{\mathrm{L}}$ (the Langmuir constant) were also estimated using isotope tracer techniques. The estimated $q_{\mathrm{m}}$ of $\mathrm{Hg}^{2+}$ adsorption on cinnabar $\left(2137.1 \mu \mathrm{g} \mathrm{g}^{-1}\right)$ 
was only one order of magnitude less than the values on some clays, illustrating the high affinity of $\mathrm{Hg}^{2+}$ toward $\mathrm{Hg}$ (e.g., Sepiolite, $q_{\mathrm{m}}=34.1 \mathrm{mg} \mathrm{g}^{-1}$ and Montmorillonite, $q_{\mathrm{m}}=$ $50.2 \mathrm{mg} \mathrm{g}^{-1}$ ). These clays have already been proposed to have the capability of removing $\mathrm{Hg}$ from polluted environmental water (149).
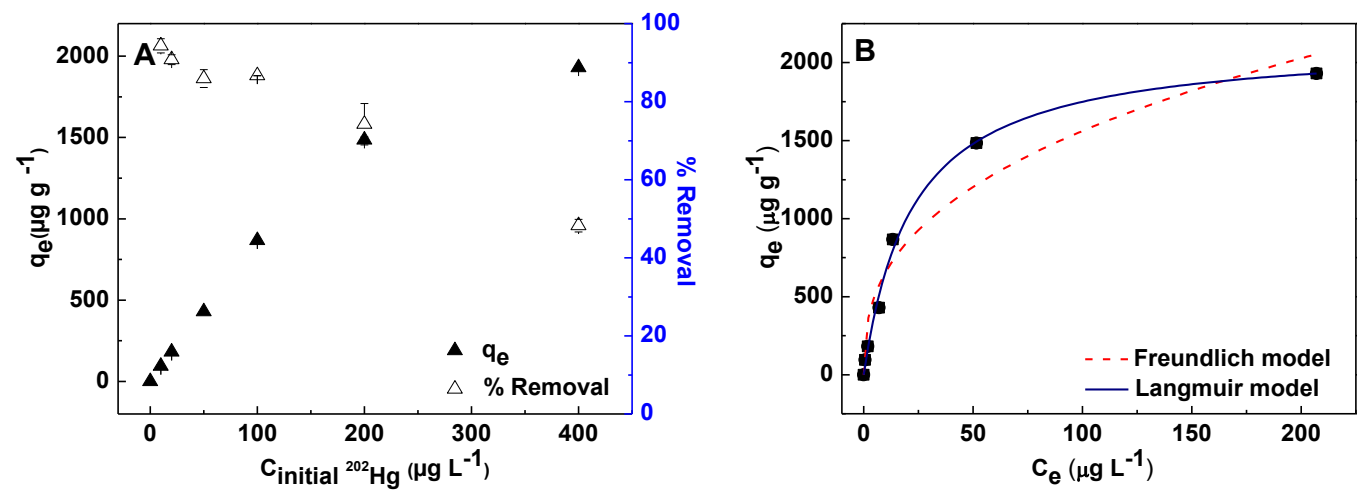

Figure 2.4 The thermodynamic of ${ }^{202} \mathrm{Hg}^{2+}$ adsorption on cinnabar. A, variation of equilibrium concentrations of ${ }^{202} \mathrm{Hg}\left(\mu \mathrm{g} \mathrm{L}^{-1}\right)$ at $24 \mathrm{~h}$ with different initial ${ }^{202} \mathrm{Hg}^{2+}$ concentrations $(0,10,20,50$, $\left.100,200,400 \mu \mathrm{g} \mathrm{L}^{-1}\right)$. B, non-linear regression of $\mathrm{q}_{\mathrm{e}}$ against $\mathrm{C}_{\mathrm{e}}$ using Langmuir and Freundlich models $\left(\mathrm{T}=20^{\circ} \mathrm{C}\right)$.
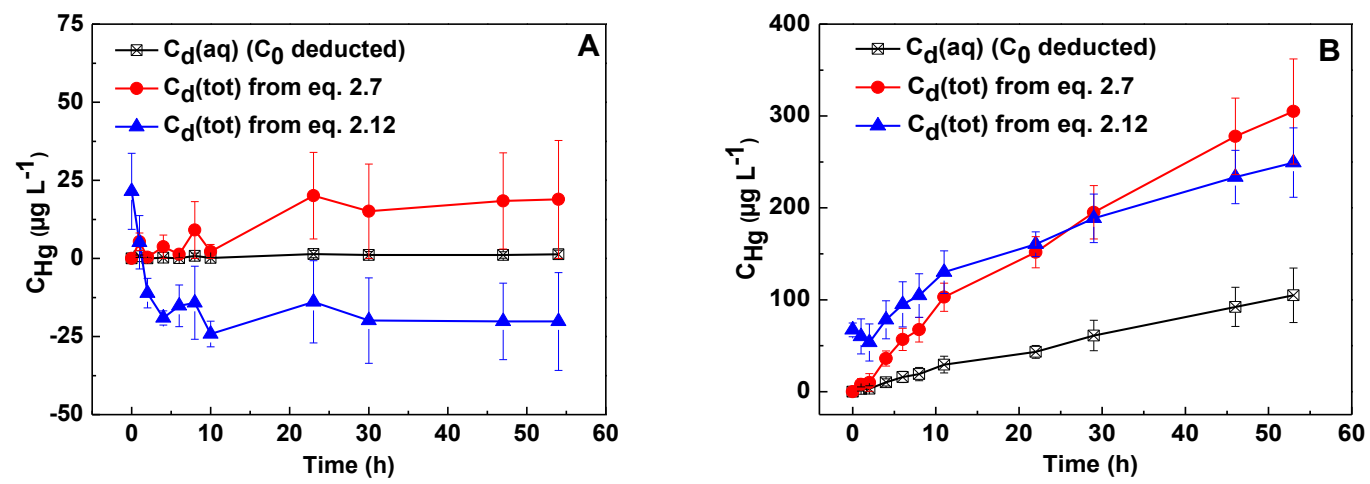

Figure 2.5 Comparisons of total dissolved $\mathrm{Hg}$ estimated by the thermodynamic equilibrium using Langmuir model (Eq.2.12) and by the new method developed in this study (Eq. 2.7). A, without $\mathrm{O}_{2}$ (purging with $\mathrm{N}_{2}$ ); B, with $\mathrm{O}_{2}$ (purging with $\mathrm{O}_{2}$ ).

Dissolution of cinnabar can serve as a continuous source for bioavailable $\mathrm{Hg}^{2+}$ in the environment, and subsequently enhances the methylation process and increasing the amount of more toxic methylmercury. Due to the lack of a feasible technique for measuring 
$\mathrm{Hg}$ adsorbed on cinnabar, only the $\mathrm{Hg}$ detected in the aqueous phase was considered to be dissolved from cinnabar in previous studies $(57,69)$, although several of which have speculated that dissolved $\mathrm{Hg}$ from cinnabar surface could be re-adsorbed back onto cinnabar surface $(56,57,69)$. The developed isotope tracer method makes it possible to simultaneously monitor both the dissolution and re-adsorption of $\mathrm{Hg}$. A variety of environmental factors, including $\mathrm{pH}$, redox potential (Eh), and $\mathrm{Hg}$ binding ligands (57, 60, 63, 69), are expected to enhance or inhibit cinnabar dissolution via affecting the fate of cinnabar dissolution products and $\mathrm{Hg}$ adsorption/desorption. It should be noted that experiments in this study were conducted in a dilute $\mathrm{NaNO}_{3}$ solution system without the addition of any inorganic or organic ligands. Future work of applying the developed method in determining cinnabar dissolution in natural waters would be helpful for better understanding the importance of cinnabar dissolution in $\mathrm{Hg}$ cycling.

\subsection{Conclusions}

In this study, an isotope tracer based method was developed to investigate both dissolution and re-adsorption of $\mathrm{Hg}$ during the course of cinnabar dissolution. The rationale of the proposed method is that re-adsorbed $\mathrm{Hg}$ on cinnabar surface can be estimated from decreasing in the amount of spiked isotope-enriched $\mathrm{Hg}\left({ }^{202} \mathrm{Hg}^{2+}\right)$ in aqueous phase. A modified isotope dilution method $\left({ }^{199} \mathrm{Hg}^{2+}\right)$ was developed to simultaneously calculate $\mathrm{Hg}$

originated from cinnabar dissolution and residual spiked ${ }^{202} \mathrm{Hg}^{2+}$ in the filtrates. The amount of re-adsorbed $\mathrm{Hg}$ was calculated from the adsorption of spiked ${ }^{202} \mathrm{Hg}^{2+}$ on cinnabar based on the validated assumption that the isotope ratios of $\mathrm{Hg}$ in the aqueous phase are approximately equal to that adsorbed on cinnabar. By using the developed method, cinnabar dissolution rate with the consideration of $\mathrm{Hg}$ re-adsorption using the 
newly developed method $\left(0.0208 \mathrm{~h}^{-1}\right)$ was approximately 2 times the value calculated solely from the $\mathrm{Hg}$ detected in the aqueous phase $\left(0.0109 \mathrm{~h}^{-1}\right)$. The results suggest that readsorption of $\mathrm{Hg}$ on cinnabar surface play an important role in accurately evaluating cinnabar dissolution, and omission of the $\mathrm{Hg}$ re-adsorbed on cinnabar surface would significantly underestimate the importance of cinnabar dissolution in $\mathrm{Hg}$ cycling. Experiments in this study were conducted in a simulated system without the addition of any inorganic or organic ligands. Future work of applying the developed method in determining cinnabar dissolution in natural waters with different water chemical characteristics is necessary for better understanding the importance of cinnabar dissolution in Hg cycling.

\section{Supplementary Data}

\section{Reagents}

Metallic ${ }^{202} \mathrm{Hg} \quad\left({ }^{202} \mathrm{Hg}(0), \quad 99.20 \%\right)$ was purchased from Cambridge Isotope Laboratories (Andover, MA). Enriched ${ }^{201} \mathrm{HgO}$ (atomic percentage, $96.17 \pm 0.56 \%$ ) and ${ }^{199} \mathrm{HgO}$ (atomic percentage, $91.09 \pm 0.05 \%$ ) were from Oak Ridge National Laboratory (Oak Ridge, Tennessee). ${ }^{202} \mathrm{Hg}\left(\mathrm{NO}_{3}\right)_{2}$ (measured atomic percentage, 99.70\%) was prepared by dissolving ${ }^{202} \mathrm{Hg}(0)$ in concentrated $\mathrm{HNO}_{3}$, while ${ }^{201} \mathrm{HgCl}_{2}$ (measured atomic percentage, 96.17\%) and ${ }^{199} \mathrm{HgCl}_{2}$ solution (measured atomic percentage, $90.66 \%$ ) were

prepared by dissolving ${ }^{201} \mathrm{HgO}$ and ${ }^{199} \mathrm{HgO}$ in $10 \% \mathrm{HCl}(\mathrm{v} / \mathrm{v})$. Cinnabar ( $\left.\mathrm{HgS}, 99 \%\right)$ was purchased from Sigma-Aldrich. Concentrated nitric acid and hydrochloric acid were trace metal grade (Fisher Scientific). Stannous chloride $\left(\mathrm{SnCl}_{2} \cdot 2 \mathrm{H}_{2} \mathrm{O}, 99.2 \%\right)$ and other chemicals were all reagent grade or higher (Fisher Scientific). Argon, nitrogen and oxygen (ultra high purity) were purchased from Airgas. $\mathrm{NaNO}_{3} / \mathrm{NaOH}$ solution was prepared by 
adding $0.01 \mathrm{~mol} \mathrm{~L}^{-1} \mathrm{NaOH}$ into $10 \mu \mathrm{mol} \mathrm{L} \mathrm{L}^{-1} \mathrm{HNO}_{3}$ solution until achieving $\mathrm{pH}$ 8.0. ${ }^{202} \mathrm{Hg}\left(\mathrm{NO}_{3}\right)_{2}$ was used for the kinetic dissolution and thermodynamic $\mathrm{Hg}$ adsorption experiments, tracing the adsorption processes of $\mathrm{Hg}^{2+}$ on cinnabar surface. ${ }^{199} \mathrm{HgCl}_{2}$ was utilized in all conducted experiments when analyzing $\mathrm{Hg}^{2+}$ concentrations using isotope dilution method, serving as an internal standard. ${ }^{201} \mathrm{HgCl}_{2}$ was adopted to investigate $\mathrm{Hg}$ isotope replacement.

\section{Selection of proper filter for cinnabar suspension filtration}

A proper filter for cinnabar suspension filtration should not adsorb $\mathrm{Hg}$ in the aqueous phase. Experiments were conducted to test the adsorption of $\mathrm{Hg}$ on four commercial filters (0.22 $\mu \mathrm{m}$ PTFE, $0.45 \mu \mathrm{m}$ PTFE, $0.22 \mu \mathrm{m}$ PVDF and $0.45 \mu \mathrm{m}$ PVDF filters) at different $\mathrm{pH}$ (4-6, and 8). PVDF and PTFE membranes were selected as the candidate filters since $\mathrm{Hg}$ is considered to have a weak affinity with these two materials. ${ }^{201} \mathrm{Hg}^{2+}$ in $\mathrm{NaNO}_{3} / \mathrm{NaOH}$ solution $\left(50 \mu \mathrm{g} \mathrm{L} \mathrm{L}^{-1}\right)$ with a $\mathrm{pH}$ of 4-6 and 8 was filtered through the candidate filters, and ${ }^{201} \mathrm{Hg}^{2+}$ concentrations in the filtrates were determined by the isotope-dilution method. PTFE membranes (both the $0.22 \mu \mathrm{m}$ and the $0.45 \mu \mathrm{m}$ ) and $0.45 \mu \mathrm{m}$ PVDF membrane showed a good recovery of $\mathrm{Hg}(>95 \%)$ at all the tested $\mathrm{pH}$ (Table S2). However, a bad recovery was observed for the $0.22 \mu \mathrm{m}$ PVDF filter, especially at higher $\mathrm{pH}(<10 \%)$. Since a smaller size of filter can reduce the amount of residual small-size particles in the filtrates, $0.22 \mu \mathrm{m}$ PTFE filter was chosen to be used in this study.

Table S2. Recoveries of spiked ${ }^{201} \mathrm{Hg}^{2+}$ after getting through different filters

\begin{tabular}{|c|c|c|c|c|}
\hline pH\Recovery\% & $\begin{array}{l}0.22 \mu \mathrm{m} \text { PTFE } \\
\text { filter(17mm) }\end{array}$ & $\begin{array}{l}0.45 \mu \mathrm{m} \text { PTFE } \\
\text { filter }(33 \mathrm{~mm})\end{array}$ & $\begin{array}{l}0.22 \mu \mathrm{m} \text { PVDF } \\
\text { filter }(33 \mathrm{~mm})\end{array}$ & $\begin{array}{l}0.45 \mu \mathrm{m} \text { PVDF } \\
\text { filter(17mm) }\end{array}$ \\
\hline $4-6$ & $99 \% \pm 2.2 \%$ & $97 \% \pm 2.2 \%$ & $10 \% \pm 80 \%$ & $97 \% \pm 1.8 \%$ \\
\hline 8 & $96 \% \pm 2.2 \%$ & $96 \% \pm 1.5 \%$ & $5 \% \pm 24 \%$ & $96 \% \pm 3.0 \%$ \\
\hline
\end{tabular}




\section{Determination of mercury isotopes in the solution}

Dissolved mercury isotopes were analyzed using a flow injection analysis system (FIAS 400, from Perkin Elmer company, MA) coupled with a ICP/MS (ELAN DRC-e ICP/MS from Perkin-Elmer company, MA). By using the FIAS system, a sample loop on the flow injection valve was filled with the acidified sample, blank or standard. $3 \%$ hydrochloric acid was adopted as the carrier solution. $\mathrm{Hg}^{2+}$ was reduced to gaseous mercury vapors by mixing with a pumped stream of $1.1 \% \mathrm{SnCl}_{2}$. Generated $\mathrm{Hg}^{0}$ was then introduced into the ICP/MS via a gas/liquid separator and $\mathrm{Hg}$ isotopes were detected. Parameters for the set-up of the ICP/MS were illustrated in Table S3.

Table S3. General operating settings of the ICP/MS system

\begin{tabular}{ll}
\hline Parameters & Values \\
\hline Nebulizer gas flow(NEB) (L min-1) & 0.89 \\
Auxiliary gas flow (L min-1) & 1.2 \\
Plasma gas flow (L min-1) & 14 \\
RF power (W) & 1400 \\
Lens Voltage (V) & 11.25 \\
Dead time of detector (ns) & 55 \\
\hline
\end{tabular}

\section{Isotherms of $\mathrm{Hg}$ adsorption on cinnabar}

Langmuir (Eq. (S1)) and Freundlich isotherms (Eq. (S2)) (134-140) are the two most commonly used adsorption isotherm equations which have been utilized to describe the adsorption of metal ions (including $\mathrm{Hg}$ ) on solid adsorbents. Both models were adopted here to calculate the thermodynamic parameters of $\mathrm{Hg}$ adsorption on cinnabar. Nonlinear regression of $q_{\mathrm{e}}$ against $C_{\mathrm{e}}$ was conducted using OriginPro 8 (OriginLab) to calculate the parameters related to the $\mathrm{Hg}$ adsorption on cinnabar $\left(q_{\mathrm{m}}\right.$ and $K_{\mathrm{L}}, K_{\mathrm{F}}$ and $\left.\mathrm{n}\right)$.

$$
q_{\mathrm{e}}=\frac{q_{\mathrm{m}} k_{\mathrm{L}} C_{\mathrm{e}}}{1+k_{\mathrm{L}} C_{\mathrm{e}}}
$$




$$
q_{\mathrm{e}}=K_{\mathrm{F}} C_{\mathrm{e}}^{1 / \mathrm{n}}
$$

where $q_{\mathrm{e}}$ is the adsorption capacity at equilibrium $\left(\mu \mathrm{g} \mathrm{g}^{-1}\right), q_{\mathrm{m}}$ is the maximum monolayer

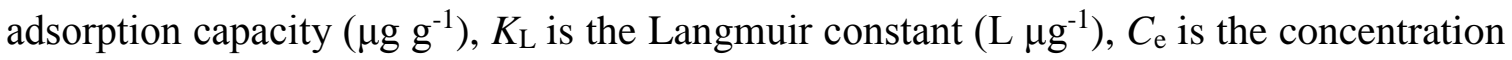
of residual ${ }^{202} \mathrm{Hg}$ in the solution after equilibrium $\left(\mu \mathrm{g} \mathrm{L}^{-1}\right), K_{\mathrm{F}}$ is the Freundlich adsorption capacity constant $\left(\mu \mathrm{g} \mathrm{g}^{-1}\right), \mathrm{n}$ is the Freundlich constant related to the surface heterogeneity. Kinetic parameters related to adsorption of $\mathrm{Hg}$ on cinnabar and dissolution of cinnabar

The kinetic adsorption of $\mathrm{Hg}^{2+}$ on cinnabar can be described as a pseudo-second order reaction (Eq. (S3)) (141) while first order reaction (Eq. (S4)) (142) has been previously used to describe cinnabar dissolution. These models were selected and tested in this study. By integrating Eq. (S3) and (S4), variations in $q_{\mathrm{t}}$ and $C$ with time can be described as Eq. (S5) and (S6), respectively. Nonlinear regression was conducted to calculate the adsorption rate constant $\left(K_{2}\right)$ and dissolution rate constant of cinnabar $(k)$.

$$
\begin{aligned}
& \frac{d q_{\mathrm{t}}}{d \mathrm{t}}=k_{2}\left(q_{\mathrm{e}}-q_{\mathrm{t}}\right)^{2} \\
& \frac{d \mathrm{C}}{d \mathrm{t}}=k\left(C_{0}-C\right) \\
& \frac{t}{q_{\mathrm{t}}}=\frac{1}{K_{2} q_{\mathrm{e}}^{2}}+\frac{1}{q_{\mathrm{e}}} \mathrm{t} \\
& C=C_{0} \cdot\left(1-e^{-k \mathrm{t}}\right)
\end{aligned}
$$

Where $q_{\mathrm{t}}$ is the adsorption capacity at time $\mathrm{t}\left(\mu \mathrm{g} \mathrm{g}^{-1}\right), K_{2}$ is the adsorption rate constant $\left(\mathrm{g}_{\mu \mathrm{g}}^{-1} \mathrm{~h}^{-1}\right), C_{0}$ is the concentration of released $\mathrm{Hg}$ after equilibrium $\left(\mu \mathrm{g} \mathrm{L} \mathrm{L}^{-1}\right), C$ is the

concentration of released $\mathrm{Hg}$ at time $\mathrm{t}\left(\mu \mathrm{g} \mathrm{L}^{-1}\right)$, and $k$ is the apparent dissolution rate constant (hour ${ }^{-1}$ ). 


\section{Hg isotope replacement experiments}

Experiments were conducted to assess the replacement between Hg isotopes in the cinnabar adsorbed phase and aqueous phase. $0.04 \mathrm{~g}$ (wt.) pretreated $\mathrm{HgS}$ on $0.45 \mu \mathrm{m}$ PVDF filter was transferred into a $500 \mathrm{~mL}$ Teflon bottle with $400 \mathrm{~mL}$ pH8.0 $\mathrm{NaNO}_{3} / \mathrm{NaOH}$ solution. The final concentration of $\mathrm{HgS}$ suspension was approximately $100 \mathrm{mg} \mathrm{L}^{-1}$. After shaking well, $10 \mathrm{~mL}$ sample was collected from each bottle using a $10 \mathrm{~mL}$ syringe and filtered through a $0.22 \mu \mathrm{m}$ PTFE membrane filter. ${ }^{201} \mathrm{HgCl}_{2}$ was added into the rest bottles with cinnabar suspension to form a final concentration of $1,6,20$, and $50 \mu \mathrm{g} \mathrm{L}^{-1}$ as ${ }^{201} \mathrm{Hg}$, respectively. After shaking well, $10 \mathrm{~mL}$ suspension sample was immediately taken from each bottle and filtered through $0.22 \mu \mathrm{m}$ PTFE membrane. Concentrations of residual spiked ${ }^{201} \mathrm{Hg}$ and natural $\mathrm{Hg}$ in these samples were analyzed using the isotope dilution technique mentioned in the Materials and method part of the main text.

Table S1. Reactions involved in the dissolution of cinnabar in natural environment

\begin{tabular}{lll}
\hline Condition & Equation & Overall equation \\
\hline $\begin{array}{l}\text { In the absence } \\
\text { of } \mathbf{O}_{2}\end{array}$ & $\mathrm{HgS}=\mathrm{Hg}^{2+}+\mathrm{S}^{2-}$ & \\
& $\mathrm{S}^{2-}+\mathrm{H}_{2} \mathrm{O}=\mathrm{HS}^{-}+\mathrm{OH}^{-}(\mathrm{pH}>7)$ & $\mathrm{HgS}_{(s)}+\mathrm{H}_{2} \mathrm{O}=\mathrm{Hg}(\mathrm{HS})^{+}+\mathrm{OH}^{-}$ \\
$\begin{array}{l}\text { In the presence } \\
\text { of } \mathrm{S}_{2}\end{array}$ & $2 \mathrm{O}_{2}+\mathrm{H}_{2} \mathrm{~S}=2 \mathrm{H}_{2} \mathrm{~S}+2 \mathrm{OH}^{-}(\mathrm{pH}<7)$ & $\mathrm{HgS}_{(s)}+\mathrm{H}_{2} \mathrm{O}=\mathrm{Hg}(\mathrm{OH})_{2}+\mathrm{H}^{+}$ \\
$\begin{array}{l}\text { In the present of } \\
\text { ligands }\end{array}$ & $\mathrm{HS}^{-}+2 \mathrm{O}_{2}+\mathrm{OH}^{-}=\mathrm{SO}_{4}^{2-}+\mathrm{H}_{2} \mathrm{O}$ & \\
$\mathrm{Hg}_{(s)}+2 \mathrm{O}_{2}+2 \mathrm{OH}^{-}=\mathrm{Hg}(\mathrm{OH})_{2}+\mathrm{SO}_{4}^{2-}$ \\
\end{tabular}

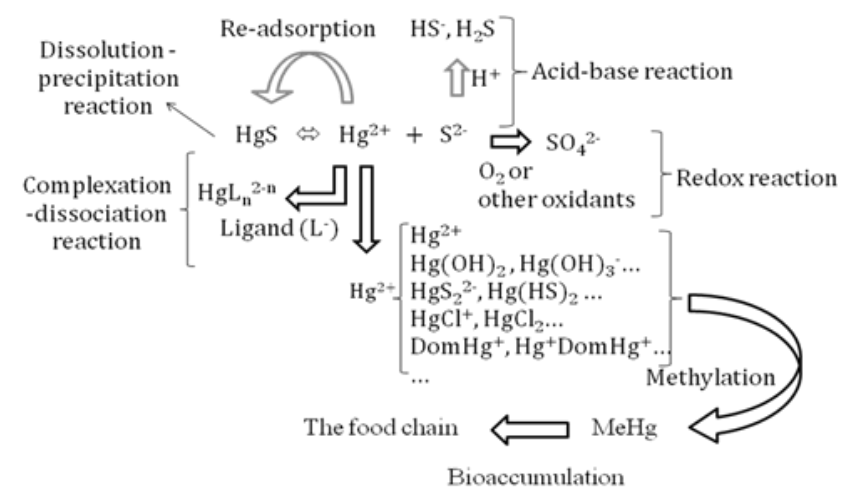

Figure S1. A conceptual model showing the reactions involved in the dissolution of cinnabar. 
Size Distribution by Intensity

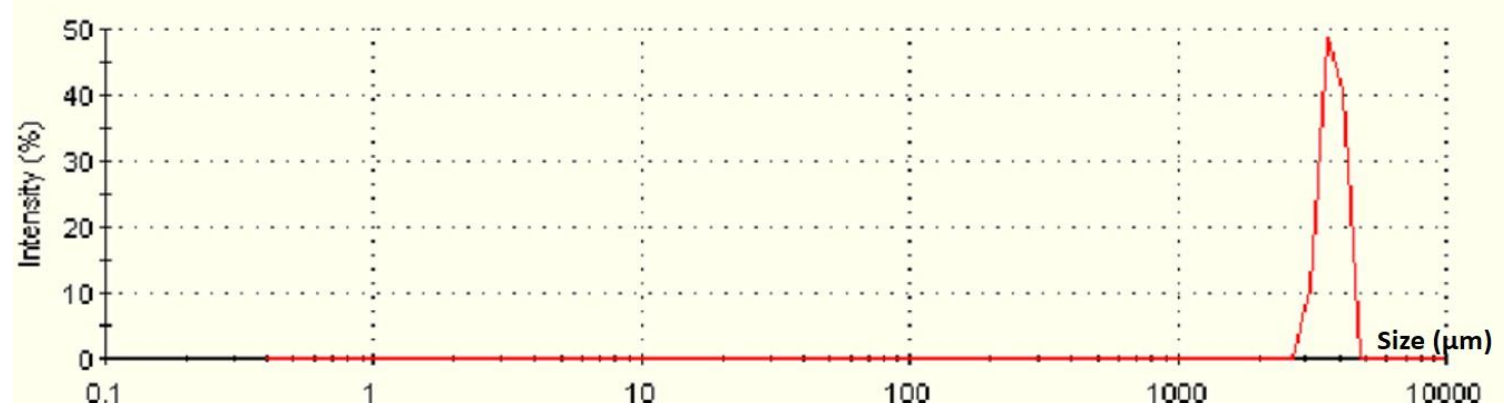

Figure S2. Size distribution of the cinnabar suspension used in this study.

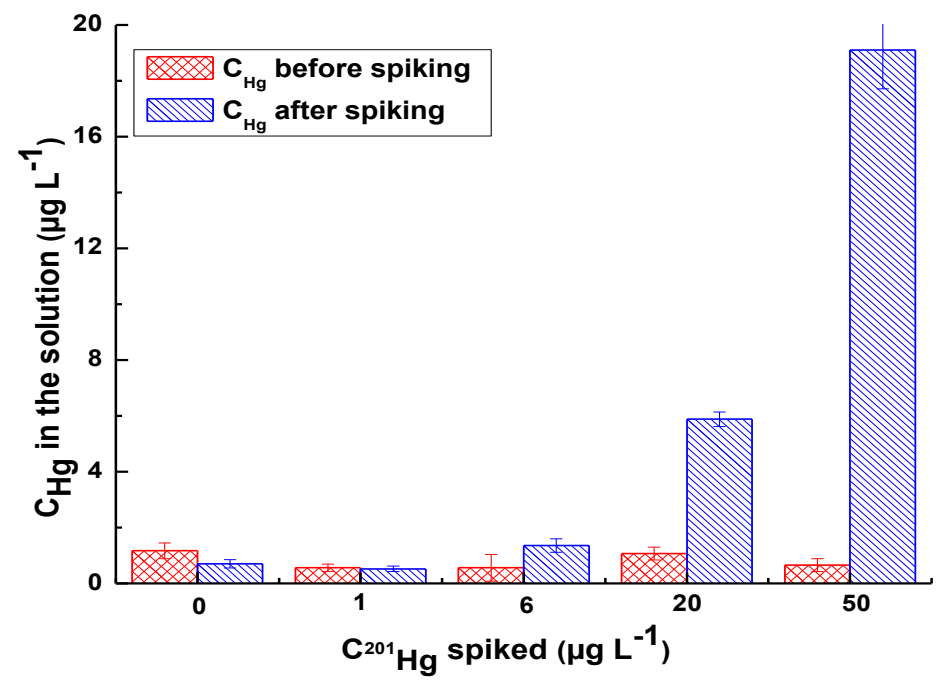

Figure S3. Concentrations of $\mathrm{Hg}$ originated from cinnabar in the aqueous phase before and after the addition of ${ }^{201} \mathrm{Hg}^{2+}$ 


\title{
Chapter 3. Effects of Thiol-containing Ligands on Cinnabar Dissolution and Re- adsorption of Released $\mathrm{Hg}(\mathrm{II})$
}

\begin{abstract}
Cinnabar dissolution is an important process during mercury $(\mathrm{Hg})$ transport and transformation and this process can be affected by a variety of environmental factors. One of the most studied factors is the presence of thiol-containing organic ligands such as dissolved organic matter (DOM) because of the ubiquitous existence of DOM in natural environment. Several processes have been proposed with respect to the interaction of DOM with cinnabar which could inhibit or enhance cinnabar dissolution. During the related processes, the roles played by thiol-containing organic ligands and re-adsorption of released $\mathrm{Hg}$, particularly through complexation with $\mathrm{Hg}$, are still not clear. Using Lcysteine (Cys) as a model compound for low molecular weight (LMW) thiol-containing ligands and Waskish fulvic acid (FA) for natural DOM, the complexation of $\mathrm{Hg}$ with these ligands and the role of $\mathrm{Hg}$-ligand complexation in cinnabar dissolution and $\mathrm{Hg}(\mathrm{II})$ readsorption were investigated. Titration methods were used to determine the ratios of $\mathrm{Hg}$ to L-cysteine when forming complexes in solution to prepare the $\mathrm{Hg}$-Cys complex and to examine its adsorption on cinnabar. Thermodynamic adsorption experiments were performed to investigate the adsorption of $\mathrm{Hg}$ and $\mathrm{Hg}$-Cys on cinnabar. The $\mathrm{Hg}$-Cys shows a lower adsorption capacity than that of unbound dissolved $\mathrm{Hg}$ on cinnabar surface. Therefore, the presence of L-cysteine during cinnabar dissolution would form complex with the released $\mathrm{Hg}$, thus enhancing cinnabar dissolution through the decreased readsorption of Hg-Cys complex. The Waskish FA used in this work did not enhance cinnabar dissolution, possibly because of the adsorption of FA on cinnabar surface that
\end{abstract}


may block dissolution sites on the cinnabar surface. The inhibitory effect of DOM on cinnabar dissolution observed here, in contrary to previously reported enhancing effect, suggest that caution should be exercised when evaluating the role of DOM in cinnabar dissolution, as the interaction of DOM with cinnabar is rather complicated depending on the varieties of DOM structures and compositions, the ratio between DOM and cinnabar, and probably other experiment conditions.

\subsection{Introduction}

Cinnabar dissolution is an important process controlling mercury cycling, making $\mathrm{Hg}$ reactive and bioavailable, increasing the possibility of $\mathrm{Hg}$ transport, methylation, and bioaccumulation in aquatic environment $(36,150)$. A variety of environmental factors can facilitate the dissolution process including the presence of iron(III) in acidic water (60), sulfide in water $(100)$, and dissolved organic matter $(\mathrm{DOM})(59,62,63)$. The important processes and reactions involved during the enhanced dissolution of cinnabar were summarized in chapter 2. Re-adsorption of released $\mathrm{Hg}$ has previously been neglected because of the lack of a feasible technique during the study of cinnabar dissolution. As a part of the overall effort to understand the dissolution of cinnabar under environmental conditions, an efficient method was developed to investigate the cinnabar dissolution and the concurrent re-adsorption of released $\mathrm{Hg}$ under both aerobic and anaerobic conditions. The results, as described in Chapter 2 showed that the cinnabar dissolution rate with readsorption was found to be two times the rate calculated from detecting $\mathrm{Hg}$ alone, clearly

indicating the significance of understanding $\mathrm{Hg}$ re-adsorption during the process of cinnabar dissolution. 
The experiments described in Chapter 2 were performed in a simple $\mathrm{NaNO}_{3} / \mathrm{NaOH}$ medium without addition of organic and other inorganic ligands. In fact, various organic ligands exist extensively in natural aquatic systems, and mercury could bind with these ligands, particularly thiol-containing moieties in dissolved organic matter (DOM). Previous studies have showed that the binding of $\mathrm{Hg}$ and the presence of various ligands could have important effects on cinnabar dissolution and the re-adsorption of $\mathrm{Hg}(63,67$, 128). For example, the presence of DOM was found to enhance the release of mercury from cinnabar under aerobic and anaerobic conditions $(58,59,63)$. The interactions between mercury and DOM play an important role in cinnabar dissolution, as shown in Fig. 3.1, which depicts the multiple processes presumably affecting cinnabar dissolution and re-adsorption of the released $\mathrm{Hg}$.

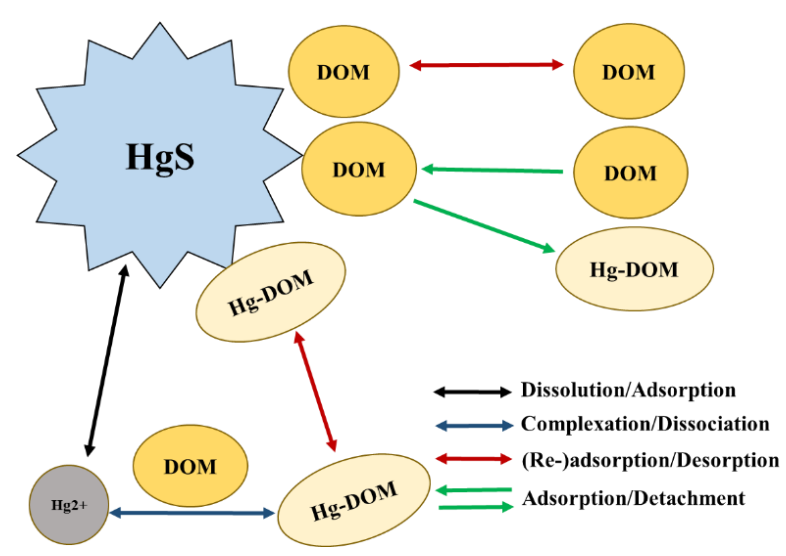

Figure 3.1 Possible reactions involved in cinnabar dissolution in the presence of DOM.

First, the complexation of DOM with dissolved $\mathrm{Hg}$ is expected to reduce the amount of free $\mathrm{Hg}^{2+}$ in the aqueous phase around the cinnabar and thus enhance cinnabar dissolution on the basis of Le Chatelier's principle (151). Second, it is speculated that DOM could be adsorbed on the cinnabar surface to form $\mathrm{Hg}$-DOM complexes through surface complexation with the mercury of cinnabar $(56,75,152)$. In this process, the Hg-DOM 
complex slowly detaches from the initial surface and a new site is regenerated. This pathway requires stronger binding between $\mathrm{Hg}$ and DOM than that of $\mathrm{Hg}$ and $\mathrm{S}$. Third, oxidation of surface sulfur (S) species by the organic matter has been also proposed as a pathway to enhance cinnabar dissolution (63). The oxidants (or the organic matter), which are adsorbed on the cinnabar surface, could oxidize $S(-2)$ to $S(0)$ or other oxidation states from the surface making the initial binding sites available (63). The sulfur oxidation pathway leading to cinnabar dissolution is not shown in the diagram (Fig. 3.1), as this research is focused on the role of $\mathrm{Hg}$-DOM complexation in cinnabar dissolution and readsorption of the released $\mathrm{Hg}$.

Contrary results have been observed regarding the effects of organic ligands on cinnabar dissolution. For instance, minor changes in cinnabar dissolution were observed in the presence and absence of some ligands (salicylic acid, acetic acid, EDTA, or cysteine), whereas major enhancement effects were observed for some DOM fractions and isolates such as fulvic acid (FA) and humic acid (HA) $(59,62,63,68)$. These inconsistent results were speculated to be attributed to the differences in binding strength between those ligands and $\mathrm{Hg}$ and/or the possible re-adsorption of released $\mathrm{Hg}$ on the cinnabar without further explanation in previous research (63). We believe that in the presence of some ligands such as cysteine and FA which have similar binding strength with $\mathrm{Hg}$, the levels of enhanced released $\mathrm{Hg}$ from $\mathrm{HgS}$ should be similar. The observation of different levels of $\mathrm{Hg}$ released from cinnabar was caused by the effects of various degrees of re-adsorption of formed $\mathrm{Hg}$ ligand complexes on cinnabar surface. However, it is not clear whether the Hg-ligand complex could be re-adsorbed on cinnabar and if the re-adsorption happens, the amount of $\mathrm{Hg}$-ligand complex that could be absorbed remains unknown. This missing information is 
important for an improved understanding of the effect of ligands during cinnabar dissolution and the re-adsorption of the released $\mathrm{Hg}$.

\subsection{Objective}

The objective of this study was to understand the role played by thiol-containing organic ligands during cinnabar dissolution and re-adsorption of the released $\mathrm{Hg}$, particularly through complexation with $\mathrm{Hg}$. To achieve this goal, L-cysteine (Cys) was selected as a model compound of low molecular weight (LMW) thiol-containing ligand and FA was chosen to represent DOM. Following investigation of the complexation of these organic ligands with $\mathrm{Hg}$, thermodynamic adsorption experiments of the $\mathrm{Hg}$-cysteine complex and cinnabar dissolution in the presence of FA were conducted to evaluate the effect of $\mathrm{Hg}$-thiol complexation in cinnabar dissolution and re-adsorption of $\mathrm{Hg}$.

\subsection{Materials and methods}

\subsubsection{Materials and Reagents}

Fulvic acid was purchased from IHSS (International Humic Substances Society, Waskish peat). Mercury(II) nitrate stock solution $\left(\mathrm{HgNO}_{3}, 1000 \mathrm{ppm}\right)$, boric acid $\left(\mathrm{H}_{3} \mathrm{BO}_{3}\right)$, sodium dihydrogen phosphate $\left(\mathrm{NaH}_{2} \mathrm{PO}_{4}\right)$, sodium hydrogen phosphate $\left(\mathrm{Na}_{2} \mathrm{HPO}_{4}\right)$, and sodium hydroxide were purchased from Fisher Scientific. Cinnabar (HgS, 99\%), Lcysteine $(\geq 97 \%$ ), and ethylenediaminetetraacetic acid (EDTA) were purchased from Sigma-Aldrich. Fluorescent reagent 4-fluoro-7-sulfobenzofurazan, ammonium salt (SBDF) ( $\geq 98.0 \%)$ was purchased from Dojindo Molecular Technologies, Inc. Concentrated nitric acid and hydrochloric acid were all trace metal grade (Fisher Scientific). Stannous chloride $\left(\mathrm{SnCl}_{2} \cdot 2 \mathrm{H}_{2} \mathrm{O}, 99.2 \%\right)$ and other chemicals were all reagent grade or higher (Fisher Scientific). Argon and nitrogen (ultra high purity) were purchased from Airgas. Borate 
buffer solution $(0.1 \mathrm{M})$ was prepared by dissolving $6.183 \mathrm{~g}$ of $\mathrm{H}_{3} \mathrm{BO}_{3}$ in $800 \mathrm{~mL}$ ultra pure water, adjusted to $\mathrm{pH} 9.5$ by $3 \mathrm{M} \mathrm{NaOH}$, then calibrated to $1000 \mathrm{~mL}$ with water. Phosphate buffer $(0.005 \mathrm{M})$ was prepared by adding $5.3 \mathrm{~mL}$ of $0.2 \mathrm{M} \mathrm{NaH}_{2} \mathrm{PO}_{4}$ solution to $94.7 \mathrm{~mL}$ of $0.2 \mathrm{M} \mathrm{Na}_{2} \mathrm{HPO}_{4}$ solution to achieve $\mathrm{pH}$ 8.0, then diluted 40 times. $0.005 \mathrm{M}$ SBD-F solutions are prepared in $0.1 \mathrm{M}$ borate buffer ( $\mathrm{pH} 9.5$ ) containing $2 \mathrm{mM}$ EDTA.

\subsubsection{Derivatization of L-cysteine with SBD-F}

To evaluate the binding ratio between $\mathrm{Hg}$ and $\mathrm{L}$-cysteine, various molar ratios of $\mathrm{HgNO}_{3}$ and L-cysteine were mixed, and the remaining unbound L-cysteine was determined via fluorescence analysis following a traditional SBD-F labeling method (153). Only free L-cysteine can be labeled to show fluorescence and the free L-cysteine can be distinguished from the cysteine in the $\mathrm{Hg}$-cysteine complexes which was proved in this work and discussed in my discussion. For SBD-F derivatization, $500 \mu \mathrm{L}$ of cysteine solution $(10 \mu \mathrm{M})$, $200 \mu \mathrm{L}$ of $0.1 \mathrm{M}$ borate buffer (pH 9.5), $40 \mu \mathrm{L}$ SBD-F, and $20 \mu \mathrm{L}$ of $1 \mathrm{M} \mathrm{NaOH}$ were mixed in a $7 \mathrm{~mL}$ glass bottle covered with aluminum foil to avoid light. After vortex mixing for $20 \mathrm{~s}$, the derivatization reaction was carried out in a water bath at $60^{\circ} \mathrm{C}$ for $1 \mathrm{~h}$. The reaction was then stopped by adding $20 \mu \mathrm{L}$ of $4 \mathrm{M} \mathrm{HCl}$. The cysteine derivatives were stored at 4 ${ }^{\circ} \mathrm{C}$ under dark for later fluorescence detection. Ultrapure water was added to each bottle to make $3 \mathrm{~mL}$ solution for fluorescence analysis by a fluorometer (Fluoromax-3, Horiba Jobin Yvon Inc.).

In order to improve the method detection limit, the amount of SBD-F was optimized for fluorescence signals for the SBD-F derivatives. A series of concentrations of $40 \mu \mathrm{L}$ of SBD-F $(0,0.05,0.1,0.25,0.5,1,2.5,5 \mathrm{mg} / \mathrm{ml})$ were used to react with $500 \mu \mathrm{L}$ of $10 \mu \mathrm{M}$ L-cysteine to obtain the derivatives and then fluorescence responses were detected. 


\subsubsection{Formation of Hg-ligand complexes}

In order to better evaluate the adsorption of $\mathrm{Hg}$-ligands complexes on cinnabar surface, the complexes of $\mathrm{Hg}$-ligands must be present in a solution without the free $\mathrm{Hg}$ (II). Such a condition, however, is very difficult to reach. In an attempt to produce $\mathrm{Hg}$-ligands complexes with minimal free $\mathrm{Hg}$ and ligands left in the system, titration methods were applied to determine the titration end points with minimum free $\mathrm{L}$-cysteine for $\mathrm{Hg}$-cysteine titration and minimum free $\mathrm{Hg}$ for $\mathrm{Hg}$-fulvic acid (Hg-FA) titration, respectively. Different titration end points were set to determine the binding ratios of L-cysteine and FA with $\mathrm{Hg}$. Since unbound $\mathrm{Hg}$ and $\mathrm{Hg}$ complexed with L-cysteine can't be distinguished by $\mathrm{Hg}$ analysis, unbound FA and FA complexes with $\mathrm{Hg}$ couldn't be identified. $\mathrm{Hg}$-cysteine complexes can be obtained by reaction of inorganic mercury with L-cysteine simply at room temperature. The reaction was reported to occur instantaneously between $\mathrm{Hg}(\mathrm{II})$ and ligand with molar ratios of 1:2 and lower without a prolonged incubation time required, while it took longer periods of time for the molar ratios of 2:1 and 1:1 which generally was completed within 15 min (154). However, more than $20 \mathrm{~h}$ was required for the formation of $\mathrm{Hg}-\mathrm{FA}(155)$.

The titration for the evaluation of Hg-cysteine formation was performed by testing separate solutions with a series of molar ratios of $\mathrm{HgNO}_{3}$ to L-cysteine $(2: 1,1: 1,1: 1.2$, $1: 1.4,1: 1.7,1: 2,1: 4)$. The solutions were prepared separately by mixing $10 \mu \mathrm{M}$ of Lcysteine solution and $\mathrm{HgNO}_{3}$ solution in corresponding decreasing concentrations (20-2.5 $\mu \mathrm{M})$. Then, $1060-138 \mu \mathrm{L}$ of $0.01 \mathrm{M} \mathrm{NaOH}$ were used to adjust the solution $\mathrm{pH}$ to 8 . After the reaction was carried out for 20 minutes, the unbound L-cysteine present in the resulting solutions was derivatized by SBD-F and followed by fluorometer detection as described. 
To evaluate Hg-FA complex formation, a titration was performed by testing separate solutions with a series of mass ratios of $\mathrm{HgNO}_{3}$ and fulvic acid (1:2, 1:5, 1:10, 1:50, and 1:100). These mass ratios were used because of the uncertainty of FA's molecular weight. The solutions were prepared separately by mixing FA $(20 \mathrm{mg} / \mathrm{L})$ and $\mathrm{HgNO}_{3}$ solution in corresponding decreasing concentrations $(10-0.02 \mathrm{mg} / \mathrm{L})$ in $7 \mathrm{~mL}$ glass vials covered with aluminum foil. The FA was prepared in a $0.005 \mathrm{M} \mathrm{NaH}_{2} \mathrm{PO}_{4} / \mathrm{Na}_{2} \mathrm{HPO}_{4}$ buffer solution (pH 8). The resulting solutions were then measured for mercury after 1,24 , and $72 \mathrm{~h}$. by cold vapor atomic fluorescence spectrometry (CV-AFS).

\subsubsection{Adsorption of Hg-cysteine complex on cinnabar surface}

An $\mathrm{HgNO}_{3}$ and L-cysteine ratio of 1:1.4 was found to be optimal for preparing $\mathrm{Hg}$ cysteine complexes (see results and discussion below). Thus a series of solutions with $\mathrm{Hg}$ cysteine complexes were prepared in this ratio $\left(\mathrm{HgNO}_{3}: \mathrm{L}\right.$-cysteine $\left.=1: 1.4\right)$ for studying isotherms of Hg-cysteine adsorption on cinnabar surface. At the ratio of 1:1.4, appropriate amounts of $\mathrm{HgNO}_{3}$ and L-cysteine solutions were mixed in $250 \mathrm{~mL}$ Teflon bottles with $130 \mathrm{~mL}$ of $0.005 \mathrm{M} \mathrm{NaH}_{2} \mathrm{PO}_{4} / \mathrm{Na}_{2} \mathrm{HPO}_{4}$ buffer solution to form $\mathrm{Hg}$-cysteine complexes with $\mathrm{Hg}$ concentrations ranging approximately from 0 to $7 \mu \mathrm{M}$. For preparation of $\mathrm{HgS}$ to be used in the adsorption experiments, $150 \mathrm{mg}$ of $\mathrm{HgS}$ was flushed using $1.5 \mathrm{~L}$ of ultrapure water through filtration with a $0.45 \mu \mathrm{m}$ PVDF membrane, and then transferred to a $250 \mathrm{~mL}$ Teflon bottle. Phosphate buffer solutions was added to adjust the volume to $150 \mathrm{~mL}$, achieving a $\mathrm{HgS}$ concentration of $0.1 \mathrm{~g} / \mathrm{L}$ in the suspension. The $\mathrm{HgS}$ suspension was mixed well and transferred into two $125 \mathrm{~mL}$ Teflon bottles with roughly $75 \mathrm{~mL}$ in each bottle. This step was performed very fast to avoid powder settlement. These procedures were performed in a glove box (Aldrich AtmosBag, Sigma-Alodrich) with continuous $\mathrm{N}_{2}$ 
purging to avoid introduction of oxygen into the system. All solutions used were purged with $\mathrm{N}_{2}$ overnight to remove $\mathrm{O}_{2}$. All samples were shaken on an orbital shaker after taken out of the glove box at $125 \mathrm{rpm}$ under purging of a flow of $50 \mathrm{~mL} / \mathrm{min} \mathrm{N}_{2}$. Samples were collected after $24 \mathrm{~h}$, and the $\mathrm{Hg}$ concentrations in solutions were detected by CV-AFS after being filtrated by $0.2 \mu \mathrm{M}$ PTFE membrane to separate $\mathrm{HgS}$ solids from solution.

\subsubsection{The role of Hg-FA complexes in cinnabar dissolution}

The results from the titration experiment of $\mathrm{Hg}$-FA showed that a considerable amount of free $\mathrm{Hg}$ was present in the solutions under all $\mathrm{Hg}$ :FA ratios. Therefore, it was not practical to prepare $\mathrm{Hg}-\mathrm{FA}$ complexes and then study the role of $\mathrm{Hg}$-FA complexes during cinnabar dissolution under the experimental conditions used here. Therefore, FA solution was added directly to cinnabar suspension, and the concentrations of $\mathrm{Hg}-\mathrm{FA}$ complexes and unbound $\mathrm{Hg}$ were determined. In this experiment, a series FA solutions were prepared in $130 \mathrm{~mL}$ of $\mathrm{NaH}_{2} \mathrm{PO}_{4} / \mathrm{Na}_{2} \mathrm{HPO}_{4}$ buffer solution $(0.005 \mathrm{M}$, pH 8) in $250 \mathrm{~mL}$ Teflon bottles. Then, $150 \mathrm{mg}$ of $\mathrm{HgS}$ was flushed by $1.5 \mathrm{~L}$ of ultrapure water through filtration with 0.45 $\mu \mathrm{m}$ PVDF membrane, and then transferred to each Teflon bottle. Phosphate buffer solution was added to adjust the volume to $150 \mathrm{~mL}$ to make $0.1 \mathrm{~g} / \mathrm{L} \mathrm{HgS}$ suspension and FA concentrations $1,2.5,5,10,20 \mathrm{mg} / \mathrm{L}$ separately. The $\mathrm{HgS}$ suspension was mixed well and divided into two aliquots ( $75 \mathrm{ml}$ each in two $125 \mathrm{~mL}$ Teflon bottles). These procedures were performed in a glove box with continuous $\mathrm{N}_{2}$ purging to avoid introduction of oxygen into the system. All solutions used were purged with $\mathrm{N}_{2}$ overnight to remove $\mathrm{O}_{2}$. All samples were shaken on an orbital shaker at $125 \mathrm{rpm}$ under purging of a flow of $50 \mathrm{~mL} / \mathrm{min} \mathrm{N}_{2}$. Samples were collected after $24 \mathrm{~h}$, and $\mathrm{Hg}$ concentrations in solutions were detected by CV-AFS followed by filtration to separate $\mathrm{HgS}$ solids from solution. 


\subsubsection{Detection of free $\mathrm{L}$-cysteine and $\mathrm{Hg}$}

A fluorometer was used to detect the concentration of SBD-F labeled L-cysteine. The excitation and emission wavelengths were set at 380 and $515 \mathrm{~nm}$, respectively. These wavelengths were determined by full wavelength scan and agree with previous work (156, 157). The fluorescent response of each sample was obtained three times. The analysis of L-cysteine was on the basis of the linear positive correlation between concentrations of Lcysteine derivative and fluorescent response.

Concentrations of mercury in various $\mathrm{Hg}$ :FA samples including free mercury and total mercury were determined by CV-AFS. Unbound Hg was detected by CV-AFS after sample filtration without further sample treatment as reported previously for the reason that this part of $\mathrm{Hg}$ can be reduced to $\mathrm{Hg}(0)$ by $\mathrm{SnCl}_{2}$ directly (94). bound $\mathrm{Hg}$ e.g., $\mathrm{Hg}$ in $\mathrm{Hg}$-FA

couldn't be reduced by $\mathrm{SnCl}_{2}$ unless extra steps such as UV irradiation, chemical oxidation, or ultrasonic treatment were taken to convert DOM bound $\mathrm{Hg}$ to 'reactive' $\mathrm{Hg}$ which are reducible $(94,155)$. Therefore, for total mercury analysis in this work, samples were diluted 100 fold in $100 \mathrm{~mL}$ quartz bottles, digested under ultraviolet radiation overnight, and oxidized by adding $2 \mathrm{~mL}$ of $0.2 \mathrm{M} \mathrm{BrCl}$ solution for 3 hours. Samples were analyzed by CV-AFS after adding $500 \mu \mathrm{L}$ of $24 \% \mathrm{NH}_{2} \mathrm{OH} \cdot \mathrm{HCl}$ solution to remove excessive $\mathrm{BrCl}$ (158).

\subsection{Results and discussion}

\subsubsection{Derivatization of L-cysteine with SBD-F}

The SBD-F derivatization technique is generally used for measuring low-molecular weight thiols, such as cysteine and glutathione in biological and environmental matrices (159-161). The major advantages of the technique are high reaction selectivity of SBD-F 
towards thiol groups and the stability of derivatives without other interferences (162). In this study, SBD-F derivatization method was used to detect free L-cysteine in the titration experiments. In order to optimize derivatization conditions, various concentrations of SBD-F were investigated. Experimental conditions such as reaction time and temperature were selected using previously reported research work (153). As shown in Fig. 3.2, a solution of $500 \mu \mathrm{L}$ of SBD-F ranging from 0 to $5 \mathrm{mg} / \mathrm{mL}$ was used to react with $40 \mu \mathrm{L}$ of $10 \mathrm{mg} / \mathrm{L} \mathrm{L-cysteine.} \mathrm{The} \mathrm{fluorescence} \mathrm{response} \mathrm{of} \mathrm{the} \mathrm{SBD-F} \mathrm{derivative} \mathrm{increased} \mathrm{with} \mathrm{the}$ concentrations of SBD-F and reached a plateau when the SBD-F concentration was 1.0 $\mathrm{mg} / \mathrm{mL}$. At this point, the molar ratio of L-cysteine and SBD-F is 1:4.17. An SBD-F concentration of $1 \mathrm{mg} / \mathrm{mL}$ was chosen for later experiments for thiol detection.

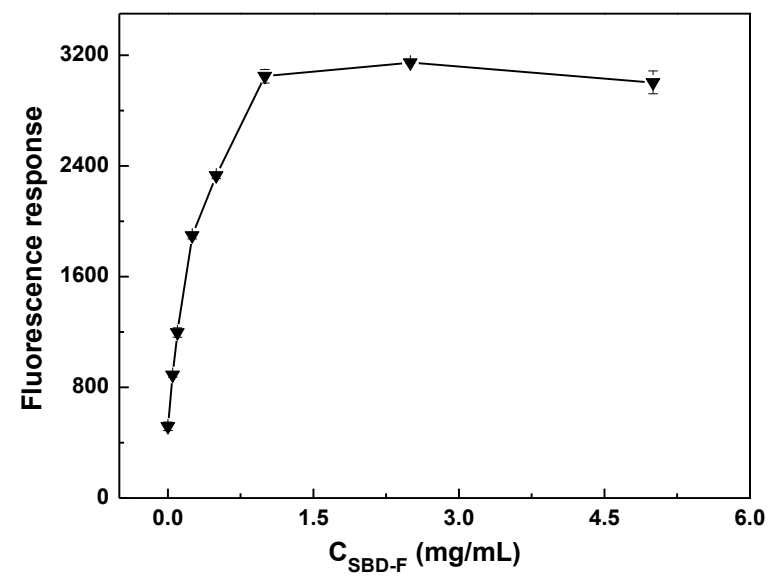

Figure 3.2 The effect of concentration of SBD-F on fluorescence response of the derivative of Lcysteine.

\subsubsection{Determination of $\mathrm{Hg}$ and $\mathrm{L}$-cysteine complexing ratio}

L-cysteine is an amino thiol $\left[\mathrm{NH}_{3}{ }^{+} \mathrm{CH}\left(\mathrm{CH}_{2} \mathrm{SH}\right) \mathrm{COOH}\right]$ that has three reactive centers: a carboxylate group, an amino group, and a thiol group. There are four different forms of L-cysteine represented as $\mathrm{H}_{3} \mathrm{Cys}^{+}, \mathrm{H}_{2} \mathrm{Cys}, \mathrm{HCys}^{-}$, and $\mathrm{Cys}^{2-}$ in the $\mathrm{pH}$ range of 2.0-12.0 
depending on the $\mathrm{pH}$ and dissociation constants of L-cysteine. The dissociation constants were obtained as $\mathrm{p} K_{\mathrm{a} 1}=1.86-2.12, \mathrm{p} K_{\mathrm{a} 2}=8.14-8.21$, and $\mathrm{p} K_{\mathrm{a} 3}=10.28-10.38$ from previous work by hydrogen titration, acid-base titration, and spectrophotometric techniques (163, 164). The equations can be expressed as:

$$
\begin{array}{ll}
\mathrm{H}_{3} \mathrm{Cys}^{+}=\mathrm{H}_{2} \mathrm{Cys}+\mathrm{H}^{+} & \mathrm{p} K_{a 1}=-\log _{10} \frac{\left[\mathrm{H}^{+}\right]\left[\mathrm{H}_{2} \mathrm{Cys}\right]}{\left[\mathrm{H}_{3} \mathrm{Cys} s^{+}\right]} \\
\mathrm{H}_{2} \mathrm{Cys}=\mathrm{HCys}^{-}+\mathrm{H}^{+} & \mathrm{p} K_{a 2}=-\log _{10} \frac{\left[\mathrm{H}^{+}\right]\left[\mathrm{HCys}^{-}\right]}{\left[\mathrm{H}_{2} \mathrm{Cys}\right]} \\
\mathrm{HCys}^{-}=\mathrm{Cys}^{2-}+\mathrm{H}^{+} & \mathrm{p} K_{a 3}=-\log _{10} \frac{\left[\mathrm{H}^{+}\right]\left[\mathrm{Cys}^{2-}\right]}{\left[\mathrm{HCys}^{-}\right]}
\end{array}
$$

The $\mathrm{p} K_{\mathrm{a} 1}$ value is low and easily identified for the carboxyl group. However, the amino and thiol groups have similar $\mathrm{p} K_{\mathrm{a}}$ which means these two groups dissociate almost at the same time (164). For this reason, it's difficult to identify the dissociation constant values between these two groups. When the $\mathrm{pH}$ equals $\left(\mathrm{p} K_{\mathrm{a} 1}+\mathrm{p} K_{\mathrm{a} 2}\right) / 2$, which is also called the isoelectric point (pI), only neutral form $\mathrm{H}_{2}$ Cys exists. Under $\mathrm{pH} 8$, cysteine exists as $\mathrm{H}_{2} \mathrm{Cys}$, HCys $^{-}$and $\mathrm{Cys}^{2-}$ with the percentages of $60.1 \%, 39.7 \%$, and $0.2 \%$, respectively.

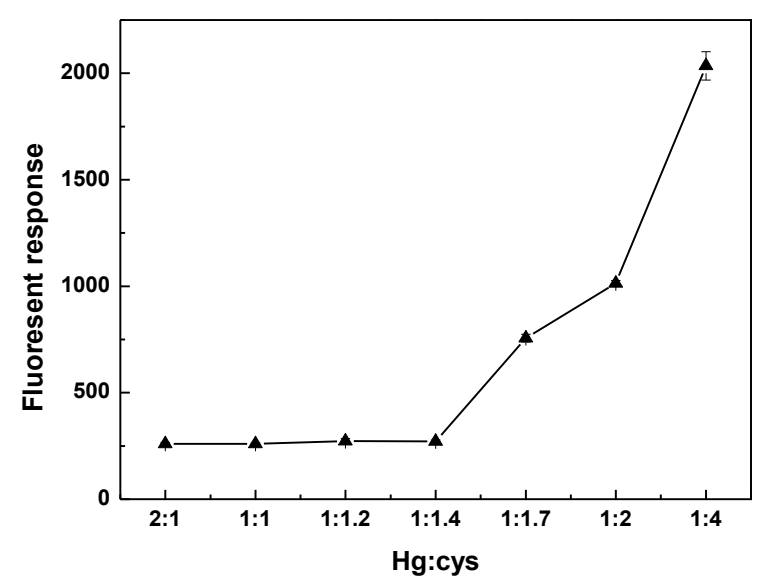

Figure 3.3 The effect of $\mathrm{HgNO}_{3}$ and cysteine molar ratio on the SBD-Cys fluorescent response of L-Cysteine. 
A titration method was used to determine the proper ratio of $\mathrm{Hg}$ and L-cysteine, and the end point was selected at the point when free L-cysteine is present in the solution. When preparing $\mathrm{Hg}$-cysteine complex under different $\mathrm{Hg}$ :Cysteine ratios, no free cysteine was detected when $\mathrm{Hg}$ concentrations were relatively higher (e.g., at $\mathrm{Hg}$ :Cysteine ratios of 2:1 to $1: 1.2$ ), as all cysteine should be bound with $\mathrm{Hg}$, giving no fluorescence signals (Fig. 3.2). With decreasing $\mathrm{Hg}$ concentrations, free cysteine became detectable after the Hg:Cysteine ratios reached 1:1.4, and when the ratios were 1:1.7 or lower. Free cysteine was apparently present in the solutions, as evidenced by the increasing fluorescence signals. Higher fluorescent responses were observed with lower $\mathrm{HgNO}_{3}$ and cysteine molar ratio (1:1.7 to $1: 4)$ because of the increase in the amount of free cysteine. A molar ratio of 1:1.4 was considered to be a proper ratio to prepare $\mathrm{Hg}$-cysteine complex with minimum amount of free cysteine. Concurrence of several forms of complexes between $\mathrm{Hg}$ and Lcysteine could occur at a binding ratio of 1:1.4 between $\mathrm{Hg}$ and L-cysteine. It was reported that 2:2, 1:2, and 3:2 of $\mathrm{Hg}$-cysteine complexes, namely $\mathrm{Hg}_{2}(\mathrm{RS})_{2}, \mathrm{Hg}(\mathrm{RS})_{2}$, and $\mathrm{Hg}_{3}(\mathrm{RS})_{2}$ are the primary forms of $\mathrm{Hg}$-cysteine $(165,166)(154,167)$. While in the range of 1:1.2-1:2 for $\mathrm{Hg}$ :Cysteine, the formation of complexes were determined to occur mainly as 1:1 or 2:2 and 1:2 (154). Therefore, it is conceivable that in this study the molar ratio of 1:1.4 could contain the complexes with molar ratios $2: 2$ and $1: 2$, specifically $57 \%$ of $\mathrm{Hg}(\mathrm{RS})_{2}$ and $43 \%$ of $\mathrm{Hg}_{2}(\mathrm{RS})_{2}$. Considering the specific charged forms, the abovementioned complexes forms can be written as $\mathrm{Hg}\left(\mathrm{H}_{2} \mathrm{Cys}\right)_{2}, \quad\left[\mathrm{Hg}(\mathrm{HCys})_{2}\right]^{-}, \mathrm{Hg}_{2}\left(\mathrm{H}_{2} \mathrm{Cys}\right)_{2}$, $\left[\mathrm{Hg}_{2}(\mathrm{HCys})_{2}\right]^{-}$, along with lower amounts of $\left[\mathrm{Hg}(\mathrm{Cys})_{2}\right]^{2-}$ and $\left[\mathrm{Hg}_{2}(\mathrm{Cys})_{2}\right]^{2-}$ at $\mathrm{pH}$ 8. It should be noted that for $\mathrm{HCys}^{-}$, half of both thiol and amino groups were considered dissociated because of their similar $\mathrm{p} K_{\mathrm{a}}$ at $\mathrm{pH}$ 8. Hg-cysteine complexes prepared at a 1:1.4 
molar ratio of $\mathrm{HgNO}_{3}$ to L-cysteine and used in adsorption experiments didn't produce fluorescent response, indicating the absence of free L-cysteine. The results also agree with the fact that only free cysteine rather than $\mathrm{Hg}$-cysteine complexes could react with SBD-F and show florescence.

\subsubsection{Adsorption of $\mathrm{Hg}$-cysteine complexes on cinnabar surface}

Reduced sulfur functional groups are considered as the strongest binding site for $\mathrm{Hg}$ complexed with DOM (59), and in this study, L-cysteine was used to represent a low molecular weight moiety of the DOM. Previous studies have suggested that organic ligands such as cysteine, salicylic acid, FA, and HA could enhance cinnabar dissolution. However, the effects of organic ligands on cinnabar dissolution vary (63). The mechanisms underlying the enhanced dissolution have been proposed, however none of them were confirmed (63). My previous studies (see Chapter 2) have indicated that re-adsorption of the released $\mathrm{Hg}$ plays an important role in determining the amount of $\mathrm{Hg}$ eventually released into solution during cinnabar dissolution. Therefore, it was speculated that cysteine-enhanced cinnabar dissolution could be related to the changes in adsorption behavior of $\mathrm{Hg}$ because of the complexation of $\mathrm{Hg}$ by cysteine. The adsorption capacity of the Hg-cysteine complex was expected to be important with respect to the dissolution of cinnabar and should be investigated. Hence, adsorption isotherm experiments were performed in $\mathrm{NaH}_{2} \mathrm{PO}_{4} / \mathrm{Na}_{2} \mathrm{HPO}_{4}$ buffer solution to study the adsorption process by spiking a series of amounts of $\mathrm{Hg}$ in the forms of $\mathrm{Hg}(\mathrm{II})\left(\mathrm{HgNO}_{3}\right)$ or $\mathrm{Hg}$-Cysteine complexes into a cinnabar suspension. Phosphate buffer solution was used to keep the $\mathrm{pH}$ steady during the dissolution and eliminate the effect of $\mathrm{pH}$ changes in the process. Experiments were first conducted to determine if the addition of phosphate buffer could alter the dissolution 
of cinnabar. The results indicated that concentrations of $\mathrm{Hg}$ released from cinnabar dissolution in $\mathrm{NaH}_{2} \mathrm{PO}_{4} / \mathrm{Na}_{2} \mathrm{HPO}_{4}$ buffer solution compared with those in $\mathrm{NaNO}_{3} / \mathrm{NaOH}$ solution were not significantly different.

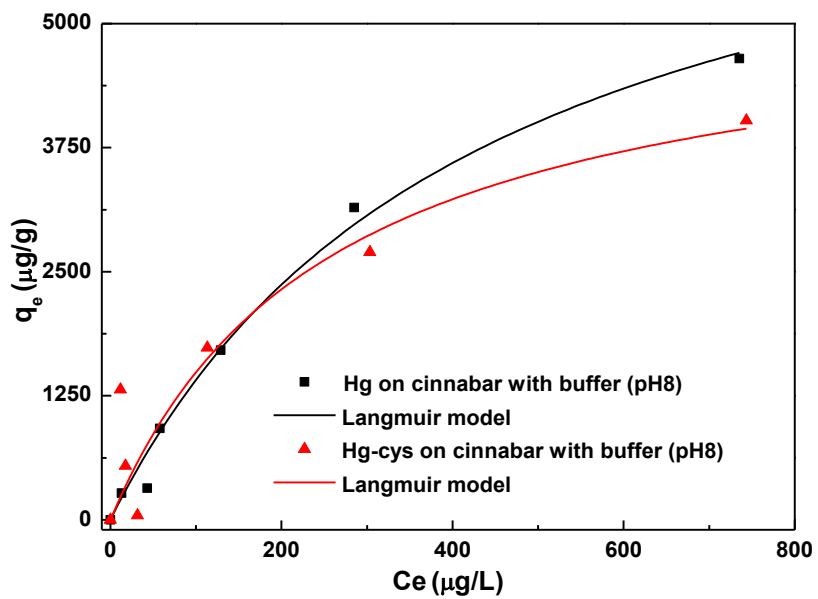

Figure 3.4 Adsorption isotherm of $\mathrm{Hg}\left(\mathrm{HgNO}_{3}\right)$ and $\mathrm{Hg}$-cysteine complex on cinnabar in $\mathrm{NaH}_{2} \mathrm{PO}_{4} / \mathrm{Na}_{2} \mathrm{HPO}_{4}$ buffer $(0.005 \mathrm{M}, \mathrm{pH} 8), \mathrm{t}=20{ }^{\circ} \mathrm{C}$.

Table 3.1 Comparisons of parameters of adsorption isotherm between $\mathrm{Hg}$ and $\mathrm{Hg}$-Cys on cinnabar

\begin{tabular}{lll}
\hline Parameters & Adsorption of Hg on cinnabar & Adsorption of Hg-cys on cinnabar \\
\hline $\mathbf{q}_{\mathbf{m}}(\boldsymbol{\mu} \mathbf{g} / \mathbf{g})$ & 7454.4 & 5304.4 \\
$\mathbf{k}_{\mathbf{L}}(\mathbf{L} / \boldsymbol{\mu g})$ & 0.0023 & 0.0039 \\
$\mathbf{R}^{2}$ & 0.9890 & 0.8599 \\
\hline
\end{tabular}

A Langmuir model was applied to fit thermodynamic data to obtain adsorption isotherms for adsorption of $\mathrm{Hg}$ as well as $\mathrm{Hg}$-cysteine complexes on the cinnabar surface (In Fig. 3.4). The maximum adsorption capacity $\left(\mathrm{q}_{\mathrm{e}}\right)$ of $\mathrm{Hg}$-cysteine was calculated to be $5304.4 \mu \mathrm{g} / \mathrm{g}$, which was $29 \%$ less than that of free $\mathrm{Hg} 7454.4 \mu \mathrm{g} / \mathrm{g}(\mathrm{p}<0.001)$ for equilibrium concentrations from $0-800 \mu \mathrm{g} / \mathrm{L}$. This result suggests that under $\mathrm{pH} 8$, there was less released $\mathrm{Hg}$ which could be re-adsorbed back on cinnabar surface in the presence 
of L-cysteine than that in the absence of L-cysteine. This phenomenon could be associated with the electric charge of $\mathrm{Hg}$ species with or without L-cysteine on cinnabar surface. The surface of cinnabar, with a zero charge point $\mathrm{pH}(\mathrm{pzc})$ of $3-4$, is expected to be negatively charged in natural aquatic environments at a $\mathrm{pH}$ of 6-8 because of the deprotonation of exposed sulfhydryl groups $(63,76)$. Since $\mathrm{Hg}$ exists primarily as neutral species such as $\mathrm{Hg}(\mathrm{OH})_{2}$ in the absence of organic ligands ( $\left.\mathrm{pH} 8\right)(77)$, surface complexation was proposed as the adsorption mechanism for released $\mathrm{Hg}$ on cinnabar $(56,152)$. With L-cysteine, $\mathrm{Hg}$ Cysteine complexes are partially negatively charged making this less conducive towards adsorption behavior. Also, surface complexation may not occur for the Hg-Cysteine complexes in the neutral form because of the lower binding strength between $\mathrm{Hg}$ and exposed sulfide on cinnabar surface when compared to complexes formed between $\mathrm{Hg}$ and

L-cysteine (63). The stability constant ( $\log \mathrm{K})$ was 42 for the formation of $\mathrm{Hg}(\mathrm{SR})_{2}$ with LMW thiols such as L-cysteine. Our results showed that less $\mathrm{Hg}$ could be re-adsorbed on cinnabar surface in the presence of L-cysteine because of Hg-cysteine complexation, partially accountable for the enhanced cinnabar dissolution (63).

\subsubsection{Determination of Hg-FA complexion ratio}

As an important component of DOM in most natural waters, including pore-waters, FA has lower molecular weight and better solubility property than the other fractions HA and can be dissolved in both acidic and basic aqueous systems (168). Several FA isolates have been obtained and found to enhance the dissolution of cinnabar $(59,63)$. Therefore, FA was chosen to represent natural DOM in this study to investigate the role of $\mathrm{Hg}$-DOM complexation in cinnabar dissolution. In particular, the study focused on the re-adsorption of $\mathrm{Hg}-\mathrm{FA}$ on cinnabar. Similar to the previous experiments on the adsorption of $\mathrm{Hg}$ - 
cysteine on cinnabar, titration was conducted to determine a proper ratio between $\mathrm{Hg}$ (II) $\left(\mathrm{HgNO}_{3}\right)$ and FA in order to prepare $\mathrm{Hg}-\mathrm{FA}$ complexes with minimal free $\mathrm{Hg}$ and $\mathrm{FA}$ present in the resulting mixture. Ether free $\mathrm{Hg}$ or FA has an impact on the adsorption of $\mathrm{Hg}-\mathrm{FA}$ by decreasing or increasing released $\mathrm{Hg}$ from cinnabar dissolution $(63,152)$. These experiments were performed by adding decreasing amounts of $\mathrm{HgNO}_{3}$ to a fixed concentration of FA to produce $\mathrm{Hg}-\mathrm{FA}$ complexes with a range of $\mathrm{Hg}$ :FA mass ratios $(1: 2$, 1:5, 1:10, 1:50, and 1:100). The range of $\mathrm{Hg}: \mathrm{FA}$ mass ratios was determined by a preliminary estimate. The elemental sulfur content of the Waskish FA was known as $0.29 \%$ (w/w, IHSS). However, it was reported that not all $\mathrm{S}$ could bind with $\mathrm{Hg}$. The reactive center (RSH) was assumed roughly accounting for $0.15 \%$ of DOC on a mass basis by Skyllberg (169). Since the FA used in this work contains $53.63 \%$ of DOC, RSH equals $0.08 \%$ of FA on the basis of Skyllberg's estimation. Reduced S fraction (moL/moL of DOM) was calculated as $0.21 \%$ for two DOM fractions isolated from Everglades (170). Therefore, if $0.0038 \mathrm{~mol}(1 \mathrm{~g})$ of $\mathrm{HgNO}_{3}$ was used to bind with FA, a similar number of moles of RSH which is $0.125 \mathrm{~g}$ should be used to form Hg-FA complex. Since the mass of $\mathrm{RSH}$ is $0.21 \%$ of FA, the FA needed should be around $60 \mathrm{~g}$. The estimated mass ratio of 1:60 just falls in the range used in this work. The titration end point for this Hg-FA complexation experiment was free $\mathrm{Hg}$ that was not bound by FA (which in some cases was called "reactive" $\mathrm{Hg}$ in previous studies). One of the key analytical steps was to distinguish $\mathrm{Hg}-\mathrm{DOM}$ from other forms of $\mathrm{Hg}$ present in the solution. Previous studies have confirmed that the $\mathrm{Hg}(\mathrm{II})$ complexes containing inorganic ligands (e.g. chloride or hydroxide) and LMW organic ligands (e.g. cysteine) are generally considered reducible by $\mathrm{SnCl}_{2}$ completely (155), whereas the Hg-FA complexed formed through complexation of $\mathrm{Hg}$ with 
Waskish FA could not be reduced, just like Hg-DOM complexes of a variety of other $\operatorname{DOM}(155)$. The $\mathrm{Hg}$ which could be reduced by $\mathrm{SnCl}_{2}$ was labeled reactive $\mathrm{Hg}$ and used to represent unbound $\mathrm{Hg}$ in my work.

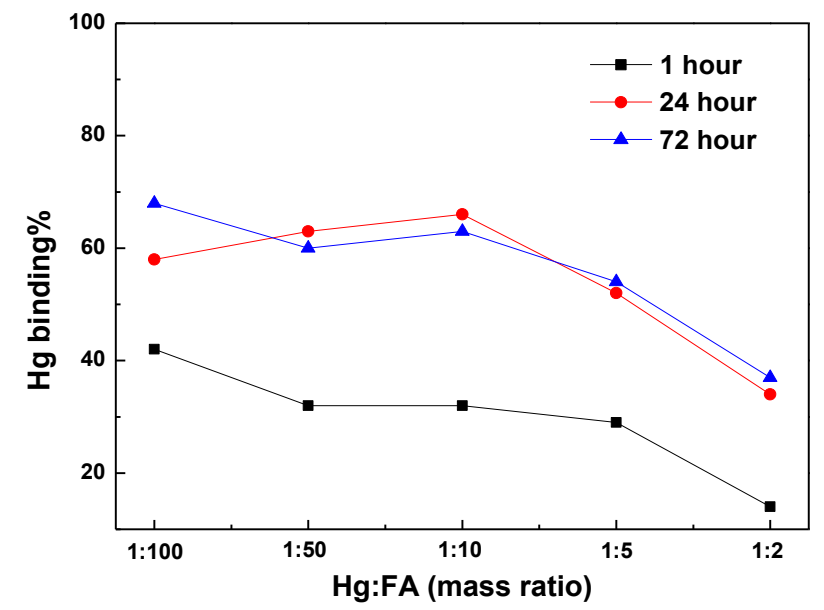

Figure 3.5 The percentage of $\mathrm{Hg}$ bound with FA with different mass ratios of $\mathrm{Hg}$ to FA at 1, 24 and 72 hours.

Previous study indicated that greater than $85 \% \mathrm{Hg}$ can bind with dissolved fraction of natural organic matter (NOM) in the presence of excess amounts of NOM after 24 hours (155). To determine a proper binding ratio between $\mathrm{Hg}$ and $\mathrm{FA}$, unbound and bound $\mathrm{Hg}$ were detected after 1, 24, and 72 hours in this work. The binding percentages for samples with different ratios of $\mathrm{Hg}$ and FA after 1, 24, and 72 hours were shown in Fig. 3.5. The binding percentage of $\mathrm{Hg}$ increased from 1 to 24 hours and no significant differences in $\mathrm{Hg}$ binding percentages were observed between 24 and 72 hours (One way ANOVA, T test, $\mathrm{P}>0.05)$. Therefore, the complexation reaction reached equilibrium in 24 hours. Largest $\mathrm{Hg}$ binding percentage by $\mathrm{FA}$ occurred at a $\mathrm{Hg}$ :FA ratio of 1:100 under the experimental conditions. Further increases in FA concentration were not tested. However, even at the $\mathrm{Hg}$ :FA ratio of 1:100, 30 - 40\% of free $\mathrm{Hg}$ existed in the solutions. It's possible 
that lower mass ratio of $\mathrm{Hg}: \mathrm{FA}(<1: 100)$ should be applied to make a complex with minimum unbound $\mathrm{Hg}$ because of the uniqueness of FA isolated in this work. While, lower $\mathrm{Hg}$ and FA ration may decrease the percentage of bound $\mathrm{Hg}$ and bring more unbound FA. The extra FA could enhance cinnabar dissolution to make the adsorption underestimated. Therefore, a proper binding ratio of Hg and FA couldn't be determined in this experimental condition.

\subsubsection{The role of $\mathrm{Hg}$-FA complexes in cinnabar dissolution}

Without preparation of a $\mathrm{Hg}$-FA complex with minimum amount of free $\mathrm{Hg}$ and FA, the role of complexation between $\mathrm{Hg}$ and FA in cinnabar dissolution was investigated by adding FA solution directly to cinnabar suspension rather than performing a thermodynamic adsorption experiment by spiking $\mathrm{Hg}$-FA to cinnabar. Reactive $\mathrm{Hg}$ was detected by directly reduced by $\mathrm{SnCl}_{2}$ and total $\mathrm{Hg}$ was detected using additional preoxidation process involving $\mathrm{UV}$ and $\mathrm{BrCl}$ treatment. Then the concentrations of complexes were calculated by subtraction of reactive $\mathrm{Hg}$ from total $\mathrm{Hg}$ and the percentage of bound $\mathrm{Hg}$ could be estimated. The effect of re-adsorption in cinnabar dissolution was expected to be evaluated by comparing the increasing extent of unbound $\mathrm{Hg}$ and complexed $\mathrm{Hg}$ with the increasing of FA. The results of cinnabar dissolution in the presence of FA are shown in Fig. 3.6. Less $\mathrm{Hg}$ was detected in solution including both unbound $\mathrm{Hg}$ and complexed $\mathrm{Hg}$ with the increase in the amounts of FA added. After $1 \mathrm{mg} / \mathrm{L}$ of FA was spiked into the cinnabar suspension, around $43 \mathrm{ppb}$ of $\mathrm{Hg}$ was released from cinnabar including $23 \mathrm{ppb}$ of unbound $\mathrm{Hg}$ and $20 \mathrm{ppb}$ of complexed $\mathrm{Hg}$. Decreasing amounts of all these $\mathrm{Hg}$ fractions were observed with higher concentrations of spiked FA. When $20 \mathrm{mg} / \mathrm{L}$ of FA was spiked, only $5.3 \mathrm{ppb}$ of total $\mathrm{Hg}$ was released from cinnabar and $2 \mathrm{ppb}$ of this $\mathrm{Hg}$ was in the bound 
form. These results indicated that FA inhibits rather than enhances cinnabar dissolution and the inhibition effect increases at higher concentrations of FA. A possible pathway that could account for the inhibitory effects of FA on cinnabar dissolution is proposed. The adsorption of FA could lead to the coating of active surface sites on cinnabar to inhibit cinnabar dissolution. Upon mixing of the FA solution with cinnabar suspension, rapid adsorption of FA onto cinnabar surface happens as proposed by Ravichandran and Waples $(59,63)$. Concentrations of DOM decreased following the reaction with cinnabar in both works. In Ravichandran's work, about $15 \%$ of DOM (10.6 mg C/L) was observed decreasing after spiked into $2 \mathrm{~g} / \mathrm{L}$ of cinnabar. In Waples's work, an adsorption isotherm was fitted by the Langmuir model and the values of $\mathrm{q}_{\mathrm{m}}$ and $\mathrm{k}$ were determined to be 0.14 $\mathrm{mg} \mathrm{C} / \mathrm{m}^{2}$ and $0.14 \mathrm{~L} / \mathrm{mg} \mathrm{C}$ using 2 to $16 \mathrm{mg} \mathrm{C} / \mathrm{L}$ of DOM spiked in $10 \mathrm{~g} / \mathrm{L}$ of $\mathrm{HgS}$ at $\mathrm{pH} 6$ (59). They also obtained an estimated amount of DOM on $\mathrm{HgS}$ that ranged from 0.03 to $0.84 \mathrm{mg} \mathrm{C} / \mathrm{m}^{2}$ when $10 \mathrm{mg} \mathrm{C} / \mathrm{L}$ of DOM was spiked in 2 to $80 \mathrm{~g} / \mathrm{L}$ of cinnabar. The adsorption of DOM on cinnabar has been further confirmed via an electrophoretic mobility experiment (63). In Ravichandran's work, the negative potential of cinnabar surface increased from -35 to $-55 \mathrm{mV}$ at $\mathrm{pH} 6$ indicating that the adsorption of humic substances on cinnabar (63). Previous work has reported that the adsorption of DOM enhances cinnabar dissolution by forming complexes with $\mathrm{Hg}$ on cinnabar surface and then releasing to the solution. In this work, the adsorption of FA on cinnabar plays another role by covering the dissolution sites and inhibiting cinnabar dissolution. The opposite reports in the literature could be the result of differences in DOM structures from various sources. The variety of DOM sources makes understanding the interaction between ether $\mathrm{Hg}$ or $\mathrm{HgS}$ and DOM complicated (59). 


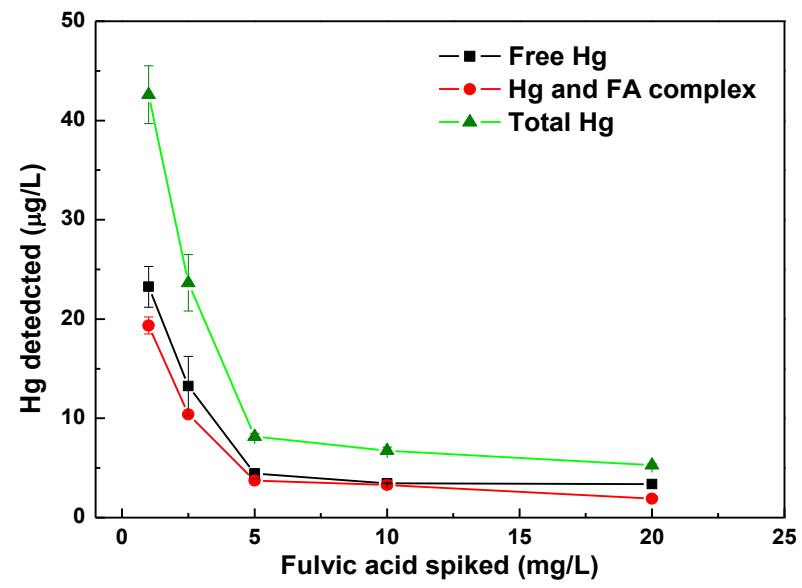

Figure 3.6 Concentrations of released $\mathrm{Hg}$ as unbound $\mathrm{Hg}$, bound $\mathrm{Hg}$, and total $\mathrm{Hg}$ from cinnabar dissolution at $24 \mathrm{~h}$ in the presence of $1,2.5,5,10$, and $20 \mathrm{mg} / \mathrm{L}$ of FA.

The inhibition effect may be related to the ratios between DOM and $\mathrm{HgS}$ used. As in this work, 1-20 mg DOM/L or 0.54-10.8 $\mathrm{mg} \mathrm{C/L}$ of FA and $0.1 \mathrm{~g} / \mathrm{L}$ of cinnabar were mixed. While in previous studies, around $10 \mathrm{mg} \mathrm{C} / \mathrm{L}$ of DOM was used with $10 \mathrm{~g} / \mathrm{L}$ of cinnabar. The ratio of DOM to cinnabar was $0.0054-0.108$ in this work, much higher than that previously used which was 0.001 (59). However, other studies with ratios as high as 0.05 showed DOM enhanced cinnabar dissolution. When the concentration of cinnabar is fixed, the concentration of dissolved $\mathrm{Hg}$ does not increase linearly with the concentrations of DOM, as observed in Ravichandran's work (63). This observation could be caused by the inhibition of the adsorption of DOM on cinnabar dissolution. Therefore, the ratio of DOM to $\mathrm{HgS}$ could be a factor affecting the role of DOM in cinnabar dissolution, among other factors such as the composition and properties of DOM.

\subsection{Conclusions}

In this work, the roles of thiol-containing organic ligands and re-adsorption of released $\mathrm{Hg}$ were investigated. The results indicate that the roles of small molecules and complex 
DOM fractions in cinnabar dissolution are different. In the presence of a small molecule L-cysteine, re-adsorption of Hg-Cys plays an important role on cinnabar dissolution. As proposed in Fig. 3.1, the complexation of $\mathrm{Hg}$-Cys decreases the concentrations of dissolved $\mathrm{Hg}$ and forces the dissolution reaction to move to the right direction, which is one role $\mathrm{L}$ cysteine plays in enhancing cinnabar dissolution. Meanwhile, the presence of L-cysteine decreases the re-adsorption of dissolved $\mathrm{Hg}$ via complexation, as Hg-Cys shows lower adsorption capacity than that of unbound dissolved $\mathrm{Hg}$ on cinnabar surface. For the role of DOM in cinnabar dissolution, the Waskish FA used in this work does not enhance but inhibits cinnabar dissolution, possibly through coating the dissolution sites on cinnabar surface. The inhibitory effect of FA on cinnabar dissolution observed here, in contrary to previously reported enhancing effect, suggest that caution should be exercised when evaluating the role of DOM in cinnabar dissolution, as the interaction of DOM with cinnabar is rather complicated depending on the varieties of DOM structures and compositions, the ratio between DOM and cinnabar, and probably other experiment conditions. 


\title{
Chapter 4. Geochemical Modeling of Mercury Speciation in Surface Water and Implications on Mercury Cycling in the Florida Everglades
}

\begin{abstract}
The speciation of mercury is of paramount importance with respect to transport, transformation, and cycling of mercury in aquatic environments, including the process of cinnabar dissolution. Since different $\mathrm{Hg}$ species may have different transport and transformation behaviors under varying environmental conditions, it would be helpful to know the distribution patterns of inorganic $\mathrm{Hg}$ species to have a better understanding of aquatic $\mathrm{Hg}$ cycling. Previous studies have shown that cinnabar dissolution can be facilitated by a variety of environmental factors to potentially make cinnabar a continuous source of dissolved inorganic $\mathrm{Hg}$ and consequently control mercury $(\mathrm{Hg})$ cycling in the aquatic environment. It would be an ideal extension to this work if the speciation of $\mathrm{Hg}$ could be investigated during cinnabar dissolution. However, it is not feasible at this stage to geochemically model $\mathrm{Hg}$ speciation during cinnabar dissolution, as this process has not been studied in sufficient detail. Therefore, in this chapter, I selected a relatively wellstudied system, the Florida Everglades for which various environmental parameters including $\mathrm{Hg}$ are available, and applied a geochemical modeling approach to examine $\mathrm{Hg}$ speciation in surface water, aiming to provide an improved understanding towards how $\mathrm{Hg}$ species distribution affects $\mathrm{MeHg}$ production and the overall $\mathrm{Hg}$ cycling in the aquatic environment.
\end{abstract}

The Florida Everglades is a subtropical wetland ecosystem located in South Florida. It provides significant ecological, water storage, flood control and recreational benefits to the region and important habitat for wildlife including endangered species. However, elevated 
levels of mercury $(\mathrm{Hg})$, especially methylmercury $(\mathrm{MeHg})$, a potent neurotoxin, have been measured in fish and wildlife in the Everglades over the last few decades. This is not only an issue for human consumption of fish, but also threatens fish-eating wildlife species and the biological diversity of this ecosystem.

Efforts have been made to investigate source, transport, transformation (reduction/oxidation and in particular methylation/demethylation), and bioaccumulation of $\mathrm{Hg}$ in fish and wildlife in the Everglades. Spatial patterns in mercury cycling and bioaccumulation in the Everglades have been investigated. However, much remains unclear about how elevated levels of $\mathrm{Hg}$ in fish and wildlife are accumulated and the biogeochemical cycling of mercury in this system. Of particular concern is the lack of studies that deal with the speciation of inorganic $\mathrm{Hg}$, whether being dissolved $\mathrm{Hg}$ ions (or neutral species) or bound to particles and organic matter, and the effect of these $\mathrm{Hg}$ species on $\mathrm{Hg}$ transformation (e.g., methylation and photochemical reactions) and bioaccumulation. The objective of this study is to understand how geochemical factors such as $\mathrm{pH}$, dissolved ions, and organic matter affect inorganic $\mathrm{Hg}$ species and subsequently control $\mathrm{Hg}$ cycling and bioaccumulation.

In this work, geochemical models are used to model the distribution of inorganic $\mathrm{Hg}$ species. The data are from the Everglades Regional Environmental Monitoring and Assessment Program (R-EMAP). The United States Environmental Protection Agency began the probability-based R-EMAP survey in 1993, and since then has collected and analyzed samples, including surface water, soil, vegetation, and fish, throughout the Everglades at about 1000 different locations. This program generated massive datasets, including total mercury, methylmercury, and biogeochemical characteristics parameters, 
for the entire Everglades freshwater marsh ecosystem, which provides an unprecedented data source for geochemical modeling. The distribution of inorganic $\mathrm{Hg}$ species in surface water throughout the entire Everglades is determined by applying geochemical models to different R-EMAP sampling sites. The distribution of inorganic $\mathrm{Hg}$ species is related to $\mathrm{MeHg}$ levels in different environmental matrices to examine how inorganic $\mathrm{Hg}$ species potentially affect the production and fate of $\mathrm{MeHg}$, and then further related to fish $\mathrm{Hg}$ levels to explore the relationship between inorganic $\mathrm{Hg}$ speciation, $\mathrm{MeHg}$ production, and $\mathrm{Hg}$ bioaccumulation. The implications of the distribution of inorganic $\mathrm{Hg}$ species on important $\mathrm{Hg}$ transformation processes and the overall $\mathrm{Hg}$ cycling in this ecosystem are discussed.

\subsection{Introduction}

The enhanced dissolution of cinnabar is an important process to control mercury $(\mathrm{Hg})$ cycling in the aquatic environment (69). A variety of environmental factors can facilitate cinnabar dissolution to potentially make cinnabar a continuous source of dissolved inorganic $\mathrm{Hg}$ being released into the aqueous phase (e.g., pore water in sediment) (56-58, 60). The forms of dissolved $\mathrm{Hg}$ species released through cinnabar dissolution are dependent upon specific environmental conditions, in particular the presence of inorganic and organic ligands $(56-60,63,68)$. Subsequently, the variety of $\mathrm{Hg}$ species released by cinnabar dissolution under varying environmental conditions may have distinct implications on aquatic $\mathrm{Hg}$ cycling, as each $\mathrm{Hg}$ species could behavior differently with respect to transport and transformation in the environment $(85-88,171)$.

The transformation, transport, toxicity, bioaccumulation, and fate of mercury are closely associated with the chemical forms of mercury present in the environment $(49,89$, 171). In aquatic environments, mercury is present primarily as various $\mathrm{Hg}(\mathrm{II})$ compounds. 
These $\mathrm{Hg}(\mathrm{II})$ compounds are found in a variety of physical and chemical forms through complexing with different inorganic (e.g., chloride and sulfide) and organic (e.g., DOM) ligands $(7,8)$. Methylmercury $(\mathrm{MeHg})$, which also exists in aquatic environments, is the most bioavailable and toxic $\mathrm{Hg}$ species and can be bioaccumulated in the food web leading to elevated $\mathrm{Hg}$ concentrations in fish and other animals, posing health risks to human beings and ecosystems $(9,52,89)$. Previous studies have shown that inorganic $\mathrm{Hg}$ biogeochemistry, in particular the relative distribution of dissolved $\mathrm{Hg}$ species, influences methylmercury production in aquatic ecosystems, as some $\mathrm{Hg}$ species may be more bioavailable to $\mathrm{Hg}$ methylating bacteria (e.g., sulfate and iron reducing bacteria) than others $(52,92,93,172)$. It would be helpful to know the distribution patterns of inorganic $\mathrm{Hg}$ species (e.g., what species are present at what percentages) for a better understanding of aquatic $\mathrm{Hg}$ cycling. Since it is practically impossible to use analytical techniques to determine all inorganic $\mathrm{Hg}$ species present through complexing with inorganic and organic ligands in aqueous phase, geochemical modeling provides a good alternative method to examine the distribution of $\mathrm{Hg}$ species.

Geochemical modeling of $\mathrm{Hg}$ speciation requires a relatively clear understanding of major $\mathrm{Hg}$ transport and transformation processes in a given system, in particular types and concentrations of inorganic and organic ligands present in the system and the stability constants of the complexes of these ligands with $\mathrm{Hg}$. Although knowing the $\mathrm{Hg}$ species released during cinnabar dissolution would be helpful to understand the role of cinnabar dissolution in aquatic $\mathrm{Hg}$ cycling, it is not feasible at this stage to geochemically model $\mathrm{Hg}$ speciation during cinnabar dissolution, as this process has not been studied in sufficient detail. Even for aquatic $\mathrm{Hg}$ cycling in general, much remains unclear about how inorganic 
Hg species are distributed in aqueous phase and how their varying bioavailability influence the uptake by methylating bacteria for production of MeHg. Applying geochemical modeling approach to a relatively well-studied system with ancillary environmental parameters (e.g., concentrations of inorganic and organic ligands) to examine $\mathrm{Hg}$ speciation would be beneficial to improve understanding towards how $\mathrm{Hg}$ species distribution affects $\mathrm{MeHg}$ production and the overall $\mathrm{Hg}$ cycling in the aquatic environment.

The Florida Everglades is a subtropical wetland ecosystem located in South Florida. It provides significant ecological, water storage, flood control and recreational benefits to the region and important habitat for wildlife including endangered species. However, elevated levels of mercury, especially $\mathrm{MeHg}$, a potent neurotoxin, have been measured in fish and wildlife e.g., wading birds, alligators, and Florida panthers in the Everglades over the last few decades (108-111). This not only is an issue for human consumption of fish, but also threatens fish-eating wildlife species and the biological diversity of the ecosystem (112114). As a result, extensive studies have been conducted in the Everglades to determine the magnitude of $\mathrm{Hg}$ contamination and biogeochemical cycling of $\mathrm{Hg}$, plus geochemical and ecological studies on this system $(79,89,119,173)$. For instance, the Everglades Regional Environmental Monitoring and Assessment Program (R-EMAP) has sampled and analyzed surface water, soil, vegetation, and fish samples throughout the entire Everglades at about 1000 locations for mercury and a variety of biogeochemical parameters by the United States Environmental Protection Agency (USEPA) Region 4 (174). Therefore, the Florida Everglades is an appropriate object to study the $\mathrm{Hg}$ species distribution, including $\mathrm{Hg}$ transformation and bioaccumulation, using geochemical models, as well as the released $\mathrm{Hg}$ 
from $\mathrm{HgS}$ and potential threat to human being and other animals. Efforts have been made to investigate source, transport, transformation (reduction/oxidation and in particular methylation/demethylation), and bioaccumulation of $\mathrm{Hg}$ in fish and wildlife in the Everglades $(45,116-118,173)$. Spatial patterns in mercury cycling and bioaccumulation in the Everglades have been investigated. However, much remains unclear about how elevated levels of $\mathrm{Hg}$ in fish and wildlife are accumulated and the biogeochemical cycling of mercury in this system $(109,175)$. One of the particular concerns is the lack of study that deals with the speciation of inorganic $\mathrm{Hg}$, whether being dissolved $\mathrm{Hg}$ ions (or neutral species) or bound to particles and organic matter, and the effect of these $\mathrm{Hg}$ species on $\mathrm{Hg}$ transformation (e.g., methylation and photochemical reactions) and bioaccumulation.

\subsection{Objective}

The objective of this study is to understand how geochemical factors such as $\mathrm{pH}$, dissolved ions, and organic matter affect inorganic $\mathrm{Hg}$ species and subsequently control $\mathrm{Hg}$ cycling and bioaccumulation in the Florida Everglades. To achieve this goal, geochemical models are used to model the distribution of inorganic $\mathrm{Hg}$ species in this work. The distribution of inorganic $\mathrm{Hg}$ species in surface water throughout the entire Everglades is determined by applying geochemical models to different R-EMAP sampling sites. The patterns of inorganic $\mathrm{Hg}$ species distribution are related to $\mathrm{MeHg}$ levels in environmental matrices to examine how inorganic $\mathrm{Hg}$ species potentially affect the production and fate of $\mathrm{MeHg}$, and then further related to fish $\mathrm{Hg}$ levels to explore the relationship between inorganic $\mathrm{Hg}$ speciation, $\mathrm{MeHg}$ production, and $\mathrm{Hg}$ bioaccumulation. The implications of the inorganic $\mathrm{Hg}$ species distribution on important $\mathrm{Hg}$ transformation processes and the overall $\mathrm{Hg}$ cycling in the Florida Everglades are discussed. 


\subsection{Methods}

\subsubsection{Data sources}

The data used for this study are mainly from R-EMAP. The ultimate goal of this program is to provide critical information to decision makers for multiple environmental issues and restoration of the Everglades ecosystem by improving environmental management decisions (176). Mercury contamination was one of these issues. To achieve this goal, the USEPA began to monitor the condition of the South Florida ecosystem in 1993 and has completed 4 phases from different environmental media at more than 1000 different locations throughout the entire freshwater Everglades so far (177). A statistical, probability-based sampling strategy was used to select sampling sites from Lake Okeechobee in the north to Florida Bay in the south, from Miami urban area on the east to Big Cypress on the west to provide the foundation for ecological risk assessment in South Florida $(176,178)$. To be specific, phase I of the project was conducted from 1992 to 1996. Measurements were made on samples from water, marsh soil, canal sediment, algae, and mosquitofish. These samples were collected from 200 sampling stations from canal and 500 from marsh during successive dry and wet season (176). In addition, four marsh transects (44 stations) were sampled during 1994. Phase II sampling was conducted during 1999 from another 126 selected marsh sites during both dry and wet seasons. Two other biogeochemical media, pore water and floc, were added at each site in phase II (179). Phase III was conducted in 2005 at another 228 Everglades marsh sites (174). Phase IV was initiated in 2013, but samples were only collected from 52 stations and not completed because of the federal government shut down during that period (177). Sampling was then restarted and completed in 2014. However, the details of the complete phase IV are still 
not publically available yet. In addition to the differences of sampling media and stations, some studies on macrophytic plants and community ecology were also added during these phases.

Data from phase III in 2005 were chosen in this work. In 2005, the R-EMAP Phase III sampling was conducted at 109 randomly selected stations in dry season (May) and 119 in wet season (November) in Arthur R. Marshall Loxahatchee National Wildlife Refuge (LNWR or Water Conservation Area 1, WCA-1), Water Conservation Areas 2 and 3 (WCA-2 and WCA-3), and Everglades National Park (ENP). Massive datasets were generated for total mercury, methylmercury, and a large number of biogeochemical parameters including $\mathrm{pH}$, dissolved oxygen, sulfide, and dissolved organic carbon (DOC) for the entire Everglades ecosystem. The unprecedented data source provides a good chance for geochemical modeling. In this research, surface water was studied using geochemical models for inorganic $\mathrm{Hg}$ speciation distribution which was subsequently related to $\mathrm{MeHg}$ in other environmental media. The locations of sampling stations which contain all necessary data were shown in Fig. 4.1 including 69 in May and 113 in November. However, the concentrations of an important geochemical factor, inorganic sulfide in surface water, were found below the detection limit $(0.02 \mathrm{mg} / \mathrm{L})$ in most sampling stations, which decreased the available modeling stations to 18 in dry season and 21 in wet season if only stations with detectable sulfide were considered.

To better evaluate the distribution of $\mathrm{Hg}$ species in surface water of Everglades, for the stations where the concentrations of sulfide were reported below the detection limit, special treatment was taken by assigning environmentally relevant sulfide concentrations to these stations. This treatment was due to the relatively high detection limit of $0.02 \mathrm{mg} / \mathrm{L}$ for the 
sulfide determination method used in R-EMAP project, which provided limited information on accurately evaluate the effect of sulfide on $\mathrm{Hg}$ speciation, as a sulfide concentration significantly (a few orders of magnitude) below $0.02 \mathrm{mg} / \mathrm{L}$ would still play a dominant role in regulating $\mathrm{Hg}$ speciation. During the process to select these values, data from the U.S. Geological Survey (USGS) were used for reference. The USGS established a Critical Ecosystems Program for South Florida for the ecosystem restoration (180). As part of the study for the evaluation of biogeochemical processes in sediments in the cycling of carbon, nitrogen, phosphorus, and sulfur, concentrations of sulfide in surface water and pore water were analyzed from 12 sites including LNWR, WCA 3, WCA 2, and ENP in South Florida which were used in this work. Detailed information on the selection of environmentally relevant sulfide concentrations and the role of sulfide in regulating $\mathrm{Hg}$ speciation can be found in the Results and discussion below.

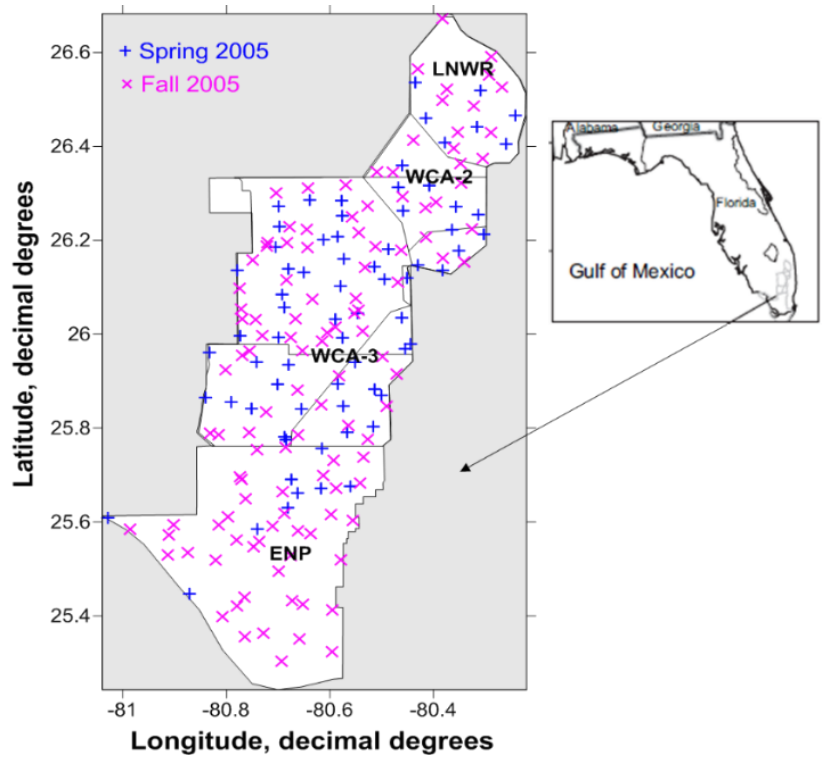

Figure 4.1 A map showing sampling sites in the Florida Everglades during the dry (spring) and wet season (fall) in 2005. 


\subsubsection{Determination of $\mathrm{THg}, \mathrm{MeHg}$, and other ancillary parameters}

In this work, THg and other ancillary parameters were applied to model the distribution of $\mathrm{Hg}$ species. Concentrations of $\mathrm{MeHg}$ in soil in surface water, soil, floc, periphyton, and mosquitofish were used to evaluate the relationship between $\mathrm{Hg}$ species and methylation. The analysis methods for some important parameters are summarized here. For THg analysis, samples from soil, floc, and periphyton were homogenized by blender first, acidified by $10 \% \mathrm{HCl}$ to release $\mathrm{CO}_{2}$, and digested with concentrated $\mathrm{HNO}_{3}$ in $10 \mathrm{~mL}$ ampoules for $1 \mathrm{~h}$ at $121^{\circ} \mathrm{C}$ using autoclave (158). The samples were then cooled and diluted for analysis. Mosquitofish samples were digested using the same closed-ampoule acid digestion process directly after were weighed without being homogenized. After dilution, concentrations of samples were determined by cold vapor atomic fluorescence spectrometry (CVAFS) (Merlin 10.035, PS Analytical, UK). Standard operating procedures (SOPs) modified after EPA method 7474 were followed $(158,181)$. EPA method 1631E was used to analyze water samples were by gold amalgamation with CVAFS (182).

For MeHg analysis, after soil, floc, and periphyton samples were homogenized and acidified, they were then isolated by an acidic $\mathrm{KBr} / \mathrm{H}_{2} \mathrm{SO}_{4} / \mathrm{CuSO}_{4}(1.5 / 1.8 / 1 \mathrm{M})$ solution followed by extraction of $\mathrm{MeHg}$ by organic phase $\mathrm{CH}_{2} \mathrm{Cl}_{2}$. Two $\mathrm{mL}$ of $\mathrm{CH}_{2} \mathrm{Cl}_{2}$ extract were transferred to $40 \mathrm{~mL}$ distilled deionized water in a $50 \mathrm{~mL}$ centrifuge tube in a $45{ }^{\circ} \mathrm{C}$ water bath with $100 \mathrm{~mL} / \mathrm{min} \mathrm{N}_{2}$ purged for $30 \mathrm{~min}$ to volatilize $\mathrm{CH}_{2} \mathrm{Cl}_{2}$ and leave $\mathrm{MeHg}$ in aqueous phase (183). Before analysis, samples were ethylated by reacting with $0.2 \mathrm{~mL}$ of $1 \%$ NaBEt4 (Strem Chemicals, Newburyport, MA) in $2 \mathrm{~mL}$ of acetate buffer (2M) for 15 min. The ethylation products were then purged and trapped on a Tenax trap, dried and 
analyzed by Brooks Rand (Seattle, WA) MeHg analytical system following aqueous ethylation-purge and trap-gas chromatography (GC)-AFS. The procedures were modified after EPA method 1630 (184). Water samples were distilled to liberate MeHg from the matrix before analysis. MeHg analysis wasn't conducted for mosquitofish samples since more than 95\% of THg in mosquitofish was $\mathrm{MeHg}$ (179). Concentrations of $\mathrm{MeHg}$ could be represented by those of THg. The calculations of $\mathrm{Hg}$ concentrations were based on dry weight for soil, floc, and periphyton and wet weight for mosquitofish. Both THg and MeHg were analyzed by Southeast Environmental Research Center at Florida International University (SERC, FIU). Mercury Laboratory at Florida International University (SERC, FIU), a testing lab accredited by the National Environmental Laboratory Accreditation Program (NELAP).

Another important parameter sulfide in surface water was sampled by a special sampling system because of the reducibility. The sampling system, included two $60 \mathrm{~mL}$ plastic syringe, a 3-way valve, and a leur-loc tip (123). One syringe was previously prepared with zinc acetate/6N sodium hydroxide preservative solution. Another syringe was used to remove air from tip of syringe by pulling sample through the side port before sampling underwater. The analysis of sulfide followed Hach method 8131 (EPA accepted method) (185). Sulfides react with N,N-dimethyl-p-phenylenediamine sulfate to form methylene blue. Since the intensity of blue color is proportional to the sulfide concentration, samples were detected by colorimeter with the measurement wavelength $610 \mathrm{~nm}$ after dilution. The method detection limit was $0.02 \mathrm{mg} / \mathrm{L}$ for sulfide. Sulfate was analyzed following EPA method 300.0 (186) using ion chromatography by Science and Ecosystem Support Division (SESD) of USEPA and DOC was analyzed using the 
Shimadzu TOC analyzer following SOP NU-062-1.19 by Florida Department of Environmental Protection (FDEP) (187). All other analytical methods used for involved parameters were summarized in EPA Technical Report (123).

\subsubsection{Geochemical modeling}

\subsubsection{Model background}

Geochemical models are mostly used to simulate chemical equilibrium with thermodynamic databases of elements considered to be of environmental interest (188). Equilibrium models assume that all reactions have completed and are in equilibrium with one another. These models have common capabilities in calculating speciation, sorption, and precipitation of aquatic chemical components (107). PHREEQC is a popular geochemical modeling program, which was first developed in 1995 by the US Geological Survey (USGS) and has been updated to version 3 by Parkhurst and Appelo in 2013 (189, 190). PHREEQC version 3 is a computer program designed for a wide variety of lowtemperature aqueous geochemical calculations including laboratory or environmental water systems. In addition to simulate speciation, saturation index, batch reaction, surface complexion, adsorption and ion exchange at equilibrium which are similar features to other models, PHREEQC also has capabilities of reversible reactions, kinetic reactions, with rate expressions defined by the modeler and one dimensional (1-D) transport simulations (190).

A geochemical model consists of several components: the input file describing the problem to be solved, the geochemical database, the parser reading the input file and deriving a series of equations from it, the solver for a series of resulting nonlinear functions (Newton-Raphson), the output file containing the results, and optional graphical or tabular presentations of results. PHREEQC is the core of the geochemical model containing the 
parser and the solver. The parser extracts species information from the input file and links it based on the equations in the database in nonlinear reaction equations. These species equations are then substituted by mole- and charge-balance equations. The goal is to reach equilibrium, where all functions relevant to a specific equilibrium calculation are equal to zero. The Newton-Raphson approach is used to find the zeros of the functions by which each function is differentiated with respect to each master unknown to form the Jacobian matrix. A set of linear equations is formed from the Jacobian matrix that can be solved to approximate iteratively a solution to the nonlinear equations (190).

\subsubsection{Selection of important mercury species and complexation reactions}

Generally, temperature, $\mathrm{pH}$, dissolved oxygen (redox potential) and concentrations of elements and (or) element valence states are the essential data needed for a speciation calculation (190). All these geochemical factors should be carefully considered and included in input interface. However, most reactions involved do not provide $\Delta \mathrm{H}$ values. Therefore, the effect of temperature was not considered during the modeling. The speciation of $\mathrm{Hg}$ is strongly regulated by redox and $\mathrm{pH}$ conditions as well as the concentrations of binding ligands in aquatic systems (7). Sulfide, dissolved organic matter (DOM) and halogens (mainly chloride) are mainly the primary complex agents with $\mathrm{Hg}$ (8). In addition, other ligands such as sulfate were also considered due to their widely existence. All these parameters were obtained from the REMAP program (Table 1). It should be noted that because of the lack of Eh or pe values, the redox condition was calculated from the $\mathrm{O}(0) / \mathrm{O}(-2)$ redox couple, which corresponds to the dissolved oxygen/water couple. The calculated pe values were used for all calculations that require a pe. However, the redox potential of an aqueous solution is a result of the sum of the redox 
potentials of different redox pairs. Although the solutions from surface water are under strong oxidation state because of high concentrations of dissolved oxygen, the oxidation state could be overestimated which then lead to the underestimate of concentration of $\operatorname{Hg}(0)$. The distribution of $\operatorname{Hg}(\mathrm{II})$ species doesn't change which was verified during the modeling by applying different concentrations of dissolved $\mathrm{O}_{2}$.

In addition, mass concentrations of DOC obtained from R-EMAP should be converted to concentrations of DOM (as thiol RS'). The concentration conversion was completed by applying characteristics of two DOM fractions isolated from the Florida Everglades. Hydrophobic and hydrophilic acid fractions (HPoA and HPiA) were isolated from surface water of WCA2 by passing through XAD- 8 and XAD- 4 resin columns. These two fractions constitute about $80-90 \%$ of humic substances which are also the most reactive fractions for the binding with trace metal like $\mathrm{Hg}$ (67). For each fraction, molecular weight, carbon content, reduced $\mathrm{S}\left(\mathrm{RS}^{-}\right)$fraction, and carboxyl group ( $\left.\mathrm{RO}^{-}\right)$fraction were determined. Therefore, the relationship between mass concentrations of DOC and molar of $\mathrm{RS}^{-}$can be obtained. The percentages of HPoA were found slightly higher than those of HPiA in approximately 100 surface waters in the USA but much less HPiA were observed than HPoA from 25 groundwater samples in the USA (191). In this work, the proportion of each fraction was roughly considered to be equal. The concentrations of $\mathrm{RS}^{-}$were calculated as the average of these of two fractions.

Database files WATEQ4F.dat, MINTEQ.dat, MINTEQ V4.dat, PHREEQC.dat and LLNL.dat were provided with the program PHREEQC. The file MINTEQ.dat was used to provide thermodynamic data for simulations in this work. This database was derived from that provided by another commonly used geochemical model MINTEQA2 (192). Most 
equilibrium constants involved are presented in Table 4.2 and used directly (reactions 4.1 to 4.18). However, important reactions and mercury species are not included in the database MINTEQ.dat in PHREEQC, for instance, $\mathrm{Hg}-\mathrm{DOM}$ and $\mathrm{Hg}-\mathrm{S}$ complexes. Because of the importance of these complexes in determining $\mathrm{Hg}$ speciation, the complexation of $\mathrm{Hg}$ with DOM or sulfide were carefully considered based on the literature, and the selection of appropriate $\mathrm{Hg}-\mathrm{DOM}$ and $\mathrm{Hg}-\mathrm{S}$ complexes and the corresponding formation constants was detailed below.

Table 4.1 List of biogeochemical parameters used in the modeling and the concentration ranges found in the Everglades surface water

\begin{tabular}{ll}
\hline Biogeochemical parameters & Ranges \\
\hline $\mathrm{pH}$ & $5.33-8.06$ \\
Dissolved oxygen & $0.85-11.22 \mathrm{mg} / \mathrm{L}$ \\
pe $(\mathrm{O}(0) / \mathrm{O}(-2))$ & $12.88-13.16$ \\
Total mercury & $1.1-7.4 \mathrm{ng} / \mathrm{L}$ \\
Fluoride & $0.025-1 \mathrm{mg} / \mathrm{L}$ \\
Chloride & $16-260 \mathrm{mg} / \mathrm{L}(* 1100 \mathrm{mg} / \mathrm{L}$ in station 12$)$ \\
Bromide & $0.059-3.7 \mathrm{mg} / \mathrm{L}$ \\
Sulfide & $0.02-0.24 \mathrm{mg} / \mathrm{L}$ \\
Sulfate & $0.012-110 \mathrm{mg} / \mathrm{L}$ \\
DOM & $9.25-100.5 \mathrm{mg} / \mathrm{L}$ \\
\hline
\end{tabular}

\section{Selection of Hg-DOM complexes}

It is well known that $\mathrm{Hg}$ interacts very strongly with DOM and the complexes formed can determine the speciation, mobility, and bioavailability of mercury in the aquatic environment $(54,63,193,194)$. The conditional formation constants for Hg-DOM complexes vary because of the differences in DOM composition and experimental conditions (67). The generally binding sites of DOM by $\mathrm{Hg}$ are the acid sites including 
carboxylic acids, phenols, amino ions, alcohols and thiols (67). The interactions between $\mathrm{Hg}$ and groups such as thiol groups $\left(\mathrm{RS}^{-}\right)$and oxygen functional groups $\left(\mathrm{RO}^{-}\right)$contained in these binding sites can be described by Hard and Soft Acid-Base Rules. On the basis of this rule, divalent $\mathrm{Hg}$ is classified as a $\mathrm{B}$ type metal cation and also soft sphere cation for its low electronegativity and high polarizability (97). Therefore, metal cations of type B coordinate preferentially with ligands containing low electronegative $\mathrm{S}$ rather than $\mathrm{O}(97)$. Carboxylic acids and phenols contribute up to $90 \%$ of the functional groups from DOM, while $\mathrm{RS}^{-}$occupies minor constituent comparing with the $\mathrm{RO}^{-}$(67). Although the percentage of $\mathrm{RS}^{-}$is small, the amount of $\mathrm{RS}^{-}$in humic substances is more abundant than the natural levels of $\mathrm{Hg}$ in environment (195). It's not surprising that $\mathrm{Hg}$ was observed to bind preferentially to $\mathrm{RS}^{-}$rather than $\mathrm{RO}^{-}$in natural environment when the ratio of $\mathrm{Hg}$ and DOM is less than $1 \mu \mathrm{g}$ of $\mathrm{Hg}$ to $1 \mathrm{mg}$ of DOM (195). While $\mathrm{Hg}(\mathrm{II}) / \mathrm{DOM}$ ratios above approximately $10 \mu \mathrm{g} \mathrm{Hg}(\mathrm{II})$ per $\mathrm{mg}$ DOM show $\mathrm{Hg}(\mathrm{II})$ binding mainly to oxygen functional groups (196). The complexation reaction can be expressed as reaction (4.19) or (4.20). Meanwhile, the conditional stability constants (K') for $\mathrm{Hg}$ complexes with DOM fractions were determined $(170,196,197)$.

$$
\begin{aligned}
& \mathrm{Hg}^{2+}+\mathrm{RS}^{(\mathrm{n}+1)-}=\mathrm{RSHg}^{(\mathrm{n}-1)-} \\
& \mathrm{Hg}^{2+}+\mathrm{RSH}^{\mathrm{n}-}=\mathrm{RSHg}^{(\mathrm{n}-1)-}+\mathrm{H}^{+}
\end{aligned}
$$

The stability constants ( $\log \mathrm{K}$ ) between $\mathrm{Hg}$ and fully ionized ligand $\mathrm{RS}^{-}$expressed as $\mathrm{RS}^{(\mathrm{n}+1)-}$ were determined from 23.8 to 28.7 for reaction 4.19 by using different techniques $(170,196,197)$. This reaction can be converted to another way by adding reaction

$$
\mathrm{RSH}^{\mathrm{n}-}=\mathrm{RS}^{(\mathrm{n}+1)-}+\mathrm{H}^{+} \quad \log \mathrm{K}=-10
$$

to get $\log \mathrm{K}$ for reaction 4.20 from 13.8 to $18.7(170,196,197)$. While $\mathrm{Log} \mathrm{K}$ for $\mathrm{Hg}$ and 
weak sites $\mathrm{RO}^{-}$was determined only 10.7 which is much lower than that for the reaction between $\mathrm{Hg}$ and $\mathrm{RS}^{-}(196)$. The average Log K obtained via various techniques was applied in this work as 14.7. To be consistent with other reactions from database where $\mathrm{Hg}$ was presented as the hydrate form, the reaction was converted to

$$
\mathrm{Hg}(\mathrm{OH})_{2}+\mathrm{RSH}^{\mathrm{n}-}+\mathrm{H}^{+}=\mathrm{RSHg}^{(\mathrm{n}-1)-}+2 \mathrm{H}_{2} \mathrm{O} \quad \log \mathrm{K}=20.8
$$

by adding another reaction

$$
\mathrm{Hg}(\mathrm{OH})_{2}+2 \mathrm{H}^{+}=\mathrm{Hg}^{2+}+2 \mathrm{H}_{2} \mathrm{O} \quad \log \mathrm{K}=6.10
$$

\begin{tabular}{|c|c|c|}
\hline Reaction number & Reactions & $\log K$ \\
\hline 4.1 & $\mathrm{Hg}(\mathrm{OH})_{2}+\mathrm{H}^{+}=\mathrm{HgOH}^{+}+\mathrm{H}_{2} \mathrm{O}$ & 2.70 \\
\hline 4.2 & $\mathrm{Hg}(\mathrm{OH})_{2}+2 \mathrm{H}^{+}=\mathrm{Hg}^{2+}+2 \mathrm{H}_{2} \mathrm{O}$ & 6.10 \\
\hline 4.3 & $\mathrm{Hg}(\mathrm{OH})_{2}+\mathrm{H}_{2} \mathrm{O}=\mathrm{Hg}(\mathrm{OH})_{3}^{-}+\mathrm{H}^{+}$ & -15.00 \\
\hline 4.4 & $\mathrm{Hg}(\mathrm{OH})_{2}+2 \mathrm{HS}^{-}=\mathrm{HgS}_{2}{ }^{2-}+2 \mathrm{H}_{2} \mathrm{O}$ & 31.24 \\
\hline 4.5 & $\mathrm{Hg}(\mathrm{OH})_{2}+2 \mathrm{HS}^{-}+2 \mathrm{H}^{+}=\mathrm{Hg}(\mathrm{HS})_{2}+2 \mathrm{H}_{2} \mathrm{O}$ & 43.82 \\
\hline 4.6 & $\mathrm{Hg}(\mathrm{OH})_{2}+\mathrm{SO}_{4}^{2-}+2 \mathrm{H}^{+}=\mathrm{HgSO}_{4}+2 \mathrm{H}_{2} \mathrm{O}$ & 7.49 \\
\hline 4.7 & $\mathrm{Hg}(\mathrm{OH})_{2}+\mathrm{Cl}^{-}+2 \mathrm{H}^{+}=\mathrm{HgCl}^{+}+2 \mathrm{H}_{2} \mathrm{O}$ & 12.85 \\
\hline 4.8 & $\mathrm{Hg}(\mathrm{OH})_{2}+2 \mathrm{Cl}^{-}+2 \mathrm{H}^{+}=\mathrm{HgCl}_{2}+2 \mathrm{H}_{2} \mathrm{O}$ & 19.22 \\
\hline 4.9 & $\mathrm{Hg}(\mathrm{OH})_{2}+3 \mathrm{Cl}^{-}+2 \mathrm{H}^{+}=\mathrm{HgCl}_{3}^{-}+2 \mathrm{H}_{2} \mathrm{O}$ & 20.12 \\
\hline 4.10 & $\mathrm{Hg}(\mathrm{OH})_{2}+4 \mathrm{Cl}^{-}+2 \mathrm{H}^{+}=\mathrm{HgCl}_{4}^{2-}+2 \mathrm{H}_{2} \mathrm{O}$ & 20.53 \\
\hline 4.11 & $\mathrm{Hg}(\mathrm{OH})_{2}+\mathrm{Cl}^{-}+\mathrm{H}^{+}=\mathrm{HgClOH}+\mathrm{H}_{2} \mathrm{O}$ & 9.31 \\
\hline 4.12 & $\mathrm{Hg}(\mathrm{OH})_{2}+\mathrm{F}^{-}+2 \mathrm{H}^{+}=\mathrm{HgF}^{+}+2 \mathrm{H}_{2} \mathrm{O}$ & 8.08 \\
\hline 4.13 & $\mathrm{Hg}(\mathrm{OH})_{2}+\mathrm{Br}-+2 \mathrm{H}^{+}=\mathrm{HgBr}^{+}+2 \mathrm{H}_{2} \mathrm{O}$ & 15.83 \\
\hline 4.14 & $\mathrm{Hg}(\mathrm{OH})_{2}+2 \mathrm{Br}-+2 \mathrm{H}^{+}=\mathrm{HgBr}_{2}+2 \mathrm{H}_{2} \mathrm{O}$ & 23.61 \\
\hline 4.15 & $\mathrm{Hg}(\mathrm{OH})_{2}+2 \mathrm{H}^{+}+3 \mathrm{Br}^{-}=\mathrm{HgBr}_{3}^{-}+2 \mathrm{H}_{2} \mathrm{O}$ & 25.79 \\
\hline 4.16 & $\mathrm{Hg}(\mathrm{OH})_{2}+2 \mathrm{H}^{+}+4 \mathrm{Br}^{-}=\mathrm{HgBr}_{4}{ }^{2-}+2 \mathrm{H}_{2} \mathrm{O}$ & 27.06 \\
\hline 4.17 & $\mathrm{Hg}(\mathrm{OH})_{2}+\mathrm{Br}^{-}+\mathrm{Cl}^{-}+2 \mathrm{H}^{+}=\mathrm{HgBrCl}+2 \mathrm{H}_{2} \mathrm{O}$ & 22.01 \\
\hline 4.18 & $\mathrm{Hg}(\mathrm{OH})_{2}+\mathrm{Br}^{-}+\mathrm{H}^{+}=\mathrm{HgBrOH}+\mathrm{H}_{2} \mathrm{O}$ & 11.60 \\
\hline
\end{tabular}

Table 4.2 The reactions and equilibrium constants of $\mathrm{Hg}$ available in PHREEQC (198). 


\section{Selection of $\mathrm{Hg}-\mathrm{S}$ complexes}

Another important $\mathrm{Hg}$ binding ligand is sulfide. The complexation of $\mathrm{Hg}$ and sulfide was found to be the main factor controlling inorganic $\mathrm{Hg}$ species even as low as $10^{-7} \mathrm{M}$ of sulfide presents(127). Sulfide could form numerous species with mercury depending on the conditions. Some of the relevant species such as $\mathrm{HgS}_{2}{ }^{2-}, \mathrm{Hg}(\mathrm{HS})_{2}$ are included in the database from PHREEQC and directly used in the modeling. In addition, to avoid missing important $\mathrm{Hg}-\mathrm{S}$ species, other $\mathrm{Hg}-\mathrm{S}$ species such as $\mathrm{HgHS}_{2}^{-}$and $\mathrm{HgHSOH}$ are also included in the modeling. The complexation reaction for species $\mathrm{HgHS}_{2}{ }^{-}$as following was obtained from the literature and the value of $\log \mathrm{K}$ was generally accepted to be 38.1 (52).

$$
\mathrm{Hg}(\mathrm{OH})_{2}+\mathrm{H}^{+}+2 \mathrm{HS}^{-}=\mathrm{HgHS}_{2}^{-}+2 \mathrm{H}_{2} \mathrm{O} \quad \log \mathrm{K}=38.1
$$

However, the neutral $\mathrm{HgHSOH}$ species had to be carefully examined for inclusion in the model, as there was a controversy about the Log $\mathrm{K}$ of this complex and even about the specific form it presents in aqueous solution. The species was generally written as $\mathrm{HgHSOH}$, but in many cases as $\mathrm{HgS}^{0}$, and the formation of this species was first proposed by Dyrssen and Wedborg on the basis of theoretical calculation (199). The reaction and Log $\mathrm{K}$ were expressed as

$$
\mathrm{HgS}(\mathrm{s})+\mathrm{H}_{2} \mathrm{O}=\mathrm{HgHSOH} \quad \log \mathrm{K}=-22.3
$$

Combine reaction (4.25) with the dissolution reaction of $\mathrm{HgS}(\mathrm{s})$ and dissociation reaction of $\mathrm{H}_{2} \mathrm{O}$ (reaction (4.26) and (4.27))

$$
\begin{aligned}
& \mathrm{HgS}(\mathrm{s})+\mathrm{H}^{+}=\mathrm{Hg}^{2+}+\mathrm{HS}^{-} \quad \log \mathrm{K}=-38.9 \\
& \mathrm{H}_{2} \mathrm{O}=\mathrm{H}^{+}+\mathrm{OH}^{-}, \quad \log \mathrm{K}=-13.7
\end{aligned}
$$

Then the $\log \mathrm{K}$ for the complexation of $\mathrm{HgHSOH}$ would be calculated as 30.3 for reaction 


$$
\begin{aligned}
& \mathrm{Hg}^{2+}+\mathrm{HS}^{-}+\mathrm{OH}^{-}=\mathrm{HgHSOH} \\
& \mathrm{Hg}(\mathrm{OH})_{2}+\mathrm{H}^{+}+\mathrm{HS}^{-}=\mathrm{HgHSOH}+\mathrm{H}_{2} \mathrm{O} \quad \log \mathrm{K}=22.70
\end{aligned}
$$

The controversy over $\mathrm{Log} \mathrm{K}$ of $\mathrm{HgHSOH}$ (or $\mathrm{HgS}^{0}$ ) was summarized as follows for a better selection of $\log \mathrm{K}$. When Dyrssen and Wedborg compared the reaction of $\mathrm{HgS}(\mathrm{s}) / \mathrm{HgHSOH}$ to the analog reaction of $\mathrm{ZnS}(\mathrm{s}) / \mathrm{ZnHSOH}$ obtained by Gubeli and SteMarie, they found that the experimental $\log \mathrm{K}$ for $\mathrm{ZnHSOH}$ was much lower than the calculation value and that the relation between them was $\log \mathrm{K}_{\mathrm{s} 1}(\mathrm{calc})=2.26 \log \mathrm{K}_{\mathrm{s} 1}(\exp )$ (199-201). This relation was also observed for $\mathrm{CdS}(\mathrm{s}) / \mathrm{CdHSOH}$. Based on this observation, $\log \mathrm{K}$ for reaction 4.25 was suggested to be changed to -10 (199). However, when Skyllberg combined this value with the solubility product of $\mathrm{HgS}(\mathrm{s})$ and ionic product of water, he got a Log K value of 40.5 for reaction 4.28 (169). It was concluded that this value was theoretically unreasonable and unacceptable. This was because this value was even higher than the $\log \mathrm{K}$ of $\mathrm{Hg}(\mathrm{HS})_{2}$ complex, which was inconsistent with the fact that $\mathrm{Hg}$ has a preference for interaction with $\mathrm{S}$ than with $\mathrm{O}$ and consequently the complex of $\mathrm{Hg}$ with two $\mathrm{HS}^{-}$groups $\left(\mathrm{Hg}(\mathrm{HS})_{2}\right)$ should have a higher $\log \mathrm{K}$ than the complex of $\mathrm{Hg}$ with a $\mathrm{HS}^{-}$and a $\mathrm{OH}^{-}$group $(\mathrm{HgHSOH})(169)$. The reason that Dyrssen and Wedborg observed a higher experimental Log K than theoretically calculated value could be because of the presence of colloids in aqueous phase during the experiment that would result in an overestimated experimental value (199). Based on these considerations, in my work, $\log \mathrm{K}=30.3$ was selected as a proper value for reaction 4.28. Reactions (4.22), (4.24), and (4.29) including related stability constants were supplemented in input interface while modeling. 
It should be noted that, when the species was written as the form of $\mathrm{HgS}^{0}$, the $\log \mathrm{K}$ was suggested by Benoit et al to be 26.5 for the reaction (52).

$$
\mathrm{Hg}^{2+}+\mathrm{HS}^{-}=\mathrm{HgS}^{0}+\mathrm{H}^{+}
$$

There are two reasons why this reaction and Log $\mathrm{K}$ value was not used in this work. Firstly, the two $\mathrm{Hg}$ forms actually represent same species and the species should exist as $\mathrm{HgHSOH}$ rather than $\mathrm{HgS}^{0}$, as $\mathrm{HgS}^{0}$ was confirmed as a theoretically unstable form in the presence of $\mathrm{H}_{2} \mathrm{O}(199,202)$. It is impossible to distinguish $\mathrm{HgS}^{0}$ and $\mathrm{HgHSOH}$ since the Log $\mathrm{K}$ for reaction

$$
\mathrm{OH}^{-}+\mathrm{SH}^{-}=\mathrm{S}^{2-}+\mathrm{H}_{2} \mathrm{O}
$$

is very small $(\sim 3)$, which proves the coexistence of $\mathrm{OH}^{-}$and $\mathrm{HS}^{-}$in same complex. Secondly, in the process of derivation of reaction 30 by Benoit et al, the Log $\mathrm{K}=-10$ for reaction (4.25) was used, which was considered theoretically unreasonable as aforementioned.

\subsubsection{Statistics analysis}

After obtaining the distribution of inorganic $\mathrm{Hg}$ species through geochemical modeling, Spearman's rank correlation was employed to examine the relationship between the dominant inorganic $\mathrm{Hg}(\mathrm{II})$ species and $\mathrm{MeHg}$ in environmental matrices, including water, periphtyon, floc, and soil, and biological body, specifically mosquitofish, by using software OriginPro 8 (OriginLab). The groups of these parameters that were found to have significant correlation coefficients were used to help explore the relationship between inorganic $\mathrm{Hg}$ speciation, $\mathrm{MeHg}$ production, and $\mathrm{Hg}$ bioaccumulation. 


\subsection{Results and discussion}

\subsubsection{Distribution of inorganic Hg species in surface water}

\subsubsection{The complexes of sulfides and inorganic mercury}

Speciation calculation for mercury using PHREEQC provides concentrations of $\mathrm{Hg}$ species in each sampling station on the basis of database and geochemical parameters described above. The modeling results are shown in appendix A. Modeling results indicate that $\mathrm{Hg}(\mathrm{II})$ was the major species while $\mathrm{Hg}(0)$ and $\mathrm{Hg}(\mathrm{I})$ were barely or not existed at all in surface waters of the Everglades. It is understandable that $\mathrm{Hg}(\mathrm{I})$ does not normally exist in surface water because of the lack of stability of $\operatorname{Hg}(\mathrm{I})$ species (7). However, $\operatorname{Hg}(0)$ has been frequently reported to be present in surface waters, including the Florida Everglades $(117,203)$. One of the major sources of $\operatorname{Hg}(0)$ in surface water is the input from atmospheric deposition (123). A large part of the $\mathrm{Hg}(0)$ from atmosphere could reemit back to the air before participating in the transformation reactions, i.e. playing a minor role in the redox and complexation equilibrium of $\mathrm{Hg}$ in water phase. Therefore, in this study, only $\mathrm{Hg}(\mathrm{II})$ species were taken into consideration to evaluate the distribution and bioavailability of $\mathrm{Hg}$ speciation.

As aforementioned, sulfide was detected only in limited sampling stations due to the lack of sensitivity of the analytical techniques used. The detection limit for sulfide was $0.02 \mathrm{mg} / \mathrm{L}$. During the course of modeling, it became very clear that mercury speciation is determined substantially by the concentration of sulfide. At all sampling stations with measurable concentrations of sulfide (>0.02 $\mathrm{mg} / \mathrm{L})$, the complexes between $\mathrm{Hg}$ and sulfide, including $\mathrm{HgS}_{2}{ }^{2-}, \mathrm{HgHS}_{2}{ }^{-}, \mathrm{Hg}(\mathrm{HS})_{2}$, and $\mathrm{HgHSOH}$ are found to be the dominant $\mathrm{Hg}$ species, accounting for almost 100\% (Figure 4.2). Among these species, the concentrations 
of $\mathrm{HgS}_{2}{ }^{2-}$ were the highest at most stations for both dry and wet seasons, followed by $\mathrm{HgHS}_{2}{ }^{-}, \mathrm{Hg}(\mathrm{HS})_{2}$, and $\mathrm{HgHSOH}$ except for some stations from $\mathrm{LNWR}$ where $\mathrm{HgHS}_{2}{ }^{-}$is the most major $\mathrm{Hg}$ species instead of $\mathrm{HgS}_{2}{ }^{2-}$. The sum of $\mathrm{HgS}_{2}{ }^{2-}$ and $\mathrm{HgHS}_{2}{ }^{-}$occupied more than $90 \%$ of inorganic $\mathrm{Hg}(\mathrm{II})$ species except for three stations located at LNWR including stations 117 and 120 (30.2\% and $48.3 \%$ separately) in dry season and station $239(70.0 \%)$ in wet season. The concentrations of $\mathrm{HgHSOH}$ were extremely low in all the stations.
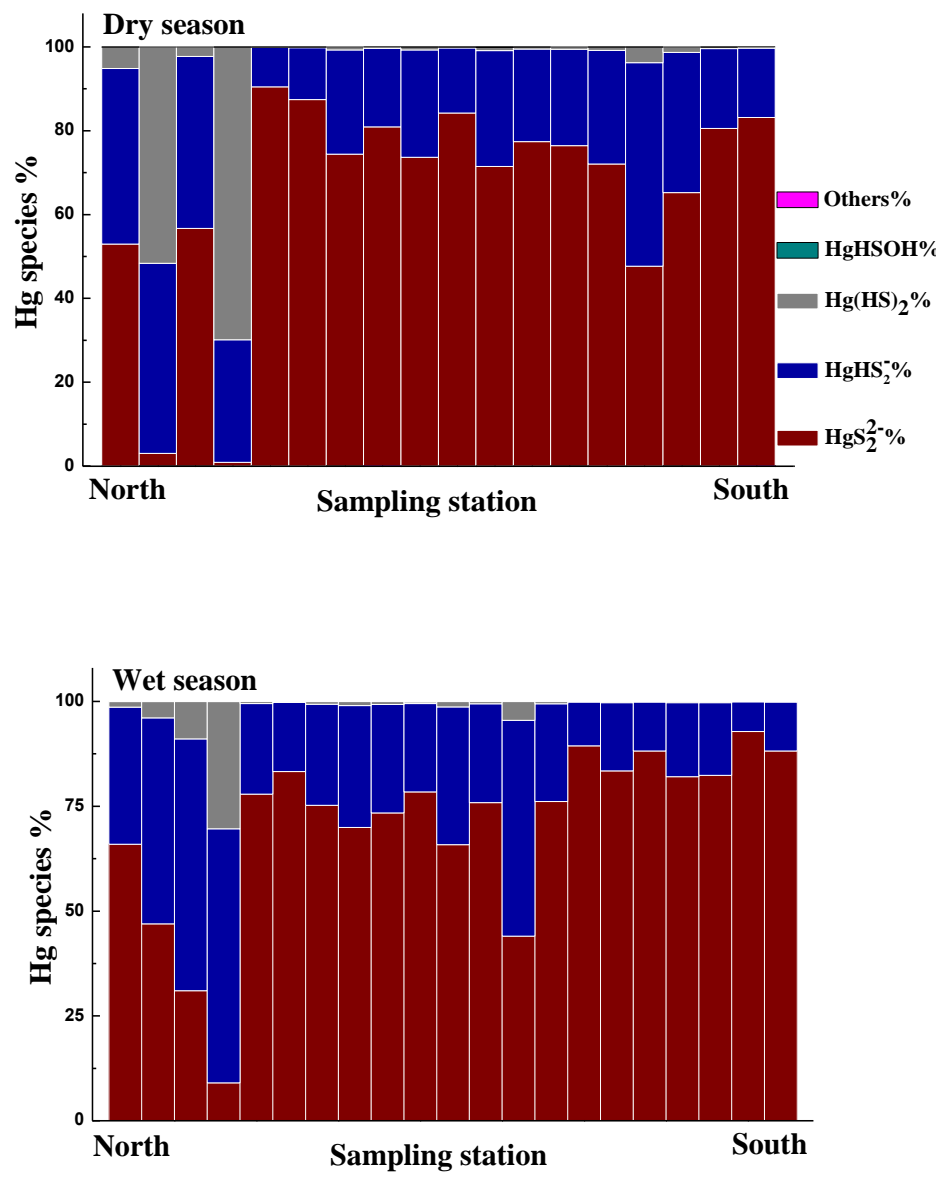

Figure 4.2 The percentages of $\mathrm{Hg}$ species in surface water of Florida Everglades in dry and wet seasons of 2005 at stations where sulfide concentrations were $>0.02 \mathrm{mg} / \mathrm{L}$. 

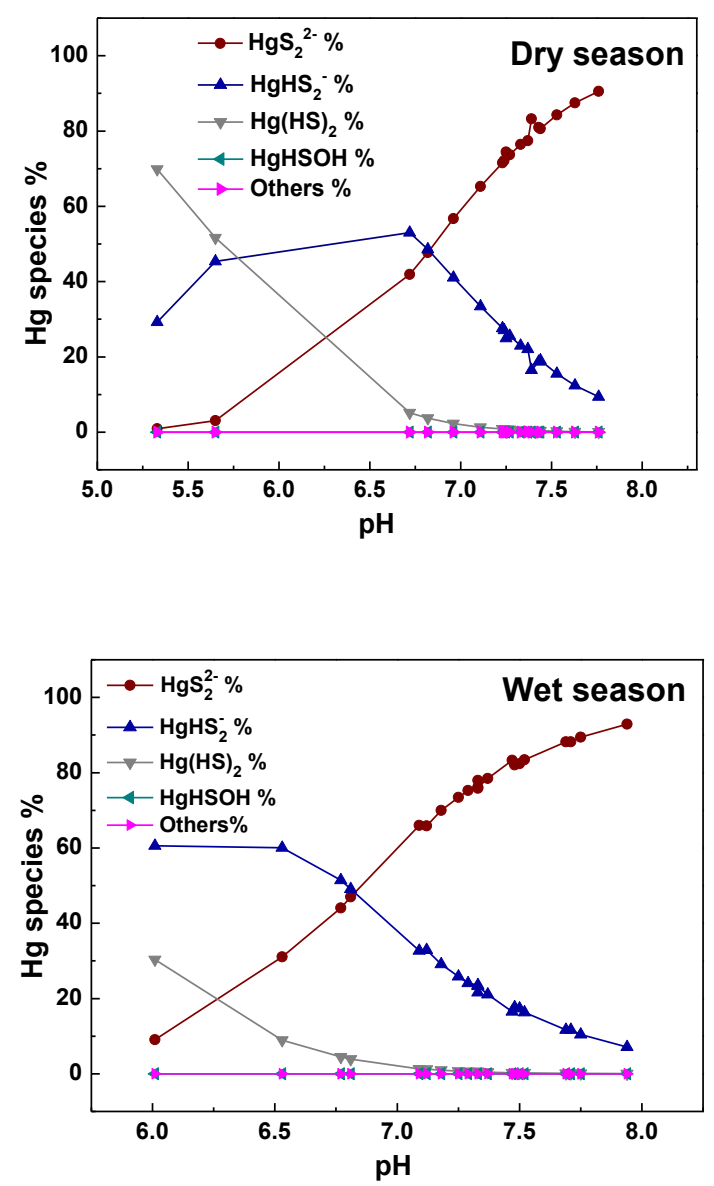

Figure 4.3 Variations of percentages of $\mathrm{Hg}$ species in surface water of Florida Everglades in dry and wet seasons of 2005 at stations where sulfide concentrations were $>0.02 \mathrm{mg} / \mathrm{L}$.

Sulfur contamination is a critical water quality issue in the Florida Everglades (174). The major form of sulfur entering the ecosystem is water-soluble sulfate (204). The highest levels of sulfate $(60-70 \mathrm{mg} / \mathrm{L})$ were found in canal water within EAA of South Florida $(204,205)$. In Everglades, the concentration levels of sulfate in $60 \%$ of the freshwater were estimated exceeding background levels and some of them were even more than 60 times higher than the background concentrations $(123,176,180,206)$. The average sulfate concentrations from the contaminated areas decrease along a north-south gradient (207). The major sources of sulfur contamination in South Florida are agricultural fertilizer, soil 
amendments, and fungicide used in EAA (both new and original sulfur in the soil) (205). Soil sulfur levels of EAA are considerably higher than those of Everglades. The total sulfur (TS) contents vary from 0.1 to $2.5 \%$ (dry wt. basis) in Everglades (204). The accumulation rates of total sulfur were $11 \mathrm{mg} / \mathrm{m}^{2}$ day in northern Everglades and $1.4 \mathrm{mg} / \mathrm{m}^{2}$ day in southern Everglades during 1995-2000 (204). The applied sulfur could be leached into canals as sulfate from EAA to the Everglades and spread out over a large area $(205,207)$. Sulfate then slowly diffuses into soils and stimulates microbial sulfate reduction (MSR) to produce sulfide under anoxic conditions (205). The concentrations of sulfide in Everglades pore water range from $<0.1$ to $13000 \mu \mathrm{g} / \mathrm{L}$ (180). Sulfide in soil pore water could diffuse or advect back to surface water and then oxidized to sulfate via sulfur oxidizing bacteria (204).Therefore, sulfide was absent in most Everglades except some heavily sulfatecontaminated sites with concentrations up to $0.100 \mu \mathrm{g} / \mathrm{L}$ in surface water during $1994-1995$ (180).

Concentrations of sulfate and sulfide were measured in surface water and pore-water during the R-EMAP 2005 investigation (174). In both dry and wet seasons, sulfide concentrations in pore water ranged from 0.02 to $11.65 \mathrm{mg} / \mathrm{L}$ with a mean value of 0.82 $\mathrm{mg} / \mathrm{L}$ and median value of $0.13 \mathrm{mg} / \mathrm{L}$ (Fig. 4.4A). Most of the sampling stations with high sulfide concentrations were located up north, in the areas of WCA2 and the north of WCA3, which are downstream of the agricultural region. Sulfide in surface water, ranging from 0.021 to 0.235 with a mean value of $0.046 \mathrm{mg} / \mathrm{L}$ and median value of $0.027 \mathrm{mg} / \mathrm{L}$, showed a different distribution pattern mainly in ENP (Fig. 4.4B). Sampling stations with sulfide concentration larger than $0.021 \mathrm{mg} / \mathrm{L}$ were scattered through the studied area with more a frequently appearance in not only the north but also the south of the Everglades. As for 
sulfate, very similar distribution patterns were observed for both surface and pore-water, decreasing from north to south, which is in good agreement with literature (Fig. 4.5A and 4.5B) $(174,180,204,205)$.

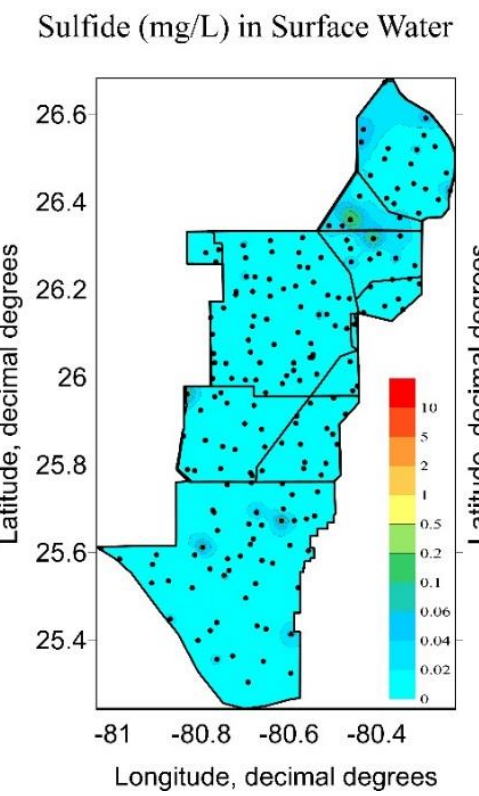

Sulfide $(\mathrm{mg} / \mathrm{L})$ in Pore Water

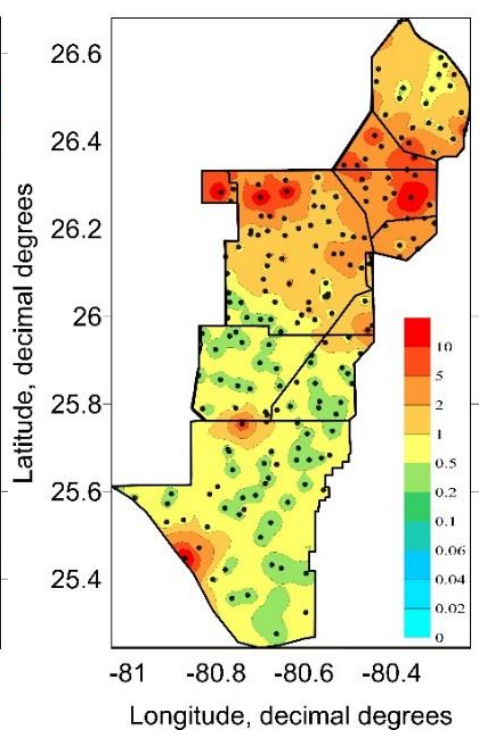

Figure 4.4 Sulfide concentrations $(\mathrm{mg} / \mathrm{L})$ in pore water and surface water from the Florida Everglades during both seasons (please note that the detection limit is $0.02 \mathrm{mg} / \mathrm{L}$ ).

Sulfur generally occurs in surface water in the oxidized state as sulfate. However, observations of sulfide in surface water at measurable levels has been reported in ocean (e.g., the Atlantic ocean) and fresh water (e.g., the Florida Everglades) systems (123, 127, 180, 208). Elevated concentrations of sulfide were found in WCA 2 and WCA 3 up to 0.1 mg/L by USGS from 22 sites of South Florida as early as 1995 (180). Sulfide concentrations from surface water were also analyzed during R-EMAP phase I and II by USEPA from 1995 to 1999 . The highest level of sulfide was from WCA 2 with median concentration of $0.21 \mathrm{mg} / \mathrm{L}$ in phase II (123). In this study, the concentrations of sulfide in Everglades surface water were below the detection limit $(0.02 \mathrm{mg} / \mathrm{L})$ in most sampling sites (Fig. 4.4). The measurable reduced sulfide was only found in 39 sampling stations in both 
seasons in 2005. Sulfide in surface water could result from several sources including the hydrolysis of carbonyl sulfide, the emissions from marine phytoplankton and the MSR from sulfate in soil pore water $(180,205-208)$. While, the first two sources were always related with ocean and the generally accepted way for sulfide to enter surface water in Everglades was from pore water by diffusion followed by the reduction of sulfate to sulfide in soil pore water as mentioned above (204). The process of MSR was considered to occur only under anoxic conditions, typically in soil/sediment. However, periphyton communities were found to be another types of site for MSR (116). The composition of periphyton communities range from filamentous green mats in eutrophic areas to calcareous mats in not heavily impacted areas (209). The occurrence of sulfide in the Everglades surface water could be associated with these pathways. These pathways may be used to explain the different trends of sulfide concentrations in pore water and surface water in this work. The main difference was the higher average concentrations of sulfide in ENP than those in southern WCA 2 in surface water. Since ENP were less impacted by contaminated runoff from canal than WCA 2 and other northern areas, both sulfide and sulfate from EAA should be shown in similar pattern which is decreasing from northern to southern areas. Obviously, they were, except the trend of sulfide concentration in surface water. This observation could be related to the MSR process happening in surface water in the sites with the presence of periphyton. As MeHg is produced during MSR as a byproduct and the concentrations of $\mathrm{MeHg}$ has been thought connected with sulfide and/or sulfate concentrations, it may also be related to the presence of periphyton in surface water. The coexistence of sulfide and dissolved oxygen in surface water has been reported because of the relatively slow oxidation of sulfide to sulfate in oxygen-containing waters through the 
activity of various sulfur oxidizing bacteria comparing with MSR in surface water and diffusion of sulfide from pore water $(180,207,210,211)$.
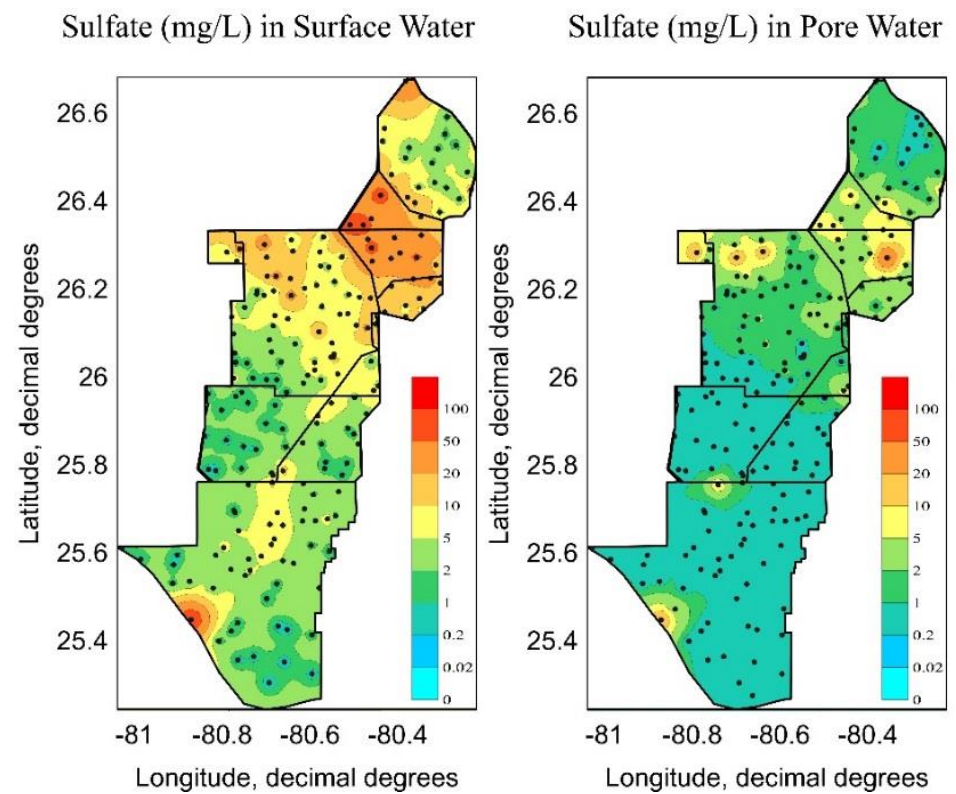

Figure 4.5 Sulfate concentrations $(\mathrm{mg} / \mathrm{L})$ in pore water and surface water from the Florida Everglades during both seasons.

The lack of sulfide data in most sampling areas of the Florida Everglades required the use of estimated sulfide levels for the sampling stations with sulfide concentrations less than detection limit to complete the modeling. The proper sulfide concentrations to be selected should be close to the actual concentrations and cover the distribution of $\mathrm{Hg}$ speciation as much as possible in the sampling stations. To reflect the sulfide concentrations in surface water in most areas of Everglades, the determinations of the data from previous work were collected. Since sulfide was usually considered not existing in surface water, not much work was found. As mentioned above, sulfide concentrations were determined by USGS and in phase I \& II by EPA. The detection limit of sulfide concentration in phase I \& II from EPA was same with this work, while that from USGS 
was $10^{-5} \mathrm{mg} / \mathrm{L}$ (180). However, dissolved sulfide level was reported even lower than 0.01 $10^{-5} \mathrm{mg} / \mathrm{L}$, even absent from surface water in most sampling stations of Everglades except in some heavily-enriched areas by USGS $(180,204)$. Therefore, the concentrations of sulfide in most areas were narrow down to $0-10^{-5} \mathrm{mg} / \mathrm{L}$. In Reddy's work, he suggested that $\mathrm{Hg}-\mathrm{DOM}$ and $\mathrm{Hg}-\mathrm{S}$ complex concentrations were equivalent under very low sulfide concentrations (about $10^{-11} \mathrm{M}$ or $3.2 \times 10^{-7} \mathrm{mg} / \mathrm{L}$ ) in surface water of Everglades by PHREEQC modeling. While about $10^{-12} \mathrm{M}\left(3.2 \times 10^{-8} \mathrm{mg} / \mathrm{L}\right)$ or less of sulfide was applied, Hg-DOM dominated $\mathrm{Hg}$ species; If $10^{-10} \mathrm{M}\left(3.2 \times 10^{-6} \mathrm{mg} / \mathrm{L}\right)$ or more of sulfide was used, Hg-S occurred primarily (127). Two concentrations of sulfide were finally selected, $3.2 \times 10^{-7} \mathrm{mg} / \mathrm{L}$ and $<<3.2 \times 10^{-7} \mathrm{mg} / \mathrm{L}$ representing the scenarios of virtual non-existence of sulfide and occurrence at a very low level, respectively, to cover situations that only $\mathrm{Hg}$ DOM or both Hg-DOM and Hg-S dominate.

\subsubsection{The complexes of DOM and inorganic mercury}

Using $3.2 \times 10^{-7} \mathrm{mg} / \mathrm{L}$ as the concentration of sulfide in the sampling stations with low levels of sulfide, the modeling results showed that Hg-DOM complexes represented 40.1 to $96.4 \%$ of surface water total inorganic mercury in the dry season and 8.67 to $97.2 \%$ in the wet season (Fig. 4.7). The Hg-DOM complexes were the dominant $\mathrm{Hg}$ species in some areas, while $\mathrm{HgS}_{2}{ }^{2-}$ preveailed in other sites. A samll fraction of $\mathrm{HgHS}_{2}{ }^{-}$was also shown in both season, ranging from 1.27 to $26.2 \%$ in dry season and 1.14 to $17.2 \%$ in wet season. From north to south, the percentages of Hg-DOM decreased which relates to the trend of reducing concentrations of dissolved organic carbon (DOC) in the wet season, while in the dry season the concentrations of Hg-DOM increased back to the similar level with the north 
area in south. DOC is largely distributed in the Everglades because of the extensively existing peat soils (174).
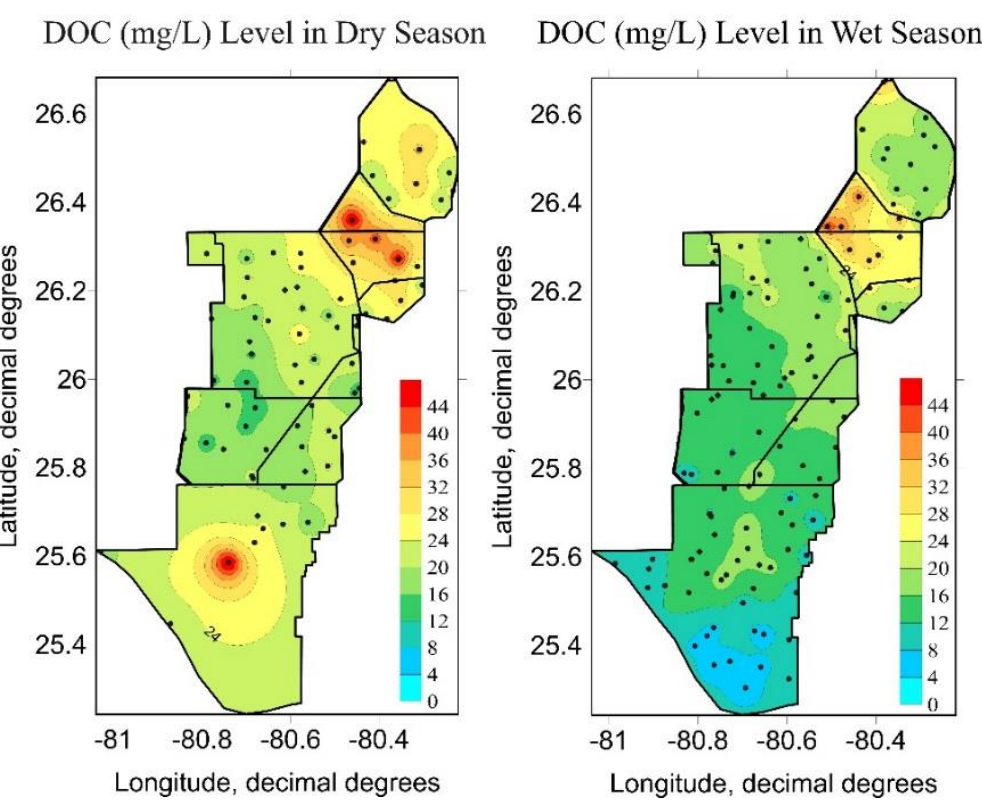

Figure 4.6 DOC concentrations $(\mathrm{mg} / \mathrm{L})$ in surface water from the Florida Everglades in dry season and wet season.

During 2005, the DOC distriobution pattern showed a high seasonality with higher values in the dry than those in the wet season (Fig. 4.6). The lowest concentrtions of DOC was found in the area of ENP with a lower organic carbon content of marl soils in the wet season. While the highest concentrations of DOC were found in the areas of WCA 2 in both seasons and central ENP in dry season near arid region. The peat soils from Everglades Agricultural Area (EAA) is the most likely source of DOC and the higher concentration of DOC in WCA 2 dues to the exportion of stormwater from EAA (174). The trend of $\mathrm{Hg}$ DOM concentrations in surface water in both seasons was also found same with that of $\mathrm{Hg}$ from north to south. The existing of $\mathrm{Hg}$ and $\mathrm{DOM}$ as $\mathrm{Hg}$-DOM complex could be the reason of the significant correlations observed in previous research between $\mathrm{Hg}$ and DOM (121). 

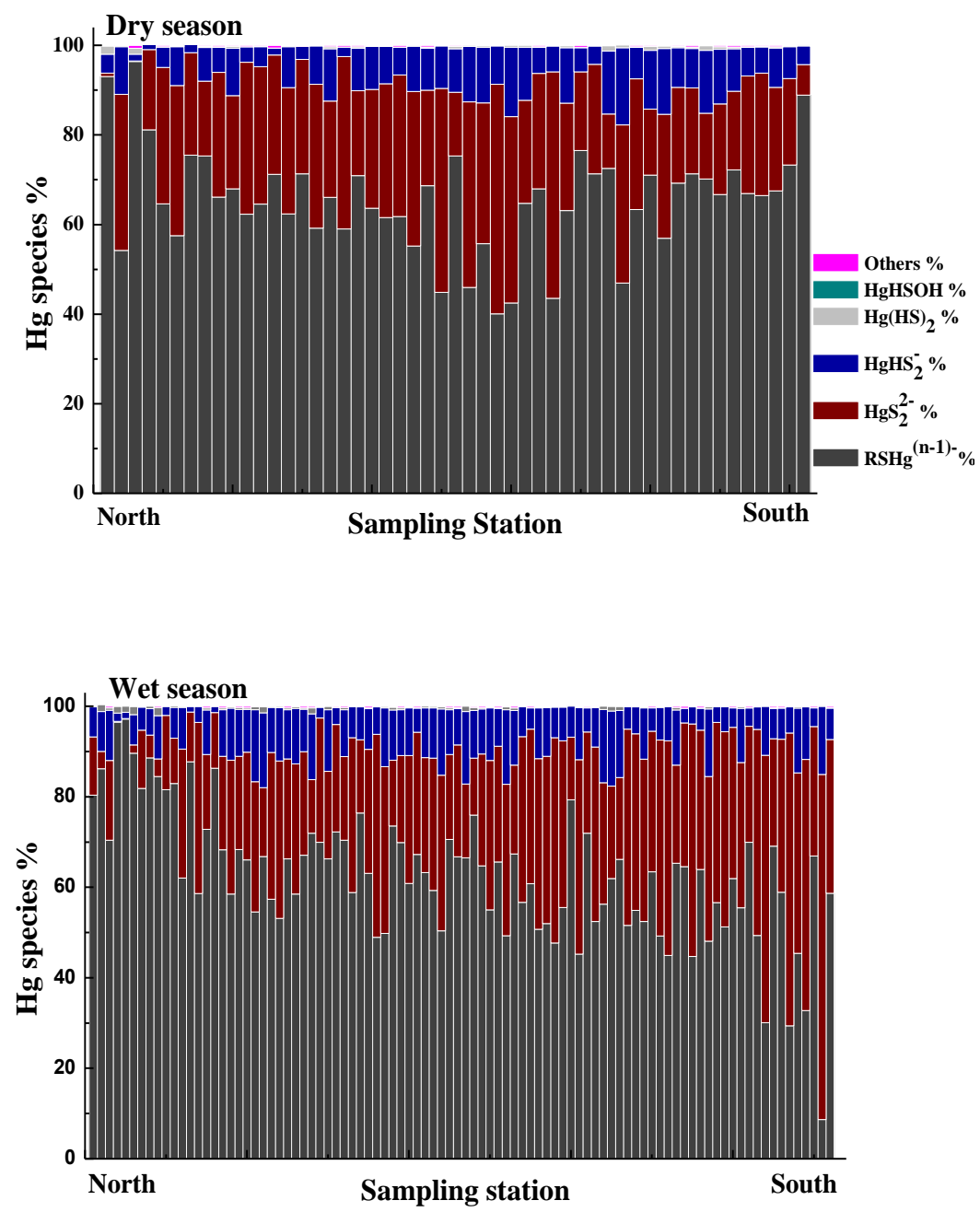

Figure 4.7 The percentages of $\mathrm{Hg}$ species in surface water of Florida Everglades in dry and wet seasons of 2005 at stations where sulfide concentrations were $<0.02 \mathrm{mg} / \mathrm{L}$ and assigned $3.2 \times 10^{-7}$ $\mathrm{mg} / \mathrm{L}$.

Another scenario modeled was that the sulfide concentration was set much lower than $3.2 \times 10^{-7} \mathrm{mg} / \mathrm{L}$. In this case, $\mathrm{Hg}$-DOM was the predominant $\mathrm{Hg}$ species in both seasons accounting for nearly $100 \%$ of total $\mathrm{Hg}$. Under this condition, concentrations of $\mathrm{Hg}$-DOM are almost same with those of total $\mathrm{Hg}$ in surface water. This result suggests that, in the Everglades which is an organic-rich wetland (with surface water DOC averaging around $\sim 20 \mathrm{mg} / \mathrm{L}$ and even higher than $50 \mathrm{mg} / \mathrm{L}$ in many areas), such inorganic ligands as chloride, 
hydroxyl group, and sulfate would play a minor rule in determining $\mathrm{Hg}$ species, in comparison to DOM. In the model, the speciation calculation of Hg-DOM was based on the binding constant between $\mathrm{Hg}$ and -HS group, rather than - $\mathrm{COOH}$, within DOM. This treatment was based on the following considerations: 1) it is unlikely that surface water DOM contains no -HS group, even under the oxidized condition, since natural water DOM is usually known for containing both oxidizing and reducing moieties due to structural complexity; and 2) $\mathrm{Hg}$ is present at extremely low concentrations in Everglades surface water (averaging $2 \mathrm{ng} / \mathrm{L}$ ) and the presence of even very low levels of -HS group within DOM should be sufficiently high for binding $\mathrm{Hg}$. In fact, the prevalence of $\mathrm{Hg}$-DOM in Everglades water and the ubiquitous presence of DOM-bound $\mathrm{Hg}$ in various natural waters in general suggest that this treatment is reasonable and the modeling results are valid.

Therefore, the concentrations of sulfide and DOM control the speciation distribution of mercury in the surface water of sampled sites in the Florida Everglades. The Hg-S complexes occur primarily in the areas with measurable sulfide, while the concentrations of $\mathrm{Hg}-\mathrm{DOM}$ and $\mathrm{Hg}-\mathrm{S}$ complexes are comparable under the condition of very low sulfide ions concentrations around $3.2 \times 10^{-7} \mathrm{mg} / \mathrm{L}$, then $\mathrm{Hg}-\mathrm{DOM}$ complexes are the major species in the absence of sulfide if considering - $\mathrm{HS}$ as the $\mathrm{Hg}$ binding site of DOM. The distribution of different $\mathrm{Hg}-\mathrm{S}$ specifically $\mathrm{HgS}_{2}{ }^{2-}, \mathrm{HgHS}_{2}{ }^{-}$, and $\mathrm{Hg}(\mathrm{HS})_{2}$ was affected by $\mathrm{pH}$ as fig. 4.3 shows. In the areas with $\mathrm{pH}$ elevated from 6.5 to 8, concentrations of $\mathrm{HgS}_{2}{ }^{2-}$ increase and the other two species decrease. The concentrations of $\mathrm{HgHSOH}$ were extremely low because of the lower binding constant than those for the other three Hg-S species. The distribution of $\mathrm{Hg}$-DOM is strongly associated with this trend of $\mathrm{Hg}$ and $\mathrm{DOC}$ in surface water with the presence of sulfide concentrations $3.2 \times 10^{-7} \mathrm{mg} / \mathrm{L}$ in both seasons $(\mathrm{r}=0.99$, 
$\mathrm{p}<0.001 ; 0.43, \mathrm{p}<0.001)$. Significant correlation was also found between $\mathrm{Hg}$ and DOC in all sampling stations $(r=0.45, \mathrm{p}<0.001)$. For the condition without the presence of sulfide and reduced -HS in DOM, $\mathrm{pH}$ and concentrations of halogen would become primary factors. Some of these results were verified by Reddy's work published in 2001 (127). They use PHREEQC to model the competition of $\mathrm{Hg}$ with negatively charged functional groups of fulvic acid and sulfide in Everglades. The fulvic acid and sulfide-bound inorganic mercury fractions were found as the function of sulfide concentration in WCA 3. Hg-FA dominates $\mathrm{Hg}$ species with the concentrations of sulfide from $10^{-13}-10^{-11} \mathrm{~mol} / \mathrm{L}$ and $\mathrm{Hg}-\mathrm{S}$ dominates when sulfide concentration was higher than $10^{-11} \mathrm{~mol} / \mathrm{L}$. Their modeling results match this work perfectly.

\subsubsection{Inorganic $\mathrm{Hg}$ species in surface water and $\mathrm{MeHg}$ in different media}

Dissolved inorganic $\mathrm{Hg}$ is the source of $\mathrm{MeHg}$ and the methylation of mercury is strongly determined by the mercury species existing in aquatic systems (90, 92, 93, 212). The widely accepted mediators of methylation are sulfate- and iron-reducing bacteria (SRB and IRB) $(52,213,214)$. The synthesis of MeHg is very complex and influenced by many environmental factors, one of which is the concentration of bioavailable $\mathrm{Hg}$ rather than total inorganic $\mathrm{Hg}$ in aquatic system $(84,92,215)$. The presence of sulfide and DOM was found to affect the formation of $\mathrm{MeHg}$ by controlling $\mathrm{Hg}$ speciation $(52,212,216,217)$. Therefore, $\mathrm{Hg}$ speciation could actually control the methylation, bioaccumulation, and consequently the cycling of $\mathrm{Hg}(52,218)$.

The correlation between $\mathrm{Hg}$ species and $\mathrm{MeHg}$ could indicate the uptake of inorganic species by $\mathrm{Hg}$ methylating bacteria. As the key Hg-methylating organisms in most aquatic systems, SRB present wildly in aquatic ecosystems $(35,213)$. As obligate anaerobes, SRB 
could obtain energy for growing through the oxidation of organic substrates. They use sulfate as the terminal electron acceptor to reduce sulfate to sulfide (219). Sulfate reduction process is linked to $\mathrm{Hg}$ methylation and the methylation can occur via the enzymatic transfer of methyl group from methylcobalamin (a vitamin $\mathrm{B}_{12}$ derivative, also called methylcorrinoid) to inorganic Hg ions inside SRB accidentally $(220,221)$. The uptake pathways of $\mathrm{Hg}$ by SRB have been proposed by many researchers, however, the mechanism is still not fully understood.

In this work, I focused on the correlation between inorganic $\mathrm{Hg}$ species in surface water and $\mathrm{MeHg}$ in different environmental media to evaluate the role of $\mathrm{Hg}$ speciation distribution on $\mathrm{Hg}$ methylation. Since not all geochemical parameters were obtained from pore water near sediments where the methylation happens, I explored the correlation between $\mathrm{Hg}$ species and $\mathrm{MeHg}$ in surface water instead of that in pore water with the assumption that the distribution patterns of $\mathrm{Hg}$ speciation in surface water, mainly as $\mathrm{Hg}$ DOM and $\mathrm{Hg}-\mathrm{S}$ complexes, were similar with those in pore water in most areas of Florida Everglades. This assumption should be valid, as the important ligands such as sulfide and DOM are mainly transferred from pore water to surface water by diffusion or advection(204). This statement could be confirmed by the significant correlation between DOM in surface water and pore water $\left(\mathrm{r}_{\mathrm{s}}=0.69, \mathrm{p}<0.001, \mathrm{~N}=189\right)$. Although for some sampling sites with higher concentrations of sulfide in surface water, they were not the "hot spot" areas for sulfide in pore water (Fig. 4.4). This observation could be because of another way that MSR occurred in ether floating mat or epiphytic periphyton to produced sulfide and then diffused to surface water(79). These sampling sites with unusual higher concentrations of sulfide in surface water than those in pore water were mostly located at 
ENP. Epiphytic periphyton could not be found in many sites, however, they were collected in these stations as predicted.

Spearman's rank correlation coefficient $\left(\mathrm{r}_{\mathrm{s}}\right)$ were obtained by evaluating the correlation between primary $\mathrm{Hg}$ species in surface water and $\mathrm{MeHg}$ present in different media, including in periphyton (floating mat and epiphytic), floc, soil, fish, and surface water of the Everglades in both seasons. In the areas with measurable sulfide (>0.02 mg/L), $\mathrm{HgS}_{2}{ }^{2-}$ and $\mathrm{HgHS}_{2}{ }^{-}$are dominant species in surface water. In wet season, significant correlation was observed between $\mathrm{HgS}_{2}{ }^{2-}$ and $\mathrm{MeHg}$ in surface water $\left(\mathrm{r}_{\mathrm{s}}=0.53, \mathrm{p}<0.001, \mathrm{~N}=21\right)$. While in dry season, significant correlations were found between $\mathrm{HgS}_{2}{ }^{2-}$ and $\mathrm{MeHg}$ in surface water $\left(\mathrm{r}_{\mathrm{s}}=0.88, \mathrm{p}<0.001, \mathrm{~N}=18\right) ; \mathrm{HgS}_{2}{ }^{2-}$ and $\mathrm{MeHg}$ in epiphytic periphyton $\left(\mathrm{r}_{\mathrm{s}}\right.$ $=0.9, \mathrm{p}<0.05, \mathrm{~N}=5) ; \mathrm{HgS}_{2}{ }^{2-}$ and $\mathrm{MeHg}$ in floc $\left(\mathrm{r}_{\mathrm{s}}=0.50, \mathrm{p}<0.05, \mathrm{~N}=16\right) ; \mathrm{HgHS}_{2}{ }^{-}$and $\mathrm{MeHg}$ in epiphytic periphyton $\left(\mathrm{r}_{\mathrm{s}}=0.9, \mathrm{p}<0.05, \mathrm{~N}=5\right) . \mathrm{Hg}$ species $\mathrm{HgHS}_{2}{ }^{-}$and $\mathrm{Hg}(\mathrm{HS})_{2}$ in surface water had significant correlation with $\mathrm{MeHg}$ in the soil $\left(\mathrm{r}_{\mathrm{s}}=0.67, \mathrm{p}<0.01, \mathrm{~N}=\right.$ $18, \mathrm{r}_{\mathrm{s}}=0.72, \mathrm{p}<0.001, \mathrm{~N}=18$, respectively). However, when we check the relationships between these each data pair, $\mathrm{Hg}(\mathrm{HS})_{2}$ concentrations of some samples located at LNWR were found extremely high which leads to the distorting of dataset. If they are removed, no more correlation would still exist. Therefore, there is actually no significant correlation between concentrations of $\mathrm{Hg}(\mathrm{HS})_{2}$ in surface water and $\mathrm{MeHg}$ in soil. Significant correlations are mostly between $\mathrm{Hg}-\mathrm{S}$ and $\mathrm{MeHg}$ in surface water, in epiphytic periphyton, and in floc. These media are all related to the activity of sulfate reduction bacteria in surface water where were proposed to happen (79). 
Table 4.3 Spearman's correlation matrix - coefficients between concentrations of $\mathrm{Hg}$ species and methylmercury in various ecosystem compartments in dry and wet seasons with measurable sulfide.

\begin{tabular}{|c|c|c|c|c|c|c|}
\hline \multirow[t]{3}{*}{ MeHg } & \multicolumn{6}{|c|}{ Surface water } \\
\hline & \multicolumn{2}{|c|}{$\mathbf{H g S}_{2}{ }^{2-}$} & \multicolumn{2}{|c|}{ HgHS $_{2}^{-}$} & \multicolumn{2}{|c|}{$\mathbf{H g}(\mathbf{H S})_{2}$} \\
\hline & Dry & Wet & Dry & Wet & Dry & Wet \\
\hline \multirow[t]{2}{*}{ Surface water } & $0.88 * *$ & 0.39 & 0.08 & $0.53 * *$ & -0.37 & 0.42 \\
\hline & $(18)$ & (21) & (18) & (21) & (18) & (21) \\
\hline Epiphytic & $0.9^{*}$ & 0.11 & $0.9^{*}$ & 0.32 & -0.3 & 0.28 \\
\hline periphyton & (5) & (11) & (5) & (11) & (5) & (11) \\
\hline \multirow[t]{2}{*}{ Floc } & $0.50 *$ & -0.10 & 0.18 & 0.42 & 0.01 & 0.45 \\
\hline & (16) & (17) & (16) & (17) & (16) & (17) \\
\hline \multirow[t]{2}{*}{ Soil } & -0.22 & 0.13 & $0.67 * *$ & 0.20 & $0.72 * *$ & 0.21 \\
\hline & $(18)$ & $(21)$ & (18) & $(21)$ & $(18)$ & (21) \\
\hline
\end{tabular}

** indicates significant correlations at $\mathrm{p}<0.001$ level; $*$ indicates significant correlations at $\mathrm{p}<0.05$ level

In the areas with sulfide concentrations lower than measurable sulfide, sulfide concentration was assigned as $3.2 \times 10^{-7} \mathrm{mg} / \mathrm{L}$. $\mathrm{Hg}$-DOM and $\mathrm{Hg}-\mathrm{S}$ complexes, including $\mathrm{RSHg}^{(\mathrm{n}-1)-}, \mathrm{HgS}_{2}{ }^{2-}, \mathrm{HgHS}_{2}{ }^{-}$, and $\mathrm{Hg}(\mathrm{HS})_{2}$ were major $\mathrm{Hg}$ species. In wet season, all $\mathrm{Hg}$ species including $\mathrm{RSHg}^{(\mathrm{n}-1)-}, \mathrm{HgS}_{2}{ }^{2-}, \mathrm{HgHS}_{2}{ }^{-}$and $\mathrm{Hg}(\mathrm{HS})_{2}$ have significant correlation with MeHg in soil $\left(r_{s}=0.30, p<0.001, N=91 ; r_{s}=0.36, p<0.001, N=91, r_{s}=0.24, p<0.05, N=91\right.$; $\left.\mathrm{r}_{\mathrm{s}}=0.30, \mathrm{p}<0.001, \mathrm{~N}=91\right)$. Significant correlations were also found between $\mathrm{HgHS}_{2}{ }^{-}$and $\mathrm{MeHg}$ in surface water $\left(\mathrm{r}_{\mathrm{s}}=0.21, \mathrm{p}<0.05, \mathrm{~N}=92\right) ; \mathrm{Hg}(\mathrm{HS})_{2}$ and $\mathrm{MeHg}$ in floc $\left(\mathrm{r}_{\mathrm{s}}=0.26\right.$, $\mathrm{p}<0.05, \mathrm{~N}=71) ; \mathrm{RSHg}^{(\mathrm{n}-1)-}$ and $\mathrm{MeHg}$ in surface water $\left(\mathrm{r}_{\mathrm{s}}=0.48, \mathrm{P}<0.001, \mathrm{~N}=92\right), \mathrm{MeHg}$ in soil $\left(\mathrm{r}_{\mathrm{s}}=0.30, \mathrm{p}<0.001, \mathrm{~N}=91\right)$, and $\mathrm{MeHg}$ in epiphytic periphyton $\left(\mathrm{r}_{\mathrm{s}}=0.40, \mathrm{p}<0.001\right.$, $\mathrm{N}=64)$. In dry season, $\mathrm{RSHg}^{(\mathrm{n}-1)-}$ has significant correlation with $\mathrm{MeHg}$ in surface water $\left(\mathrm{r}_{\mathrm{s}}=0.41, \mathrm{p}<0.001, \mathrm{~N}=51\right)$. Under this circumstance, all $\mathrm{Hg}$ species were found have significant correlation with $\mathrm{MeHg}$ in soil which reflect the methylation via sulfate reducing bacteria in soil pore water. The high percentages species $\operatorname{RSHg}^{(\mathrm{n}-1)-}$ has significant correlation with $\mathrm{MeHg}$ in periphyton, floc, and soil. 
Table 4.4 Spearman's correlation matrix - coefficients and sample numbers between concentrations of $\mathrm{Hg}$ species in surface water and $\mathrm{MeHg}$ in various ecosystem compartments in both seasons $\left(\left[\mathrm{S}^{2-}\right]=3.2 \times 10^{-7} \mathrm{mg} / \mathrm{L}\right)$.

\begin{tabular}{|c|c|c|c|c|c|c|c|c|}
\hline \multirow{3}{*}{ MeHg } & \multicolumn{8}{|c|}{ Surface water } \\
\hline & \multicolumn{2}{|c|}{$\mathrm{HgS}_{2}{ }^{2-}$} & \multicolumn{2}{|c|}{ HgHS $_{2}^{-}$} & \multicolumn{2}{|c|}{$\mathrm{Hg}(\mathrm{HS})_{2}$} & \multicolumn{2}{|c|}{ RSHg $^{(\mathrm{n}-1)-}$} \\
\hline & Dry & Wet & Dry & Wet & Dry & Wet & Dry & Wet \\
\hline Surface water & $\begin{array}{l}0.27 \\
(51)\end{array}$ & $\begin{array}{l}-0.12 \\
(92)\end{array}$ & $\begin{array}{l}-0.12 \\
(51)\end{array}$ & $\begin{array}{l}0.21 * \\
(92)\end{array}$ & $\begin{array}{l}-0.18 \\
(51)\end{array}$ & $\begin{array}{l}0.20 \\
(92)\end{array}$ & $\begin{array}{l}0.41 * * \\
(51)\end{array}$ & $\begin{array}{l}0.48^{* *} \\
(92)\end{array}$ \\
\hline Floating mat periphyton & $\begin{array}{l}0.09 \\
(6)\end{array}$ & $\begin{array}{l}-0.10 \\
(16)\end{array}$ & $\begin{array}{l}-0.26 \\
(6)\end{array}$ & $\begin{array}{l}0.21 \\
(16)\end{array}$ & $\begin{array}{l}-0.26 \\
(6)\end{array}$ & $\begin{array}{l}0.15 \\
(16)\end{array}$ & $\begin{array}{l}0.09 \\
(6)\end{array}$ & $\begin{array}{l}0.48 \\
(16)\end{array}$ \\
\hline Epiphytic periphyton & $\begin{array}{l}0.34 \\
(17)\end{array}$ & $\begin{array}{l}-0.12 \\
(64)\end{array}$ & $\begin{array}{l}-0.34 \\
(17)\end{array}$ & $\begin{array}{l}0.24 \\
(64)\end{array}$ & $\begin{array}{l}-0.35 \\
(17)\end{array}$ & $\begin{array}{l}0.22 \\
(64)\end{array}$ & $\begin{array}{l}0.34 \\
(17)\end{array}$ & $\begin{array}{l}0.40 \text { ** } \\
(64)\end{array}$ \\
\hline Floc & $\begin{array}{l}0.26 \\
(50)\end{array}$ & $\begin{array}{l}-0.25 \\
(71)\end{array}$ & $\begin{array}{l}-0.27 \\
(50)\end{array}$ & $\begin{array}{l}0.15 \\
(71)\end{array}$ & $\begin{array}{l}-0.23 \\
(50)\end{array}$ & $\begin{array}{l}0.27 * \\
(71)\end{array}$ & $\begin{array}{l}0.19 \\
(50)\end{array}$ & $\begin{array}{l}0.26^{*} \\
(71)\end{array}$ \\
\hline Soil & $\begin{array}{l}0.07 \\
(51)\end{array}$ & $\begin{array}{l}0.30^{* * *} \\
(91)\end{array}$ & $\begin{array}{l}-0.20 \\
(51)\end{array}$ & $\begin{array}{l}0.24 * \\
(91)\end{array}$ & $\begin{array}{l}-0.01 \\
(51)\end{array}$ & $\begin{array}{l}0.36 * * \\
(91)\end{array}$ & $\begin{array}{l}0.31 * \\
(51)\end{array}$ & $\begin{array}{l}0.30 \text { ** } \\
(91)\end{array}$ \\
\hline
\end{tabular}

** indicates significant correlations at $\mathrm{p}<0.001$ level; * indicates significant correlations at $\mathrm{p}<0.05$ level

In the scenario where sulfide concentration was assigned much lower than $3.2 \times 10^{-7}$ $\mathrm{mg} / \mathrm{L}$ to represent the situation with extremely low concentrations of sulfide in surface water, $\mathrm{Hg}$-DOM complexes, specifically $\mathrm{RSHg}^{(\mathrm{n}-1)-}$, dominated $\mathrm{Hg}$ speciation. In both season, significant correlations were observed between $\mathrm{RSHg}^{(\mathrm{n}-1)-}$ and $\mathrm{MeHg}$ in surface water (dry season: $\mathrm{r}_{\mathrm{s}}=0.45, \mathrm{P}<0.001, \mathrm{~N}=51$; wet season: $\mathrm{r}_{\mathrm{s}}=0.46, \mathrm{P}<0.001, \mathrm{~N}=92$ ) or $\mathrm{MeHg}$ in soil (dry season: $\mathrm{r}_{\mathrm{s}}=0.31, \mathrm{P}<0.05, \mathrm{~N}=51$; wet season: $\mathrm{r}_{\mathrm{s}}=0.26, \mathrm{P}<0.05, \mathrm{~N}=92$ ). In wet season, significant correlation was found between $\mathrm{RSHg}^{(\mathrm{n}-1)-}$ and $\mathrm{MeHg}$ in floating mat and epiphytic periphyton, suggesting that $\mathrm{RSHg}^{(\mathrm{n}-1)-}$ is an inorganic $\mathrm{Hg}$ species that could be related to $\mathrm{MeHg}$ production. It is worth noting that significant correlations were observed between total $\mathrm{Hg}$ and DOC and between total $\mathrm{Hg}$ and $\mathrm{MeHg}$ in surface water of the Everglades (121). As a consequence, the correlations between $\mathrm{RSHg}^{(\mathrm{n}-1)-}$ species and $\mathrm{MeHg}$ in water, soil, or periphyton might be unable to reflect the actual causal effect of $\mathrm{RSHg}^{(\mathrm{n}-}$ 1)- on $\mathrm{MeHg}$ production, since $\mathrm{RSHg}^{(\mathrm{n}-1)-}$ was the predominant species of inorganic $\mathrm{Hg}$ formed through complexation with DOM that could be used as a surrogate for $\mathrm{THg}$. 
Table 4.5 Spearman's correlation matrix - coefficients and sample numbers between concentrations of $\mathrm{Hg}$ species and $\mathrm{MeHg}$ in various ecosystem compartments in both seasons $\left(\left[\mathrm{S}^{2-}\right]\right.$ $\left.<3.2 \times 10^{-7} \mathrm{mg} / \mathrm{L}\right)$.

\begin{tabular}{lll}
\hline \multirow{2}{*}{ MeHg } & \multicolumn{2}{c}{ RSHg $^{(\mathbf{n}-\mathbf{1})}$ in surface water } \\
\cline { 2 - 3 } & Dry & Wet \\
\hline \multirow{2}{*}{ Surface water } & $0.45^{* *}$ & $0.46^{* *}$ \\
\multirow{2}{*}{ Floating mat periphyton } & $(51)$ & $(92)$ \\
& -0.14 & $0.51^{*}$ \\
Epiphytic periphyton & $(6)$ & $(16)$ \\
& 0.34 & $0.37^{* *}$ \\
Floc & $(17)$ & $(64)$ \\
& 0.23 & 0.23 \\
Soil & $(50)$ & $(71)$ \\
\end{tabular}

** indicates significant correlations at $\mathrm{p}<0.001$ level; $*$ indicates significant correlations at $\mathrm{p}<0.05$ level

To summarize the relationship between $\mathrm{Hg}$ speciation and $\mathrm{MeHg}$ in environmental matrices, the results here suggest that in the sites with measurable sulfide where $\mathrm{Hg}-\mathrm{S}$ complexes, mostly $\mathrm{HgS}_{2}{ }^{2-}, \mathrm{HgHS}_{2}{ }^{-}, \mathrm{Hg}(\mathrm{HS})_{2}$, are major $\mathrm{Hg}$ species, negatively charged $\mathrm{Hg}-\mathrm{S}$ species show significant correlation with $\mathrm{MeHg}$ in periphyton, floc and surface water. In the sampling stations with an assigned sulfide level of $3.2 \times 10^{-7} \mathrm{mg} / \mathrm{L}$ (where lower than $0.02 \mathrm{mg} / \mathrm{L}$ detection limit was reported), all major $\mathrm{Hg}-\mathrm{S}$ species have significant correlations with methylmercury in soil and Hg-DOM shows significant correlation with MeHg in surface water, periphyton, floc, and soil. In the sampling stations with sulfide concentrations much lower than $3.2 \times 10^{-7} \mathrm{mg} / \mathrm{L}$, significant correlations were found between $\mathrm{Hg}-\mathrm{DOM}$ and $\mathrm{MeHg}$ in surface water, periphyton, and soil. This may indicate that both major $\mathrm{Hg}-\mathrm{S}$ and $\mathrm{Hg}-\mathrm{DOM}$ complexes can be taken up by $\mathrm{Hg}$ methylators such as SRB and IRB in periphyton, floc, and soil. For different species of $\mathrm{Hg}-\mathrm{S}$, no preference was observed for being taken up, probably because of the existence of multiple uptake pathways of $\mathrm{Hg}$ species by microbes (see discussion below). 
Some researchers consider passive diffusion of neutral $\mathrm{Hg}(\mathrm{II})$ species as the uptake pathway of Hg by SRB cells through external membranes (92). Diffusion rather than active transport tends to occur because methylation process is an accidental side reaction. This speculation was also supported by the studies of the diffusion of neutral $\mathrm{Hg}$ species $\left(\mathrm{HgCl}_{2}{ }^{0}\right)$ across artificial membranes and diatoms by Mason's group $(222,223)$. During these experiments, Hg species calculated by MINEQL were controlled by adjusting the chloride concentration and $\mathrm{pH}$. The uptake rate of $\mathrm{Hg}(\mathrm{II})$ appeared to decrease with the lower concentration of $\mathrm{HgCl}_{2}$ in their experimental media. The octanol-water partitioning coefficient of neutral $\mathrm{Hg}$ species was also shown in proportion to the permeability of $\mathrm{Hg}$ to cell membranes (223). Barkay observed that negatively charged $\mathrm{Hg}$ species $\mathrm{HgCl}_{3}{ }^{-}$and $\mathrm{HgCl}_{4}{ }^{2-}$ induced less light production than neutral form $\mathrm{HgCl}_{2}$ by using Escherichia coli HMS174(pRB28) as an indicator. This observation indicated that negatively charged species reduced their bioavailability to bacteria by reaching the bacteria cytoplasm (91). Another evidence is that under sulfidic conditions, correlation was found between $\mathrm{HgS}^{0}$ species in pore water and MeHg in sediment in Florida Everglades and Patuxent River by Benoit by using a model constructed (52). Their group suggested that the $\mathrm{HgS}^{0}$ is the dominant neutral dissolved complex in sulfidic sediments which was also confirmed by the model. Speciation were calculated by the MINEQL ${ }^{+}$program (52).

Other researchers suggested that $\mathrm{Hg}$ species could be taken up by bacteria via facilitated transport. Schaefer suggested that $\delta$-proteobacterium Geobacter sulfurreducens may take up $\mathrm{Hg}$ by transport of $\mathrm{Hg}$ and specific thiols and/or sulfide complexes to cells, rather than diffusion of neutral species by cell membranes (224). The formation of Hg-cysteine complex promotes the uptake of $\mathrm{Hg}$ by SRB and this process occurs via a cysteine 
transporter (224). Several experiments were conducted by Golding to evaluate how the $\mathrm{Hg}$ species affect the uptake of them by bacteria Vibrio anguillarum and Escherichia coli (93). $\mathrm{Hg}$ species $\mathrm{Hg}(\mathrm{OH})_{2}, \mathrm{Hg}\left(\mathrm{NH}_{3}\right)_{2}{ }^{2+}, \mathrm{HgCl}_{2}, \mathrm{HgOHCl}$ were all observed occupying high percentages of $\mathrm{Hg}$ species taken up and methylated by bacteria without discrimination which coincide with the proposed uptake way that it was kinetically controlled facilitated uptake by Hudson (93). $\mathrm{Hg}(\mathrm{II})$ has stronger affinity with transport ligand and faster rate to entry the cell than that with extracellular complex. Hence, the uptake of $\mathrm{Hg}$ (II) under anaerobic conditions were proportional to the abundance of total concentration of $\mathrm{Hg}$. This observation was also observed between the concentration of $\mathrm{Hg}$ and $\mathrm{MeHg}$ in surface water in the Florida Everglades in my work ( $\mathrm{r}_{\mathrm{s}}=0.50, \mathrm{P}<0.001, \mathrm{~N}=182$ ). In Golding's work, low molecule organic acid was also found enhance the uptake of $\mathrm{Hg}(\mathrm{II})$ by bacteria. Facilitated transport requires transport agent, no energy is needed. However, Schaefer demonstrated that $\mathrm{Hg}(\mathrm{II})$ uptake occurs by active transport which is energy dependent, through an electrogenic or ATP-driven mechanism to the cells of G. sulfurreducens (90). His results doubt the point of view that $\mathrm{Hg}$ (II) uptake by bacteria is an accident and bring up that the process may be specific for $\mathrm{Hg}$ (II) via some essential metal importer (90).

According to the Spearman correlation analysis results in this work, major $\mathrm{Hg}-\mathrm{S}$ species and Hg-DOM may be taken up by bacteria. The uptake pathways could be related to active transport, passive transport, and facilitated transport. Many factors can affect the uptake process including the type of bacteria and the methylation location. In addition to SRB, IRB was also confirmed as an important type of bacteria to methylate Hg. Even for the same type of bacteria, various specific bacteria strains could take up $\mathrm{Hg}$ for methylation in different media and locations. Therefore, it is possible that a variety of $\mathrm{Hg}$ species could 
be taken up by bacteria in Everglades, since multiple inorganic $\mathrm{Hg}$ species were related to $\mathrm{MeHg}$ in the environmental matrices.

\subsubsection{The influences of distribution of $\mathrm{Hg}$ species on bioavailability and}

\section{bioaccumulation}

Spearman correlation analysis was also applied between $\mathrm{Hg}$ species in surface water and $\mathrm{MeHg}$ in fish to estimate the role of $\mathrm{Hg}$ speciation distribution in $\mathrm{MeHg}$ bioaccumulation. The results were shown in Table 4.6. No significant correlation was found between $\mathrm{Hg}$ species and $\mathrm{MeHg}$ in fish. Therefore, the distribution of inorganic $\mathrm{Hg}$ species in surface water alone could not be used to estimate the bioaccumulation of $\mathrm{MeHg}$. The result is not unexpected, as $\mathrm{MeHg}$ bioaccumulation is an extremely complicated process involving not only $\mathrm{Hg}$ methylation processes, but also $\mathrm{MeHg}$ bioaccumulation through the food web. The methylation of $\mathrm{Hg}(\mathrm{II})$ could happen in sediment, soil, water body including fresh water and marine, and periphyton (10). In the Everglades, the relative $\mathrm{MeHg}$ ( $\mathrm{MeHg}$ to $\mathrm{THg}$ ratios) concentrations were found highest in water, then periphyton, followed by floc and soil in Everglades by Liu et al.(121). After methylation, MeHg could be released from these environmental matrices to water column and re-distributed among these compartments (121). MeHg in these ecosystem compartments could enter the food web and then be transferred to mosquitofish or taken up directly by mosquitofish. $\mathrm{MeHg}$ in periphyton and floc may be particularly important with respect of $\mathrm{Hg}$ bioaccumulation, since periphyton could serve as a primary food source for small fishes, while floc acts as an active medium on the top layer of soil preventing $\mathrm{MeHg}$ deposition into soil to make $\mathrm{MeHg}$ more mobile and bioavailable (121). All these processes affect $\mathrm{MeHg}$ bioaccumulation, and thus the distribution of inorganic $\mathrm{Hg}$ species in surface water, albeit 
possibly correlated to $\mathrm{MeHg}$ production in periphyton, floc, and soil, could probably not a good indicator for estimating the bioaccumulation of $\mathrm{MeHg}$.

Table 4.6 Spearman's correlation matrix - coefficients and sample numbers between concentrations of $\mathrm{Hg}$ species in surface water and $\mathrm{MeHg}$ in fish in both seasons.

\begin{tabular}{llll}
\hline \multirow{2}{*}{ Sulfide concentrations } & Hg species in surface & \multicolumn{2}{c}{ MeHg in fish } \\
\cline { 3 - 4 } water & $\mathrm{HgS}_{2}{ }^{2-}$ & 0.47 & Wet season \\
\hline$[\mathrm{S}]>0.02 \mathrm{mg} / \mathrm{L}$ & & $(16)$ & 0.11 \\
& $\mathrm{HgHS}_{2}{ }^{-}$ & -0.16 & $(20)$ \\
& & $(16)$ & -0.14 \\
& $\mathrm{Hg}(\mathrm{HS})_{2}$ & -0.29 & $(20)$ \\
& & $(16)$ & -0.21 \\
& & 0.06 & $(20)$ \\
{$[\mathrm{S}]=3.2 \times 10^{-7} \mathrm{mg} / \mathrm{L}$} & $\mathrm{RSH}^{(\mathrm{n}-1)-}$ & $(39)$ & 0.15 \\
& & 0.02 & $(85)$ \\
& $\mathrm{HgS}_{2}{ }^{2-}$ & $(39)$ & -0.02 \\
& & 0.18 & $(85)$ \\
& $\mathrm{HgHS}_{2}{ }^{-}$ & $(39)$ & 0.14 \\
& & 0.06 & $(85)$ \\
& $\mathrm{Hg}_{(\mathrm{HS})_{2}}$ & $(39)$ & 0.06 \\
& & 0.08 & $(85)$ \\
& $\mathrm{RSHg}^{(\mathrm{n}-1)-}$ & $(39)$ & 0.17 \\
& & & $(85)$ \\
\hline
\end{tabular}

\subsection{Conclusions}

Geochemical modeling results of $\mathrm{Hg}$ speciation in surface water suggest that sulfide and DOM are important factors that regulate inorganic $\mathrm{Hg}$ speciation, the bioavailability of inorganic $\mathrm{Hg}$ species for $\mathrm{Hg}$ methylation, and the bioaccumulation of $\mathrm{MeHg}$ in the Florida Everglades. In the sampling stations with measurable concentrations of sulfide (> $0.02 \mathrm{mg} / \mathrm{L}$ ), Hg-S species dominate $\mathrm{Hg}$ species, occurring with the highest concentration of $\mathrm{HgS}_{2}{ }^{2-}$ followed by $\mathrm{HgHS}_{2}{ }^{-}$and $\mathrm{Hg}(\mathrm{HS})_{2}$ in most areas, except for some sites in LNWR where the percentages of $\mathrm{HgHS}_{2}{ }^{-}$and $\mathrm{Hg}(\mathrm{HS})_{2}$ are higher than those of $\mathrm{HgS}_{2}{ }^{2-}$. The distribution of these $\mathrm{Hg}-\mathrm{S}$ species is affected by $\mathrm{pH}$, among other factors. In the sampling stations with low concentrations of sulfide $(<0.02 \mathrm{mg} / \mathrm{L})$, when a sulfide concentration of $3.2 \times 10^{-7} \mathrm{mg} / \mathrm{L}$ was assigned to represent the scenario of the presence of very low sulfide in natural waters, both $\mathrm{Hg}-\mathrm{DOM}$ and $\mathrm{Hg}-\mathrm{S}$ exist, and both of them are major $\mathrm{Hg}$ species. 
In some stations, percentages of $\mathrm{Hg}-\mathrm{DOM}$ were higher than 50\%, while the percentages were not completely dependent on the concentrations of DOC, with other environmental factors playing a role as well. In the areas where concentrations of sulfide were reported below $0.02 \mathrm{mg} / \mathrm{L}$ and assigned much lower than $3.2 \times 10^{-7} \mathrm{mg} / \mathrm{L}, \mathrm{Hg}-\mathrm{DOM}$ occurs as the predominant $\mathrm{Hg}$ species, accounting for almost $100 \%$ of all $\mathrm{Hg}$ species. Under different circumstances of these three scenarios, the major significant correlations could be observed between $\mathrm{Hg}-\mathrm{S} \mathrm{Hg}$ species or $\mathrm{Hg}-\mathrm{DOM}$ complex and $\mathrm{MeHg}$ in environmental media, although with a few exceptions. These results suggest that these $\mathrm{Hg}$ species could be taken up by bacteria via passive, active, and facilitated transport for $\mathrm{Hg}$ methylatoin, and that multiple $\mathrm{Hg}$ species being bioavailable, depending on specific environmental and ecological conditions, could be related to the existence of multiple pathways for $\mathrm{Hg}$ uptake. No significant correlation was found between $\mathrm{Hg}$ species in surface water and $\mathrm{MeHg}$ in fish, which suggests that inorganic $\mathrm{Hg}$ species distribution in surface water alone is not an accurate way to assess $\mathrm{Hg}$ bioaccumulation in fish because of the complexity of $\mathrm{Hg}$ methylation, distribution of $\mathrm{MeHg}$, and sources and pathways of $\mathrm{MeHg}$ during $\mathrm{Hg}$ bioaccumulation. 


\section{Chapter 5. Summary and Future work}

\subsection{Summary}

An isotope tracer based method was developed to investigate both dissolution and readsorption of $\mathrm{Hg}$ during the course of cinnabar dissolution in Chapter 2 of this dissertation. It was found that the released $\mathrm{Hg}$ for trials purged with oxygen could reach several hundred $\mu \mathrm{g} \mathrm{L} \mathrm{L}^{-1}$, while no significant cinnabar dissolution was detected under anaerobic conditions. The cinnabar dissolution rate when considering $\mathrm{Hg}$ re-adsorption was approximately two times the value calculated solely with the $\mathrm{Hg}$ detected in the aqueous phase. These results suggest that ignoring the $\mathrm{Hg}$ re-adsorption process can significantly underestimate the importance of cinnabar dissolution, highlighting the necessity of applying the developed method in future cinnabar dissolution studies.

Various organic ligands exist extensively in natural aquatic systems, and mercury could bind with these ligands, particularly thiol-containing moieties in dissolved organic matter (DOM). Several processes have been proposed with respect to the interaction of DOM with cinnabar which could inhibit or enhance cinnabar dissolution. During these processes, the roles played by these thiol-containing organic ligands and re-adsorption of released $\mathrm{Hg}$, particularly through complexation with $\mathrm{Hg}$, are still not clear. Using L-cysteine (Cys) as a model compound for low molecular weight (LMW) thiol-containing ligands and Waskish fulvic acid (FA) for natural DOM, the complexation of $\mathrm{Hg}$ with these ligands and the role of $\mathrm{Hg}$-ligand complexation in cinnabar dissolution and $\mathrm{Hg}(\mathrm{II})$ re-adsorption were investigated. $\mathrm{Hg}$-Cys shows lower adsorption capacity than that of unbound dissolved $\mathrm{Hg}$ on cinnabar surface. Therefore, the presence of L-cysteine during cinnabar dissolution would form complex with the released $\mathrm{Hg}$, thus enhancing cinnabar dissolution through 
the decreased re-adsorption of Hg-Cys complex. The Waskish FA used in this work did not enhance but instead showed inhibiting effect on cinnabar dissolution, possibly because of the adsorption of FA on cinnabar surface that might be able to cover dissolution sites on the cinnabar surface.

In chapter 4, the distribution of inorganic $\mathrm{Hg}$ species in surface water throughout the entire Everglades was determined by applying geochemical model PHREEQC to different R-EMAP sampling sites. The patterns of inorganic $\mathrm{Hg}$ species distribution were related to $\mathrm{MeHg}$ levels in environmental matrices to examine how inorganic $\mathrm{Hg}$ species potentially affect the production and fate of $\mathrm{MeHg}$, and then further related to fish $\mathrm{Hg}$ levels to explore the relationship between inorganic $\mathrm{Hg}$ speciation, $\mathrm{MeHg}$ production, and $\mathrm{Hg}$ bioaccumulation. It was found that Sulfur and DOM are important factors to regulate $\mathrm{Hg}$ speciation in the surface water of Florida Everglades. The distribution of $\mathrm{Hg}-\mathrm{S}$ was controlled by $\mathrm{pH}$. Through statistical analysis, the major significant correlations were observed between all $\mathrm{Hg}$ species and $\mathrm{MeHg}$ in all media which reflect that these $\mathrm{Hg}$ species could be uptaken by bacteria via passive, active, and facilitated transport. No significant correlation was found between $\mathrm{Hg}$ species and $\mathrm{MeHg}$ in fish which suggests that $\mathrm{Hg}$ species distribution is not a way to assess bioaccumulation in fish or other organism because of the multi sources of $\mathrm{MeHg}$ and pathways for organism to take up.

\subsection{Future work}

This dissertation investigated the role of Waskish FA in cinnabar dissolution in chapter 3. Contrary results comparing with other studies suggest that the role of DOM during cinnabar dissolution is rather complicated and could be determined by the structure and properties of DOM and specific environmental conditions. Although it is known through 
this work that Waskish FA affects cinnabar dissolution by covering dissolution sites on cinnabar surface to inhibit cinnabar dissolution. But large remains unclear about under what conditions what types (or fractions) of DOM could be adsorbed onto cinnabar surface and how they are adsorbed. In future work, more work will be focused on the characterization of properties of Waskish FA and other DOM fractions which enhance cinnabar dissolution. The properties and roles in cinnabar dissolution of DOM fractions will then be compared to investigate the connection between them.

In Everglades, no directly connection was found between inorganic Hg species and $\mathrm{MeHg}$ in fish. As bioaccumulation of MeHg in fish involves several food sources including water, soil, floc, and periohyton and complicated food chains. In future work, a model is expected to be built to evaluate the contribution of each factor on bioaccumulation of $\mathrm{MeHg}$ in fish by combining the preference uptake of MeHg species by organisms, the contribute of each food source for organisms, and the transfer of food through food chain. 


\section{References}

1. Selin, N. E. (2005) Mercury Rising: Is Global Action Needed to Protect Human Health and the Environment?, Environment: Science and Policy for Sustainable Development 47, 22-35.

2. Nriagu, J. O. (1989) A global assessment of natural sources of atmospheric trace metals, Nature $338,47-49$.

3. Schroeder, W. H., and Munthe, J. (1998) Atmospheric mercury - An overview, Atmospheric Environment 32, 809-822.

4. Camargo, J. A. (1993) Which source of mercury pollution?, Nature 365, 302-302.

5. Jiang, G.-B., Shi, J.-B., and Feng, X.-B. (2006) Mercury Pollution in China, Environmental science \& technology 40, 3672-3678.

6. Jackson, T. A. (1997) Long-range atmospheric transport of mercury to ecosystems, and the importance of anthropogenic emissions - a critical review and evaluation of the published evidence, Environmental Reviews 5, 99-120.

7. Ullrich, S. M., Tanton, T. W., and Abdrashitova, S. A. (2001) Mercury in the aquatic environment: A review of factors affecting methylation, Critical Reviews in Environmental Science and Technology 31, 241-293.

8. Morel, F. M. M., Kraepiel, A. M. L., and Amyot, M. (1998) The Chemical Cycle and Bioaccumulation of Mercury Annual Review of Ecology and Systematics 29, 543-566.

9. Fitzgerald, W. F., and Clarkson, T. W. (1991) Mercury and monomethylmercury: present and future concerns, Environmental Health Perspectives 96, 159-166.

10. Li, Y., and Cai, Y. (2013) Progress in the study of mercury methylation and demethylation in aquatic environments, Chinese Science Bulletin 58, 177-185.

11. UNEP. (2002) Global Mercury Assessment, United Nations Environment Programme Chemicals Branch, Geneva.

12. Clarkson, T. W., and Magos, L. (2006) The toxicology of mercury and its chemical compounds, Critical Reviews in Toxicology 36, 609-662.

13. Clarkson, T. W. (1993) Mercury: major issues in environmental health, Environmental Health Perspectives 100, 31-38.

14. Grandjean, P., Weihe, P., Jorgensen, P. J., Clarkson, T., Cernichiari, E., and Videro, T. (1992) Impact of Maternal Seafood Diet on Fetal Exposure to Mercury, Selenium, and Lead, Archives of Environmental Health 47.

15. Feng, X., Li, P., Qiu, G., Wang, S., Li, G., Shang, L., Meng, B., Jiang, H., Bai, W., Li, Z., and Fu, X. (2008) Human Exposure To Methylmercury through Rice Intake in Mercury Mining Areas, Guizhou Province, China, Environmental science \& technology 42, 326-332.

16. Barrett, J. R. (2010) Rice Is a Significant Source of Methylmercury: Research in China Assesses Exposures, Environmental Health Perspectives 118, A398-A398.

17. Li, P., Feng, X., and Qiu, G. (2010) Methylmercury Exposure and Health Effects from Rice and 
Fish Consumption: A Review, International Journal of Environmental Research and Public Health 7, 2666-2691.

18. USEPA. (1997) Mercury Study Report to Congress, In Volume V: Health Effects of Mercury and Mercury Compounds, Office of Air Quality Planning and Standards and Office of Research and Development, U.S. Environmental Protection Agency.

19. Jo, S., Woo, H., Kwon, H.-J., Oh, S.-Y., Park, J.-D., Hong, Y.-S., Pyo, H., Park, K., Ha, M., Kim, H., Sohn, S.-J., Kim, Y.-M., Lim, J.-A., Lee, S.-A., Eom, S.-Y., Kim, B.-G., Lee, K.-M., Lee, J.H., Hwang, M., and Kim, J. (2015) Estimation of the Biological Half-Life of Methylmercury Using a Population Toxicokinetic Model, International Journal of Environmental Research and Public Health 12, 9054.

20. Nuttall, K. L. (2004) Interpreting mercury in blood and urine of individual patients, Annals of Clinical and Laboratory Science 34, 235-250.

21. Koos, B. J., and Longo, L. D. (1976) Mercury toxicity in the pregnant woman, fetus, and newborn infant. A review, American Journal of Obstetrics and Gynecology 126, 390-409.

22. UNEP. (2013) Minamata Convention on Mercury, UNEP Geneva.

23. USEPA. (1997) Mercury Study Report to Congress, In Volume III. Fate and transport of mercury in the environment, Office of Air Quality Planning and Standards and Office of Research and Development, U.S. Environmental Protection Agency.

24. Mason, R. P. (2005) Air-sea Exchange and Marine Boundary Layer Atmospheric Transformation of $\mathrm{Hg}$ and their Importance in the Global Mercury Cycle, In Dynamics of Mercury Pollution on Regional and Global Scales:: Atmospheric Processes and Human Exposures Around the World (Pirrone, N., and Mahaffey, K. R., Eds.), pp 213-239, Springer US, Boston, MA.

25. Cai, Y., Liu, G., and O'Driscoll, N. J. (2012) Environmental chemistry and toxicology of mercury, Wiley, Hoboken, N.J.

26. Lindberg, S. E., and Stratton, W. J. (1998) Atmospheric Mercury Speciation: Concentrations and Behavior of Reactive Gaseous Mercury in Ambient Air, Environmental science \& technology 32, 49-57.

27. UNEP. (2008) Global Atmospheric Mercury Assessment. Sources, Emissions and Transport., United Nations Environment Programme Chemicals Branch, Geneva.

28. USEPA. (1997) Mercury Study Report to Congress, In Volume 3. Fate and transport of mercury in the environment, Office of Air Quality Planning and Standards and Office of Research and Development, U.S. Environmental Protection Agency.

29. Selin, N. E. (2009) Global Biogeochemical Cycling of Mercury: A Review, Annual Review of Environment and Resources 34, 43-63.

30. Skyllberg, U. (2003) Distribution of mercury, methyl mercury and organic sulphur species in soil, soil solution and stream of a boreal forest catchment, Biogeochemistry 64, 53-76.

31. Pirrone, N., and Mahaffey, K. R. (2005) Where We Stand on Mercury Pollution and its Health Effects on Regional and Global Scales, In Dynamics of Mercury Pollution on Regional and Global Scales:: Atmospheric Processes and Human Exposures Around the World (Pirrone, N., and Mahaffey, K. R., Eds.), pp 1-21, Springer US, Boston, MA. 
32. Mason, R. P., Morel, F. M. M., and Hemond, H. F. (1995) The role of microorganisms in elemental mercury formation in natural waters, Water, Air, and Soil Pollution 80, 775-787.

33. Alberts, J. J., Schindler, J. E., Miller, R. W., and Nutter, D. E. (1974) Elemental Mercury Evolution Mediated by Humic Acid, Science 184, 895-897.

34. King, J. K., Kostka, J. E., Frischer, M. E., Saunders, F. M., and Jahnke, R. A. (2001) A Quantitative Relationship that Demonstrates Mercury Methylation Rates in Marine Sediments Are Based on the Community Composition and Activity of Sulfate-Reducing Bacteria, Environmental science \& technology 35, 2491-2496.

35. Compeau, G. C., and Bartha, R. (1985) Sulfate-Reducing Bacteria: Principal Methylators of Mercury in Anoxic Estuarine Sediment, Applied and Environmental Microbiology 50, 498-502.

36. Fitzgerald, W. F., Lamborg, C. H., and Hammerschmidt, C. R. (2007) Marine Biogeochemical Cycling of Mercury, Chemical Reviews 107, 641-662.

37. Yin, Y., Chen, B., Mao, Y., Wang, T., Liu, J., Cai, Y., and Jiang, G. (2012) Possible alkylation of inorganic $\mathrm{Hg}$ (II) by photochemical processes in the environment, Chemosphere 88, 8-16.

38. Yin, Y. (2014) Fumigant methyl iodide can methylate inorganic mercury species in natural waters, Nature communications 5, 4633.

39. Gårdfeldt, K., Munthe, J., Strömberg, D., and Lindqvist, O. (2003) A kinetic study on the abiotic methylation of divalent mercury in the aqueous phase, Science of the Total Environment 304, 127136.

40. Oremland, R. S., Miller, L. G., Dowdle, P., Connell, T., and Barkay, T. (1995) Methylmercury Oxidative Degradation Potentials in Contaminated and Pristine Sediments of the Carson River, Nevada, Applied and Environmental Microbiology 61, 2745-2753.

41. Baldi, F., Pepi, M., and Filippelli, M. (1993) Methylmercury Resistance in Desulfovibrio desulfuricans Strains in Relation to Methylmercury Degradation, Applied and Environmental Microbiology 59, 2479-2485.

42. Hammerschmidt, C. R., and Fitzgerald, W. F. (2010) Iron-Mediated Photochemical Decomposition of Methylmercury in an Arctic Alaskan Lake, Environmental science \& technology 44, 6138-6143.

43. Lehnherr, I., and St. Louis, V. L. (2009) Importance of Ultraviolet Radiation in the Photodemethylation of Methylmercury in Freshwater Ecosystems, Environmental science \& technology 43, 5692-5698.

44. Khan, M. A. K., and Wang, F. (2010) Chemical Demethylation of Methylmercury by Selenoamino Acids, Chemical Research in Toxicology 23, 1202-1206.

45. Marvin-DiPasquale, M. C., and Oremland, R. S. (1998) Bacterial Methylmercury Degradation in Florida Everglades Peat Sediment, Environmental science \& technology 32, 2556-2563.

46. Oremland, R. S., Culbertson, C. W., and Winfrey, M. R. (1991) Methylmercury Decomposition in Sediments and Bacterial Cultures: Involvement of Methanogens and Sulfate Reducers in Oxidative Demethylation, Applied and Environmental Microbiology 57, 130-137.

47. Barnett, M. O., Harris, L. A., Turner, R. R., Stevenson, R. J., Henson, T. J., Melton, R. C., and 
Hoffman, D. P. (1997) Formation of mercuric sulfide in soil, Environmental Science \& Technology 31, 3037-3043.

48. Rytuba, J. J. (2003) Mercury from mineral deposits and potential environmental impact, Environmental Geology 43, 326-338.

49. Kim, C. S., Rytuba, J. J., and Brown, G. E. (2004) Geological and anthropogenic factors influencing mercury speciation in mine wastes: an EXAFS spectroscopy study, Applied Geochemistry 19, 379-393.

50. Stein, E. D., Cohen, Y., and Winer, A. M. (1996) Environmental distribution and transformation of mercury compounds, Critical Reviews in Environmental Science and Technology 26, 1-43.

51. Dickson, F., and Tunell, G. (1959) The stability relations of cinnabar and metacinnabar, American Mineralogist 44, 471-\&.

52. Benoit, J. M., Gilmour, C. C., Mason, R. P., and Heyes, A. (1999) Sulfide controls on mercury speciation and bioavailability to methylating bacteria in sediment pore waters, Environmental Science \& Technology 33, 951-957.

53. Compeau, G. C., and Bartha, R. (1987) Effect of Salinity on Mercury-Methylating Activity of Sulfate-Reducing Bacteria in Estuarine Sediments, Applied and Environmental Microbiology 53, 261-265.

54. Ravichandran, M., Aiken, G. R., Ryan, J. N., and Reddy, M. M. (1999) Inhibition of precipitation and aggregation of metacinnabar (mercuric sulfide) by dissolved organic matter isolated from the Florida Everglades, Environmental Science \& Technology 33, 1418-1423.

55. Wolfenden, S., Charnock, J. M., Hilton, J., Livens, F. R., and Vaughan, D. J. (2005) Sulfide Species as a Sink for Mercury in Lake Sediments, Environmental science \& technology 39, 66446648.

56. Barnett, M. O., Turner, R. R., and Singer, P. C. (2001) Oxidative dissolution of metacinnabar (beta-HgS) by dissolved oxygen, Applied Geochemistry 16, 1499-1512.

57. He, Z., Traina, S. J., and Weavers, L. K. (2007) Sonochemical Dissolution of Cinnabar ( $\alpha-H g S)$, Environmental Science \& Technology 41, 773-778.

58. Nagy, K. L., and Kerr, M. (2010) Enhanced dissolution of cinnabar by dissolved organic matter in anoxic solutions, Geochimica Et Cosmochimica Acta 74, A744-A744.

59. Waples, J. S., Nagy, K. L., Aiken, G. R., and Ryan, J. N. (2005) Dissolution of cinnabar (HgS) in the presence of natural organic matter, Geochimica et Cosmochimica Acta 69, 1575-1588.

60. Burkstaller, J. E., McCarty, P. L., and Parks, G. A. (1975) Oxidation of cinnabar by iron(III) in acid mine waters, Environmental Science \& Technology 9, 676-678.

61. Paquette, K., and Helz, G. (1995) Solubility of cinnabar(red HgS) and implications for mercury speciation sulfidic waters, Water Air and Soil Pollution 80, 1053-1056.

62. Ravichandran, M., Aiken, G. R., Reddy, M. M., and Ryan, J. N. (1998) Enhanced dissolution of cinnabar (mercuric sulfide) by aquatic humic substances, Abstracts of Papers of the American Chemical Society 216, U785-U785. 
63. Ravichandran, M., Aiken, G. R., Reddy, M. M., and Ryan, J. N. (1998) Enhanced dissolution of cinnabar (mercuric sulfide) by dissolved organic matter isolated from the Florida Everglades, Environmental Science \& Technology 32, 3305-3311.

64. Wang, Y. J., Li, H. Y., Hu, H. F., Li, D. P., Yang, Y. J., and Liu, C. (2013) Using biochemical system to improve cinnabar dissolution, Bioresource Technology 132, 1-4.

65. Wang, Y. J., Yang, Y. J., Li, D. P., Hu, H. F., Li, H. Y., and He, X. H. (2013) Bioxidative dissolution of cinnabar by iron-oxidizing bacteria, Biochemical Engineering Journal 74, 102-106.

66. Liu, G., Cabrera, J., Allen, M., and Cai, Y. (2006) Mercury characterization in a soil sample collected nearby the DOE Oak Ridge Reservation utilizing sequential extraction and thermal desorption method, Science of the Total Environment 369, 384-392.

67. Ravichandran, M. (2004) Interactions between mercury and dissolved organic matter - a review, Chemosphere 55, 319-331.

68. Aiken, G. W., J.; Nagy, K. L.; Ryan, J.; Ravichandran, M. (2001) Dissolution of cinnabar by dissolved organic matter, Abstracts of Papers of the American Chemical Society 222, U425-U425.

69. Holley, E. A., McQuillan, A. J., Craw, D., Kim, J. P., and Sander, S. G. (2007) Mercury mobilization by oxidative dissolution of cinnabar (alpha- $\mathrm{HgS}$ ) and metacinnabar (beta-HgS), Chemical Geology 240, 313-325.

70. Hsieh, Y. H., Tokunaga, S., and Huang, C. P. (1991) Some chemical reactions at the HgS(s) water interface as affected by photoirradiation, Colloids and Surfaces 53, 257-274.

71. Lockwood, R. A., and Chen, K. Y. (1973) Adsorption of mercury(II) by hydrous manganese oxides, Environmental Science \& Technology 7, 1028-1034.

72. Yin, Y., Allen, H. E., Huang, C. P., Sparks, D. L., and Sanders, P. F. (1997) Kinetics of Mercury(II) Adsorption and Desorption on Soil, Environmental Science \& Technology 31, 496503.

73. Hintelmann, H., and Harris, R. (2004) Application of multiple stable mercury isotopes to determine the adsorption and desorption dynamics of $\mathrm{Hg}(\mathrm{II})$ and $\mathrm{MeHg}$ to sediments, Marine Chemistry 90, 165-173.

74. Miretzky, P., Bisinoti, M. C., Jardim, W. F., and Rocha, J. C. (2005) Factors affecting Hg (II) adsorption in soils from the Rio Negro basin (Amazon), Química Nova 28, 438-443.

75. Bonnissel-Gissinger, P., Alnot, M., Lickes, J.-P., Ehrhardt, J.-J., and Behra, P. (1999) Modeling the Adsorption of Mercury(II) on (Hydr)oxides II: $\alpha$-FeOOH (Goethite) and Amorphous Silica, Journal of Colloid and Interface Science 215, 313-322.

76. Balsley, S. D., Brady, P. V., Krumhansl, J. L., and Anderson, H. L. (1996) Iodide Retention by Metal Sulfide Surfaces: Cinnabar and Chalcocite, Environmental Science \& Technology 30, 30253027.

77. Schuster, E. (1991) The behavior of mercury in the soil with special emphasis on complexation and adsorption processes - A review of the literature, Water Air and Soil Pollution 56, 667-680. 
78. Aiken, G., Waples, J., Nagy, K. L., Ryan, J., and Ravichandran, M. (2001) Dissolution of cinnabar by dissolved organic matter, Abstracts of Papers of the American Chemical Society 222, U425U425.

79. Li, Y., Yin, Y., Liu, G., Tachiev, G., Roelant, D., Jiang, G., and Cai, Y. (2012) Estimation of the Major Source and Sink of Methylmercury in the Florida Everglades, Environmental Science \& Technology 46, 5885-5893.

80. Whalin, L., Kim, E.-H., and Mason, R. (2007) Factors influencing the oxidation, reduction, methylation and demethylation of mercury species in coastal waters, Mar. Chem. 107, 278-294.

81. Hoggarth, C. G. J., Hall, B. D., and Mitchell, C. P. J. (2015) Mercury methylation in high and lowsulphate impacted wetland ponds within the prairie pothole region of North America,

Environmental Pollution 205, 269-277.

82. Rodríguez Martín-Doimeadios, R. C., Tessier, E., Amouroux, D., Guyoneaud, R., Duran, R., Caumette, P., and Donard, O. F. X. (2004) Mercury methylation/demethylation and volatilization pathways in estuarine sediment slurries using species-specific enriched stable isotopes, Marine Chemistry 90, 107-123.

83. Jiskra, M., Saile, D., Wiederhold, J. G., Bourdon, B., Björn, E., and Kretzschmar, R. (2014) Kinetics of $\mathrm{Hg}(\mathrm{II})$ Exchange between Organic Ligands, Goethite, and Natural Organic Matter Studied with an Enriched Stable Isotope Approach, Environmental science \& technology 48, 13207-13217.

84. Jonsson, S., Skyllberg, U., Nilsson, M. B., Westlund, P.-O., Shchukarev, A., Lundberg, E., and Björn, E. (2012) Mercury Methylation Rates for Geochemically Relevant HgII Species in Sediments, Environmental science \& technology 46, 11653-11659.

85. Navarro, A., Cardellach, E., and Corbella, M. (2009) Mercury mobility in mine waste from Hgmining areas in Almería, Andalusia (Se Spain), Journal of Geochemical Exploration 101, 236246.

86. Han, S., Lehman, R. D., Choe, K.-Y., and Gill, G. A. (2007) Chemical and physical speciation of mercury in Offatts Bayou: A seasonally anoxic bayou in Galveston Bay, Limnology and Oceanography 52, 1380-1392.

87. Shaw, S. A., Al, T. A., and MacQuarrie, K. T. B. (2006) Mercury mobility in unsaturated gold mine tailings, Murray Brook mine, New Brunswick, Canada, Applied Geochemistry 21, 19861998.

88. Navarro, A., Biester, H., Mendoza, L. J., and Cardellach, E. (2006) Mercury speciation and mobilization in contaminated soils of the Valle del Azogue Hg mine (SE, Spain), Environmental Geology 49, 1089-1101.

89. Gilmour, C. C., Riedel, G., Ederington, M., Bell, J., Gill, G., and Stordal, M. (1998) Methylmercury concentrations and production rates across a trophic gradient in the northern Everglades, Biogeochemistry 40, 327-345.

90. Schaefer, J. K., Rocks, S. S., Zheng, W., Liang, L., Gu, B., and Morel, F. M. M. (2011) Active transport, substrate specificity, and methylation of $\mathrm{Hg}(\mathrm{II})$ in anaerobic bacteria, Proceedings of the National Academy of Sciences 108, 8714-8719. 
91. Barkay, T., Gillman, M., and Turner, R. R. (1997) Effects of dissolved organic carbon and salinity on bioavailability of mercury, Applied and Environmental Microbiology 63, 4267-4271.

92. Benoit, J., Gilmour, C., Heyes, A., Mason, R., and Miller, C. (2003) Geochemical and biological controls over methylmercury production and degradation in aquatic ecosystems, In ACS Symposium Series, pp 262-297, Washington, DC; American Chemical Society; 1999.

93. Golding, G. R., Kelly, C. A., Sparling, R., Loewen, P. C., Rudd, J. W. M., and Barkay, T. (2002) Evidence for facilitated uptake of $\mathrm{Hg}$ (II) by Vibrio anguillarum and Escherichia coli under anaerobic and aerobic conditions, Limnology and Oceanography 47, 967-975.

94. Gao, Y., Shi, Z., Long, Z., Wu, P., Zheng, C., and Hou, X. (2012) Determination and speciation of mercury in environmental and biological samples by analytical atomic spectrometry, Microchemical Journal 103, 1-14.

95. Leopold, K., Foulkes, M., and Worsfold, P. (2010) Methods for the determination and speciation of mercury in natural waters-A review, Analytica Chimica Acta 663, 127-138.

96. Amde, M., Yin, Y., Zhang, D., and Liu, J. (2016) Methods and recent advances in speciation analysis of mercury chemical species in environmental samples: a review, Chemical Speciation \& Bioavailability 28, 51-65.

97. Stumm, W., and Morgan, J. J. (2012) Aquatic chemistry: chemical equilibria and rates in natural waters, Vol. 126, John Wiley \& Sons.

98. Hahne, H., and Kroontje, W. (1973) Significance of pH and chloride concentration on behavior of heavy metal pollutants: mercury (II), cadmium (II), zinc (II), and lead (II), Journal of Environmental Quality 2, 444-450.

99. Turner, D., Whitfield, M., and Dickson, A. (1981) The equilibrium speciation of dissolved components in freshwater and sea water at $25 \mathrm{C}$ and $1 \mathrm{~atm}$ pressure, Geochimica et Cosmochimica Acta 45, 855-881.

100. Paquette, K., and Helz, G. (1995) Solubility of cinnabar (red HgS) and implications for mercury speciation in sulfidic waters, Water, Air, and Soil Pollution 80, 1053-1056.

101. Skyllberg, U. (2000) Binding of Mercury(II) to Reduced Sulfur in Soil Organic Matter along Upland-Peat Soil Transects, Journal of Environmental Quality 29, 855.

102. Han, S., and Gill, G. A. (2005) Determination of Mercury Complexation in Coastal and Estuarine Waters Using Competitive Ligand Exchange Method, Environmental science \& technology 39, 6607-6615.

103. Lamborg, C. H., Tseng, C.-M., Fitzgerald, W. F., Balcom, P. H., and Hammerschmidt, C. R. (2003) Determination of the Mercury Complexation Characteristics of Dissolved Organic Matter in Natural Waters with "Reducible Hg" Titrations, Environmental science \& technology 37, 33163322 .

104. Lamborg, C. H., Fitzgerald, W. F., Skoog, A., and Visscher, P. T. (2004) The abundance and source of mercury-binding organic ligands in Long Island Sound, Marine Chemistry 90, 151-163.

105. Noosai, N. (2014) Development of an Enhanced Hydro-geochemical Model to Address Mercuryspeciation Fate and Transport in Aquatic Environments, FLORIDA INTERNATIONAL UNIVERSITY. 
106. Caruso, B. S., Cox, T. J., Runkel, R. L., Velleux, M. L., Bencala, K. E., Nordstrom, D. K., Julien, P. Y., Butler, B. A., Alpers, C. N., Marion, A., and Smith, K. S. (2008) Metals fate and transport modelling in streams and watersheds: state of the science and USEPA workshop review, Hydrological Processes 22, 4011-4021.

107. Merkel, B. J., and Planer-Friedrich, B. (2008) Groundwater Geochemistry, Springer-Verlag Berlin Heidelberg.

108. Ware, F. J., Royals, H., and Lange, T. (1990) Mercury contamination in Florida largemouth bass, Proceedings of the Annual Conference Southeastern Association of Fish and Wildlife Agencies 44, $5-12$.

109. Lange, T. R., Royals, H. E., and Connor, L. L. (1994) Mercury accumulation in largemouth bass (Micropterus salmoides) in a Florida Lake, Archives of Environmental Contamination and Toxicology 27, 466-471.

110. Rumbold, D. G., Lange, T. R., Axelrad, D. M., and Atkeson, T. D. (2008) Ecological risk of methylmercury in Everglades National Park, Florida, USA, Ecotoxicology 17, 632-641.

111. Jordan, D. (1990) Mercury contamination: Another threat to the Florida panther, Fish and Wildlife Service Endangered Species Technical Bulletin 15, 1.

112. Scheuhammer, A. M., Meyer, M. W., Sandheinrich, M. B., and Murray, M. W. (2007) Effects of Environmental Methylmercury on the Health of Wild Birds, Mammals, and Fish, Ambio 36, 1219.

113. Duvall, S. E., and Barron, M. G. (2000) A Screening Level Probabilistic Risk Assessment of Mercury in Florida Everglades Food Webs, Ecotoxicology and Environmental Safety 47, 298-305.

114. Fleming, L. E., Watkins, S., Kaderman, R., Levin, B., Ayyar, D. R., Bizzio, M., Stephens, D., and Bean, J. A. (1995) Mercury Exposure in Humans Through Food Consumption from the Everglades of Florida, In Mercury as a Global Pollutant: Proceedings of the Third International Conference held in Whistler, British Columbia, July 10-14, 1994 (Porcella, D. B., Huckabee, J. W., and Wheatley, B., Eds.), pp 41-48, Springer Netherlands, Dordrecht.

115. Cleckner, L. B., Garrison, P. J., Hurley, J. P., Olson, M. L., and Krabbenhoft, D. P. Trophic transfer of methyl mercury in the northern Florida Everglades, Biogeochemistry 40, 347-361.

116. Cleckner, L. B. (1999) Mercury methylation in periphyton of the Florida Everglades, Limnology and Oceanography 44, 1815-1825.

117. Zhang, H. (2000) Air/water exchange of mercury in the Everglades I: the behavior of dissolved gaseous mercury in the Everglades Nutrient Removal Project, The Science of the Total Environment 259, 123-133.

118. Drexel, R. T., Haitzer, M., Ryan, J. N., Aiken, G. R., and Nagy, K. L. (2002) Mercury(II) Sorption to Two Florida Everglades Peats: Evidence for Strong and Weak Binding and Competition by Dissolved Organic Matter Released from the Peat, Environmental science \& technology 36, 40584064.

119. Liu, G. L., Cai, Y., Kalla, P., Scheidt, D., Richards, J., Scinto, L. J., Gaiser, E., and Appleby, C. (2008) Mercury mass budget estimates and cycling seasonality in the Florida everglades, Environmental Science \& Technology 42, 1954-1960. 
120. Liu, G. L., Cai, Y., Mao, Y. X., Scheidt, D., Kalla, P., Richards, J., Scinto, L. J., Tachiev, G., Roelant, D., and Appleby, C. (2009) Spatial Variability in Mercury Cycling and Relevant Biogeochemical Controls in the Florida Everglades, Environmental Science \& Technology 43, 4361-4366.

121. Liu, G. L., Cai, Y., Philippi, T., Kalla, P., Scheidt, D., Richards, J., Scinto, L., and Appleby, C. (2008) Distribution of total and methylmercury in different ecosystem compartments in the Everglades: Implications for mercury bioaccumulation, Environmental Pollution 153, 257-265.

122. Liu, G. L., Naja, G. M., Kalla, P., Scheidt, D., Gaiser, E., and Cai, Y. (2011) Legacy and Fate of Mercury and Methylmercury in the Florida Everglades, Environmental Science \& Technology 45, 496-501.

123. Stober, Q., Thornton, K., Jones, R., Richards, J., Ivey, C., Welch, R., Madden, M., Trexler, J., Gaiser, E., and Scheidt, D. (2001) South Florida Ecosystem Assessment: Phase I/II (Technical Report) - Everglades Stressor Interactions: Hydropatterns, Eutrophication, Habitat Alteration, and Mercury Contamination, In Water Management Division, and Office of Research and Development. EPA-904-R-01-003.

124. Arfstrom, C., Macfarlane, A. W., and Jones, R. D. (2000) Distributions of Mercury and Phosphorous in Everglades Soils From Water Conservation Area 3A, Florida, U.S.A, Water, Air, and Soil Pollution 121, 133-159.

125. Gilmour, C. C., and Riedel, G. S. (1995) Measurement of Hg methylation in sediments using high specific-activity $203 \mathrm{Hg}$ and ambient incubation, Water, Air, and Soil Pollution 80, 747-756.

126. Hammerschmidt, C. R., and Fitzgerald, W. F. (2004) Geochemical Controls on the Production and Distribution of Methylmercury in Near-Shore Marine Sediments, Environmental science \& technology 38, 1487-1495.

127. Reddy, M. M., and Aiken, G. R. (2001) Fulvic acid-sulfide ion competition for mercury ion binding in the Florida Everglades, Water, Air, and Soil Pollution 132, 89-104.

128. Gu, B., Bian, Y., Miller, C. L., Dong, W., Jiang, X., and Liang, L. (2011) Mercury reduction and complexation by natural organic matter in anoxic environments, Proceedings of the National Academy of Sciences of the United States of America 108, 1479-1483.

129. HURLEY, J. P., KRABBENHOFT, D. P., LISA B. CLECKNER, MARK L. OLSON, AIKEN4, G. R., and JR, P. S. R. (1998) System controls on the aqueous distribution of mercury in the northern Florida Everglades, Biogeochemistry 40, 293-311.

130. Drott, A. (2013) Refining Thermodynamic Constants for Mercury(II)-Sulfides in Equilibrium with Metacinnabar at Sub-Micromolar Aqueous Sulfide Concentrations, Environmental science \& technology 47, 4197-4203.

131. Hasany, S. M., Saeed, M. M., and Ahmed, M. (1999) Retention of Hg(II) by Solid Mercury Sulfide from Acidic Solution, Separation Science and Technology 34, 487-499.

132. Bravo, A. G. (2014) Species-specific isotope tracers to study the accumulation and biotransformation of mixtures of inorganic and methyl mercury by the microalga Chlamydomonas reinhardtii, Environmental pollution (1987) 192, 212-215. 
133. Mann, J. L., Long, S. E., and Kelly, W. R. (2003) Direct determination of mercury at picomole L1 levels in bottled water by isotope dilution cold-vapor generation inductively coupled plasma mass spectrometry, Journal of Analytical Atomic Spectrometry 18, 1293-1296.

134. Farooq, U., Kozinski, J. A., Khan, M. A., and Athar, M. (2010) Biosorption of heavy metal ions using wheat based biosorbents - A review of the recent literature, Bioresource Technology 101, 5043-5053.

135. Freundlich, H. (1906) Over the Adsorption in Solution, Journal of Physical Chemistry 57, 385471.

136. Hasany, S. M., and Chaudhary, M. H. (1996) Sorption potential of Haro river sand for the removal of antimony from acidic aqueous solution, Applied Radiation and Isotopes 47, 467-471.

137. Kołodyńska, D., Wnętrzak, R., Leahy, J. J., Hayes, M. H. B., Kwapiński, W., and Hubicki, Z. (2012) Kinetic and adsorptive characterization of biochar in metal ions removal, Chemical Engineering Journal 197, 295-305.

138. Langmuir, I. (1918) The adsorption of gases on plane surfaces of glass, mica and platinum, Journal of the American Chemical Society 40, 1361-1403.

139. Lazaridis, N. K., and Asouhidou, D. D. (2003) Kinetics of sorptive removal of chromium(VI) from aqueous solutions by calcined Mg-Al-CO3 hydrotalcite, Water Research 37, 2875-2882.

140. Senthil Kumar, P., Senthamarai, C., and Durgadevi, A. (2014) Adsorption kinetics, mechanism, isotherm, and thermodynamic analysis of copper ions onto the surface modified agricultural waste, Environmental Progress \& Sustainable Energy 33, 28-37.

141. Ho, Y. S., and McKay, G. (1999) Pseudo-second order model for sorption processes, Process Biochemistry 34, 451-465.

142. Sut, M., Fischer, T., Repmann, F., and Raab, T. (2013) Long-Term Release of Iron-Cyanide Complexes from the Soils of a Manufactured Gas Plant Site, Journal of Environmental Protection $4,8-19$.

143. Heumann, K. G., Gallus, S. M., Rädlinger, G., and Vogl, J. (1998) Accurate determination of element species by on-line coupling of chromatographic systems with ICP-MS using isotope dilution technique, Spectrochimica Acta, Part B: Atomic Spectroscopy 53, 273-287.

144. Hintelmann, H., and Evans, R. D. (1997) Application of stable isotopes in environmental tracer studies - Measurement of monomethylmercury $(\mathrm{CH} 3 \mathrm{Hg}+)$ by isotope dilution ICP-MS and detection of species transformation, Fresenius' Journal of Analytical Chemistry 358, 378-385.

145. Long, S. E., and Kelly, W. R. (2002) Determination of Mercury in Coal by Isotope Dilution ColdVapor Generation Inductively Coupled Plasma Mass Spectrometry, Analytical Chemistry 74, 1477-1483.

146. Smith, R. G. (1993) Determination of mercury in environmental samples by isotope dilution/ICPMS, Analytical Chemistry 65, 2485-2488.

147. Rodríguez-González, P., Marchante-Gayón, J. M., García Alonso, J. I., and Sanz-Medel, A. (2005) Isotope dilution analysis for elemental speciation: a tutorial review, Spectrochimica Acta Part B: Atomic Spectroscopy 60, 151-207. 
148. Javadian, H., Ghaemy, M., and Taghavi, M. (2014) Adsorption kinetics, isotherm, and thermodynamics of $\mathrm{Hg} 2+$ to polyaniline/hexagonal mesoporous silica nanocomposite in water/wastewater, Journal of Materials Science 49, 232-242.

149. Celis, R., HermosÍn, M. C., and Cornejo, J. (2000) Heavy Metal Adsorption by Functionalized Clays, Environmental science \& technology 34, 4593-4599.

150. Gray, J. E., and Hines, M. E. (2006) Mercury: Distribution, transport, and geochemical and microbial transformations from natural and anthropogenic sources, Applied Geochemistry 21, $1819-1820$.

151. Oxtoby, D. W., Gillis, H. P., and Butler, L. J. (2015) Principles of modern chemistry, Cengage Learning.

152. Jiang, P., Li, Y., Liu, G., Yang, G., Lagos, L., Yin, Y., Gu, B., Jiang, G., and Cai, Y. (2016) Evaluating the role of re-adsorption of dissolved $\mathrm{Hg} 2+$ during cinnabar dissolution using isotope tracer technique, Journal of Hazardous Materials 317, 466-475.

153. Yoshida, Y., Ohiwa, Y., Shimamura, M., Izumi, T., Yoshida, S., Takahashi, K., Miyairi, S., Makimura, M., and Naganuma, A. (2003) Optimum Conditions for Derivatization of Glutathione, Cysteine and Cysteinylglycine in Human Plasma with Ammonium 7-Fluorobenzo-2-Oxa-1,3Diazole-4-Sulfonate for Accurate Quantitation by High-Performance Liquid Chromatography, Journal of Health Science 49, 527-530.

154. Bramanti, E., D'Ulivo, A., Lampugnani, L., Raspi, G., and Zamboni, R. (1999) Cold vapour atomic fluorescence studies on the behaviour of mercury(II) and mercury(II)-thiol complexes. An alternative route for characterization of -SH binding groups, Journal of Analytical Atomic Spectrometry 14, 179-185.

155. Miller, C. L., Southworth, G., Brooks, S., Liang, L., and Gu, B. (2009) Kinetic Controls on the Complexation between Mercury and Dissolved Organic Matter in a Contaminated Environment, Environmental Science \& Technology 43, 8548-8553.

156. Araki, A., and Sako, Y. (1987) Determination of free and total homocysteine in human plasma by high-performance liquid chromatography with fluorescence detection, Journal of Chromatography B: Biomedical Sciences and Applications 422, 43-52.

157. Imai, K., Toyo'oka, T., and Watanabe, Y. (1983) A novel fluorogenic reagent for thiols: ammonium 7-fluorobenzo-2-oxa-1, 3-diazole-4-sulfonate, Analytical biochemistry 128, 471-473.

158. Jones, R. D., Jacobson, M. E., Jaffe, R., West-Thomas, J., Arfstrom, C., and Alli, A. (1995) Method Development and Sample Processing of Water, Soil, and Tissue for the Analysis of Total and Organic Mercury by Cold Vapor Atomic Fluorescence Spectrometry, In Mercury as a Global Pollutant: Proceedings of the Third International Conference held in Whistler, British Columbia, July 10-14, 1994 (Porcella, D. B., Huckabee, J. W., and Wheatley, B., Eds.), pp 1285-1294, Springer Netherlands, Dordrecht.

159. Tang, D., Wen, L.-S., and Santschi, P. H. (2000) Analysis of biogenic thiols in natural water samples by high-performance liquid chromatographic separation and fluorescence detection with ammonium 7-fluorobenzo-2-oxa-1,3-diazole-4-sulfonate (SBD-F), Analytica Chimica Acta 408, 299-307. 
160. Zhang, J., Wang, F., House, J. D., and Page, B. (2004) Thiols in Wetland Interstitial Waters and Their Role in Mercury and Methylmercury Speciation, Limnology and Oceanography 49, 22762286.

161. Daskalakis, I., Lucock, M. D., Anderson, A., Wild, J., Schorah, C. J., and Levene, M. I. (1996) Determination of Plasma Total Homocysteine and Cysteine Using HPLC with Fluorescence Detection and an Ammonium 7-fluoro-2,1,3-benzoxadiazole-4-sulphonate (SBD-F) Derivatization Protocol Optimized for Antioxidant Concentration, Derivatization Reagent Concentration, Temperature and Matrix pH, Biomedical Chromatography 10, 205-212.

162. Toyo'oka, T., and Imai, K. (1983) VII. International symposium on column liquid chromatographyHigh-performance liquid chromatography and fluorometric detection of biologically important thiols, derivatized with ammonium 7-fluorobenzo-2-oxa-1,3-diazole-4sulphonate (SBD-F), Journal of Chromatography A 282, 495-500.

163. Cannan, R. K., and Knight, B. C. J. G. (1927) Dissociation Constants of Cystine, Cysteine, Thioglycollic Acid and $\alpha$-Thiolactic Acid, Biochemical Journal 21, 1384-1390.

164. Clement, G. E., and Hartz, T. P. (1971) Determination of the microscopic ionization constants, Journal of Chemical Education 48, 395.

165. Van Der Linden, W. E., and Beers, C. (1974) Determination of the composition and the stability constants of complexes of mercury(II) with amino acids, Analytica Chimica Acta 68, 143-154.

166. Stricks, W. (1953) Reactions between Mercuric Mercury and Cysteine and Glutathione. Apparent Dissociation Constants, Heats and Entropies of Formation of Various Forms of Mercuric Mercapto-Cysteine and -Glutathione, Journal of the American Chemical Society 75, 5673-5681.

167. Perkins, D. J. (1953) A study of the effect of amino acid structure on the stabilities of the complexes formed with metals of group II of the periodic classification, Biochemical Journal 55, 649.

168. Thurman, E. M. (2012) Organic geochemistry of natural waters, Vol. 2, Springer Science \& Business Media.

169. Skyllberg, U. (2008) Competition among thiols and inorganic sulfides and polysulfides for $\mathrm{Hg}$ and $\mathrm{MeHg}$ in wetland soils and sediments under suboxic conditions: Illumination of controversies and implications for MeHg net production, Journal of Geophysical Research: Biogeosciences 113.

170. Benoit, J. M., Mason, R. P., Gilmour, C. C., and Aiken, G. R. (2001) Constants for mercury binding by dissolved organic matter isolates from the Florida Everglades, Geochimica et Cosmochimica Acta 65, 4445-4451.

171. Gai, K., Hoelen, T. P., Hsu-Kim, H., and Lowry, G. V. (2016) Mobility of Four Common Mercury Species in Model and Natural Unsaturated Soils, Environmental science \& technology 50, 33423351.

172. Schaefer, J. K., Yagi, J., Reinfelder, J. R., Cardona, T., Ellickson, K. M., Tel-Or, S., and Barkay, T. (2004) Role of the Bacterial Organomercury Lyase (MerB) in Controlling Methylmercury Accumulation in Mercury-Contaminated Natural Waters, Environmental science \& technology 38, 4304-4311.

173. Cleckner, L. B., Garrison, P. J., Hurley, J. P., Olson, M. L., and Krabbenhoft, D. P. (1998) Trophic transfer of methyl mercury in the northern Florida Everglades, Biogeochemistry 40, 347-361. 
174. Scheidt, D., and Kalla, P. (2007) Everglades ecosystem assessment: water management and quality, eutrophication, mercury contamination, soils and habitat: monitoring for adaptive management: a R-EMAP status report. USEPA Region 4, Athens, GA, In USEPA Region, p 98.

175. Hurley, J. P. (1998) System controls on the aqueous distribution of mercury in the northern Florida Everglades, Biogeochemistry 40, 293-311.

176. Stober, J., D. Scheidt, R. Jones, K. Thornton, R. Ambrose, and D. France. (1996) South Florida Ecosystem Assessment: Monitoring for Adaptive Management, Implications for Ecosystem Restoration (Interim Report), United States Environmental Protection Agency, Science and Ecosystem Support Division Region 4 and Office of Research and Development.

177. USEPA. (2013) Everglades Ecosystem Assessment Phase IV 2013 Report, United States Environmental Protection Agency Region 4 Science and Ecosystem Support Division.

178. Stober, Q., Thornton, K., Jones, R., Richards, J., Ivey, C., Welch, R., Madden, M., Trexler, J., Gaiser, E., and Scheidt, D. (2001) South Florida Ecosystem Assessment: Phase I/II (summary) Everglades Stressor Interactions: Hydropatterns, Eutrophication, Habitat Alteration, and Mercury Contamination (Summary), In Water Management Division, and Office of Research and Development. EPA-904-R-01-002.

179. Stober, J., D. Scheidt, R. Jones, K. Thornton, L. Gandy, D. Stevens, J. Trexler, and S. Rathbun. (1998) South Florida Ecosystem Assessment Monitoring for Ecosystem Restoration: Implications for Ecosystem Restoration Final Technical Report - Phase I, USEPA Region 4 Science and Ecosystem Support Division and Office of Research and Development.

180. Orem, W. H., Lerch, H. E., and Rawlik, P. (1997) Geochemistry of surface and pore water at USGS coring sites in wetlands of south Florida: 1994 and 1995. Open File Report 97-454, US Geological Survey, Denver, CO.

181. USEPA. (1998) Method 7474: Mercury in Sediment and Tissue Samples by Atomic Fluorescence Spectrometry, Office of Water.

182. USEPA. (2002) Method 1631 Revision E: Mercury in Water by Oxidation, Purge and Trap, and Cold Vapor Atomic Fluorescence Spectrometry, Office of Water.

183. Cai, Y., Tang, G., Jaffé, R., and Jones, R. (1997) Evaluation of some Isolation Methods for Organomercury Determination in Soil and Fish Samples by Capillary Gas ChromatographyAtomic Fluorescence Spectrometry, International Journal of Environmental Analytical Chemistry $68,331-345$.

184. USEPA. (2001) Method 1630: Methyl Mercury in Water by Distillation, Aqueous Ethylation, Purge and Trap, and CVAFS, Office of Water.

185. Hach. (2001) Method 8131 Sulfide, Methylene Blue Hach company.

186. USEPA. (1993) Method 300.0 Determination of inorganic anions by ion chromatography, Environmental monitoring systems liboratory office of research and development, U.S. Environmental Protection Agency, Cincinnati, OHIO.

187. FDEP. (2016) Determination of Total Organic Carbon (TOC) and Dissolved Organic Carbon (DOC) Using the Shimadzu TOC Analyzer, Bureau of Laboratories SOPs, Florida Department of Environmental Protection, Tallahassee, Florida. 
188. Noosai, N. (2013) Development of an Enhanced Hydro-geochemical Model to Address Mercuryspeciation Fate and Transport in Aquatic Environments, FIU Electronic Theses and Dissertations.

189. Parkhurst, D. L. (1995) User's guide to PHREEQC: A computer program for speciation, reactionpath, advective-transport, and inverse geochemical calculations, US Geological Survey.

190. Parkhurst, D. L., and Appelo, C. (2013) Description of input and examples for PHREEQC version 3: a computer program for speciation, batch-reaction, one-dimensional transport, and inverse geochemical calculations, US Geological Survey.

191. Steinberg, C. (2013) Ecology of humic substances in freshwaters, Springer Science \& Business Media.

192. Allison, J., Brown, D., and Novo-Gradac, K. (1998) MINTEQA2/PRODEFA2, A geochemical assessment model for environmental systems: user manual supplement for version 4.0, Environmental Protection Agency, Athens.

193. Mason, R. P., and Lawrence, A. L. (1999) Concentration, distribution, and bioavailability of mercury and methylmercury in sediments of Baltimore Harbor and Chesapeake Bay, Maryland, USA, Environmental toxicology and chemistry 18, 2438-2447.

194. Sjöblom, Å., Meili, M., and Sundbom, M. (2000) The influence of humic substances on the speciation and bioavailability of dissolved mercury and methylmercury, measured as uptake by Chaoborus larvae and loss by volatilization, Science of the Total Environment 261, 115-124.

195. Xia, K., Skyllberg, U. L., Bleam, W. F., Bloom, P. R., Nater, E. A., and Helmke, P. A. (1999) Xray Absorption Spectroscopic Evidence for the Complexation of $\mathrm{Hg}$ (II) by Reduced Sulfur in Soil Humic Substances, Environmental Science \& Technology 33, 257-261.

196. Haitzer, M., Aiken, G. R., and Ryan, J. N. (2002) Binding of Mercury(II) to Dissolved Organic Matter: The Role of the Mercury-to-DOM Concentration Ratio, Environmental science \& technology 36, 3564-3570.

197. Haitzer, M., Aiken, G. R., and Ryan, J. N. (2003) Binding of Mercury(II) to Aquatic Humic Substances: Influence of $\mathrm{pH}$ and Source of Humic Substances, Environmental science \& technology 37, 2436-2441.

198. Parkhurst, D. L., and Appelo, C. (1999) User's guide to PHREEQC (Version 2): A computer program for speciation, batch-reaction, one-dimensional transport, and inverse geochemical calculations, US Geological Survey.

199. Dyrssen, D., and Wedborg, M. (1991) The sulphur-mercury(II) system in natural waters, Water Air \& Soil Pollution 56, 507-519.

200. Gubeli, A., and Ste-Marie, J. (1967) Constantes de stabilité de thiocomplexes et produits de solubilité de sulfures de métaux. II Sulfure de zinc, Canadian Journal of Chemistry 45, 21012108.

201. Ste-Marie, J., Torma, A., and Gübeli, A. (1964) The stability of thiocomplexes and solubility products of metal sulphides: I. Cadmium sulphide, Canadian Journal of Chemistry 42, 662-668.

202. Tossell, J. A. (2001) Calculation of the Structures, Stabilities, and Properties of Mercury Sulfide Species in Aqueous Solution, The Journal of Physical Chemistry A 105, 935-941. 
203. Krabbenhoft, D. P., Hurley, J. P., Olson, M. L., and Cleckner, L. B. (1998) Diel variability of mercury phase and species distributions in the Florida Everglades, Biogeochemistry 40, 311-325.

204. Orem, W., Gilmour, C., Axelrad, D., Krabbenhoft, D., Scheidt, D., Kalla, P., McCormick, P., Gabriel, M., and Aiken, G. (2011) Sulfur in the South Florida Ecosystem: Distribution, Sources, Biogeochemistry, Impacts, and Management for Restoration, Critical Reviews in Environmental Science and Technology 41, 249-288.

205. Orem, W. (2007) Sulfur Contamination in the Florida Everglades: Initial Examination of Mitigation Strategies, U.S. Geological Survey Open-File Report 2007-1374.

206. Orem, W. H. (2004) Impacts of sulfate contamination on the Florida Everglades ecosystem, US Department of the Interior, US Geological Survey.

207. Bates, A. L. (2002) Tracing Sources of Sulfur in the Florida Everglades, Journal of Environmental Quality 31, 287.

208. Cutter, G. A., S. Walsh, R., and Silva de Echols, C. (1999) Production and speciation of hydrogen sulfide in surface waters of the high latitude North Atlantic Ocean, Deep Sea Research Part II: Topical Studies in Oceanography 46, 991-1010.

209. McCormick, P. V., Rawlik, P. S., Lurding, K., Smith, E. P., and Sklar, F. H. (1996) PeriphytonWater Quality Relationships along a Nutrient Gradient in the Northern Florida Everglades, Journal of the North American Benthological Society 15, 433-449.

210. Hoffmann, M. R. (1977) Kinetics and mechanism of oxidation of hydrogen sulfide by hydrogen peroxide in acidic solution, Environmental science \& technology 11, 61-66.

211. Millero, F. J., LeFerriere, A., Fernandez, M., Hubinger, S., and Hershey, J. P. (1989) Oxidation of hydrogen sulfide with hydrogen peroxide in natural waters, Environmental science \& technology 23, 209-213.

212. Benoit, J. M., Mason, R. P., and Gilmour, C. C. (1999) Estimation of mercury-sulfide speciation in sediment pore waters using octanol — water partitioning and implications for availability to methylating bacteria, Environmental toxicology and chemistry 18, 2138-2141.

213. Gilmour, C. C., Henry, E. A., and Mitchell, R. (1992) Sulfate stimulation of mercury methylation in freshwater sediments, Environmental science \& technology 26, 2281-2287.

214. Fleming, E. J., Mack, E. E., Green, P. G., and Nelson, D. C. (2006) Mercury methylation from unexpected sources: molybdate-inhibited freshwater sediments and an iron-reducing bacterium, Applied and Environmental Microbiology 72, 457-464.

215. Kelly, C. A., Rudd, J. W., St Vincent, L. L., and Heyes, A. (1995) Is total mercury concentration a good predictor of methyl mercury concentration in aquatic systems?, Water, Air, and Soil Pollution 80, 715-724.

216. Benoit, J. M., Gilmour, C. C., and Mason, R. P. (2001) Aspects of Bioavailability of Mercury for Methylation in Pure Cultures of Desulfobulbus propionicus (1pr3), Applied and Environmental Microbiology 67, 51-58.

217. Benoit, J. M., Gilmour, C. C., and Mason, R. P. (2001) The Influence of Sulfide on Solid-Phase Mercury Bioavailability for Methylation by Pure Cultures of Desulfobulbus propionicus (1pr3), Environmental science \& technology 35, 127-132. 
218. Benoit, J., Gilmour, C. C., Mason, R., Riedel, G., and Riedel, G. (1998) Behavior of mercury in the Patuxent River estuary, Biogeochemistry 40, 249-265.

219. Harmon, S. M., King, J. K., Gladden, J. B., and Newman, L. A. (2007) Using Sulfate-Amended Sediment Slurry Batch Reactors to Evaluate Mercury Methylation, Archives of Environmental Contamination and Toxicology 52, 326-331.

220. Choi, S. C., Chase, T., and Bartha, R. (1994) Enzymatic catalysis of mercury methylation by Desulfovibrio desulfuricans LS, Applied and Environmental Microbiology 60, 1342-1346.

221. Ridley, W., Dizikes, L., and Wood, J. (1977) Biomethylation of toxic elements in the environment, Science 197, 329-332.

222. Gutknecht, J. (1981) Inorganic mercury $(\mathrm{Hg} 2+)$ transport through lipid bilayer membranes, The Journal of Membrane Biology 61, 61-66.

223. Mason, R. P., Reinfelder, J. R., and Morel, F. M. M. (1996) Uptake, Toxicity, and Trophic Transfer of Mercury in a Coastal Diatom, Environmental Science \& Technology 30, 1835-1845.

224. Schaefer, J. K., and Morel, F. M. M. (2009) High methylation rates of mercury bound to cysteine by Geobacter sulfurreducens, Nature Geoscience 2, 123-126. 
Appendices

Appendices show the distribution of $\mathrm{Hg}$ speciation calculated by PHREEQC modeling from surface water of the Florida Everglades in dry (spring) and wet (fall) seasons in 2005.

Table A1 Concentrations of $\mathrm{Hg}$ species in surface water of Everglades in spring 2005 ([ $\left.\mathrm{S}^{2-}\right]>$ $0.02 \mathrm{mg} / \mathrm{L}$ )

\begin{tabular}{|c|c|c|c|c|c|c|c|}
\hline Station & $\begin{array}{c}\mathrm{Hg} \\
\mathrm{mol} / \mathrm{L}\end{array}$ & $\begin{array}{l}\mathrm{HgS}_{2}{ }^{2-} \\
\mathrm{mol} / \mathrm{L}\end{array}$ & $\begin{array}{c}\mathrm{HgHS}_{2}^{-} \\
\mathrm{mol} / \mathrm{L}\end{array}$ & $\begin{array}{c}\mathrm{Hg}(\mathrm{HS})_{2} \\
\mathrm{~mol} / \mathrm{L}\end{array}$ & $\begin{array}{c}\mathrm{HgHSOH} \\
\mathrm{mol} / \mathrm{L}\end{array}$ & $\begin{array}{c}\mathrm{RSHg}^{(\mathrm{n}-1)-} \\
\mathrm{mol} / \mathrm{L}\end{array}$ & $\begin{array}{l}\mathrm{HgCl}_{2} \\
\mathrm{~mol} / \mathrm{L}\end{array}$ \\
\hline 12 & $1.45 \mathrm{E}-11$ & $1.20 \mathrm{E}-11$ & $2.39 \mathrm{E}-12$ & $4.43 \mathrm{E}-14$ & $1.70 \mathrm{E}-21$ & $1.94 \mathrm{E}-22$ & $3.44 \mathrm{E}-29$ \\
\hline 35 & $9.97 \mathrm{E}-12$ & 8.04E-12 & $1.90 \mathrm{E}-12$ & $3.48 \mathrm{E}-14$ & $2.81 \mathrm{E}-22$ & $5.42 \mathrm{E}-24$ & $4.19 \mathrm{E}-33$ \\
\hline 40 & $1.70 \mathrm{E}-11$ & $1.11 \mathrm{E}-11$ & $5.67 \mathrm{E}-12$ & $2.23 \mathrm{E}-13$ & $2.30 \mathrm{E}-21$ & $1.15 \mathrm{E}-22$ & $9.01 \mathrm{E}-32$ \\
\hline 64 & 8.97E-12 & $4.28 \mathrm{E}-12$ & $4.36 \mathrm{E}-12$ & $3.36 \mathrm{E}-13$ & $1.18 \mathrm{E}-21$ & 4.49E-23 & $3.43 \mathrm{E}-32$ \\
\hline 72 & $6.48 \mathrm{E}-12$ & $4.67 \mathrm{E}-12$ & $1.76 \mathrm{E}-12$ & $5.10 \mathrm{E}-14$ & $1.22 \mathrm{E}-21$ & $1.16 \mathrm{E}-22$ & $1.29 \mathrm{E}-31$ \\
\hline 74 & $5.98 \mathrm{E}-12$ & $4.57 \mathrm{E}-12$ & $1.38 \mathrm{E}-12$ & $3.23 \mathrm{E}-14$ & 7.99E-22 & $5.28 \mathrm{E}-23$ & $4.48 \mathrm{E}-32$ \\
\hline 76 & $1.15 \mathrm{E}-11$ & $8.88 \mathrm{E}-12$ & $2.53 \mathrm{E}-12$ & $5.48 \mathrm{E}-14$ & $1.73 \mathrm{E}-21$ & $1.17 \mathrm{E}-22$ & $5.20 \mathrm{E}-32$ \\
\hline 86 & $1.15 \mathrm{E}-11$ & $8.20 \mathrm{E}-12$ & $3.17 \mathrm{E}-12$ & $9.42 \mathrm{E}-14$ & $2.83 \mathrm{E}-21$ & $2.53 \mathrm{E}-22$ & $2.88 \mathrm{E}-31$ \\
\hline 96 & $1.10 \mathrm{E}-11$ & $9.24 \mathrm{E}-12$ & $1.70 \mathrm{E}-12$ & $2.49 \mathrm{E}-14$ & $1.39 \mathrm{E}-21$ & $2.16 \mathrm{E}-22$ & $2.56 \mathrm{E}-31$ \\
\hline 97 & $3.09 \mathrm{E}-11$ & $2.28 \mathrm{E}-11$ & $7.91 \mathrm{E}-12$ & $2.14 \mathrm{E}-13$ & $3.71 \mathrm{E}-21$ & $2.59 \mathrm{E}-22$ & $2.43 \mathrm{E}-31$ \\
\hline 100 & $1.30 \mathrm{E}-11$ & $1.05 \mathrm{E}-11$ & $2.43 \mathrm{E}-12$ & $4.48 \mathrm{E}-14$ & $1.31 \mathrm{E}-21$ & $1.34 \mathrm{E}-22$ & $1.66 \mathrm{E}-31$ \\
\hline 102 & $1.40 \mathrm{E}-11$ & $1.04 \mathrm{E}-11$ & $3.48 \mathrm{E}-12$ & $9.55 \mathrm{E}-14$ & $2.72 \mathrm{E}-21$ & $6.59 \mathrm{E}-22$ & $1.90 \mathrm{E}-30$ \\
\hline 110 & $3.49 \mathrm{E}-11$ & $3.16 \mathrm{E}-11$ & $3.28 \mathrm{E}-12$ & $2.78 \mathrm{E}-14$ & $2.31 \mathrm{E}-22$ & $5.12 \mathrm{E}-24$ & $6.31 \mathrm{E}-33$ \\
\hline 117 & $2.54 \mathrm{E}-11$ & $2.34 \mathrm{E}-13$ & $7.43 \mathrm{E}-12$ & $1.78 \mathrm{E}-11$ & $1.67 \mathrm{E}-19$ & $7.16 \mathrm{E}-19$ & $7.12 \mathrm{E}-27$ \\
\hline 118 & $1.65 \mathrm{E}-11$ & $9.33 \mathrm{E}-12$ & $6.75 \mathrm{E}-12$ & $3.74 \mathrm{E}-13$ & $7.93 \mathrm{E}-21$ & $1.10 \mathrm{E}-21$ & $1.39 \mathrm{E}-30$ \\
\hline 120 & $3.29 \mathrm{E}-11$ & $9.97 \mathrm{E}-13$ & $1.49 \mathrm{E}-11$ & $1.70 \mathrm{E}-11$ & $1.43 \mathrm{E}-19$ & $2.65 \mathrm{E}-19$ & $3.03 \mathrm{E}-27$ \\
\hline 121 & $7.98 \mathrm{E}-12$ & $3.34 \mathrm{E}-12$ & $4.23 \mathrm{E}-12$ & $4.08 \mathrm{E}-13$ & $2.68 \mathrm{E}-21$ & $2.49 \mathrm{E}-22$ & 3.67E-31 \\
\hline 350 & $2.24 \mathrm{E}-11$ & $1.96 \mathrm{E}-11$ & $2.78 \mathrm{E}-12$ & $3.20 \mathrm{E}-14$ & $3.38 \mathrm{E}-22$ & $1.10 \mathrm{E}-23$ & $2.40 \mathrm{E}-32$ \\
\hline
\end{tabular}

Table A1 (Cont.)

\begin{tabular}{cccccccc}
\hline Station & $\begin{array}{c}\mathbf{H g B r C l} \\
\mathbf{m o l} / \mathbf{L}\end{array}$ & $\begin{array}{c}\mathbf{H g C l}^{-} \\
\mathbf{m o l} / \mathbf{L}\end{array}$ & $\begin{array}{c}\mathbf{H g C l O H} \\
\mathbf{m o l} / \mathbf{L}\end{array}$ & $\begin{array}{c}\mathbf{H g}(\mathbf{O H})_{2} \\
\mathbf{m o l} / \mathbf{L}\end{array}$ & $\begin{array}{c}\mathbf{H g B r}_{\mathbf{2}} \\
\mathbf{m o l} / \mathbf{L}\end{array}$ & $\begin{array}{c}\mathbf{H g B r O H} \\
\mathbf{m o l} / \mathbf{L}\end{array}$ & $\begin{array}{c}\mathbf{H g C l}_{\mathbf{4}}^{2-} \\
\mathbf{m o l} / \mathbf{L}\end{array}$ \\
\hline $\mathbf{1 2}$ & $3.21 \mathrm{E}-29$ & $8.52 \mathrm{E}-30$ & $3.37 \mathrm{E}-30$ & $1.70 \mathrm{E}-30$ & $1.31 \mathrm{E}-30$ & $1.12 \mathrm{E}-30$ & $8.84 \mathrm{E}-31$ \\
$\mathbf{3 5}$ & $2.28 \mathrm{E}-33$ & $6.23 \mathrm{E}-35$ & $8.22 \mathrm{E}-33$ & $5.94 \mathrm{E}-32$ & $8.25 \mathrm{E}-35$ & $1.34 \mathrm{E}-33$ & $3.21 \mathrm{E}-37$ \\
$\mathbf{4 0}$ & $6.22 \mathrm{E}-32$ & $8.93 \mathrm{E}-34$ & $1.62 \mathrm{E}-31$ & $6.22 \mathrm{E}-31$ & $5.61 \mathrm{E}-33$ & $2.55 \mathrm{E}-32$ & $3.04 \mathrm{E}-36$ \\
$\mathbf{6 4}$ & $2.87 \mathrm{E}-32$ & $2.55 \mathrm{E}-34$ & $3.31 \mathrm{E}-32$ & $1.09 \mathrm{E}-31$ & $1.75 \mathrm{E}-33$ & $8.01 \mathrm{E}-33$ & $6.43 \mathrm{E}-37$ \\
$\mathbf{7 2}$ & $5.56 \mathrm{E}-32$ & $1.85 \mathrm{E}-33$ & $2.03 \mathrm{E}-31$ & $7.70 \mathrm{E}-31$ & $2.71 \mathrm{E}-33$ & $2.12 \mathrm{E}-32$ & $9.25 \mathrm{E}-36$ \\
$\mathbf{7 4}$ & $3.26 \mathrm{E}-32$ & $5.75 \mathrm{E}-34$ & $7.69 \mathrm{E}-32$ & $5.17 \mathrm{E}-31$ & $1.46 \mathrm{E}-33$ & $1.73 \mathrm{E}-32$ & $2.58 \mathrm{E}-36$ \\
$\mathbf{7 6}$ & $3.59 \mathrm{E}-32$ & $4.69 \mathrm{E}-34$ & $1.58 \mathrm{E}-31$ & $1.43 \mathrm{E}-30$ & $2.16 \mathrm{E}-33$ & $2.94 \mathrm{E}-32$ & $1.44 \mathrm{E}-36$ \\
$\mathbf{8 6}$ & $1.73 \mathrm{E}-31$ & $3.56 \mathrm{E}-33$ & $3.84 \mathrm{E}-31$ & $2.22 \mathrm{E}-30$ & $5.71 \mathrm{E}-33$ & $7.52 \mathrm{E}-32$ & $1.52 \mathrm{E}-35$ \\
$\mathbf{9 6}$ & $1.54 \mathrm{E}-31$ & $6.35 \mathrm{E}-33$ & $3.40 \mathrm{E}-31$ & $2.03 \mathrm{E}-30$ & $4.83 \mathrm{E}-33$ & $6.80 \mathrm{E}-32$ & $5.60 \mathrm{E}-35$ \\
$\mathbf{9 7}$ & $2.63 \mathrm{E}-31$ & $3.51 \mathrm{E}-33$ & $4.73 \mathrm{E}-31$ & $1.68 \mathrm{E}-30$ & $4.47 \mathrm{E}-32$ & $1.08 \mathrm{E}-31$ & $1.76 \mathrm{E}-35$ \\
$\mathbf{1 0 0}$ & $6.41 \mathrm{E}-32$ & $3.73 \mathrm{E}-33$ & $2.17 \mathrm{E}-31$ & $1.00 \mathrm{E}-30$ & $1.74 \mathrm{E}-33$ & $2.47 \mathrm{E}-32$ & $3.00 \mathrm{E}-35$ \\
\hline
\end{tabular}




\begin{tabular}{llllllll}
\hline $\mathbf{1 0 2}$ & $4.59 \mathrm{E}-31$ & $6.84 \mathrm{E}-32$ & $1.10 \mathrm{E}-30$ & $2.03 \mathrm{E}-30$ & $8.82 \mathrm{E}-33$ & $7.42 \mathrm{E}-32$ & $9.07 \mathrm{E}-34$ \\
$\mathbf{1 1 0}$ & $4.87 \mathrm{E}-33$ & $2.70 \mathrm{E}-34$ & $1.00 \mathrm{E}-32$ & $5.00 \mathrm{E}-32$ & $3.05 \mathrm{E}-34$ & $2.14 \mathrm{E}-33$ & $4.25 \mathrm{E}-36$ \\
$\mathbf{1 1 7}$ & $7.87 \mathrm{E}-27$ & $4.01 \mathrm{E}-29$ & $2.14 \mathrm{E}-28$ & $4.12 \mathrm{E}-29$ & $2.91 \mathrm{E}-28$ & $9.34 \mathrm{E}-29$ & $7.61 \mathrm{E}-32$ \\
$\mathbf{1 1 8}$ & $8.33 \mathrm{E}-31$ & $1.44 \mathrm{E}-32$ & $1.19 \mathrm{E}-30$ & $4.40 \mathrm{E}-30$ & $2.71 \mathrm{E}-32$ & $2.32 \mathrm{E}-31$ & $5.12 \mathrm{E}-35$ \\
$\mathbf{1 2 0}$ & $2.14 \mathrm{E}-27$ & $2.66 \mathrm{E}-29$ & $1.63 \mathrm{E}-28$ & $3.17 \mathrm{E}-29$ & $1.04 \mathrm{E}-28$ & $3.43 \mathrm{E}-29$ & $7.95 \mathrm{E}-32$ \\
$\mathbf{1 2 1}$ & $2.41 \mathrm{E}-31$ & $3.47 \mathrm{E}-33$ & $2.73 \mathrm{E}-31$ & $4.60 \mathrm{E}-31$ & $1.93 \mathrm{E}-32$ & $4.22 \mathrm{E}-32$ & $1.12 \mathrm{E}-35$ \\
$\mathbf{3 5 0}$ & $1.56 \mathrm{E}-32$ & $1.08 \mathrm{E}-33$ & $3.07 \mathrm{E}-32$ & $9.33 \mathrm{E}-32$ & $1.15 \mathrm{E}-33$ & $4.80 \mathrm{E}-33$ & $1.77 \mathrm{E}-35$ \\
\hline
\end{tabular}

Table A1 (Cont.)

\begin{tabular}{|c|c|c|c|c|c|c|c|}
\hline Station & $\begin{array}{l}\mathrm{HgBr}_{3}^{-} \\
\mathrm{mol} / \mathrm{L}\end{array}$ & $\begin{array}{l}\mathrm{HgBr}^{+} \\
\mathrm{mol} / \mathrm{L}\end{array}$ & $\begin{array}{l}\mathrm{HgCl}^{+} \\
\mathrm{mol} / \mathrm{L}\end{array}$ & $\begin{array}{c}\mathrm{HgOH}^{+} \\
\mathrm{mol} / \mathrm{L}\end{array}$ & $\begin{array}{c}\mathrm{HgBr}_{4}{ }^{2-} \\
\mathrm{mol} / \mathrm{L}\end{array}$ & $\begin{array}{c}\mathrm{Hg}(\mathrm{OH})_{3} \\
\mathrm{~mol} / \mathrm{L}\end{array}$ & $\begin{array}{c}\mathrm{Hg}^{2+} \\
\mathrm{mol} / \mathrm{L}\end{array}$ \\
\hline 12 & $1.32 \mathrm{E}-32$ & $9.00 \mathrm{E}-34$ & $6.22 \mathrm{E}-34$ & $3.97 \mathrm{E}-35$ & $1.51 \mathrm{E}-35$ & $4.75 \mathrm{E}-38$ & $5.30 \mathrm{E}-39$ \\
\hline 35 & $1.92 \mathrm{E}-38$ & $8.71 \mathrm{E}-37$ & $1.03 \mathrm{E}-36$ & $1.11 \mathrm{E}-36$ & $0.00 \mathrm{E}+00$ & $1.68 \mathrm{E}-39$ & $1.15 \mathrm{E}-40$ \\
\hline 40 & $5.61 \mathrm{E}-37$ & $3.53 \mathrm{E}-35$ & $3.29 \mathrm{E}-35$ & $2.48 \mathrm{E}-35$ & $0.00 \mathrm{E}+00$ & $8.19 \mathrm{E}-39$ & $6.90 \mathrm{E}-39$ \\
\hline 64 & $2.85 \mathrm{E}-37$ & $2.14 \mathrm{E}-35$ & $1.65 \mathrm{E}-35$ & $8.45 \mathrm{E}-36$ & $0.00 \mathrm{E}+00$ & $7.34 \mathrm{E}-40$ & $3.65 \mathrm{E}-39$ \\
\hline 72 & $2.85 \mathrm{E}-37$ & $2.18 \mathrm{E}-35$ & $3.26 \mathrm{E}-35$ & $2.28 \mathrm{E}-35$ & $0.00 \mathrm{E}+00$ & $1.37 \mathrm{E}-38$ & $4.52 \mathrm{E}-39$ \\
\hline 74 & 4.22E-37 & $1.45 \mathrm{E}-35$ & $1.29 \mathrm{E}-35$ & $1.25 \mathrm{E}-35$ & $0.00 \mathrm{E}+00$ & $1.14 \mathrm{E}-38$ & $1.65 \mathrm{E}-39$ \\
\hline 76 & $2.95 \mathrm{E}-37$ & $2.22 \mathrm{E}-35$ & $2.08 \mathrm{E}-35$ & $3.12 \mathrm{E}-35$ & $0.00 \mathrm{E}+00$ & $3.41 \mathrm{E}-38$ & $4.08 \mathrm{E}-39$ \\
\hline 86 & $1.4 \mathrm{C}$ & 7.90 & 8.4 & $6.73 \mathrm{~F}$ & $0.00 \mathrm{E}+00$ & -38 & -38 \\
\hline 96 & $2.66 \mathrm{E}-36$ & $3.64 \mathrm{E}-35$ & $3.89 \mathrm{E}-35$ & $3.15 \mathrm{E}-35$ & $1.67 \mathrm{E}-40$ & $7.18 \mathrm{E}-38$ & $2.53 \mathrm{E}-39$ \\
\hline 97 & $8.42 \mathrm{E}-36$ & $1.04 \mathrm{E}-34$ & $6.20 \mathrm{E}-35$ & $4.68 \mathrm{E}-35$ & $5.38 \mathrm{E}-40$ & $3.22 \mathrm{E}-38$ & $9.83 \mathrm{E}-39$ \\
\hline 100 & 4.12E-37 & $1.66 \mathrm{E}-35$ & $2.77 \mathrm{E}-35$ & $1.96 \mathrm{E}-35$ & $0.00 \mathrm{E}+00$ & $2.82 \mathrm{E}-38$ & $2.20 \mathrm{E}-39$ \\
\hline 102 & $1.85 \mathrm{E}-36$ & 7.69E-35 & $2.05 \mathrm{E}-34$ & $6.07 \mathrm{E}-35$ & $0.00 \mathrm{E}+00$ & $3.82 \mathrm{E}-38$ & $1.14 \mathrm{E}-38$ \\
\hline 110 & $2.37 \mathrm{E}-37$ & $6.85 \mathrm{E}-37$ & $5.73 \mathrm{E}-37$ & $4.62 \mathrm{E}-37$ & $0.00 \mathrm{E}+00$ & $3.04 \mathrm{E}-39$ & $0.00 \mathrm{E}+00$ \\
\hline 117 & $1.03 \mathrm{E}-31$ & $7.70 \mathrm{E}-30$ & $4.50 \mathrm{E}-30$ & $9.80 \mathrm{E}-32$ & $2.56 \mathrm{E}-36$ & $8.91 \mathrm{E}-39$ & $9.80 \mathrm{E}-34$ \\
\hline 118 & $5.94 \mathrm{E}-36$ & $4.52 \mathrm{E}-34$ & $4.85 \mathrm{E}-34$ & $2.48 \mathrm{E}-34$ & $1.50 \mathrm{E}-40$ & $4.10 \mathrm{E}-38$ & $7.11 \mathrm{E}-38$ \\
\hline 120 & $1.80 \mathrm{E}-32$ & $1.36 \mathrm{E}-30$ & $1.24 \mathrm{E}-30$ & $3.63 \mathrm{E}-32$ & $4.51 \mathrm{E}-37$ & $1.44 \mathrm{E}-38$ & $2.28 \mathrm{E}-34$ \\
\hline 121 & $1.89 \mathrm{E}-36$ & $1.43 \mathrm{E}-34$ & $1.40 \mathrm{E}-34$ & $4.50 \mathrm{E}-35$ & $0.00 \mathrm{E}+00$ & $2.46 \mathrm{E}-39$ & $2.97 \mathrm{E}-38$ \\
\hline 350 & $5.65 \mathrm{E}-37$ & $2.06 \mathrm{E}-36$ & $2.05 \mathrm{E}-36$ & $1.16 \mathrm{E}-36$ & $0.00 \mathrm{E}+00$ & 4.19E-39 & $1.01 \mathrm{E}-40$ \\
\hline
\end{tabular}

Table A2 Concentrations of $\mathrm{Hg}$ species in surface water of Everglades in fall 2005 ([S $\left.{ }^{2-}\right]>0.02$ $\mathrm{mg} / \mathrm{L}$ )

\begin{tabular}{cccccccc}
\hline Station & $\begin{array}{c}\mathbf{H g} \\
\mathbf{m o l} / \mathbf{L}\end{array}$ & $\begin{array}{c}\mathbf{H g S}_{2}{ }^{2-} \\
\mathbf{m o l} / \mathbf{L}\end{array}$ & $\begin{array}{c}\mathbf{H g H S}_{2} \mathbf{2}^{-} \\
\mathbf{m o l} / \mathbf{L}\end{array}$ & $\begin{array}{c}\mathbf{H g}(\mathbf{H S})_{2} \\
\mathbf{m o l} / \mathbf{L}\end{array}$ & $\begin{array}{c}\mathbf{H g H S O H} \\
\mathbf{m o l} / \mathbf{L}\end{array}$ & $\begin{array}{c}\mathbf{R S H g}^{(\mathbf{n}-\mathbf{1})-} \\
\mathbf{m o l} / \mathbf{L}\end{array}$ & $\begin{array}{c}\mathbf{H g C l}_{\mathbf{2}} \\
\mathbf{m o l} / \mathbf{L}\end{array}$ \\
\hline $\mathbf{1 3 1}$ & $8.48 \mathrm{E}-12$ & $7.48 \mathrm{E}-12$ & $9.90 \mathrm{E}-13$ & $9.87 \mathrm{E}-15$ & $6.38 \mathrm{E}-22$ & $1.09 \mathrm{E}-23$ & $3.24 \mathrm{E}-33$ \\
$\mathbf{1 4 6}$ & $1.65 \mathrm{E}-11$ & $1.35 \mathrm{E}-11$ & $2.91 \mathrm{E}-12$ & $4.84 \mathrm{E}-14$ & $1.75 \mathrm{E}-21$ & $1.26 \mathrm{E}-22$ & $9.73 \mathrm{E}-32$ \\
$\mathbf{1 5 0}$ & $7.98 \mathrm{E}-12$ & $7.03 \mathrm{E}-12$ & $9.33 \mathrm{E}-13$ & $9.59 \mathrm{E}-15$ & $6.53 \mathrm{E}-22$ & $4.90 \mathrm{E}-23$ & $2.92 \mathrm{E}-32$ \\
$\mathbf{1 5 5}$ & $9.47 \mathrm{E}-12$ & $8.47 \mathrm{E}-12$ & $9.91 \mathrm{E}-13$ & $8.90 \mathrm{E}-15$ & $1.74 \mathrm{E}-22$ & $2.51 \mathrm{E}-24$ & $8.32 \mathrm{E}-34$ \\
$\mathbf{1 7 2}$ & $9.47 \mathrm{E}-12$ & $4.17 \mathrm{E}-12$ & $4.87 \mathrm{E}-12$ & $4.25 \mathrm{E}-13$ & $6.49 \mathrm{E}-21$ & $5.44 \mathrm{E}-22$ & $2.45 \mathrm{E}-31$ \\
$\mathbf{1 8 9}$ & $2.09 \mathrm{E}-11$ & $1.59 \mathrm{E}-11$ & $4.94 \mathrm{E}-12$ & $1.17 \mathrm{E}-13$ & $4.03 \mathrm{E}-21$ & $3.08 \mathrm{E}-22$ & $1.58 \mathrm{E}-31$ \\
$\mathbf{2 0 5}$ & $8.97 \mathrm{E}-12$ & $5.91 \mathrm{E}-12$ & $2.95 \mathrm{E}-12$ & $1.13 \mathrm{E}-13$ & $2.13 \mathrm{E}-21$ & $1.63 \mathrm{E}-22$ & $1.65 \mathrm{E}-31$ \\
$\mathbf{2 1 1}$ & $1.89 \mathrm{E}-11$ & $1.49 \mathrm{E}-11$ & $3.99 \mathrm{E}-12$ & $8.47 \mathrm{E}-14$ & $3.33 \mathrm{E}-21$ & $4.05 \mathrm{E}-22$ & $4.66 \mathrm{E}-31$ \\
\hline
\end{tabular}




\begin{tabular}{llllllll}
\hline $\mathbf{2 1 6}$ & $1.45 \mathrm{E}-11$ & $1.06 \mathrm{E}-11$ & $3.74 \mathrm{E}-12$ & $1.04 \mathrm{E}-13$ & $3.20 \mathrm{E}-21$ & $4.34 \mathrm{E}-22$ & $1.64 \mathrm{E}-30$ \\
$\mathbf{2 2 8}$ & $1.35 \mathrm{E}-11$ & $9.42 \mathrm{E}-12$ & $3.92 \mathrm{E}-12$ & $1.29 \mathrm{E}-13$ & $2.99 \mathrm{E}-21$ & $3.46 \mathrm{E}-22$ & $6.08 \mathrm{E}-31$ \\
$\mathbf{2 3 1}$ & $1.79 \mathrm{E}-11$ & $1.35 \mathrm{E}-11$ & $4.33 \mathrm{E}-12$ & $1.10 \mathrm{E}-13$ & $3.08 \mathrm{E}-21$ & $3.74 \mathrm{E}-22$ & $8.54 \mathrm{E}-31$ \\
$\mathbf{2 3 4}$ & $1.35 \mathrm{E}-11$ & $1.12 \mathrm{E}-11$ & $2.22 \mathrm{E}-12$ & $3.65 \mathrm{E}-14$ & $1.50 \mathrm{E}-21$ & $2.91 \mathrm{E}-22$ & $6.09 \mathrm{E}-31$ \\
$\mathbf{2 3 6}$ & $2.14 \mathrm{E}-11$ & $1.67 \mathrm{E}-11$ & $4.63 \mathrm{E}-12$ & $1.05 \mathrm{E}-13$ & $2.28 \mathrm{E}-21$ & $2.57 \mathrm{E}-22$ & $2.20 \mathrm{E}-30$ \\
$\mathbf{2 3 9}$ & $2.14 \mathrm{E}-11$ & $1.94 \mathrm{E}-12$ & $1.30 \mathrm{E}-11$ & $6.50 \mathrm{E}-12$ & $7.65 \mathrm{E}-20$ & $4.14 \mathrm{E}-20$ & $1.14 \mathrm{E}-28$ \\
$\mathbf{2 4 9}$ & $2.49 \mathrm{E}-11$ & $1.17 \mathrm{E}-11$ & $1.22 \mathrm{E}-11$ & $9.67 \mathrm{E}-13$ & $6.57 \mathrm{E}-21$ & $3.88 \mathrm{E}-22$ & $3.18 \mathrm{E}-31$ \\
$\mathbf{2 5 1}$ & $1.10 \mathrm{E}-11$ & $9.15 \mathrm{E}-12$ & $1.79 \mathrm{E}-12$ & $2.71 \mathrm{E}-14$ & $1.19 \mathrm{E}-21$ & $8.95 \mathrm{E}-23$ & $7.87 \mathrm{E}-32$ \\
$\mathbf{2 5 2}$ & $1.30 \mathrm{E}-11$ & $9.87 \mathrm{E}-12$ & $3.02 \mathrm{E}-12$ & $7.14 \mathrm{E}-14$ & $2.47 \mathrm{E}-21$ & $1.79 \mathrm{E}-22$ & $2.03 \mathrm{E}-31$ \\
$\mathbf{2 5 3}$ & $1.79 \mathrm{E}-11$ & $1.67 \mathrm{E}-11$ & $1.27 \mathrm{E}-12$ & $7.43 \mathrm{E}-15$ & $9.97 \mathrm{E}-22$ & $3.14 \mathrm{E}-23$ & $1.07 \mathrm{E}-32$ \\
$\mathbf{2 5 5}$ & $6.98 \mathrm{E}-12$ & $5.75 \mathrm{E}-12$ & $1.21 \mathrm{E}-12$ & $1.94 \mathrm{E}-14$ & $4.49 \mathrm{E}-22$ & $7.69 \mathrm{E}-24$ & $5.97 \mathrm{E}-33$ \\
$\mathbf{3 6 7}$ & $2.64 \mathrm{E}-11$ & $8.21 \mathrm{E}-12$ & $1.59 \mathrm{E}-11$ & $2.36 \mathrm{E}-12$ & $1.19 \mathrm{E}-20$ & $1.21 \mathrm{E}-21$ & $5.46 \mathrm{E}-30$ \\
$\mathbf{4 8 8}$ & $1.15 \mathrm{E}-11$ & $7.57 \mathrm{E}-12$ & $3.75 \mathrm{E}-12$ & $1.50 \mathrm{E}-13$ & $2.97 \mathrm{E}-21$ & $4.82 \mathrm{E}-22$ & $1.72 \mathrm{E}-30$ \\
\hline
\end{tabular}

Table A2 (Cont.)

\begin{tabular}{|c|c|c|c|c|c|c|c|}
\hline Station & $\begin{array}{c}\mathrm{HgBrCl} \\
\mathrm{mol} / \mathrm{L}\end{array}$ & $\begin{array}{l}\mathrm{HgCl}_{3-} \\
\mathrm{mol} / \mathrm{L}\end{array}$ & $\begin{array}{c}\mathrm{HgClOH} \\
\mathrm{mol} / \mathrm{L}\end{array}$ & $\underset{\mathrm{Hgl}(\mathrm{OH})_{2}}{\mathrm{~mol}}$ & $\begin{array}{l}\mathrm{HgBr}_{2} \\
\mathrm{~mol} / \mathrm{L}\end{array}$ & $\underset{\mathrm{HgBrOH}}{\mathrm{mol} / \mathrm{L}}$ & $\begin{array}{l}\mathrm{HgCl}_{4}{ }^{2-} \\
\mathrm{mol} / \mathrm{L}\end{array}$ \\
\hline 131 & $3.59 \mathrm{E}-33$ & $1.83 \mathrm{E}-35$ & $3.44 \mathrm{E}-32$ & $1.08 \mathrm{E}-30$ & $3.44 \mathrm{E}-34$ & $1.02 \mathrm{E}-32$ & $3.47 \mathrm{E}-38$ \\
\hline 146 & 4.07E-32 & $1.45 \mathrm{E}-33$ & $2.09 \mathrm{E}-31$ & $1.66 \mathrm{E}-30$ & $1.13 \mathrm{E}-33$ & $2.63 \mathrm{E}-32$ & $7.46 \mathrm{E}-36$ \\
\hline 150 & $1.15 \mathrm{E}-32$ & 4.61E-34 & $9.71 \mathrm{E}-32$ & $1.17 \mathrm{E}-30$ & $3.10 \mathrm{E}-34$ & $1.14 \mathrm{E}-32$ & $2.52 \mathrm{E}-36$ \\
\hline 155 & 4.69E-34 & $9.19 \mathrm{E}-36$ & $3.94 \mathrm{E}-33$ & $8.86 \mathrm{E}-32$ & $1.29 \mathrm{E}-35$ & $7.56 \mathrm{E}-34$ & $3.49 \mathrm{E}-38$ \\
\hline 172 & 4.22E-31 & $8.81 \mathrm{E}-34$ & 3.57E-31 & $2.60 \mathrm{E}-30$ & $3.33 \mathrm{E}-32$ & $2.15 \mathrm{E}-31$ & $1.06 \mathrm{E}-36$ \\
\hline 189 & $1.09 \mathrm{E}-31$ & $1.43 \mathrm{E}-33$ & $4.21 \mathrm{E}-31$ & 3.63E-30 & $5.89 \mathrm{E}-33$ & $8.18 \mathrm{E}-32$ & $4.40 \mathrm{E}-36$ \\
\hline 205 & $9.70 \mathrm{E}-32$ & $1.75 \mathrm{E}-33$ & $2.24 \mathrm{E}-31$ & $1.05 \mathrm{E}-30$ & $4.13 \mathrm{E}-33$ & $3.82 \mathrm{E}-32$ & $6.36 \mathrm{E}-36$ \\
\hline 211 & $2.28 \mathrm{E}-31$ & $8.29 \mathrm{E}-33$ & 7.01E-31 & $3.42 \mathrm{E}-30$ & $8.71 \mathrm{E}-33$ & $9.66 \mathrm{E}-32$ & $5.23 \mathrm{E}-35$ \\
\hline 216 & 7.31E-31 & 4.79E-32 & $1.16 \mathrm{E}-30$ & $2.56 \mathrm{E}-30$ & $2.69 \mathrm{E}-32$ & $1.43 \mathrm{E}-31$ & $5.00 \mathrm{E}-34$ \\
\hline 228 & $3.15 \mathrm{E}-31$ & $1.09 \mathrm{E}-32$ & $5.74 \mathrm{E}-31$ & $1.81 \mathrm{E}-30$ & $1.23 \mathrm{E}-32$ & 8.49E-32 & $6.99 \mathrm{E}-35$ \\
\hline 231 & $4.08 \mathrm{E}-31$ & $2.12 \mathrm{E}-32$ & 7.87E-31 & $2.25 \mathrm{E}-30$ & $1.60 \mathrm{E}-32$ & $1.03 \mathrm{E}-31$ & $1.87 \mathrm{E}-34$ \\
\hline 234 & $4.95 \mathrm{E}-31$ & $2.33 \mathrm{E}-32$ & $5.24 \mathrm{E}-31$ & $1.61 \mathrm{E}-30$ & $2.79 \mathrm{E}-32$ & $1.26 \mathrm{E}-31$ & $3.32 \mathrm{E}-34$ \\
\hline 236 & $9.12 \mathrm{E}-31$ & $1.29 \mathrm{E}-31$ & $9.77 \mathrm{E}-31$ & $1.29 \mathrm{E}-30$ & $3.27 \mathrm{E}-32$ & $1.09 \mathrm{E}-31$ & $2.78 \mathrm{E}-33$ \\
\hline 239 & $1.58 \mathrm{E}-28$ & $5.15 \mathrm{E}-31$ & 2.87E-29 & $2.36 \mathrm{E}-29$ & $1.68 \mathrm{E}-29$ & $1.12 \mathrm{E}-29$ & $7.79 \mathrm{E}-34$ \\
\hline 249 & 2.93E-31 & $2.15 \mathrm{E}-33$ & $3.42 \mathrm{E}-31$ & $1.17 \mathrm{E}-30$ & $2.15 \mathrm{E}-32$ & $8.76 \mathrm{E}-32$ & $4.91 \mathrm{E}-36$ \\
\hline 251 & $3.02 \mathrm{E}-32$ & $1.28 \mathrm{E}-33$ & $1.71 \mathrm{E}-31$ & $1.36 \mathrm{E}-30$ & 7.77E-34 & $1.96 \mathrm{E}-32$ & $7.21 \mathrm{E}-36$ \\
\hline 252 & $9.67 \mathrm{E}-32$ & $2.65 \mathrm{E}-33$ & 3.77E-31 & $2.23 \mathrm{E}-30$ & $3.66 \mathrm{E}-33$ & $5.01 \mathrm{E}-32$ & $1.20 \mathrm{E}-35$ \\
\hline 253 & $6.84 \mathrm{E}-33$ & $1.03 \mathrm{E}-34$ & $9.97 \mathrm{E}-32$ & $3.50 \mathrm{E}-30$ & $2.86 \mathrm{E}-34$ & $1.94 \mathrm{E}-32$ & $3.41 \mathrm{E}-37$ \\
\hline 255 & $3.93 \mathrm{E}-33$ & $5.65 \mathrm{E}-35$ & $2.21 \mathrm{E}-32$ & 2.71E-31 & $1.96 \mathrm{E}-34$ & $4.14 \mathrm{E}-33$ & $1.83 \mathrm{E}-37$ \\
\hline 367 & $2.65 \mathrm{E}-30$ & 7.01E-32 & $1.86 \mathrm{E}-30$ & $1.56 \mathrm{E}-30$ & $1.40 \mathrm{E}-31$ & $2.21 \mathrm{E}-31$ & $3.11 \mathrm{E}-34$ \\
\hline 488 & $1.11 \mathrm{E}-30$ & 4.64E-32 & $9.17 \mathrm{E}-31$ & $1.54 \mathrm{E}-30$ & $5.80 \mathrm{E}-32$ & $1.64 \mathrm{E}-31$ & $4.54 \mathrm{E}-34$ \\
\hline
\end{tabular}


Table A2 (Cont.)

\begin{tabular}{|c|c|c|c|c|c|c|c|}
\hline Station & $\begin{array}{l}\mathrm{HgBr}_{3}^{-} \\
\mathrm{mol} / \mathrm{L}\end{array}$ & $\begin{array}{l}\mathrm{HgBr}^{+} \\
\mathrm{mol} / \mathrm{L}\end{array}$ & $\begin{array}{l}\mathrm{HgCl}^{+} \\
\mathrm{mol} / \mathrm{L}\end{array}$ & $\begin{array}{c}\mathrm{HgOH}^{+} \\
\mathrm{mol} / \mathrm{L}\end{array}$ & $\begin{array}{c}\mathrm{HgBr}_{4}{ }^{2-} \\
\mathrm{mol} / \mathrm{L}\end{array}$ & $\underset{\mathrm{mol} / \mathrm{L}}{\mathrm{Hg}(\mathrm{OH})_{3}}$ & $\begin{array}{c}\mathrm{Hg}^{2+} \\
\mathrm{mol} / \mathrm{L}\end{array}$ \\
\hline 131 & $4.70 \mathrm{E}-38$ & $3.51 \mathrm{E}-36$ & $2.05 \mathrm{E}-36$ & $1.07 \mathrm{E}-35$ & $0.00 \mathrm{E}+00$ & $5.60 \mathrm{E}-38$ & $6.28 \mathrm{E}-40$ \\
\hline 146 & $2.02 \mathrm{E}-37$ & $1.56 \mathrm{E}-35$ & $2.40 \mathrm{E}-35$ & 2.84E-35 & $0.00 \mathrm{E}+00$ & $5.14 \mathrm{E}-38$ & $2.68 \mathrm{E}-39$ \\
\hline 150 & $5.41 \mathrm{E}-38$ & $4.16 \mathrm{E}-36$ & $6.79 \mathrm{E}-36$ & $1.23 \mathrm{E}-35$ & $0.00 \mathrm{E}+00$ & $5.86 \mathrm{E}-38$ & $7.24 \mathrm{E}-40$ \\
\hline 155 & $3.14 \mathrm{E}-39$ & $2.40 \mathrm{E}-37$ & $2.74 \mathrm{E}-37$ & $8.11 \mathrm{E}-37$ & $0.00 \mathrm{E}+00$ & $5.10 \mathrm{E}-39$ & $0.00 \mathrm{E}+00$ \\
\hline 172 & $8.65 \mathrm{E}-36$ & $6.41 \mathrm{E}-34$ & $2.39 \mathrm{E}-34$ & $2.24 \mathrm{E}-34$ & $2.13 \mathrm{E}-40$ & $1.54 \mathrm{E}-38$ & $8.96 \mathrm{E}-38$ \\
\hline 189 & 8.97E-37 & $6.80 \mathrm{E}-35$ & $6.35 \mathrm{E}-35$ & $8.71 \mathrm{E}-35$ & $0.00 \mathrm{E}+00$ & $7.92 \mathrm{E}-38$ & $1.21 \mathrm{E}-38$ \\
\hline 205 & $6.77 \mathrm{E}-37$ & $5.16 \mathrm{E}-35$ & $5.66 \mathrm{E}-35$ & $4.09 \mathrm{E}-35$ & $0.00 \mathrm{E}+00$ & $1.41 \mathrm{E}-38$ & $9.03 \mathrm{E}-39$ \\
\hline 211 & $1.86 \mathrm{E}-36$ & $7.45 \mathrm{E}-35$ & $9.81 \mathrm{E}-35$ & 7.62E-35 & $0.00 \mathrm{E}+00$ & $8.32 \mathrm{E}-38$ & $1.02 \mathrm{E}-38$ \\
\hline 216 & $8.14 \mathrm{E}-36$ & $1.46 \mathrm{E}-34$ & $2.10 \mathrm{E}-34$ & $7.54 \mathrm{E}-35$ & 4.47E-40 & $4.74 \mathrm{E}-38$ & $1.36 \mathrm{E}-38$ \\
\hline 228 & $2.91 \mathrm{E}-36$ & $1.01 \mathrm{E}-34$ & $1.26 \mathrm{E}-34$ & $6.25 \mathrm{E}-35$ & $1.14 \mathrm{E}-40$ & $2.84 \mathrm{E}-38$ & $1.27 \mathrm{E}-38$ \\
\hline 231 & $4.40 \mathrm{E}-36$ & $9.61 \mathrm{E}-35$ & $1.30 \mathrm{E}-34$ & $6.03 \mathrm{E}-35$ & $2.19 \mathrm{E}-40$ & $4.56 \mathrm{E}-38$ & $9.93 \mathrm{E}-39$ \\
\hline 234 & $2.39 \mathrm{E}-35$ & $7.90 \mathrm{E}-35$ & $6.26 \mathrm{E}-35$ & $2.92 \mathrm{E}-35$ & $3.28 \mathrm{E}-39$ & $5.05 \mathrm{E}-38$ & $3.19 \mathrm{E}-39$ \\
\hline 236 & $1.75 \mathrm{E}-35$ & $9.43 \mathrm{E}-35$ & $1.47 \mathrm{E}-34$ & $3.22 \mathrm{E}-35$ & $1.86 \mathrm{E}-39$ & $2.92 \mathrm{E}-38$ & $5.20 \mathrm{E}-39$ \\
\hline 239 & $2.59 \mathrm{E}-33$ & $1.92 \mathrm{E}-31$ & $8.98 \mathrm{E}-32$ & $1.17 \mathrm{E}-32$ & $6.39 \mathrm{E}-38$ & $2.43 \mathrm{E}-38$ & $3.27 \mathrm{E}-35$ \\
\hline 249 & $3.20 \mathrm{E}-36$ & $2.40 \mathrm{E}-34$ & $1.68 \mathrm{E}-34$ & $9.23 \mathrm{E}-35$ & $0.00 \mathrm{E}+00$ & $7.65 \mathrm{E}-39$ & $4.21 \mathrm{E}-38$ \\
\hline 251 & $1.38 \mathrm{E}-37$ & $1.06 \mathrm{E}-35$ & $1.79 \mathrm{E}-35$ & $2.13 \mathrm{E}-35$ & $0.00 \mathrm{E}+00$ & $4.64 \mathrm{E}-38$ & $1.85 \mathrm{E}-39$ \\
\hline 252 & $5.47 \mathrm{E}-37$ & $4.18 \mathrm{E}-35$ & $5.66 \mathrm{E}-35$ & $5.39 \mathrm{E}-35$ & $0.00 \mathrm{E}+00$ & $4.89 \mathrm{E}-38$ & $7.61 \mathrm{E}-39$ \\
\hline 253 & $5.22 \mathrm{E}-38$ & $3.95 \mathrm{E}-36$ & $3.96 \mathrm{E}-36$ & $2.06 \mathrm{E}-35$ & $0.00 \mathrm{E}+00$ & $3.10 \mathrm{E}-37$ & $6.54 \mathrm{E}-40$ \\
\hline 255 & $3.07 \mathrm{E}-38$ & $2.32 \mathrm{E}-36$ & $2.28 \mathrm{E}-36$ & $4.40 \mathrm{E}-36$ & $0.00 \mathrm{E}+00$ & $8.74 \mathrm{E}-39$ & 4.07E-40 \\
\hline 367 & $1.52 \mathrm{E}-35$ & $1.16 \mathrm{E}-33$ & $1.55 \mathrm{E}-33$ & $2.38 \mathrm{E}-34$ & $3.87 \mathrm{E}-40$ & $5.43 \mathrm{E}-39$ & $2.38 \mathrm{E}-37$ \\
\hline 488 & $2.38 \mathrm{E}-35$ & $2.43 \mathrm{E}-34$ & $2.43 \mathrm{E}-34$ & $6.59 \mathrm{E}-35$ & $1.77 \mathrm{E}-39$ & $1.98 \mathrm{E}-38$ & $1.75 \mathrm{E}-38$ \\
\hline
\end{tabular}

Table A3 Concentrations of $\mathrm{Hg}$ species in surface water of Everglades in spring 2005 ([S $\left.\mathrm{S}^{2-}\right]=$ $3.2 \times 10^{-7} \mathrm{mg} / \mathrm{L}$ )

\begin{tabular}{|c|c|c|c|c|c|c|c|}
\hline Station & $\mathrm{Hg} \mathrm{mol} / \mathrm{L}$ & $\begin{array}{c}\mathbf{R S H g}^{(\mathbf{n}-1)-} \\
\mathrm{mol} / \mathrm{L}\end{array}$ & $\begin{array}{l}\mathbf{H g S}_{2}{ }^{2-} \\
\mathrm{mol} / \mathrm{L}\end{array}$ & $\begin{array}{c}\text { HgHS2- } \\
\mathrm{mol} / \mathrm{L}\end{array}$ & $\begin{array}{c}\mathrm{Hg}(\mathrm{HS}) 2 \\
\mathrm{~mol} / \mathrm{L}\end{array}$ & $\begin{array}{c}\mathrm{HgHSOH} \\
\mathrm{mol} / \mathrm{L}\end{array}$ & $\begin{array}{l}\mathrm{HgCl}_{2} \\
\mathrm{~mol} / \mathrm{L}\end{array}$ \\
\hline 28 & $3.34 \mathrm{E}-11$ & $2.97 \mathrm{E}-11$ & $2.28 \mathrm{E}-12$ & $1.39 \mathrm{E}-12$ & $6.56 \mathrm{E}-14$ & $3.78 \mathrm{E}-16$ & $1.99 \mathrm{E}-20$ \\
\hline 30 & $1.50 \mathrm{E}-11$ & $1.10 \mathrm{E}-11$ & $2.89 \mathrm{E}-12$ & $1.07 \mathrm{E}-12$ & $3.03 \mathrm{E}-14$ & $3.23 \mathrm{E}-16$ & $1.23 \mathrm{E}-20$ \\
\hline 31 & $1.10 \mathrm{E}-11$ & 7.43E-12 & $2.54 \mathrm{E}-12$ & $9.71 \mathrm{E}-13$ & $2.88 \mathrm{E}-14$ & $2.08 \mathrm{E}-16$ & $7.97 \mathrm{E}-21$ \\
\hline 33 & $1.20 \mathrm{E}-11$ & $7.98 \mathrm{E}-12$ & $3.28 \mathrm{E}-12$ & $7.02 \mathrm{E}-13$ & $1.17 \mathrm{E}-14$ & $1.90 \mathrm{E}-16$ & $5.02 \mathrm{E}-21$ \\
\hline 37 & $1.25 \mathrm{E}-11$ & 8.37E-12 & $3.28 \mathrm{E}-12$ & $7.99 \mathrm{E}-13$ & $1.50 \mathrm{E}-14$ & $2.51 \mathrm{E}-16$ & $4.31 \mathrm{E}-21$ \\
\hline 43 & $1.35 \mathrm{E}-11$ & $9.75 \mathrm{E}-12$ & $2.37 \mathrm{E}-12$ & $1.28 \mathrm{E}-12$ & $5.30 \mathrm{E}-14$ & $3.55 \mathrm{E}-16$ & $8.20 \mathrm{E}-21$ \\
\hline 45 & $1.05 \mathrm{E}-11$ & $7.01 \mathrm{E}-12$ & $2.12 \mathrm{E}-12$ & $1.28 \mathrm{E}-12$ & $5.91 \mathrm{E}-14$ & $2.83 \mathrm{E}-16$ & $9.19 \mathrm{E}-21$ \\
\hline 46 & $9.47 \mathrm{E}-12$ & $6.65 \mathrm{E}-12$ & $1.39 \mathrm{E}-12$ & $1.33 \mathrm{E}-12$ & $9.76 \mathrm{E}-14$ & $2.68 \mathrm{E}-16$ & $1.16 \mathrm{E}-20$ \\
\hline 47 & $1.35 \mathrm{E}-11$ & $9.63 \mathrm{E}-12$ & $2.59 \mathrm{E}-12$ & $1.19 \mathrm{E}-12$ & $4.19 \mathrm{E}-14$ & $3.40 \mathrm{E}-16$ & $8.34 \mathrm{E}-21$ \\
\hline 49 & $1.20 \mathrm{E}-11$ & $8.31 \mathrm{E}-12$ & $2.57 \mathrm{E}-12$ & $1.06 \mathrm{E}-12$ & $3.36 \mathrm{E}-14$ & $2.43 \mathrm{E}-16$ & $1.04 \mathrm{E}-20$ \\
\hline 51 & $7.48 \mathrm{E}-12$ & $4.26 \mathrm{E}-12$ & $2.07 \mathrm{E}-12$ & $1.10 \mathrm{E}-12$ & $4.44 \mathrm{E}-14$ & $2.17 \mathrm{E}-16$ & $3.51 \mathrm{E}-21$ \\
\hline 52 & $1.10 \mathrm{E}-11$ & $7.82 \mathrm{E}-12$ & $1.62 \mathrm{E}-12$ & $1.44 \mathrm{E}-12$ & $9.66 \mathrm{E}-14$ & $3.48 \mathrm{E}-16$ & $6.90 \mathrm{E}-21$ \\
\hline
\end{tabular}




\begin{tabular}{|c|c|c|c|c|c|c|c|}
\hline 53 & $1.10 \mathrm{E}-11$ & $6.97 \mathrm{E}-12$ & $3.21 \mathrm{E}-12$ & $7.74 \mathrm{E}-13$ & $1.42 \mathrm{E}-14$ & $2.14 \mathrm{E}-16$ & $2.93 \mathrm{E}-21$ \\
\hline 54 & $5.98 \mathrm{E}-12$ & $2.81 \mathrm{E}-12$ & $2.11 \mathrm{E}-12$ & $1.03 \mathrm{E}-12$ & $3.82 \mathrm{E}-14$ & $1.89 \mathrm{E}-16$ & $1.27 \mathrm{E}-21$ \\
\hline 55 & $9.47 \mathrm{E}-12$ & $6.87 \mathrm{E}-12$ & $1.15 \mathrm{E}-12$ & $1.33 \mathrm{E}-12$ & $1.18 \mathrm{E}-13$ & $2.96 \mathrm{E}-16$ & $1.01 \mathrm{E}-20$ \\
\hline 56 & $1.50 \mathrm{E}-11$ & $1.07 \mathrm{E}-11$ & $3.67 \mathrm{E}-12$ & $6.15 \mathrm{E}-13$ & $7.96 \mathrm{E}-15$ & $2.35 \mathrm{E}-16$ & $7.22 \mathrm{E}-21$ \\
\hline 57 & $1.75 \mathrm{E}-11$ & $1.34 \mathrm{E}-11$ & $3.07 \mathrm{E}-12$ & $9.40 \mathrm{E}-13$ & $2.22 \mathrm{E}-14$ & $2.86 \mathrm{E}-16$ & $1.10 \mathrm{E}-20$ \\
\hline 59 & $9.47 \mathrm{E}-12$ & $5.98 \mathrm{E}-12$ & $2.27 \mathrm{E}-12$ & $1.17 \mathrm{E}-12$ & 4.60E-14 & $2.73 \mathrm{E}-16$ & $6.16 \mathrm{E}-21$ \\
\hline 61 & $7.48 \mathrm{E}-12$ & $3.26 \mathrm{E}-12$ & $3.78 \mathrm{E}-12$ & 4.34E-13 & $3.76 \mathrm{E}-15$ & $1.49 \mathrm{E}-16$ & $4.72 \mathrm{E}-22$ \\
\hline 62 & $9.97 \mathrm{E}-12$ & $6.46 \mathrm{E}-12$ & $2.29 \mathrm{E}-12$ & $1.18 \mathrm{E}-12$ & 4.65E-14 & $2.62 \mathrm{E}-16$ & $5.37 \mathrm{E}-21$ \\
\hline 63 & $1.30 \mathrm{E}-11$ & $8.84 \mathrm{E}-12$ & $3.35 \mathrm{E}-12$ & $7.61 \mathrm{E}-13$ & $1.33 \mathrm{E}-14$ & $2.38 \mathrm{E}-16$ & $4.66 \mathrm{E}-21$ \\
\hline 66 & $5.48 \mathrm{E}-12$ & $2.33 \mathrm{E}-12$ & $2.28 \mathrm{E}-12$ & $8.48 \mathrm{E}-13$ & $2.45 \mathrm{E}-14$ & $1.49 \mathrm{E}-16$ & 4.42E-21 \\
\hline 67 & $6.48 \mathrm{E}-12$ & $2.60 \mathrm{E}-12$ & $3.32 \mathrm{E}-12$ & $5.53 \mathrm{E}-13$ & $7.03 \mathrm{E}-15$ & $1.32 \mathrm{E}-16$ & $1.13 \mathrm{E}-21$ \\
\hline 68 & $7.48 \mathrm{E}-12$ & $4.17 \mathrm{E}-12$ & $2.35 \mathrm{E}-12$ & $9.29 \mathrm{E}-13$ & $2.83 \mathrm{E}-14$ & $1.77 \mathrm{E}-16$ & $4.22 \mathrm{E}-21$ \\
\hline 69 & $6.98 \mathrm{E}-12$ & $3.21 \mathrm{E}-12$ & $2.89 \mathrm{E}-12$ & $8.64 \mathrm{E}-13$ & $1.96 \mathrm{E}-14$ & $1.99 \mathrm{E}-16$ & $1.62 \mathrm{E}-21$ \\
\hline 70 & $1.50 \mathrm{E}-11$ & $1.13 \mathrm{E}-11$ & $2.13 \mathrm{E}-12$ & $1.46 \mathrm{E}-12$ & $7.58 \mathrm{E}-14$ & $4.34 \mathrm{E}-16$ & $6.67 \mathrm{E}-21$ \\
\hline 73 & $6.48 \mathrm{E}-12$ & $2.91 \mathrm{E}-12$ & $2.95 \mathrm{E}-12$ & $6.15 \mathrm{E}-13$ & $9.99 \mathrm{E}-15$ & $1.17 \mathrm{E}-16$ & $3.21 \mathrm{E}-21$ \\
\hline 75 & $1.25 \mathrm{E}-11$ & $8.59 \mathrm{E}-12$ & $2.66 \mathrm{E}-12$ & $1.17 \mathrm{E}-12$ & $3.93 \mathrm{E}-14$ & $3.39 \mathrm{E}-16$ & $6.67 \mathrm{E}-21$ \\
\hline 77 & $7.48 \mathrm{E}-12$ & 4.13E-12 & $2.58 \mathrm{E}-12$ & $7.59 \mathrm{E}-13$ & $1.74 \mathrm{E}-14$ & $1.34 \mathrm{E}-16$ & $2.49 \mathrm{E}-21$ \\
\hline 80 & $1.05 \mathrm{E}-11$ & $6.49 \mathrm{E}-12$ & $3.32 \mathrm{E}-12$ & $6.47 \mathrm{E}-13$ & $9.80 \mathrm{E}-15$ & $1.71 \mathrm{E}-16$ & $4.76 \mathrm{E}-21$ \\
\hline 81 & $9.97 \mathrm{E}-12$ & $6.14 \mathrm{E}-12$ & $2.98 \mathrm{E}-12$ & $8.29 \mathrm{E}-13$ & $1.78 \mathrm{E}-14$ & $2.07 \mathrm{E}-16$ & $6.33 \mathrm{E}-21$ \\
\hline 82 & $9.97 \mathrm{E}-12$ & $6.35 \mathrm{E}-12$ & $2.64 \mathrm{E}-12$ & $9.57 \mathrm{E}-13$ & $2.70 \mathrm{E}-14$ & $2.15 \mathrm{E}-16$ & 8.97E-21 \\
\hline 83 & $1.30 \mathrm{E}-11$ & $9.22 \mathrm{E}-12$ & $2.47 \mathrm{E}-12$ & $1.23 \mathrm{E}-12$ & $4.72 \mathrm{E}-14$ & $3.37 \mathrm{E}-16$ & $1.07 \mathrm{E}-20$ \\
\hline 84 & $1.05 \mathrm{E}-11$ & $6.20 \mathrm{E}-12$ & 4.04E-12 & $2.23 \mathrm{E}-13$ & $9.69 \mathrm{E}-16$ & $9.03 \mathrm{E}-17$ & $2.02 \mathrm{E}-21$ \\
\hline 85 & $1.05 \mathrm{E}-11$ & $6.94 \mathrm{E}-12$ & $2.26 \mathrm{E}-12$ & $1.22 \mathrm{E}-12$ & $5.10 \mathrm{E}-14$ & $2.98 \mathrm{E}-16$ & $1.49 \mathrm{E}-20$ \\
\hline 88 & $9.47 \mathrm{E}-12$ & $5.61 \mathrm{E}-12$ & $3.04 \mathrm{E}-12$ & $8.11 \mathrm{E}-13$ & $1.67 \mathrm{E}-14$ & $2.01 \mathrm{E}-16$ & $4.38 \mathrm{E}-21$ \\
\hline 89 & $1.50 \mathrm{E}-11$ & $1.07 \mathrm{E}-11$ & $3.83 \mathrm{E}-12$ & $4.39 \mathrm{E}-13$ & $3.98 \mathrm{E}-15$ & $1.63 \mathrm{E}-16$ & $6.42 \mathrm{E}-21$ \\
\hline 90 & $9.47 \mathrm{E}-12$ & $5.91 \mathrm{E}-12$ & $2.67 \mathrm{E}-12$ & $8.66 \mathrm{E}-13$ & $2.18 \mathrm{E}-14$ & $1.82 \mathrm{E}-16$ & $6.31 \mathrm{E}-21$ \\
\hline 91 & $1.60 \mathrm{E}-11$ & $1.14 \mathrm{E}-11$ & $4.26 \mathrm{E}-12$ & $2.48 \mathrm{E}-13$ & $1.12 \mathrm{E}-15$ & $1.51 \mathrm{E}-16$ & $1.76 \mathrm{E}-21$ \\
\hline 93 & $1.20 \mathrm{E}-11$ & $7.75 \mathrm{E}-12$ & $3.68 \mathrm{E}-12$ & $5.35 \mathrm{E}-13$ & $6.03 \mathrm{E}-15$ & $1.82 \mathrm{E}-16$ & $3.30 \mathrm{E}-21$ \\
\hline 94 & $1.15 \mathrm{E}-11$ & $7.17 \mathrm{E}-12$ & $3.90 \mathrm{E}-12$ & $3.97 \mathrm{E}-13$ & $3.11 \mathrm{E}-15$ & $1.55 \mathrm{E}-16$ & $1.63 \mathrm{E}-21$ \\
\hline 95 & $1.10 \mathrm{E}-11$ & $7.48 \mathrm{E}-12$ & $2.29 \mathrm{E}-12$ & $1.16 \mathrm{E}-12$ & $4.52 \mathrm{E}-14$ & $2.63 \mathrm{E}-16$ & $1.22 \mathrm{E}-20$ \\
\hline 99 & $1.20 \mathrm{E}-11$ & 7.94E-12 & $3.34 \mathrm{E}-12$ & $6.73 \mathrm{E}-13$ & $1.05 \mathrm{E}-14$ & $1.86 \mathrm{E}-16$ & $4.04 \mathrm{E}-21$ \\
\hline 101 & $1.84 \mathrm{E}-11$ & $1.39 \mathrm{E}-11$ & $4.21 \mathrm{E}-12$ & $3.33 \mathrm{E}-13$ & $2.02 \mathrm{E}-15$ & $2.09 \mathrm{E}-16$ & $1.45 \mathrm{E}-21$ \\
\hline 105 & $8.48 \mathrm{E}-12$ & $4.88 \mathrm{E}-12$ & $2.84 \mathrm{E}-12$ & $7.38 \mathrm{E}-13$ & $1.48 \mathrm{E}-14$ & $1.50 \mathrm{E}-16$ & $2.98 \mathrm{E}-21$ \\
\hline 106 & $1.20 \mathrm{E}-11$ & $7.76 \mathrm{E}-12$ & $3.65 \mathrm{E}-12$ & $5.51 \mathrm{E}-13$ & $6.39 \mathrm{E}-15$ & $1.86 \mathrm{E}-16$ & $1.40 \mathrm{E}-21$ \\
\hline 107 & $2.34 \mathrm{E}-11$ & $1.90 \mathrm{E}-11$ & 4.19E-12 & $2.67 \mathrm{E}-13$ & $1.38 \mathrm{E}-15$ & $1.45 \mathrm{E}-16$ & $1.00 \mathrm{E}-20$ \\
\hline 114 & $1.40 \mathrm{E}-11$ & $1.35 \mathrm{E}-11$ & $1.73 \mathrm{E}-14$ & $2.09 \mathrm{E}-13$ & $1.90 \mathrm{E}-13$ & $1.53 \mathrm{E}-16$ & $6.26 \mathrm{E}-20$ \\
\hline 119 & $1.30 \mathrm{E}-11$ & $1.21 \mathrm{E}-11$ & $9.62 \mathrm{E}-14$ & $5.52 \mathrm{E}-13$ & $2.39 \mathrm{E}-13$ & $2.40 \mathrm{E}-16$ & $5.86 \mathrm{E}-20$ \\
\hline 351 & $1.50 \mathrm{E}-11$ & $1.13 \mathrm{E}-11$ & $2.51 \mathrm{E}-12$ & $1.12 \mathrm{E}-12$ & $3.87 \mathrm{E}-14$ & $2.84 \mathrm{E}-16$ & $1.70 \mathrm{E}-20$ \\
\hline 365 & $7.98 \mathrm{E}-12$ & $4.33 \mathrm{E}-12$ & $2.78 \mathrm{E}-12$ & $8.50 \mathrm{E}-13$ & $2.01 \mathrm{E}-14$ & $1.81 \mathrm{E}-16$ & $2.99 \mathrm{E}-21$ \\
\hline
\end{tabular}


Table A3 (Cont.)

\begin{tabular}{|c|c|c|c|c|c|c|c|}
\hline Station & $\begin{array}{c}\mathrm{HgBrCl} \\
\mathrm{mol} / \mathrm{L}\end{array}$ & $\begin{array}{l}\mathrm{HgCl}_{3-} \\
\mathrm{mol} / \mathrm{L}\end{array}$ & $\begin{array}{c}\mathrm{HgClOH} \\
\mathrm{mol} / \mathrm{L}\end{array}$ & $\begin{array}{c}\mathrm{Hg}(\mathrm{OH})_{2} \\
\mathrm{~mol} / \mathrm{L}\end{array}$ & $\begin{array}{l}\mathrm{HgBr}_{2} \\
\mathrm{~mol} / \mathrm{L}\end{array}$ & $\begin{array}{c}\mathrm{HgBrOH} \\
\mathrm{mol} / \mathrm{L}\end{array}$ & $\begin{array}{c}\mathrm{HgCl}_{4}^{2-} \\
\mathrm{mol} / \mathrm{L}\end{array}$ \\
\hline 28 & $4.92 \mathrm{E}-20$ & $2.55 \mathrm{E}-22$ & $1.15 \mathrm{E}-20$ & $5.69 \mathrm{E}-20$ & $2.87 \mathrm{E}-21$ & $1.30 \mathrm{E}-20$ & $1.13 \mathrm{E}-24$ \\
\hline 30 & $9.77 \mathrm{E}-21$ & $1.63 \mathrm{E}-22$ & $1.74 \mathrm{E}-20$ & $9.01 \mathrm{E}-20$ & $5.22 \mathrm{E}-22$ & $4.14 \mathrm{E}-21$ & $7.47 \mathrm{E}-25$ \\
\hline 31 & $6.06 \mathrm{E}-21$ & $1.24 \mathrm{E}-22$ & $9.60 \mathrm{E}-21$ & $3.93 \mathrm{E}-20$ & $3.38 \mathrm{E}-22$ & $2.10 \mathrm{E}-21$ & $6.69 \mathrm{E}-25$ \\
\hline 33 & 3.47E-21 & 7.69E-23 & $9.21 \mathrm{E}-21$ & $8.09 \mathrm{E}-20$ & $1.15 \mathrm{E}-22$ & $2.17 \mathrm{E}-21$ & $4.10 \mathrm{E}-25$ \\
\hline 37 & $1.46 \mathrm{E}-21$ & $4.66 \mathrm{E}-23$ & $1.34 \mathrm{E}-20$ & $1.10 \mathrm{E}-19$ & $4.96 \mathrm{E}-23$ & $1.15 \mathrm{E}-21$ & $1.74 \mathrm{E}-25$ \\
\hline 43 & 4.48E-21 & 7.39E-23 & $1.35 \mathrm{E}-20$ & $6.22 \mathrm{E}-20$ & $2.28 \mathrm{E}-22$ & $1.92 \mathrm{E}-21$ & $2.27 \mathrm{E}-25$ \\
\hline 45 & $5.08 \mathrm{E}-21$ & $1.03 \mathrm{E}-22$ & $6.25 \mathrm{E}-21$ & $3.56 \mathrm{E}-20$ & $6.78 \mathrm{E}-23$ & $1.56 \mathrm{E}-21$ & $4.00 \mathrm{E}-25$ \\
\hline 46 & $6.65 \mathrm{E}-21$ & $1.25 \mathrm{E}-22$ & $6.84 \mathrm{E}-21$ & $1.93 \mathrm{E}-20$ & $1.85 \mathrm{E}-22$ & $1.34 \mathrm{E}-21$ & $4.63 \mathrm{E}-25$ \\
\hline 47 & $5.24 \mathrm{E}-21$ & $8.27 \mathrm{E}-23$ & $1.45 \mathrm{E}-20$ & $7.22 \mathrm{E}-20$ & $2.97 \mathrm{E}-22$ & $2.41 \mathrm{E}-21$ & $2.80 \mathrm{E}-25$ \\
\hline 49 & $6.37 \mathrm{E}-21$ & $1.60 \mathrm{E}-22$ & $9.15 \mathrm{E}-21$ & $4.61 \mathrm{E}-20$ & $1.49 \mathrm{E}-22$ & $2.09 \mathrm{E}-21$ & $8.48 \mathrm{E}-25$ \\
\hline 51 & $2.43 \mathrm{E}-21$ & $3.17 \mathrm{E}-23$ & $5.88 \mathrm{E}-21$ & $2.78 \mathrm{E}-20$ & $1.54 \mathrm{E}-22$ & $1.07 \mathrm{E}-21$ & $9.72 \mathrm{E}-26$ \\
\hline 52 & $6.15 \mathrm{E}-21$ & $4.82 \mathrm{E}-23$ & $9.18 \mathrm{E}-21$ & $3.28 \mathrm{E}-20$ & $5.38 \mathrm{E}-22$ & $2.10 \mathrm{E}-21$ & $1.14 \mathrm{E}-25$ \\
\hline 53 & $1.76 \mathrm{E}-21$ & $3.04 \mathrm{E}-23$ & $6.93 \mathrm{E}-21$ & $8.45 \mathrm{E}-20$ & $4.64 \mathrm{E}-23$ & $1.48 \mathrm{E}-21$ & $1.08 \mathrm{E}-25$ \\
\hline 54 & $1.26 \mathrm{E}-21$ & 8.03E-24 & $2.97 \mathrm{E}-21$ & $2.45 \mathrm{E}-20$ & $8.66 \mathrm{E}-23$ & $8.61 \mathrm{E}-22$ & $1.71 \mathrm{E}-26$ \\
\hline 55 & 7.52E-21 & $8.39 \mathrm{E}-23$ & $9.14 \mathrm{E}-21$ & $1.94 \mathrm{E}-20$ & $6.53 \mathrm{E}-22$ & $1.63 \mathrm{E}-21$ & $2.38 \mathrm{E}-25$ \\
\hline 56 & 3.42E-21 & $1.14 \mathrm{E}-22$ & $2.15 \mathrm{E}-20$ & $1.81 \mathrm{E}-19$ & $1.48 \mathrm{E}-22$ & $2.68 \mathrm{E}-21$ & $6.22 \mathrm{E}-25$ \\
\hline 57 & 7.96E-21 & $1.61 \mathrm{E}-22$ & $1.71 \mathrm{E}-20$ & $9.66 \mathrm{E}-20$ & $3.86 \mathrm{E}-22$ & $3.68 \mathrm{E}-21$ & $8.16 \mathrm{E}-25$ \\
\hline 59 & 4.25E-21 & $6.10 \mathrm{E}-23$ & $1.03 \mathrm{E}-20$ & $4.24 \mathrm{E}-20$ & $3.24 \mathrm{E}-22$ & $1.74 \mathrm{E}-21$ & $2.07 \mathrm{E}-25$ \\
\hline 61 & 4.50E-22 & $3.08 \mathrm{E}-24$ & $3.28 \mathrm{E}-21$ & $1.54 \mathrm{E}-19$ & $1.34 \mathrm{E}-23$ & $1.27 \mathrm{E}-21$ & $6.81 \mathrm{E}-27$ \\
\hline 62 & 3.79E-21 & $5.20 \mathrm{E}-23$ & $5.91 \mathrm{E}-21$ & $3.86 \mathrm{E}-20$ & $9.90 \mathrm{E}-23$ & $1.59 \mathrm{E}-21$ & $1.72 \mathrm{E}-25$ \\
\hline 63 & $2.43 \mathrm{E}-21$ & $5.56 \mathrm{E}-23$ & $8.66 \mathrm{E}-21$ & $1.12 \mathrm{E}-19$ & $3.85 \mathrm{E}-23$ & $1.86 \mathrm{E}-21$ & $2.29 \mathrm{E}-25$ \\
\hline 66 & $2.69 \mathrm{E}-21$ & $6.77 \mathrm{E}-23$ & $7.82 \mathrm{E}-21$ & $2.36 \mathrm{E}-20$ & $2.82 \mathrm{E}-22$ & $9.72 \mathrm{E}-22$ & $3.61 \mathrm{E}-25$ \\
\hline 67 & $6.62 \mathrm{E}-22$ & 1.19E-23 & $4.56 \mathrm{E}-21$ & $6.50 \mathrm{E}-20$ & $2.73 \mathrm{E}-23$ & $7.86 \mathrm{E}-22$ & $4.33 \mathrm{E}-26$ \\
\hline 68 & $2.05 \mathrm{E}-21$ & $5.42 \mathrm{E}-23$ & $7.23 \mathrm{E}-21$ & $2.89 \mathrm{E}-20$ & $1.16 \mathrm{E}-22$ & 8.37E-22 & $2.40 \mathrm{E}-25$ \\
\hline 69 & $1.28 \mathrm{E}-21$ & $1.28 \mathrm{E}-23$ & $3.29 \mathrm{E}-21$ & $5.28 \mathrm{E}-20$ & $2.62 \mathrm{E}-23$ & $1.14 \mathrm{E}-21$ & $3.42 \mathrm{E}-26$ \\
\hline 70 & $6.58 \mathrm{E}-21$ & $4.21 \mathrm{E}-23$ & $1.32 \mathrm{E}-20$ & $6.49 \mathrm{E}-20$ & $7.03 \mathrm{E}-22$ & $3.21 \mathrm{E}-21$ & $9.04 \mathrm{E}-26$ \\
\hline 73 & $1.79 \mathrm{E}-21$ & $6.07 \mathrm{E}-23$ & $3.80 \mathrm{E}-21$ & $3.56 \mathrm{E}-20$ & $2.59 \mathrm{E}-23$ & $9.33 \mathrm{E}-22$ & $4.01 \mathrm{E}-25$ \\
\hline 75 & 4.61E-21 & $6.01 \mathrm{E}-23$ & $1.24 \mathrm{E}-20$ & $7.65 \mathrm{E}-20$ & $2.42 \mathrm{E}-22$ & $2.44 \mathrm{E}-21$ & $1.85 \mathrm{E}-25$ \\
\hline 77 & $1.15 \mathrm{E}-21$ & $3.37 \mathrm{E}-23$ & $4.40 \mathrm{E}-21$ & $2.71 \mathrm{E}-20$ & $3.75 \mathrm{E}-23$ & $5.91 \mathrm{E}-22$ & $1.59 \mathrm{E}-25$ \\
\hline 80 & $1.78 \mathrm{E}-21$ & $7.94 \mathrm{E}-23$ & $8.62 \mathrm{E}-21$ & $7.81 \mathrm{E}-20$ & $3.03 \mathrm{E}-23$ & $1.13 \mathrm{E}-21$ & $4.62 \mathrm{E}-25$ \\
\hline 81 & $2.87 \mathrm{E}-21$ & $9.55 \mathrm{E}-23$ & $1.24 \mathrm{E}-20$ & $6.30 \mathrm{E}-20$ & $1.34 \mathrm{E}-22$ & $1.41 \mathrm{E}-21$ & $4.99 \mathrm{E}-25$ \\
\hline 82 & $4.48 \mathrm{E}-21$ & $1.46 \mathrm{E}-22$ & $1.14 \mathrm{E}-20$ & $4.48 \mathrm{E}-20$ & $1.84 \mathrm{E}-22$ & $1.56 \mathrm{E}-21$ & $8.23 \mathrm{E}-25$ \\
\hline 83 & $6.05 \mathrm{E}-21$ & $1.18 \mathrm{E}-22$ & $1.46 \mathrm{E}-20$ & $6.27 \mathrm{E}-20$ & $2.73 \mathrm{E}-22$ & $2.29 \mathrm{E}-21$ & $4.50 \mathrm{E}-25$ \\
\hline 84 & 8.92E-22 & $4.54 \mathrm{E}-23$ & $8.18 \mathrm{E}-21$ & $2.20 \mathrm{E}-19$ & $1.27 \mathrm{E}-23$ & $1.46 \mathrm{E}-21$ & $3.61 \mathrm{E}-25$ \\
\hline 85 & $9.28 \mathrm{E}-21$ & $2.08 \mathrm{E}-22$ & $1.64 \mathrm{E}-20$ & $4.56 \mathrm{E}-20$ & $6.17 \mathrm{E}-22$ & $2.54 \mathrm{E}-21$ & $1.01 \mathrm{E}-24$ \\
\hline 88 & 2.09E-21 & $5.73 \mathrm{E}-23$ & $7.72 \mathrm{E}-21$ & $6.36 \mathrm{E}-20$ & $4.93 \mathrm{E}-23$ & $1.24 \mathrm{E}-21$ & $2.58 \mathrm{E}-25$ \\
\hline 89 & $2.96 \mathrm{E}-21$ & $1.39 \mathrm{E}-22$ & $1.24 \mathrm{E}-20$ & $1.75 \mathrm{E}-19$ & $3.90 \mathrm{E}-23$ & $2.41 \mathrm{E}-21$ & $1.06 \mathrm{E}-24$ \\
\hline 90 & $2.42 \mathrm{E}-21$ & $1.02 \mathrm{E}-22$ & $9.60 \mathrm{E}-21$ & $3.96 \mathrm{E}-20$ & $9.01 \mathrm{E}-23$ & $9.48 \mathrm{E}-22$ & $5.78 \mathrm{E}-25$ \\
\hline
\end{tabular}




\begin{tabular}{cccccccc}
\hline $\mathbf{9 1}$ & $8.40 \mathrm{E}-22$ & $2.30 \mathrm{E}-23$ & $1.09 \mathrm{E}-20$ & $5.36 \mathrm{E}-19$ & $1.04 \mathrm{E}-23$ & $2.29 \mathrm{E}-21$ & $1.04 \mathrm{E}-25$ \\
$\mathbf{9 3}$ & $1.50 \mathrm{E}-21$ & $4.53 \mathrm{E}-23$ & $7.66 \mathrm{E}-21$ & $1.44 \mathrm{E}-19$ & $1.70 \mathrm{E}-23$ & $1.54 \mathrm{E}-21$ & $2.16 \mathrm{E}-25$ \\
$\mathbf{9 4}$ & $8.67 \mathrm{E}-22$ & $1.91 \mathrm{E}-23$ & $5.48 \mathrm{E}-21$ & $2.03 \mathrm{E}-19$ & $7.90 \mathrm{E}-24$ & $1.51 \mathrm{E}-21$ & $7.71 \mathrm{E}-26$ \\
$\mathbf{9 5}$ & $5.26 \mathrm{E}-21$ & $1.76 \mathrm{E}-22$ & $1.24 \mathrm{E}-20$ & $4.01 \mathrm{E}-20$ & $1.82 \mathrm{E}-22$ & $1.49 \mathrm{E}-21$ & $8.77 \mathrm{E}-25$ \\
$\mathbf{9 9}$ & $1.77 \mathrm{E}-21$ & $5.73 \mathrm{E}-23$ & $7.72 \mathrm{E}-21$ & $8.65 \mathrm{E}-20$ & $2.91 \mathrm{E}-23$ & $1.28 \mathrm{E}-21$ & $2.81 \mathrm{E}-25$ \\
$\mathbf{1 0 1}$ & $1.06 \mathrm{E}-21$ & $1.24 \mathrm{E}-23$ & $9.46 \mathrm{E}-21$ & $5.63 \mathrm{E}-19$ & $1.66 \mathrm{E}-23$ & $3.25 \mathrm{E}-21$ & $3.67 \mathrm{E}-26$ \\
$\mathbf{1 0 5}$ & $1.73 \mathrm{E}-21$ & $4.16 \mathrm{E}-23$ & $6.26 \mathrm{E}-21$ & $3.97 \mathrm{E}-20$ & $8.51 \mathrm{E}-23$ & $9.85 \mathrm{E}-22$ & $2.01 \mathrm{E}-25$ \\
$\mathbf{1 0 6}$ & $9.93 \mathrm{E}-22$ & $1.23 \mathrm{E}-23$ & $4.27 \mathrm{E}-21$ & $1.42 \mathrm{E}-19$ & $1.23 \mathrm{E}-23$ & $1.56 \mathrm{E}-21$ & $3.72 \mathrm{E}-26$ \\
$\mathbf{1 0 7}$ & $4.95 \mathrm{E}-21$ & $3.16 \mathrm{E}-22$ & $2.29 \mathrm{E}-20$ & $3.97 \mathrm{E}-19$ & $6.63 \mathrm{E}-23$ & $4.86 \mathrm{E}-21$ & $3.61 \mathrm{E}-24$ \\
$\mathbf{1 1 4}$ & $7.86 \mathrm{E}-20$ & $3.10 \mathrm{E}-22$ & $7.89 \mathrm{E}-21$ & $3.22 \mathrm{E}-21$ & $7.68 \mathrm{E}-21$ & $2.79 \mathrm{E}-21$ & $5.16 \mathrm{E}-25$ \\
$\mathbf{1 1 9}$ & $5.06 \mathrm{E}-20$ & $4.22 \mathrm{E}-22$ & $1.20 \mathrm{E}-20$ & $6.28 \mathrm{E}-21$ & $4.60 \mathrm{E}-21$ & $2.59 \mathrm{E}-21$ & $1.03 \mathrm{E}-24$ \\
$\mathbf{3 5 1}$ & $1.48 \mathrm{E}-20$ & $2.79 \mathrm{E}-22$ & $2.06 \mathrm{E}-20$ & $5.47 \mathrm{E}-20$ & $1.62 \mathrm{E}-21$ & $4.14 \mathrm{E}-21$ & $1.61 \mathrm{E}-24$ \\
$\mathbf{3 6 5}$ & $1.62 \mathrm{E}-21$ & $3.44 \mathrm{E}-23$ & $4.66 \mathrm{E}-21$ & $4.27 \mathrm{E}-20$ & $3.27 \mathrm{E}-23$ & $9.56 \mathrm{E}-22$ & $1.37 \mathrm{E}-25$ \\
\hline
\end{tabular}

Table A3 (Cont.)

\begin{tabular}{|c|c|c|c|c|c|c|c|}
\hline Station & $\begin{array}{c}\mathrm{HgBr}^{-} \\
\mathrm{mol} / \mathrm{L}\end{array}$ & $\begin{array}{c}\mathrm{HgBr}^{+} \\
\mathrm{mol} / \mathrm{L}\end{array}$ & $\begin{array}{l}\mathrm{HgCl}^{+} \\
\mathrm{mol} / \mathrm{L}\end{array}$ & $\begin{array}{c}\mathrm{HgOH}^{+} \\
\mathrm{mol} / \mathrm{L}\end{array}$ & $\begin{array}{c}\mathrm{HgBr}_{4}^{2-} \\
\mathrm{mol} / \mathrm{L}\end{array}$ & $\begin{array}{c}\mathrm{Hg}(\mathrm{OH})_{3}{ }^{-} \\
\mathrm{mol} / \mathrm{L}\end{array}$ & $\begin{array}{c}\mathrm{Hg}^{2+} \\
\mathrm{mol} / \mathrm{L}\end{array}$ \\
\hline 28 & $7.36 \mathrm{E}-24$ & $2.16 \mathrm{E}-23$ & $5.64 \mathrm{E}-24$ & $2.74 \mathrm{E}-24$ & $9.52 \mathrm{E}-28$ & $6.24 \mathrm{E}-28$ & $4.99 \mathrm{E}-28$ \\
\hline 30 & $1.57 \mathrm{E}-25$ & 4.15E-24 & $3.36 \mathrm{E}-24$ & $2.61 \mathrm{E}-24$ & $6.76 \mathrm{E}-30$ & $1.64 \mathrm{E}-27$ & $4.16 \mathrm{E}-28$ \\
\hline 31 & $1.04 \mathrm{E}-25$ & $2.22 \mathrm{E}-24$ & $1.88 \mathrm{E}-24$ & $1.20 \mathrm{E}-24$ & $5.05 \mathrm{E}-30$ & $6.87 \mathrm{E}-28$ & $2.09 \mathrm{E}-28$ \\
\hline 33 & 4.84E-26 & $1.29 \mathrm{E}-24$ & $1.20 \mathrm{E}-24$ & $1.39 \mathrm{E}-24$ & $2.10 \mathrm{E}-30$ & $2.51 \mathrm{E}-27$ & $1.17 \mathrm{E}-28$ \\
\hline 37 & $3.48 \mathrm{E}-27$ & $7.65 \mathrm{E}-25$ & $1.45 \mathrm{E}-24$ & $2.10 \mathrm{E}-24$ & $5.21 \mathrm{E}-32$ & $3.03 \mathrm{E}-27$ & $2.56 \mathrm{E}-28$ \\
\hline 43 & $2.29 \mathrm{E}-26$ & $2.78 \mathrm{E}-24$ & $3.28 \mathrm{E}-24$ & $2.59 \mathrm{E}-24$ & $4.54 \mathrm{E}-31$ & $7.80 \mathrm{E}-28$ & $6.63 \mathrm{E}-28$ \\
\hline 45 & $3.33 \mathrm{E}-26$ & $2.53 \mathrm{E}-24$ & $2.95 \mathrm{E}-24$ & $1.67 \mathrm{E}-24$ & $8.40 \mathrm{E}-31$ & $3.98 \mathrm{E}-28$ & $2.97 \mathrm{E}-28$ \\
\hline 46 & $4.55 \mathrm{E}-26$ & $3.45 \mathrm{E}-24$ & $3.86 \mathrm{E}-24$ & $1.43 \mathrm{E}-24$ & $1.14 \mathrm{E}-30$ & $1.36 \mathrm{E}-28$ & $5.17 \mathrm{E}-28$ \\
\hline 47 & $3.90 \mathrm{E}-26$ & $2.96 \mathrm{E}-24$ & $3.04 \mathrm{E}-24$ & $2.56 \mathrm{E}-24$ & $9.81 \mathrm{E}-31$ & $1.06 \mathrm{E}-27$ & $5.52 \mathrm{E}-28$ \\
\hline 49 & $6.91 \mathrm{E}-26$ & $2.36 \mathrm{E}-24$ & $2.49 \mathrm{E}-24$ & $1.50 \mathrm{E}-24$ & $2.64 \mathrm{E}-30$ & $7.50 \mathrm{E}-28$ & $2.21 \mathrm{E}-28$ \\
\hline 51 & $1.99 \mathrm{E}-26$ & $1.50 \mathrm{E}-24$ & $1.40 \mathrm{E}-24$ & $1.13 \mathrm{E}-24$ & $4.98 \mathrm{E}-31$ & $3.57 \mathrm{E}-28$ & $2.81 \mathrm{E}-28$ \\
\hline 52 & $6.51 \mathrm{E}-26$ & $4.88 \mathrm{E}-24$ & $3.53 \mathrm{E}-24$ & $2.21 \mathrm{E}-24$ & $1.62 \mathrm{E}-30$ & $2.53 \mathrm{E}-28$ & $9.21 \mathrm{E}-28$ \\
\hline 53 & $1.26 \mathrm{E}-26$ & $9.53 \mathrm{E}-25$ & $1.02 \mathrm{E}-24$ & $1.57 \mathrm{E}-24$ & $3.16 \mathrm{E}-31$ & $2.37 \mathrm{E}-27$ & $1.38 \mathrm{E}-28$ \\
\hline 54 & $1.47 \mathrm{E}-26$ & $1.10 \mathrm{E}-24$ & $7.20 \mathrm{E}-25$ & $9.06 \mathrm{E}-25$ & $3.65 \mathrm{E}-31$ & $3.43 \mathrm{E}-28$ & $1.83 \mathrm{E}-28$ \\
\hline 55 & $6.66 \mathrm{E}-26$ & $5.02 \mathrm{E}-24$ & 4.33E-24 & $1.73 \mathrm{E}-24$ & $1.66 \mathrm{E}-30$ & $1.14 \mathrm{E}-28$ & $1.01 \mathrm{E}-27$ \\
\hline 56 & $2.31 \mathrm{E}-26$ & $1.23 \mathrm{E}-24$ & $1.68 \mathrm{E}-24$ & $2.41 \mathrm{E}-24$ & $7.06 \mathrm{E}-31$ & $7.25 \mathrm{E}-27$ & $1.98 \mathrm{E}-28$ \\
\hline 57 & $1.16 \mathrm{E}-25$ & $3.07 \mathrm{E}-24$ & $2.74 \mathrm{E}-24$ & $2.33 \mathrm{E}-24$ & $5.01 \mathrm{E}-30$ & $2.12 \mathrm{E}-27$ & $3.11 \mathrm{E}-28$ \\
\hline 59 & $3.84 \mathrm{E}-26$ & $2.40 \mathrm{E}-24$ & $2.25 \mathrm{E}-24$ & $1.69 \mathrm{E}-24$ & $1.06 \mathrm{E}-30$ & $5.57 \mathrm{E}-28$ & $4.41 \mathrm{E}-28$ \\
\hline 61 & $5.09 \mathrm{E}-27$ & $3.81 \mathrm{E}-25$ & $2.58 \mathrm{E}-25$ & $1.34 \mathrm{E}-24$ & $1.26 \mathrm{E}-31$ & $9.22 \mathrm{E}-27$ & 4.77E-29 \\
\hline 62 & $3.50 \mathrm{E}-26$ & $2.19 \mathrm{E}-24$ & $2.00 \mathrm{E}-24$ & $1.54 \mathrm{E}-24$ & $9.67 \mathrm{E}-31$ & $5.07 \mathrm{E}-28$ & $2.69 \mathrm{E}-28$ \\
\hline 63 & $1.50 \mathrm{E}-26$ & $1.15 \mathrm{E}-24$ & $1.42 \mathrm{E}-24$ & $2.00 \mathrm{E}-24$ & $3.81 \mathrm{E}-31$ & $3.30 \mathrm{E}-27$ & $1.48 \mathrm{E}-28$ \\
\hline 66 & $2.93 \mathrm{E}-26$ & $1.00 \mathrm{E}-24$ & $1.06 \mathrm{E}-24$ & 7.03E-25 & $1.12 \mathrm{E}-30$ & $4.22 \mathrm{E}-28$ & $1.63 \mathrm{E}-28$ \\
\hline 67 & 4.62E-27 & $3.51 \mathrm{E}-25$ & $3.85 \mathrm{E}-25$ & $8.38 \mathrm{E}-25$ & $1.16 \mathrm{E}-31$ & $2.64 \mathrm{E}-27$ & $6.02 \mathrm{E}-29$ \\
\hline 68 & $1.18 \mathrm{E}-26$ & 8.99E-25 & $1.20 \mathrm{E}-24$ & $8.98 \mathrm{E}-25$ & $2.98 \mathrm{E}-31$ & $4.92 \mathrm{E}-28$ & $1.87 \mathrm{E}-28$ \\
\hline
\end{tabular}




\begin{tabular}{|c|c|c|c|c|c|c|c|}
\hline 69 & $1.20 \mathrm{E}-26$ & $9.02 \mathrm{E}-25$ & $7.37 \mathrm{E}-25$ & $1.21 \mathrm{E}-24$ & $2.99 \mathrm{E}-31$ & $1.20 \mathrm{E}-27$ & $1.07 \mathrm{E}-28$ \\
\hline 70 & 7.71E-26 & $5.82 \mathrm{E}-24$ & $3.80 \mathrm{E}-24$ & $3.40 \mathrm{E}-24$ & $1.93 \mathrm{E}-30$ & $6.46 \mathrm{E}-28$ & $1.15 \mathrm{E}-27$ \\
\hline 73 & $2.03 \mathrm{E}-26$ & $5.42 \mathrm{E}-25$ & $6.25 \mathrm{E}-25$ & $5.97 \mathrm{E}-25$ & $8.84 \mathrm{E}-31$ & $1.13 \mathrm{E}-27$ & $3.96 \mathrm{E}-29$ \\
\hline 75 & $3.78 \mathrm{E}-26$ & $2.86 \mathrm{E}-24$ & $2.67 \mathrm{E}-24$ & $2.59 \mathrm{E}-24$ & $9.48 \mathrm{E}-31$ & $1.18 \mathrm{E}-27$ & $4.99 \mathrm{E}-28$ \\
\hline 77 & $6.27 \mathrm{E}-27$ & $4.85 \mathrm{E}-25$ & $6.79 \mathrm{E}-25$ & $6.43 \mathrm{E}-25$ & $1.61 \mathrm{E}-31$ & $6.11 \mathrm{E}-28$ & 8.67E-29 \\
\hline 80 & $7.89 \mathrm{E}-27$ & $6.09 \mathrm{E}-25$ & $1.05 \mathrm{E}-24$ & $1.22 \mathrm{E}-24$ & $2.02 \mathrm{E}-31$ & $2.66 \mathrm{E}-27$ & $9.28 \mathrm{E}-29$ \\
\hline 81 & $1.70 \mathrm{E}-26$ & $1.08 \mathrm{E}-24$ & $1.53 \mathrm{E}-24$ & $1.39 \mathrm{E}-24$ & 4.76E-31 & $1.52 \mathrm{E}-27$ & $1.97 \mathrm{E}-28$ \\
\hline 82 & $3.45 \mathrm{E}-26$ & $1.58 \mathrm{E}-24$ & $2.04 \mathrm{E}-24$ & $1.30 \mathrm{E}-24$ & $1.15 \mathrm{E}-30$ & $8.20 \mathrm{E}-28$ & $2.28 \mathrm{E}-28$ \\
\hline 83 & 4.05E-26 & $3.09 \mathrm{E}-24$ & $3.53 \mathrm{E}-24$ & $2.45 \mathrm{E}-24$ & $1.03 \mathrm{E}-30$ & $8.46 \mathrm{E}-28$ & $5.60 \mathrm{E}-28$ \\
\hline 84 & 7.49E-27 & $2.29 \mathrm{E}-25$ & $3.34 \mathrm{E}-25$ & $1.00 \mathrm{E}-24$ & $3.11 \mathrm{E}-31$ & $2.62 \mathrm{E}-26$ & $1.97 \mathrm{E}-29$ \\
\hline 85 & $9.63 \mathrm{E}-26$ & $3.78 \mathrm{E}-24$ & $3.91 \mathrm{E}-24$ & $1.96 \mathrm{E}-24$ & $3.44 \mathrm{E}-30$ & $5.63 \mathrm{E}-28$ & $5.53 \mathrm{E}-28$ \\
\hline 88 & $1.18 \mathrm{E}-26$ & $9.03 \mathrm{E}-25$ & $1.22 \mathrm{E}-24$ & $1.33 \mathrm{E}-24$ & $3.00 \mathrm{E}-31$ & $1.60 \mathrm{E}-27$ & $1.39 \mathrm{E}-28$ \\
\hline 89 & $2.59 \mathrm{E}-26$ & 7.94E-25 & $1.11 \mathrm{E}-24$ & $1.66 \mathrm{E}-24$ & $1.08 \mathrm{E}-30$ & $9.99 \mathrm{E}-27$ & $6.60 \mathrm{E}-29$ \\
\hline 90 & $1.10 \mathrm{E}-26$ & $8.51 \mathrm{E}-25$ & $1.43 \mathrm{E}-24$ & $1.03 \mathrm{E}-24$ & $2.83 \mathrm{E}-31$ & $8.13 \mathrm{E}-28$ & $1.69 \mathrm{E}-28$ \\
\hline 91 & $4.75 \mathrm{E}-27$ & $3.64 \mathrm{E}-25$ & $4.93 \mathrm{E}-25$ & $2.46 \mathrm{E}-24$ & $1.21 \mathrm{E}-31$ & $6.16 \mathrm{E}-26$ & $4.45 \mathrm{E}-29$ \\
\hline 93 & $8.04 \mathrm{E}-27$ & $6.18 \mathrm{E}-25$ & $8.80 \mathrm{E}-25$ & $1.67 \mathrm{E}-24$ & $2.05 \mathrm{E}-31$ & $6.61 \mathrm{E}-27$ & $7.52 \mathrm{E}-29$ \\
\hline 94 & $5.47 \mathrm{E}-27$ & 4.17E-25 & $5.06 \mathrm{E}-25$ & $1.62 \mathrm{E}-24$ & $1.38 \mathrm{E}-31$ & $1.34 \mathrm{E}-26$ & $4.35 \mathrm{E}-29$ \\
\hline 95 & $2.69 \mathrm{E}-26$ & $2.07 \mathrm{E}-24$ & $3.09 \mathrm{E}-24$ & $1.61 \mathrm{E}-24$ & $6.87 \mathrm{E}-31$ & $5.31 \mathrm{E}-28$ & $3.82 \mathrm{E}-28$ \\
\hline 99 & $9.22 \mathrm{E}-27$ & $7.07 \mathrm{E}-25$ & $1.04 \mathrm{E}-24$ & $1.38 \mathrm{E}-24$ & $2.35 \mathrm{E}-31$ & $2.87 \mathrm{E}-27$ & $9.89 \mathrm{E}-29$ \\
\hline 101 & $9.13 \mathrm{E}-27$ & $6.97 \mathrm{E}-25$ & $6.18 \mathrm{E}-25$ & $3.49 \mathrm{E}-24$ & $2.31 \mathrm{E}-31$ & $4.80 \mathrm{E}-26$ & $7.93 \mathrm{E}-29$ \\
\hline 105 & $1.54 \mathrm{E}-26$ & $7.00 \mathrm{E}-25$ & $7.80 \mathrm{E}-25$ & $8.17 \mathrm{E}-25$ & $5.11 \mathrm{E}-31$ & $1.02 \mathrm{E}-27$ & $1.01 \mathrm{E}-28$ \\
\hline 106 & $8.36 \mathrm{E}-27$ & $6.36 \mathrm{E}-25$ & $5.79 \mathrm{E}-25$ & $1.67 \mathrm{E}-24$ & $2.11 \mathrm{E}-31$ & $6.32 \mathrm{E}-27$ & $6.67 \mathrm{E}-29$ \\
\hline 107 & $7.25 \mathrm{E}-26$ & $9.32 \mathrm{E}-25$ & $1.22 \mathrm{E}-24$ & $2.20 \mathrm{E}-24$ & 4.83E-30 & $3.98 \mathrm{E}-26$ & $5.09 \mathrm{E}-29$ \\
\hline 114 & $1.17 \mathrm{E}-24$ & $8.72 \mathrm{E}-23$ & $4.48 \mathrm{E}-23$ & $2.91 \mathrm{E}-24$ & 2.89E-29 & $1.83 \mathrm{E}-30$ & $1.49 \mathrm{E}-26$ \\
\hline 119 & $5.18 \mathrm{E}-25$ & $3.89 \mathrm{E}-23$ & $2.91 \mathrm{E}-23$ & $2.73 \mathrm{E}-24$ & $1.29 \mathrm{E}-29$ & 7.49E-30 & $7.55 \mathrm{E}-27$ \\
\hline 351 & $3.52 \mathrm{E}-25$ & $5.15 \mathrm{E}-24$ & $3.81 \mathrm{E}-24$ & $1.96 \mathrm{E}-24$ & $2.08 \mathrm{E}-29$ & $8.15 \mathrm{E}-28$ & $4.93 \mathrm{E}-28$ \\
\hline 365 & $1.04 \mathrm{E}-26$ & $7.99 \mathrm{E}-25$ & $9.50 \mathrm{E}-25$ & $1.03 \mathrm{E}-24$ & $2.65 \mathrm{E}-31$ & $9.35 \mathrm{E}-28$ & $1.11 \mathrm{E}-28$ \\
\hline
\end{tabular}

Table A4 Concentrations of $\mathrm{Hg}$ species in surface water of Everglades in fall 2005 ([ $\left.\mathrm{S}^{2-}\right]=$ $3.2 \times 10^{-7} \mathrm{mg} / \mathrm{L}$ )

\begin{tabular}{cccccccc}
\hline Station & $\begin{array}{c}\mathbf{H g} \\
\mathbf{m o l} / \mathbf{L}\end{array}$ & $\begin{array}{c}\mathbf{R S H g}^{(\mathbf{n}-\mathbf{1})-} \\
\mathbf{m o l} / \mathbf{L}\end{array}$ & $\begin{array}{c}\mathbf{H g S}_{2} \mathbf{2}^{-2} \\
\mathbf{m o l} / \mathbf{L}\end{array}$ & $\begin{array}{c}\mathbf{H g H S}_{2}{ }^{-} \\
\mathbf{m o l} / \mathbf{L}\end{array}$ & $\begin{array}{c}\mathbf{H g}(\mathbf{H S})_{2} \\
\mathbf{m o l} / \mathbf{L}\end{array}$ & $\begin{array}{c}\mathbf{H g H S O H} \\
\mathbf{m o l} / \mathbf{L}\end{array}$ & $\begin{array}{c}\mathbf{H g C l}_{\mathbf{2}} \\
\mathbf{m o l} / \mathbf{L}\end{array}$ \\
\hline $\mathbf{1 2 8}$ & $2.49 \mathrm{E}-12$ & $2.16 \mathrm{E}-13$ & $1.90 \mathrm{E}-12$ & $3.74 \mathrm{E}-13$ & $5.61 \mathrm{E}-15$ & $3.74 \mathrm{E}-17$ & $1.14 \mathrm{E}-22$ \\
$\mathbf{1 3 0}$ & $1.40 \mathrm{E}-11$ & $9.37 \mathrm{E}-12$ & $4.01 \mathrm{E}-12$ & $5.77 \mathrm{E}-13$ & $6.28 \mathrm{E}-15$ & $3.78 \mathrm{E}-16$ & $3.51 \mathrm{E}-21$ \\
$\mathbf{1 3 5}$ & $5.98 \mathrm{E}-12$ & $1.96 \mathrm{E}-12$ & $3.32 \mathrm{E}-12$ & $6.94 \mathrm{E}-13$ & $1.09 \mathrm{E}-14$ & $1.95 \mathrm{E}-16$ & $8.54 \mathrm{E}-22$ \\
$\mathbf{1 3 6}$ & $7.48 \mathrm{E}-12$ & $3.40 \mathrm{E}-12$ & $2.98 \mathrm{E}-12$ & $1.07 \mathrm{E}-12$ & $2.86 \mathrm{E}-14$ & $3.55 \mathrm{E}-16$ & $1.95 \mathrm{E}-21$ \\
$\mathbf{1 3 8}$ & $5.98 \mathrm{E}-12$ & $1.76 \mathrm{E}-12$ & $3.87 \mathrm{E}-12$ & $3.45 \mathrm{E}-13$ & $2.32 \mathrm{E}-15$ & $1.21 \mathrm{E}-16$ & $3.03 \mathrm{E}-22$ \\
$\mathbf{1 4 1}$ & $1.35 \mathrm{E}-11$ & $9.33 \mathrm{E}-12$ & $3.21 \mathrm{E}-12$ & $9.03 \mathrm{E}-13$ & $1.95 \mathrm{E}-14$ & $2.99 \mathrm{E}-16$ & $7.60 \mathrm{E}-21$ \\
$\mathbf{1 4 2}$ & $5.48 \mathrm{E}-12$ & $1.65 \mathrm{E}-12$ & $3.24 \mathrm{E}-12$ & $5.92 \mathrm{E}-13$ & $8.28 \mathrm{E}-15$ & $1.38 \mathrm{E}-16$ & $9.99 \mathrm{E}-22$ \\
$\mathbf{1 4 3}$ & $8.48 \mathrm{E}-12$ & $4.19 \mathrm{E}-12$ & $3.86 \mathrm{E}-12$ & $4.21 \mathrm{E}-13$ & $3.53 \mathrm{E}-15$ & $1.58 \mathrm{E}-16$ & $2.12 \mathrm{E}-21$ \\
$\mathbf{1 4 5}$ & $1.50 \mathrm{E}-11$ & $1.05 \mathrm{E}-11$ & $3.84 \mathrm{E}-12$ & $6.09 \mathrm{E}-13$ & $7.40 \mathrm{E}-15$ & $3.01 \mathrm{E}-16$ & $5.74 \mathrm{E}-21$ \\
$\mathbf{1 4 7}$ & $7.98 \mathrm{E}-12$ & $4.43 \mathrm{E}-12$ & $2.56 \mathrm{E}-12$ & $9.57 \mathrm{E}-13$ & $2.77 \mathrm{E}-14$ & $2.05 \mathrm{E}-16$ & $7.43 \mathrm{E}-21$ \\
\hline
\end{tabular}




\begin{tabular}{|c|c|c|c|c|c|c|c|}
\hline 148 & $1.15 \mathrm{E}-11$ & $7.13 \mathrm{E}-12$ & $3.84 \mathrm{E}-12$ & $4.92 \mathrm{E}-13$ & $4.85 \mathrm{E}-15$ & $1.99 \mathrm{E}-16$ & $2.93 \mathrm{E}-21$ \\
\hline 149 & 8.97E-12 & $4.60 \mathrm{E}-12$ & $3.87 \mathrm{E}-12$ & $4.99 \mathrm{E}-13$ & $4.85 \mathrm{E}-15$ & $2.11 \mathrm{E}-16$ & $8.64 \mathrm{E}-22$ \\
\hline 151 & $9.97 \mathrm{E}-12$ & $5.65 \mathrm{E}-12$ & $3.97 \mathrm{E}-12$ & $3.47 \mathrm{E}-13$ & $2.35 \mathrm{E}-15$ & $1.39 \mathrm{E}-16$ & $2.35 \mathrm{E}-21$ \\
\hline 152 & $6.98 \mathrm{E}-12$ & $3.36 \mathrm{E}-12$ & $2.54 \mathrm{E}-12$ & $1.04 \mathrm{E}-12$ & $3.21 \mathrm{E}-14$ & $2.35 \mathrm{E}-16$ & $1.19 \mathrm{E}-21$ \\
\hline 153 & 7.98E-12 & $3.57 \mathrm{E}-12$ & $4.10 \mathrm{E}-12$ & $3.05 \mathrm{E}-13$ & $1.71 \mathrm{E}-15$ & $1.44 \mathrm{E}-16$ & $3.26 \mathrm{E}-22$ \\
\hline 154 & $1.30 \mathrm{E}-11$ & $8.40 \mathrm{E}-12$ & $4.13 \mathrm{E}-12$ & $4.21 \mathrm{E}-13$ & $3.24 \mathrm{E}-15$ & $2.58 \mathrm{E}-16$ & $1.79 \mathrm{E}-21$ \\
\hline 156 & $1.05 \mathrm{E}-11$ & $6.86 \mathrm{E}-12$ & $2.28 \mathrm{E}-12$ & $1.28 \mathrm{E}-12$ & $5.51 \mathrm{E}-14$ & $3.26 \mathrm{E}-16$ & $1.32 \mathrm{E}-20$ \\
\hline 157 & $6.98 \mathrm{E}-12$ & $3.14 \mathrm{E}-12$ & $3.31 \mathrm{E}-12$ & $5.26 \mathrm{E}-13$ & $6.50 \mathrm{E}-15$ & $1.21 \mathrm{E}-16$ & $1.83 \mathrm{E}-21$ \\
\hline 158 & $7.98 \mathrm{E}-12$ & $3.93 \mathrm{E}-12$ & $3.46 \mathrm{E}-12$ & $5.74 \mathrm{E}-13$ & $7.29 \mathrm{E}-15$ & $1.60 \mathrm{E}-16$ & $1.52 \mathrm{E}-21$ \\
\hline 159 & $1.15 \mathrm{E}-11$ & $7.30 \mathrm{E}-12$ & $3.57 \mathrm{E}-12$ & $5.91 \mathrm{E}-13$ & 7.63E-15 & $1.90 \mathrm{E}-16$ & $4.22 \mathrm{E}-21$ \\
\hline 160 & $8.48 \mathrm{E}-12$ & $4.45 \mathrm{E}-12$ & $3.04 \mathrm{E}-12$ & $9.62 \mathrm{E}-13$ & $2.29 \mathrm{E}-14$ & $2.90 \mathrm{E}-16$ & $2.22 \mathrm{E}-21$ \\
\hline 161 & $9.47 \mathrm{E}-12$ & $5.20 \mathrm{E}-12$ & $3.70 \mathrm{E}-12$ & $5.62 \mathrm{E}-13$ & $6.42 \mathrm{E}-15$ & $2.05 \mathrm{E}-16$ & $7.35 \mathrm{E}-22$ \\
\hline 162 & $8.97 \mathrm{E}-12$ & 4.63E-12 & $3.89 \mathrm{E}-12$ & $4.48 \mathrm{E}-13$ & $3.89 \mathrm{E}-15$ & $1.81 \mathrm{E}-16$ & $5.42 \mathrm{E}-22$ \\
\hline 163 & 8.97E-12 & $5.94 \mathrm{E}-12$ & $1.62 \mathrm{E}-12$ & $1.33 \mathrm{E}-12$ & $8.46 \mathrm{E}-14$ & $2.89 \mathrm{E}-16$ & $1.76 \mathrm{E}-20$ \\
\hline 165 & $8.97 \mathrm{E}-12$ & $5.56 \mathrm{E}-12$ & $1.83 \mathrm{E}-12$ & $1.49 \mathrm{E}-12$ & $9.12 \mathrm{E}-14$ & $3.90 \mathrm{E}-16$ & $6.23 \mathrm{E}-21$ \\
\hline 166 & $7.48 \mathrm{E}-12$ & $4.21 \mathrm{E}-12$ & $2.01 \mathrm{E}-12$ & $1.21 \mathrm{E}-12$ & $5.58 \mathrm{E}-14$ & $2.58 \mathrm{E}-16$ & $7.73 \mathrm{E}-21$ \\
\hline 167 & $8.48 \mathrm{E}-12$ & $4.45 \mathrm{E}-12$ & $3.27 \mathrm{E}-12$ & $7.38 \mathrm{E}-13$ & $1.27 \mathrm{E}-14$ & $2.08 \mathrm{E}-16$ & $1.75 \mathrm{E}-21$ \\
\hline 169 & $6.98 \mathrm{E}-12$ & $3.16 \mathrm{E}-12$ & $3.00 \mathrm{E}-12$ & $8.03 \mathrm{E}-13$ & $1.63 \mathrm{E}-14$ & $1.91 \mathrm{E}-16$ & $1.27 \mathrm{E}-21$ \\
\hline 170 & $9.47 \mathrm{E}-12$ & $5.26 \mathrm{E}-12$ & $3.49 \mathrm{E}-12$ & $7.08 \mathrm{E}-13$ & $1.07 \mathrm{E}-14$ & $2.43 \mathrm{E}-16$ & $4.11 \mathrm{E}-22$ \\
\hline 171 & $1.84 \mathrm{E}-11$ & $1.46 \mathrm{E}-11$ & $2.55 \mathrm{E}-12$ & $1.27 \mathrm{E}-12$ & 4.95E-14 & $3.84 \mathrm{E}-16$ & $2.42 \mathrm{E}-20$ \\
\hline 173 & $7.98 \mathrm{E}-12$ & $3.81 \mathrm{E}-12$ & $3.62 \mathrm{E}-12$ & $5.39 \mathrm{E}-13$ & $6.03 \mathrm{E}-15$ & $1.72 \mathrm{E}-16$ & 4.49E-22 \\
\hline 174 & $7.98 \mathrm{E}-12$ & $4.15 \mathrm{E}-12$ & $2.95 \mathrm{E}-12$ & $8.57 \mathrm{E}-13$ & $1.90 \mathrm{E}-14$ & $2.08 \mathrm{E}-16$ & $2.76 \mathrm{E}-21$ \\
\hline 175 & $7.98 \mathrm{E}-12$ & $4.05 \mathrm{E}-12$ & $3.01 \mathrm{E}-12$ & $8.95 \mathrm{E}-13$ & $2.00 \mathrm{E}-14$ & $2.39 \mathrm{E}-16$ & $1.04 \mathrm{E}-21$ \\
\hline 176 & $1.10 \mathrm{E}-11$ & $6.69 \mathrm{E}-12$ & $3.76 \mathrm{E}-12$ & $5.15 \mathrm{E}-13$ & $5.43 \mathrm{E}-15$ & $1.91 \mathrm{E}-16$ & $3.29 \mathrm{E}-21$ \\
\hline 177 & $9.47 \mathrm{E}-12$ & $5.37 \mathrm{E}-12$ & $3.47 \mathrm{E}-12$ & $6.28 \mathrm{E}-13$ & $8.75 \mathrm{E}-15$ & $1.89 \mathrm{E}-16$ & $2.82 \mathrm{E}-21$ \\
\hline 178 & $1.15 \mathrm{E}-11$ & $7.75 \mathrm{E}-12$ & $2.26 \mathrm{E}-12$ & $1.39 \mathrm{E}-12$ & $6.45 \mathrm{E}-14$ & $3.93 \mathrm{E}-16$ & $7.13 \mathrm{E}-21$ \\
\hline 179 & $5.98 \mathrm{E}-12$ & $2.95 \mathrm{E}-12$ & $2.00 \mathrm{E}-12$ & $9.87 \mathrm{E}-13$ & $3.77 \mathrm{E}-14$ & $1.70 \mathrm{E}-16$ & 4.76E-21 \\
\hline 180 & $1.15 \mathrm{E}-11$ & $7.55 \mathrm{E}-12$ & $2.94 \mathrm{E}-12$ & $9.57 \mathrm{E}-13$ & $2.42 \mathrm{E}-14$ & $2.67 \mathrm{E}-16$ & $1.07 \mathrm{E}-20$ \\
\hline 181 & $8.48 \mathrm{E}-12$ & 4.67E-12 & $2.80 \mathrm{E}-12$ & $9.82 \mathrm{E}-13$ & $2.58 \mathrm{E}-14$ & $2.48 \mathrm{E}-16$ & $8.32 \mathrm{E}-22$ \\
\hline 182 & $1.05 \mathrm{E}-11$ & $6.80 \mathrm{E}-12$ & $2.60 \mathrm{E}-12$ & $1.04 \mathrm{E}-12$ & $3.22 \mathrm{E}-14$ & $2.50 \mathrm{E}-16$ & $1.33 \mathrm{E}-20$ \\
\hline 183 & $1.50 \mathrm{E}-11$ & $1.14 \mathrm{E}-11$ & $1.89 \mathrm{E}-12$ & $1.58 \mathrm{E}-12$ & $9.93 \mathrm{E}-14$ & $4.56 \mathrm{E}-16$ & $5.09 \mathrm{E}-21$ \\
\hline 184 & $8.97 \mathrm{E}-12$ & $5.97 \mathrm{E}-12$ & $1.46 \mathrm{E}-12$ & $1.44 \mathrm{E}-12$ & $1.06 \mathrm{E}-13$ & $3.26 \mathrm{E}-16$ & $3.67 \mathrm{E}-21$ \\
\hline 185 & $1.25 \mathrm{E}-11$ & $8.35 \mathrm{E}-12$ & $3.09 \mathrm{E}-12$ & $1.00 \mathrm{E}-12$ & $2.44 \mathrm{E}-14$ & $3.33 \mathrm{E}-16$ & $2.89 \mathrm{E}-21$ \\
\hline 186 & $1.30 \mathrm{E}-11$ & $9.18 \mathrm{E}-12$ & $2.44 \mathrm{E}-12$ & $1.29 \mathrm{E}-12$ & $5.22 \mathrm{E}-14$ & $3.68 \mathrm{E}-16$ & 7.35E-21 \\
\hline 187 & $6.98 \mathrm{E}-12$ & $3.52 \mathrm{E}-12$ & $2.40 \mathrm{E}-12$ & $1.02 \mathrm{E}-12$ & $3.30 \mathrm{E}-14$ & $2.11 \mathrm{E}-16$ & $1.39 \mathrm{E}-21$ \\
\hline 188 & $9.47 \mathrm{E}-12$ & $5.62 \mathrm{E}-12$ & $2.77 \mathrm{E}-12$ & $1.05 \mathrm{E}-12$ & $3.02 \mathrm{E}-14$ & $2.80 \mathrm{E}-16$ & $2.29 \mathrm{E}-21$ \\
\hline 190 & $9.97 \mathrm{E}-12$ & $6.31 \mathrm{E}-12$ & $2.53 \mathrm{E}-12$ & $1.10 \mathrm{E}-12$ & $3.67 \mathrm{E}-14$ & $2.63 \mathrm{E}-16$ & $5.89 \mathrm{E}-21$ \\
\hline 191 & $1.30 \mathrm{E}-11$ & $8.75 \mathrm{E}-12$ & $3.51 \mathrm{E}-12$ & $6.94 \mathrm{E}-13$ & $1.06 \mathrm{E}-14$ & $2.39 \mathrm{E}-16$ & $3.66 \mathrm{E}-21$ \\
\hline 192 & $9.97 \mathrm{E}-12$ & $6.07 \mathrm{E}-12$ & $2.82 \mathrm{E}-12$ & $1.05 \mathrm{E}-12$ & $2.95 \mathrm{E}-14$ & $2.91 \mathrm{E}-16$ & $1.94 \mathrm{E}-21$ \\
\hline 193 & $1.30 \mathrm{E}-11$ & $9.09 \mathrm{E}-12$ & $2.50 \mathrm{E}-12$ & $1.32 \mathrm{E}-12$ & $5.22 \mathrm{E}-14$ & $4.00 \mathrm{E}-16$ & $3.51 \mathrm{E}-21$ \\
\hline 194 & $1.40 \mathrm{E}-11$ & $1.03 \mathrm{E}-11$ & $2.04 \mathrm{E}-12$ & $1.55 \mathrm{E}-12$ & $8.88 \mathrm{E}-14$ & $4.79 \mathrm{E}-16$ & $6.74 \mathrm{E}-21$ \\
\hline
\end{tabular}




\begin{tabular}{|c|c|c|c|c|c|c|c|}
\hline 195 & $6.98 \mathrm{E}-12$ & $3.48 \mathrm{E}-12$ & $2.57 \mathrm{E}-12$ & $9.09 \mathrm{E}-13$ & $2.47 \mathrm{E}-14$ & $1.83 \mathrm{E}-16$ & $2.58 \mathrm{E}-21$ \\
\hline 197 & $7.98 \mathrm{E}-12$ & $3.91 \mathrm{E}-12$ & $3.58 \mathrm{E}-12$ & $4.84 \mathrm{E}-13$ & $5.00 \mathrm{E}-15$ & $1.38 \mathrm{E}-16$ & $9.94 \mathrm{E}-22$ \\
\hline 198 & $1.10 \mathrm{E}-11$ & $6.94 \mathrm{E}-12$ & $3.02 \mathrm{E}-12$ & $9.83 \mathrm{E}-13$ & $2.41 \mathrm{E}-14$ & $3.02 \mathrm{E}-16$ & $1.39 \mathrm{E}-21$ \\
\hline 199 & $1.74 \mathrm{E}-11$ & $1.33 \mathrm{E}-11$ & $2.82 \mathrm{E}-12$ & $1.26 \mathrm{E}-12$ & $4.24 \mathrm{E}-14$ & $4.72 \mathrm{E}-16$ & $5.93 \mathrm{E}-21$ \\
\hline 200 & $9.97 \mathrm{E}-12$ & $5.87 \mathrm{E}-12$ & $3.41 \mathrm{E}-12$ & $6.85 \mathrm{E}-13$ & $1.05 \mathrm{E}-14$ & $2.07 \mathrm{E}-16$ & $1.95 \mathrm{E}-21$ \\
\hline 202 & $1.30 \mathrm{E}-11$ & $9.16 \mathrm{E}-12$ & $2.40 \mathrm{E}-12$ & $1.35 \mathrm{E}-12$ & $5.72 \mathrm{E}-14$ & $4.05 \mathrm{E}-16$ & $4.09 \mathrm{E}-21$ \\
\hline 203 & $1.55 \mathrm{E}-11$ & $1.12 \mathrm{E}-11$ & $3.68 \mathrm{E}-12$ & $5.84 \mathrm{E}-13$ & $7.31 \mathrm{E}-15$ & $2.16 \mathrm{E}-16$ & $7.16 \mathrm{E}-21$ \\
\hline 204 & $9.97 \mathrm{E}-12$ & $6.61 \mathrm{E}-12$ & $1.93 \mathrm{E}-12$ & $1.36 \mathrm{E}-12$ & $7.28 \mathrm{E}-14$ & $3.33 \mathrm{E}-16$ & $4.03 \mathrm{E}-21$ \\
\hline 206 & $1.50 \mathrm{E}-11$ & $1.05 \mathrm{E}-11$ & $4.12 \mathrm{E}-12$ & $3.57 \mathrm{E}-13$ & $2.37 \mathrm{E}-15$ & $1.87 \mathrm{E}-16$ & $2.25 \mathrm{E}-21$ \\
\hline 207 & $1.10 \mathrm{E}-11$ & 7.92E-12 & $1.30 \mathrm{E}-12$ & $1.60 \mathrm{E}-12$ & $1.48 \mathrm{E}-13$ & $4.27 \mathrm{E}-16$ & $9.79 \mathrm{E}-21$ \\
\hline 208 & $1.15 \mathrm{E}-11$ & 7.72E-12 & $2.63 \mathrm{E}-12$ & $1.08 \mathrm{E}-12$ & $3.44 \mathrm{E}-14$ & $2.72 \mathrm{E}-16$ & $9.61 \mathrm{E}-21$ \\
\hline 210 & $7.98 \mathrm{E}-12$ & 4.67E-12 & $2.30 \mathrm{E}-12$ & $9.74 \mathrm{E}-13$ & $3.22 \mathrm{E}-14$ & $1.86 \mathrm{E}-16$ & $7.92 \mathrm{E}-21$ \\
\hline 212 & $1.15 \mathrm{E}-11$ & $7.63 \mathrm{E}-12$ & $2.54 \mathrm{E}-12$ & $1.25 \mathrm{E}-12$ & $4.61 \mathrm{E}-14$ & $3.56 \mathrm{E}-16$ & $2.98 \mathrm{E}-21$ \\
\hline 213 & $7.98 \mathrm{E}-12$ & $4.24 \mathrm{E}-12$ & $2.78 \mathrm{E}-12$ & $9.38 \mathrm{E}-13$ & $2.40 \mathrm{E}-14$ & $2.21 \mathrm{E}-16$ & $1.42 \mathrm{E}-21$ \\
\hline 214 & $8.48 \mathrm{E}-12$ & $5.67 \mathrm{E}-12$ & $1.29 \mathrm{E}-12$ & $1.40 \mathrm{E}-12$ & $1.16 \mathrm{E}-13$ & $3.13 \mathrm{E}-16$ & $7.02 \mathrm{E}-21$ \\
\hline 215 & 8.97E-12 & $5.15 \mathrm{E}-12$ & $2.91 \mathrm{E}-12$ & $8.92 \mathrm{E}-13$ & 2.07E-14 & $2.22 \mathrm{E}-16$ & $1.88 \mathrm{E}-21$ \\
\hline 217 & $6.98 \mathrm{E}-12$ & $3.81 \mathrm{E}-12$ & $2.01 \mathrm{E}-12$ & $1.11 \mathrm{E}-12$ & $4.70 \mathrm{E}-14$ & $2.13 \mathrm{E}-16$ & $3.50 \mathrm{E}-21$ \\
\hline 218 & $1.10 \mathrm{E}-11$ & 7.27E-12 & $2.62 \mathrm{E}-12$ & $1.04 \mathrm{E}-12$ & $3.23 \mathrm{E}-14$ & $2.52 \mathrm{E}-16$ & $8.91 \mathrm{E}-21$ \\
\hline 219 & $1.05 \mathrm{E}-11$ & $7.18 \mathrm{E}-12$ & $2.16 \mathrm{E}-12$ & $1.09 \mathrm{E}-12$ & $4.38 \mathrm{E}-14$ & $2.21 \mathrm{E}-16$ & $2.77 \mathrm{E}-20$ \\
\hline 220 & $7.98 \mathrm{E}-12$ & 4.67E-12 & $2.36 \mathrm{E}-12$ & $9.18 \mathrm{E}-13$ & $2.82 \mathrm{E}-14$ & $1.72 \mathrm{E}-16$ & $6.31 \mathrm{E}-21$ \\
\hline 221 & $1.15 \mathrm{E}-11$ & $7.86 \mathrm{E}-12$ & 2.37E-12 & $1.19 \mathrm{E}-12$ & $4.57 \mathrm{E}-14$ & $2.89 \mathrm{E}-16$ & $8.23 \mathrm{E}-21$ \\
\hline 223 & $3.29 \mathrm{E}-11$ & $2.84 \mathrm{E}-11$ & $4.06 \mathrm{E}-12$ & $4.55 \mathrm{E}-13$ & $4.15 \mathrm{E}-15$ & $2.54 \mathrm{E}-16$ & $3.69 \mathrm{E}-20$ \\
\hline 224 & $1.40 \mathrm{E}-11$ & $1.02 \mathrm{E}-11$ & $2.31 \mathrm{E}-12$ & $1.38 \mathrm{E}-12$ & $6.24 \mathrm{E}-14$ & $4.01 \mathrm{E}-16$ & $9.18 \mathrm{E}-21$ \\
\hline 225 & $9.97 \mathrm{E}-12$ & $5.85 \mathrm{E}-12$ & $3.77 \mathrm{E}-12$ & $3.51 \mathrm{E}-13$ & 2.63E-15 & $1.07 \mathrm{E}-16$ & 4.46E-21 \\
\hline 227 & $3.69 \mathrm{E}-11$ & $3.24 \mathrm{E}-11$ & 4.04E-12 & $4.66 \mathrm{E}-13$ & $4.43 \mathrm{E}-15$ & $2.57 \mathrm{E}-16$ & $3.84 \mathrm{E}-20$ \\
\hline 229 & $9.97 \mathrm{E}-12$ & $6.19 \mathrm{E}-12$ & $2.84 \mathrm{E}-12$ & $9.21 \mathrm{E}-13$ & $2.28 \mathrm{E}-14$ & $2.26 \mathrm{E}-16$ & $3.38 \mathrm{E}-21$ \\
\hline 230 & $2.29 \mathrm{E}-11$ & $1.90 \mathrm{E}-11$ & $2.30 \mathrm{E}-12$ & $1.55 \mathrm{E}-12$ & 7.92E-14 & $5.64 \mathrm{E}-16$ & $1.12 \mathrm{E}-20$ \\
\hline 233 & $2.34 \mathrm{E}-11$ & $1.91 \mathrm{E}-11$ & $3.84 \mathrm{E}-12$ & $4.67 \mathrm{E}-13$ & 4.72E-15 & $1.82 \mathrm{E}-16$ & $3.64 \mathrm{E}-20$ \\
\hline 237 & $1.55 \mathrm{E}-11$ & $1.31 \mathrm{E}-11$ & $6.06 \mathrm{E}-13$ & $1.48 \mathrm{E}-12$ & $2.75 \mathrm{E}-13$ & $4.58 \mathrm{E}-16$ & $2.79 \mathrm{E}-20$ \\
\hline 238 & $2.04 \mathrm{E}-11$ & $1.67 \mathrm{E}-11$ & $2.63 \mathrm{E}-12$ & $1.04 \mathrm{E}-12$ & $3.43 \mathrm{E}-14$ & $2.58 \mathrm{E}-16$ & $7.70 \mathrm{E}-20$ \\
\hline 240 & $1.94 \mathrm{E}-11$ & $1.74 \mathrm{E}-11$ & $3.53 \mathrm{E}-13$ & $1.30 \mathrm{E}-12$ & $3.57 \mathrm{E}-13$ & $5.12 \mathrm{E}-16$ & $2.82 \mathrm{E}-20$ \\
\hline 242 & $1.79 \mathrm{E}-11$ & $1.74 \mathrm{E}-11$ & $1.84 \mathrm{E}-14$ & $2.47 \mathrm{E}-13$ & $2.46 \mathrm{E}-13$ & $1.99 \mathrm{E}-16$ & $6.57 \mathrm{E}-20$ \\
\hline 244 & $2.29 \mathrm{E}-11$ & $2.21 \mathrm{E}-11$ & $4.02 \mathrm{E}-14$ & $4.25 \mathrm{E}-13$ & $3.37 \mathrm{E}-13$ & $3.10 \mathrm{E}-16$ & $9.11 \mathrm{E}-20$ \\
\hline 245 & $1.74 \mathrm{E}-11$ & $1.50 \mathrm{E}-11$ & $6.69 \mathrm{E}-13$ & $1.54 \mathrm{E}-12$ & $2.67 \mathrm{E}-13$ & $4.59 \mathrm{E}-16$ & $1.73 \mathrm{E}-20$ \\
\hline 254 & $1.20 \mathrm{E}-11$ & $7.68 \mathrm{E}-12$ & $3.69 \mathrm{E}-12$ & $5.82 \mathrm{E}-13$ & $7.05 \mathrm{E}-15$ & $2.17 \mathrm{E}-16$ & 4.06E-21 \\
\hline 256 & $1.50 \mathrm{E}-11$ & $1.08 \mathrm{E}-11$ & $3.35 \mathrm{E}-12$ & $8.02 \mathrm{E}-13$ & $1.49 \mathrm{E}-14$ & $2.69 \mathrm{E}-16$ & $8.21 \mathrm{E}-21$ \\
\hline 257 & $1.10 \mathrm{E}-11$ & $6.46 \mathrm{E}-12$ & $3.74 \mathrm{E}-12$ & $7.59 \mathrm{E}-13$ & $1.17 \mathrm{E}-14$ & $4.24 \mathrm{E}-16$ & $5.33 \mathrm{E}-21$ \\
\hline 258 & $1.05 \mathrm{E}-11$ & $6.19 \mathrm{E}-12$ & $3.55 \mathrm{E}-12$ & $7.23 \mathrm{E}-13$ & $1.13 \mathrm{E}-14$ & $2.78 \mathrm{E}-16$ & $6.43 \mathrm{E}-21$ \\
\hline 368 & $1.99 \mathrm{E}-11$ & $1.60 \mathrm{E}-11$ & $2.56 \mathrm{E}-12$ & $1.32 \mathrm{E}-12$ & $5.14 \mathrm{E}-14$ & $4.29 \mathrm{E}-16$ & $3.02 \mathrm{E}-21$ \\
\hline 374 & $1.20 \mathrm{E}-11$ & $8.45 \mathrm{E}-12$ & $2.12 \mathrm{E}-12$ & $1.33 \mathrm{E}-12$ & $6.34 \mathrm{E}-14$ & $3.29 \mathrm{E}-16$ & $4.70 \mathrm{E}-21$ \\
\hline 489 & $2.99 \mathrm{E}-11$ & $2.65 \mathrm{E}-11$ & $1.50 \mathrm{E}-12$ & $1.76 \mathrm{E}-12$ & $1.63 \mathrm{E}-13$ & $5.65 \mathrm{E}-16$ & $1.66 \mathrm{E}-19$ \\
\hline
\end{tabular}


Table A4 (Cont.)

\begin{tabular}{|c|c|c|c|c|c|c|c|}
\hline Station & $\begin{array}{c}\mathrm{HgBrCl} \\
\mathrm{mol} / \mathrm{L}\end{array}$ & $\begin{array}{c}\mathrm{HgCl}_{3-} \\
\mathrm{mol} / \mathrm{L}\end{array}$ & $\begin{array}{c}\mathrm{HgClOH} \\
\mathrm{mol} / \mathrm{L}\end{array}$ & $\begin{array}{c}\mathrm{Hg}(\mathrm{OH})_{2} \\
\mathrm{~mol} / \mathrm{L}\end{array}$ & $\begin{array}{l}\mathrm{HgBr}_{2} \\
\mathrm{~mol} / \mathrm{L}\end{array}$ & $\begin{array}{c}\mathrm{HgBrOH} \\
\mathrm{mol} / \mathrm{L}\end{array}$ & $\begin{array}{l}\mathrm{HgCl}_{4}{ }^{2-} \\
\mathrm{mol} / \mathrm{L}\end{array}$ \\
\hline 128 & $7.87 \mathrm{E}-23$ & $1.03 \mathrm{E}-24$ & $5.58 \mathrm{E}-22$ & $6.54 \mathrm{E}-21$ & $6.17 \mathrm{E}-24$ & $9.31 \mathrm{E}-23$ & $3.15 \mathrm{E}-27$ \\
\hline 130 & $3.03 \mathrm{E}-21$ & $2.53 \mathrm{E}-23$ & $1.81 \mathrm{E}-20$ & $5.97 \mathrm{E}-19$ & $8.76 \mathrm{E}-23$ & $6.17 \mathrm{E}-21$ & $6.19 \mathrm{E}-26$ \\
\hline 135 & $8.43 \mathrm{E}-22$ & $5.39 \mathrm{E}-24$ & $4.41 \mathrm{E}-21$ & $9.04 \mathrm{E}-20$ & $5.02 \mathrm{E}-23$ & $1.35 \mathrm{E}-21$ & $1.15 \mathrm{E}-26$ \\
\hline 136 & $2.45 \mathrm{E}-21$ & $9.66 \mathrm{E}-24$ & $8.86 \mathrm{E}-21$ & $1.15 \mathrm{E}-19$ & $2.79 \mathrm{E}-22$ & $2.94 \mathrm{E}-21$ & $1.61 \mathrm{E}-26$ \\
\hline 138 & $2.88 \mathrm{E}-22$ & $1.98 \mathrm{E}-24$ & $2.77 \mathrm{E}-21$ & $1.64 \mathrm{E}-19$ & $9.07 \mathrm{E}-24$ & $1.05 \mathrm{E}-21$ & $4.37 \mathrm{E}-27$ \\
\hline 141 & $3.96 \mathrm{E}-21$ & $9.08 \mathrm{E}-23$ & $1.48 \mathrm{E}-20$ & $1.20 \mathrm{E}-19$ & $1.19 \mathrm{E}-22$ & $2.46 \mathrm{E}-21$ & $3.73 \mathrm{E}-25$ \\
\hline 142 & $6.58 \mathrm{E}-22$ & $9.46 \mathrm{E}-24$ & $4.60 \mathrm{E}-21$ & $5.99 \mathrm{E}-20$ & $3.99 \mathrm{E}-23$ & $7.95 \mathrm{E}-22$ & $3.06 \mathrm{E}-26$ \\
\hline 143 & $1.01 \mathrm{E}-21$ & $2.76 \mathrm{E}-23$ & $8.95 \mathrm{E}-21$ & $1.85 \mathrm{E}-19$ & $2.26 \mathrm{E}-23$ & $1.47 \mathrm{E}-21$ & $1.24 \mathrm{E}-25$ \\
\hline 145 & $3.17 \mathrm{E}-21$ & $6.46 \mathrm{E}-23$ & $2.31 \mathrm{E}-20$ & $3.21 \mathrm{E}-19$ & $1.26 \mathrm{E}-22$ & $3.70 \mathrm{E}-21$ & $2.50 \mathrm{E}-25$ \\
\hline 147 & $3.02 \mathrm{E}-21$ & $1.14 \mathrm{E}-22$ & 9.37E-21 & $3.96 \mathrm{E}-20$ & $9.18 \mathrm{E}-23$ & $1.09 \mathrm{E}-21$ & $6.05 \mathrm{E}-25$ \\
\hline 148 & $1.50 \mathrm{E}-21$ & $3.57 \mathrm{E}-23$ & $1.04 \mathrm{E}-20$ & $2.14 \mathrm{E}-19$ & $2.93 \mathrm{E}-23$ & $2.00 \mathrm{E}-21$ & $1.49 \mathrm{E}-25$ \\
\hline 149 & $8.52 \mathrm{E}-22$ & $5.45 \mathrm{E}-24$ & $6.58 \mathrm{E}-21$ & $2.41 \mathrm{E}-19$ & 4.03E-23 & $2.22 \mathrm{E}-21$ & $1.16 \mathrm{E}-26$ \\
\hline 151 & $9.28 \mathrm{E}-22$ & $3.71 \mathrm{E}-23$ & $9.88 \mathrm{E}-21$ & $2.15 \mathrm{E}-19$ & $1.60 \mathrm{E}-23$ & $1.39 \mathrm{E}-21$ & $2.03 \mathrm{E}-25$ \\
\hline 152 & $1.37 \mathrm{E}-21$ & $6.45 \mathrm{E}-24$ & $3.67 \mathrm{E}-21$ & $4.51 \mathrm{E}-20$ & $9.52 \mathrm{E}-23$ & $1.32 \mathrm{E}-21$ & $1.17 \mathrm{E}-26$ \\
\hline 153 & $3.46 \mathrm{E}-22$ & $1.91 \mathrm{E}-24$ & $3.95 \mathrm{E}-21$ & $3.17 \mathrm{E}-19$ & $1.18 \mathrm{E}-23$ & $1.69 \mathrm{E}-21$ & $3.77 \mathrm{E}-27$ \\
\hline 154 & $1.46 \mathrm{E}-21$ & $1.37 \mathrm{E}-23$ & $1.24 \mathrm{E}-20$ & $5.40 \mathrm{E}-19$ & $4.08 \mathrm{E}-23$ & $3.95 \mathrm{E}-21$ & $3.57 \mathrm{E}-26$ \\
\hline 156 & $6.77 \mathrm{E}-21$ & $1.61 \mathrm{E}-22$ & $1.36 \mathrm{E}-20$ & $5.05 \mathrm{E}-20$ & $2.33 \mathrm{E}-22$ & $2.07 \mathrm{E}-21$ & $6.73 \mathrm{E}-25$ \\
\hline 157 & $7.80 \mathrm{E}-22$ & $2.69 \mathrm{E}-23$ & 4.62E-21 & $5.88 \mathrm{E}-20$ & $1.49 \mathrm{E}-23$ & $6.90 \mathrm{E}-22$ & $1.37 \mathrm{E}-25$ \\
\hline 158 & $9.13 \mathrm{E}-22$ & $1.57 \mathrm{E}-23$ & $5.35 \mathrm{E}-21$ & $9.17 \mathrm{E}-20$ & $2.58 \mathrm{E}-23$ & $1.11 \mathrm{E}-21$ & $5.60 \mathrm{E}-26$ \\
\hline 159 & $1.97 \mathrm{E}-21$ & $6.18 \mathrm{E}-23$ & $1.03 \mathrm{E}-20$ & $1.24 \mathrm{E}-19$ & 4.29E-23 & $1.67 \mathrm{E}-21$ & $3.16 \mathrm{E}-25$ \\
\hline 160 & $2.12 \mathrm{E}-21$ & $1.45 \mathrm{E}-23$ & $7.26 \mathrm{E}-21$ & $9.57 \mathrm{E}-20$ & $1.20 \mathrm{E}-22$ & $2.17 \mathrm{E}-21$ & $3.20 \mathrm{E}-26$ \\
\hline 161 & $7.81 \mathrm{E}-22$ & $4.30 \mathrm{E}-24$ & $4.91 \mathrm{E}-21$ & $1.72 \mathrm{E}-19$ & $3.58 \mathrm{E}-23$ & $1.86 \mathrm{E}-21$ & $8.51 \mathrm{E}-27$ \\
\hline 162 & $5.76 \mathrm{E}-22$ & $3.17 \mathrm{E}-24$ & $5.62 \mathrm{E}-21$ & $2.20 \mathrm{E}-19$ & $3.94 \mathrm{E}-23$ & $1.81 \mathrm{E}-21$ & $6.27 \mathrm{E}-27$ \\
\hline 163 & $1.07 \mathrm{E}-20$ & $2.34 \mathrm{E}-22$ & $1.21 \mathrm{E}-20$ & $2.59 \mathrm{E}-20$ & $5.35 \mathrm{E}-22$ & $2.03 \mathrm{E}-21$ & $1.07 \mathrm{E}-24$ \\
\hline 165 & $6.15 \mathrm{E}-21$ & $3.93 \mathrm{E}-23$ & $8.98 \mathrm{E}-21$ & $4.36 \mathrm{E}-20$ & $4.50 \mathrm{E}-22$ & $2.54 \mathrm{E}-21$ & $8.38 \mathrm{E}-26$ \\
\hline 166 & 4.36E-21 & $8.53 \mathrm{E}-23$ & $8.94 \mathrm{E}-21$ & $3.12 \mathrm{E}-20$ & $2.09 \mathrm{E}-22$ & $1.37 \mathrm{E}-21$ & $3.23 \mathrm{E}-25$ \\
\hline 167 & $1.30 \mathrm{E}-21$ & $1.45 \mathrm{E}-23$ & $5.65 \mathrm{E}-21$ & $8.90 \mathrm{E}-20$ & $4.58 \mathrm{E}-23$ & $1.45 \mathrm{E}-21$ & $4.14 \mathrm{E}-26$ \\
\hline 169 & $1.06 \mathrm{E}-21$ & $9.44 \mathrm{E}-24$ & $3.79 \mathrm{E}-21$ & $5.85 \mathrm{E}-20$ & $3.88 \mathrm{E}-23$ & $1.13 \mathrm{E}-21$ & $2.38 \mathrm{E}-26$ \\
\hline 170 & $7.10 \mathrm{E}-22$ & $1.48 \mathrm{E}-24$ & $4.00 \mathrm{E}-21$ & $1.45 \mathrm{E}-19$ & $8.08 \mathrm{E}-23$ & $2.08 \mathrm{E}-21$ & $1.78 \mathrm{E}-27$ \\
\hline 171 & $1.34 \mathrm{E}-20$ & $3.54 \mathrm{E}-22$ & $2.31 \mathrm{E}-20$ & 7.79E-20 & $5.20 \mathrm{E}-22$ & $3.75 \mathrm{E}-21$ & $1.81 \mathrm{E}-24$ \\
\hline 173 & $5.17 \mathrm{E}-22$ & $2.43 \mathrm{E}-24$ & $3.70 \mathrm{E}-21$ & $1.29 \mathrm{E}-19$ & $3.33 \mathrm{E}-23$ & $1.37 \mathrm{E}-21$ & $4.42 \mathrm{E}-27$ \\
\hline 174 & $1.73 \mathrm{E}-21$ & $2.73 \mathrm{E}-23$ & $5.77 \mathrm{E}-21$ & $5.99 \mathrm{E}-20$ & $5.02 \mathrm{E}-23$ & $1.26 \mathrm{E}-21$ & $9.25 \mathrm{E}-26$ \\
\hline 175 & $1.20 \mathrm{E}-21$ & $5.62 \mathrm{E}-24$ & $3.92 \mathrm{E}-21$ & $7.48 \mathrm{E}-20$ & $6.19 \mathrm{E}-23$ & $1.59 \mathrm{E}-21$ & $1.02 \mathrm{E}-26$ \\
\hline 176 & $1.54 \mathrm{E}-21$ & 4.37E-23 & $1.11 \mathrm{E}-20$ & $1.75 \mathrm{E}-19$ & $3.53 \mathrm{E}-23$ & $1.76 \mathrm{E}-21$ & $2.01 \mathrm{E}-25$ \\
\hline 177 & $1.47 \mathrm{E}-21$ & $3.37 \mathrm{E}-23$ & $9.67 \mathrm{E}-21$ & $1.07 \mathrm{E}-19$ & $6.00 \mathrm{E}-23$ & $1.42 \mathrm{E}-21$ & $1.39 \mathrm{E}-25$ \\
\hline 178 & $5.97 \mathrm{E}-21$ & $5.30 \mathrm{E}-23$ & $1.08 \mathrm{E}-20$ & $6.26 \mathrm{E}-20$ & $3.14 \mathrm{E}-22$ & $2.76 \mathrm{E}-21$ & $1.34 \mathrm{E}-25$ \\
\hline 179 & $2.95 \mathrm{E}-21$ & $6.22 \mathrm{E}-23$ & $5.31 \mathrm{E}-21$ & $2.00 \mathrm{E}-20$ & $1.35 \mathrm{E}-22$ & $9.44 \mathrm{E}-22$ & $2.82 \mathrm{E}-25$ \\
\hline 180 & 4.43E-21 & $1.62 \mathrm{E}-22$ & $1.74 \mathrm{E}-20$ & $7.75 \mathrm{E}-20$ & $1.73 \mathrm{E}-22$ & $1.86 \mathrm{E}-21$ & $8.48 \mathrm{E}-25$ \\
\hline
\end{tabular}




\begin{tabular}{|c|c|c|c|c|c|c|c|}
\hline 181 & $1.15 \mathrm{E}-21$ & $3.75 \mathrm{E}-24$ & $3.72 \mathrm{E}-21$ & $6.22 \mathrm{E}-20$ & $1.04 \mathrm{E}-22$ & $1.55 \mathrm{E}-21$ & $5.67 \mathrm{E}-27$ \\
\hline 182 & $4.89 \mathrm{E}-21$ & $2.24 \mathrm{E}-22$ & $1.49 \mathrm{E}-20$ & $5.07 \mathrm{E}-20$ & $1.53 \mathrm{E}-22$ & $1.49 \mathrm{E}-21$ & $1.32 \mathrm{E}-24$ \\
\hline 183 & $6.39 \mathrm{E}-21$ & $2.52 \mathrm{E}-23$ & 8.36E-21 & $5.48 \mathrm{E}-20$ & 4.83E-22 & $3.28 \mathrm{E}-21$ & $4.21 \mathrm{E}-26$ \\
\hline 184 & $4.41 \mathrm{E}-21$ & $1.90 \mathrm{E}-23$ & $5.05 \mathrm{E}-21$ & $2.62 \mathrm{E}-20$ & $3.42 \mathrm{E}-22$ & $1.84 \mathrm{E}-21$ & $3.31 \mathrm{E}-26$ \\
\hline 185 & $2.75 \mathrm{E}-21$ & $1.89 \mathrm{E}-23$ & $8.93 \mathrm{E}-21$ & $1.19 \mathrm{E}-19$ & $1.44 \mathrm{E}-22$ & $2.76 \mathrm{E}-21$ & $4.17 \mathrm{E}-26$ \\
\hline 186 & $5.49 \mathrm{E}-21$ & $6.12 \mathrm{E}-23$ & $1.20 \mathrm{E}-20$ & $6.80 \mathrm{E}-20$ & $2.96 \mathrm{E}-22$ & $2.61 \mathrm{E}-21$ & $1.74 \mathrm{E}-25$ \\
\hline 187 & $1.37 \mathrm{E}-21$ & $8.78 \mathrm{E}-24$ & $3.65 \mathrm{E}-21$ & $3.54 \mathrm{E}-20$ & $8.95 \mathrm{E}-23$ & $1.08 \mathrm{E}-21$ & $1.87 \mathrm{E}-26$ \\
\hline 188 & $2.18 \mathrm{E}-21$ & $1.49 \mathrm{E}-23$ & $6.28 \mathrm{E}-21$ & $6.82 \mathrm{E}-20$ & $1.26 \mathrm{E}-22$ & $1.86 \mathrm{E}-21$ & $3.30 \mathrm{E}-26$ \\
\hline 190 & $3.46 \mathrm{E}-21$ & $6.24 \mathrm{E}-23$ & 8.32E-21 & $4.93 \mathrm{E}-20$ & $1.15 \mathrm{E}-22$ & $1.57 \mathrm{E}-21$ & $2.27 \mathrm{E}-25$ \\
\hline 191 & $2.32 \mathrm{E}-21$ & $3.96 \mathrm{E}-23$ & $1.00 \mathrm{E}-20$ & $1.41 \mathrm{E}-19$ & $6.46 \mathrm{E}-23$ & $2.25 \mathrm{E}-21$ & $1.48 \mathrm{E}-25$ \\
\hline 192 & $2.07 \mathrm{E}-21$ & $1.14 \mathrm{E}-23$ & $6.00 \mathrm{E}-21$ & $7.54 \mathrm{E}-20$ & $1.29 \mathrm{E}-22$ & $2.01 \mathrm{E}-21$ & $2.25 \mathrm{E}-26$ \\
\hline 193 & $4.04 \mathrm{E}-21$ & $1.90 \mathrm{E}-23$ & $8.85 \mathrm{E}-21$ & $8.00 \mathrm{E}-20$ & $3.19 \mathrm{E}-22$ & $3.01 \mathrm{E}-21$ & $3.46 \mathrm{E}-26$ \\
\hline 194 & $7.45 \mathrm{E}-21$ & $3.79 \mathrm{E}-23$ & $1.25 \mathrm{E}-20$ & $6.78 \mathrm{E}-20$ & 7.34E-22 & $3.69 \mathrm{E}-21$ & $7.21 \mathrm{E}-26$ \\
\hline 195 & $1.58 \mathrm{E}-21$ & $2.61 \mathrm{E}-23$ & $4.90 \mathrm{E}-21$ & $3.56 \mathrm{E}-20$ & $6.18 \mathrm{E}-23$ & $9.19 \mathrm{E}-22$ & $9.10 \mathrm{E}-26$ \\
\hline 197 & $6.24 \mathrm{E}-22$ & $9.85 \mathrm{E}-24$ & 4.83E-21 & $9.90 \mathrm{E}-20$ & $2.20 \mathrm{E}-23$ & $9.73 \mathrm{E}-22$ & $3.35 \mathrm{E}-26$ \\
\hline 198 & $1.74 \mathrm{E}-21$ & $6.88 \mathrm{E}-24$ & $6.44 \mathrm{E}-21$ & $9.90 \mathrm{E}-20$ & $1.66 \mathrm{E}-22$ & $2.30 \mathrm{E}-21$ & $1.15 \mathrm{E}-26$ \\
\hline 199 & $5.85 \mathrm{E}-21$ & $3.74 \mathrm{E}-23$ & $1.67 \mathrm{E}-20$ & $1.38 \mathrm{E}-19$ & $5.13 \mathrm{E}-22$ & $4.40 \mathrm{E}-21$ & $7.98 \mathrm{E}-26$ \\
\hline 200 & $1.35 \mathrm{E}-21$ & $1.76 \mathrm{E}-23$ & $6.83 \mathrm{E}-21$ & $1.07 \mathrm{E}-19$ & 4.87E-23 & $1.56 \mathrm{E}-21$ & $5.40 \mathrm{E}-26$ \\
\hline 202 & $4.53 \mathrm{E}-21$ & $2.31 \mathrm{E}-23$ & $1.04 \mathrm{E}-20$ & $7.51 \mathrm{E}-20$ & $4.58 \mathrm{E}-22$ & $3.03 \mathrm{E}-21$ & $4.39 \mathrm{E}-26$ \\
\hline 203 & $4.22 \mathrm{E}-21$ & $1.21 \mathrm{E}-22$ & $1.71 \mathrm{E}-20$ & $1.67 \mathrm{E}-19$ & $1.46 \mathrm{E}-22$ & $3.19 \mathrm{E}-21$ & $7.22 \mathrm{E}-25$ \\
\hline 204 & $4.12 \mathrm{E}-21$ & $2.45 \mathrm{E}-23$ & $7.89 \mathrm{E}-21$ & $3.99 \mathrm{E}-20$ & 4.34E-22 & $2.03 \mathrm{E}-21$ & $5.03 \mathrm{E}-26$ \\
\hline 206 & $1.19 \mathrm{E}-21$ & $2.63 \mathrm{E}-23$ & $1.41 \mathrm{E}-20$ & $3.87 \mathrm{E}-19$ & $3.43 \mathrm{E}-23$ & $2.45 \mathrm{E}-21$ & $1.06 \mathrm{E}-25$ \\
\hline 207 & $1.00 \mathrm{E}-20$ & $5.95 \mathrm{E}-23$ & $9.57 \mathrm{E}-21$ & $3.22 \mathrm{E}-20$ & 7.41E-22 & $2.84 \mathrm{E}-21$ & $1.22 \mathrm{E}-25$ \\
\hline 208 & $4.50 \mathrm{E}-21$ & $1.28 \mathrm{E}-22$ & $1.17 \mathrm{E}-20$ & $5.64 \mathrm{E}-20$ & $1.28 \mathrm{E}-22$ & $1.70 \mathrm{E}-21$ & $5.88 \mathrm{E}-25$ \\
\hline 210 & $3.90 \mathrm{E}-21$ & $1.30 \mathrm{E}-22$ & $8.17 \mathrm{E}-21$ & $2.80 \mathrm{E}-20$ & $1.45 \mathrm{E}-22$ & $1.14 \mathrm{E}-21$ & $7.50 \mathrm{E}-25$ \\
\hline 212 & $3.29 \mathrm{E}-21$ & $1.68 \mathrm{E}-23$ & $7.50 \mathrm{E}-21$ & 7.19E-20 & $2.32 \mathrm{E}-22$ & $2.53 \mathrm{E}-21$ & $3.19 \mathrm{E}-26$ \\
\hline 213 & $1.35 \mathrm{E}-21$ & $9.29 \mathrm{E}-24$ & $4.42 \mathrm{E}-21$ & $5.35 \mathrm{E}-20$ & $8.01 \mathrm{E}-23$ & $1.30 \mathrm{E}-21$ & $2.06 \mathrm{E}-26$ \\
\hline 214 & $6.25 \mathrm{E}-21$ & $4.90 \mathrm{E}-23$ & $6.91 \mathrm{E}-21$ & $2.21 \mathrm{E}-20$ & 4.33E-22 & $1.73 \mathrm{E}-21$ & $1.16 \mathrm{E}-25$ \\
\hline 215 & $1.53 \mathrm{E}-21$ & $1.44 \mathrm{E}-23$ & $5.85 \mathrm{E}-21$ & $6.22 \mathrm{E}-20$ & $9.03 \mathrm{E}-23$ & $1.37 \mathrm{E}-21$ & $3.76 \mathrm{E}-26$ \\
\hline 217 & $2.41 \mathrm{E}-21$ & $3.15 \mathrm{E}-23$ & $4.96 \mathrm{E}-21$ & $2.53 \mathrm{E}-20$ & $1.14 \mathrm{E}-22$ & $1.01 \mathrm{E}-21$ & $9.68 \mathrm{E}-26$ \\
\hline 218 & $5.25 \mathrm{E}-21$ & $1.22 \mathrm{E}-22$ & $1.13 \mathrm{E}-20$ & $5.15 \mathrm{E}-20$ & $2.13 \mathrm{E}-22$ & $1.97 \mathrm{E}-21$ & $5.86 \mathrm{E}-25$ \\
\hline 219 & $9.06 \mathrm{E}-21$ & $6.87 \mathrm{E}-22$ & $1.56 \mathrm{E}-20$ & $2.92 \mathrm{E}-20$ & $2.21 \mathrm{E}-22$ & $1.45 \mathrm{E}-21$ & $6.10 \mathrm{E}-24$ \\
\hline 220 & $5.89 \mathrm{E}-21$ & $1.01 \mathrm{E}-22$ & 7.42E-21 & $2.73 \mathrm{E}-20$ & 4.47E-22 & $1.92 \mathrm{E}-21$ & $5.71 \mathrm{E}-25$ \\
\hline 221 & $4.64 \mathrm{E}-21$ & $9.08 \mathrm{E}-23$ & $1.02 \mathrm{E}-20$ & $4.79 \mathrm{E}-20$ & $1.70 \mathrm{E}-22$ & $1.75 \mathrm{E}-21$ & $3.44 \mathrm{E}-25$ \\
\hline 223 & $2.04 \mathrm{E}-20$ & $1.25 \mathrm{E}-21$ & $6.68 \mathrm{E}-20$ & $4.05 \mathrm{E}-19$ & $8.42 \mathrm{E}-22$ & $1.06 \mathrm{E}-20$ & $1.54 \mathrm{E}-23$ \\
\hline 224 & $6.86 \mathrm{E}-21$ & $7.65 \mathrm{E}-23$ & $1.37 \mathrm{E}-20$ & $6.74 \mathrm{E}-20$ & $3.93 \mathrm{E}-22$ & $2.90 \mathrm{E}-21$ & $2.17 \mathrm{E}-25$ \\
\hline 225 & $1.64 \mathrm{E}-21$ & $1.21 \mathrm{E}-22$ & $1.23 \mathrm{E}-20$ & $1.14 \mathrm{E}-19$ & 4.46E-23 & $1.30 \mathrm{E}-21$ & $1.17 \mathrm{E}-24$ \\
\hline 227 & $2.83 \mathrm{E}-20$ & $1.30 \mathrm{E}-21$ & $6.25 \mathrm{E}-20$ & $3.90 \mathrm{E}-19$ & 1.32E-21 & $1.41 \mathrm{E}-20$ & $1.62 \mathrm{E}-23$ \\
\hline 229 & $2.12 \mathrm{E}-21$ & $3.35 \mathrm{E}-23$ & $7.71 \mathrm{E}-21$ & $5.85 \mathrm{E}-20$ & $1.01 \mathrm{E}-22$ & $1.38 \mathrm{E}-21$ & $1.14 \mathrm{E}-25$ \\
\hline 230 & $1.06 \mathrm{E}-20$ & $7.28 \mathrm{E}-23$ & $2.00 \mathrm{E}-20$ & $1.05 \mathrm{E}-19$ & $8.89 \mathrm{E}-22$ & $5.10 \mathrm{E}-21$ & $1.61 \mathrm{E}-25$ \\
\hline 233 & $1.36 \mathrm{E}-20$ & $1.64 \mathrm{E}-21$ & 4.35E-20 & $1.83 \mathrm{E}-19$ & $3.56 \mathrm{E}-22$ & $4.76 \mathrm{E}-21$ & $2.76 \mathrm{E}-23$ \\
\hline
\end{tabular}




\begin{tabular}{llllllll}
\hline $\mathbf{2 3 7}$ & $2.65 \mathrm{E}-20$ & $1.82 \mathrm{E}-22$ & $1.17 \mathrm{E}-20$ & $2.00 \mathrm{E}-20$ & $1.48 \mathrm{E}-21$ & $3.51 \mathrm{E}-21$ & $4.02 \mathrm{E}-25$ \\
$\mathbf{2 3 8}$ & $4.76 \mathrm{E}-20$ & $2.95 \mathrm{E}-21$ & $3.21 \mathrm{E}-20$ & $5.09 \mathrm{E}-20$ & $1.88 \mathrm{E}-21$ & $6.05 \mathrm{E}-21$ & $4.19 \mathrm{E}-23$ \\
$\mathbf{2 4 0}$ & $3.90 \mathrm{E}-20$ & $1.27 \mathrm{E}-22$ & $1.38 \mathrm{E}-20$ & $1.93 \mathrm{E}-20$ & $4.93 \mathrm{E}-21$ & $5.03 \mathrm{E}-21$ & $1.92 \mathrm{E}-25$ \\
$\mathbf{2 4 2}$ & $1.01 \mathrm{E}-19$ & $2.67 \mathrm{E}-22$ & $8.92 \mathrm{E}-21$ & $4.19 \mathrm{E}-21$ & $1.11 \mathrm{E}-20$ & $3.98 \mathrm{E}-21$ & $3.62 \mathrm{E}-25$ \\
$\mathbf{2 4 4}$ & $1.26 \mathrm{E}-19$ & $4.11 \mathrm{E}-22$ & $1.59 \mathrm{E}-20$ & $7.48 \mathrm{E}-21$ & $1.70 \mathrm{E}-20$ & $5.63 \mathrm{E}-21$ & $6.21 \mathrm{E}-25$ \\
$\mathbf{2 4 5}$ & $1.99 \mathrm{E}-20$ & $9.34 \mathrm{E}-23$ & $8.47 \mathrm{E}-21$ & $2.06 \mathrm{E}-20$ & $1.05 \mathrm{E}-21$ & $3.40 \mathrm{E}-21$ & $1.70 \mathrm{E}-25$ \\
$\mathbf{2 5 4}$ & $1.97 \mathrm{E}-21$ & $5.21 \mathrm{E}-23$ & $1.55 \mathrm{E}-20$ & $1.76 \mathrm{E}-19$ & $8.33 \mathrm{E}-23$ & $2.02 \mathrm{E}-21$ & $2.31 \mathrm{E}-25$ \\
$\mathbf{2 5 6}$ & $5.12 \mathrm{E}-21$ & $1.15 \mathrm{E}-22$ & $1.67 \mathrm{E}-20$ & $1.27 \mathrm{E}-19$ & $2.10 \mathrm{E}-22$ & $3.14 \mathrm{E}-21$ & $5.58 \mathrm{E}-25$ \\
$\mathbf{2 5 7}$ & $4.33 \mathrm{E}-21$ & $4.08 \mathrm{E}-23$ & $2.52 \mathrm{E}-20$ & $4.03 \mathrm{E}-19$ & $2.59 \mathrm{E}-22$ & $5.88 \mathrm{E}-21$ & $1.06 \mathrm{E}-25$ \\
$\mathbf{2 5 8}$ & $3.23 \mathrm{E}-21$ & $7.97 \mathrm{E}-23$ & $2.05 \mathrm{E}-20$ & $1.79 \mathrm{E}-19$ & $1.55 \mathrm{E}-22$ & $2.67 \mathrm{E}-21$ & $3.39 \mathrm{E}-25$ \\
$\mathbf{3 6 8}$ & $3.98 \mathrm{E}-21$ & $1.43 \mathrm{E}-23$ & $9.94 \mathrm{E}-21$ & $9.38 \mathrm{E}-20$ & $4.73 \mathrm{E}-22$ & $3.46 \mathrm{E}-21$ & $2.27 \mathrm{E}-26$ \\
$\mathbf{3 7 4}$ & $4.18 \mathrm{E}-21$ & $3.28 \mathrm{E}-23$ & $7.41 \mathrm{E}-21$ & $4.45 \mathrm{E}-20$ & $2.37 \mathrm{E}-22$ & $2.01 \mathrm{E}-21$ & $7.75 \mathrm{E}-26$ \\
$\mathbf{4 8 9}$ & $6.77 \mathrm{E}-20$ & $3.29 \mathrm{E}-21$ & $4.54 \mathrm{E}-20$ & $5.13 \mathrm{E}-20$ & $1.59 \mathrm{E}-21$ & $5.88 \mathrm{E}-21$ & $2.31 \mathrm{E}-23$ \\
\hline
\end{tabular}

Table A4 (Cont.)

\begin{tabular}{|c|c|c|c|c|c|c|c|}
\hline Station & $\begin{array}{c}\mathrm{HgBr}_{3}^{-} \\
\mathrm{mol} / \mathrm{L}\end{array}$ & $\begin{array}{l}\mathrm{HgBr}^{+} \\
\mathrm{mol} / \mathrm{L}\end{array}$ & $\begin{array}{l}\mathrm{HgCl}^{+} \\
\mathrm{mol} / \mathrm{L}\end{array}$ & $\begin{array}{c}\mathrm{HgOH}^{+} \\
\mathrm{mol} / \mathrm{L}\end{array}$ & $\begin{array}{c}\mathrm{HgBr}_{4}^{2-} \\
\mathrm{mol} / \mathrm{L}\end{array}$ & $\begin{array}{c}\mathrm{Hg}(\mathrm{OH})_{3}{ }^{-} \\
\mathrm{mol} / \mathrm{L}\end{array}$ & $\begin{array}{c}\mathrm{Hg}^{2+} \\
\mathrm{mol} / \mathrm{L}\end{array}$ \\
\hline 128 & $6.46 \mathrm{E}-28$ & $4.87 \mathrm{E}-26$ & $4.55 \mathrm{E}-26$ & $9.88 \mathrm{E}-26$ & $1.62 \mathrm{E}-32$ & $2.25 \mathrm{E}-28$ & $9.81 \mathrm{E}-30$ \\
\hline 130 & $3.11 \mathrm{E}-26$ & $2.33 \mathrm{E}-24$ & $1.74 \mathrm{E}-24$ & $6.51 \mathrm{E}-24$ & 7.74E-31 & $2.83 \mathrm{E}-26$ & $3.00 \mathrm{E}-28$ \\
\hline 135 & $9.87 \mathrm{E}-27$ & $7.39 \mathrm{E}-25$ & $4.83 \mathrm{E}-25$ & $1.43 \mathrm{E}-24$ & $2.45 \mathrm{E}-31$ & $2.97 \mathrm{E}-27$ & $1.17 \mathrm{E}-28$ \\
\hline 136 & $3.65 \mathrm{E}-26$ & $2.72 \mathrm{E}-24$ & $1.39 \mathrm{E}-24$ & $3.07 \mathrm{E}-24$ & $9.01 \mathrm{E}-31$ & $2.22 \mathrm{E}-27$ & $4.91 \mathrm{E}-28$ \\
\hline 138 & $3.26 \mathrm{E}-27$ & $2.44 \mathrm{E}-25$ & $1.65 \mathrm{E}-25$ & $1.10 \mathrm{E}-24$ & $8.11 \mathrm{E}-32$ & $1.26 \mathrm{E}-26$ & $3.11 \mathrm{E}-29$ \\
\hline 141 & $2.45 \mathrm{E}-26$ & $1.87 \mathrm{E}-24$ & $2.31 \mathrm{E}-24$ & $2.63 \mathrm{E}-24$ & $6.20 \mathrm{E}-31$ & $2.88 \mathrm{E}-27$ & $3.01 \mathrm{E}-28$ \\
\hline 142 & $5.14 \mathrm{E}-27$ & $3.89 \mathrm{E}-25$ & $3.81 \mathrm{E}-25$ & $8.46 \mathrm{E}-25$ & $1.29 \mathrm{E}-31$ & $2.22 \mathrm{E}-27$ & 7.32E-29 \\
\hline 143 & $5.70 \mathrm{E}-27$ & $4.35 \mathrm{E}-25$ & $5.89 \mathrm{E}-25$ & $1.58 \mathrm{E}-24$ & $1.44 \mathrm{E}-31$ & $1.14 \mathrm{E}-26$ & $6.53 \mathrm{E}-29$ \\
\hline 145 & $2.08 \mathrm{E}-26$ & $1.58 \mathrm{E}-24$ & $1.84 \mathrm{E}-24$ & $3.95 \mathrm{E}-24$ & $5.24 \mathrm{E}-31$ & $1.37 \mathrm{E}-26$ & $2.74 \mathrm{E}-28$ \\
\hline 147 & $1.46 \mathrm{E}-26$ & $1.12 \mathrm{E}-24$ & $1.78 \mathrm{E}-24$ & $1.18 \mathrm{E}-24$ & $3.72 \mathrm{E}-31$ & 7.07E-28 & $2.02 \mathrm{E}-28$ \\
\hline 148 & $9.11 \mathrm{E}-27$ & $6.95 \mathrm{E}-25$ & $8.77 \mathrm{E}-25$ & $2.15 \mathrm{E}-24$ & $2.31 \mathrm{E}-31$ & $1.12 \mathrm{E}-26$ & $9.69 \mathrm{E}-29$ \\
\hline 149 & $9.99 \mathrm{E}-27$ & $7.47 \mathrm{E}-25$ & 4.88E-25 & $2.34 \mathrm{E}-24$ & $2.48 \mathrm{E}-31$ & $1.28 \mathrm{E}-26$ & $1.09 \mathrm{E}-28$ \\
\hline 151 & $4.35 \mathrm{E}-27$ & $3.35 \mathrm{E}-25$ & $5.47 \mathrm{E}-25$ & $1.50 \mathrm{E}-24$ & $1.11 \mathrm{E}-31$ & $1.64 \mathrm{E}-26$ & $4.99 \mathrm{E}-29$ \\
\hline 152 & $1.88 \mathrm{E}-26$ & $1.40 \mathrm{E}-24$ & $7.84 \mathrm{E}-25$ & $1.38 \mathrm{E}-24$ & 4.65E-31 & 7.57E-28 & $2.20 \mathrm{E}-28$ \\
\hline 153 & 4.37E-27 & $3.26 \mathrm{E}-25$ & $1.98 \mathrm{E}-25$ & $1.77 \mathrm{E}-24$ & $1.08 \mathrm{E}-31$ & $2.93 \mathrm{E}-26$ & 4.10E-29 \\
\hline 154 & $1.41 \mathrm{E}-26$ & $1.06 \mathrm{E}-24$ & $8.39 \mathrm{E}-25$ & $4.17 \mathrm{E}-24$ & $3.51 \mathrm{E}-31$ & $3.62 \mathrm{E}-26$ & $1.38 \mathrm{E}-28$ \\
\hline 156 & $4.12 \mathrm{E}-26$ & $3.13 \mathrm{E}-24$ & $3.95 \mathrm{E}-24$ & $2.21 \mathrm{E}-24$ & $1.04 \mathrm{E}-30$ & $6.07 \mathrm{E}-28$ & $5.33 \mathrm{E}-28$ \\
\hline 157 & $3.94 \mathrm{E}-27$ & $3.03 \mathrm{E}-25$ & $4.60 \mathrm{E}-25$ & $7.46 \mathrm{E}-25$ & $1.01 \mathrm{E}-31$ & $2.46 \mathrm{E}-27$ & 4.56E-29 \\
\hline 158 & $6.51 \mathrm{E}-27$ & $4.95 \mathrm{E}-25$ & $5.32 \mathrm{E}-25$ & $1.18 \mathrm{E}-24$ & $1.64 \mathrm{E}-31$ & $3.73 \mathrm{E}-27$ & $7.40 \mathrm{E}-29$ \\
\hline 159 & $1.21 \mathrm{E}-26$ & $7.70 \mathrm{E}-25$ & $1.06 \mathrm{E}-24$ & $1.65 \mathrm{E}-24$ & $3.40 \mathrm{E}-31$ & $4.96 \mathrm{E}-27$ & $1.07 \mathrm{E}-28$ \\
\hline 160 & $2.39 \mathrm{E}-26$ & $1.79 \mathrm{E}-24$ & $1.21 \mathrm{E}-24$ & $2.28 \mathrm{E}-24$ & $5.95 \mathrm{E}-31$ & $2.08 \mathrm{E}-27$ & $2.82 \mathrm{E}-28$ \\
\hline 161 & $9.85 \mathrm{E}-27$ & $7.36 \mathrm{E}-25$ & 4.47E-25 & $1.96 \mathrm{E}-24$ & $2.44 \mathrm{E}-31$ & 7.77E-27 & $1.03 \mathrm{E}-28$ \\
\hline 162 & $7.26 \mathrm{E}-27$ & $5.43 \mathrm{E}-25$ & $3.29 \mathrm{E}-25$ & $1.90 \mathrm{E}-24$ & $1.80 \mathrm{E}-31$ & $1.31 \mathrm{E}-26$ & $8.75 \mathrm{E}-29$ \\
\hline 163 & $1.01 \mathrm{E}-25$ & $4.56 \mathrm{E}-24$ & $4.83 \mathrm{E}-24$ & $1.68 \mathrm{E}-24$ & $3.32 \mathrm{E}-30$ & $2.10 \mathrm{E}-28$ & $6.45 \mathrm{E}-28$ \\
\hline
\end{tabular}




\begin{tabular}{|c|c|c|c|c|c|c|c|}
\hline 165 & $7.20 \mathrm{E}-26$ & $5.39 \mathrm{E}-24$ & $3.52 \mathrm{E}-24$ & $2.67 \mathrm{E}-24$ & $1.79 \mathrm{E}-30$ & $3.68 \mathrm{E}-28$ & $9.19 \mathrm{E}-28$ \\
\hline 166 & $2.92 \mathrm{E}-26$ & $2.22 \mathrm{E}-24$ & $2.54 \mathrm{E}-24$ & $1.46 \mathrm{E}-24$ & 7.37E-31 & $3.50 \mathrm{E}-28$ & $4.10 \mathrm{E}-28$ \\
\hline 167 & $1.16 \mathrm{E}-26$ & $8.74 \mathrm{E}-25$ & $7.55 \mathrm{E}-25$ & $1.55 \mathrm{E}-24$ & $2.90 \mathrm{E}-31$ & $2.68 \mathrm{E}-27$ & $1.29 \mathrm{E}-28$ \\
\hline 169 & $1.06 \mathrm{E}-26$ & $7.93 \mathrm{E}-25$ & $6.11 \mathrm{E}-25$ & $1.19 \mathrm{E}-24$ & $2.63 \mathrm{E}-31$ & $1.49 \mathrm{E}-27$ & $1.12 \mathrm{E}-28$ \\
\hline 170 & $1.46 \mathrm{E}-26$ & $1.08 \mathrm{E}-24$ & $4.02 \mathrm{E}-25$ & $2.16 \mathrm{E}-24$ & $3.57 \mathrm{E}-31$ & $4.94 \mathrm{E}-27$ & $1.72 \mathrm{E}-28$ \\
\hline 171 & $1.14 \mathrm{E}-25$ & $5.22 \mathrm{E}-24$ & $6.09 \mathrm{E}-24$ & $3.14 \mathrm{E}-24$ & $3.81 \mathrm{E}-30$ & $1.03 \mathrm{E}-27$ & 7.17E-28 \\
\hline 173 & 7.07E-27 & $5.27 \mathrm{E}-25$ & $2.95 \mathrm{E}-25$ & $1.43 \mathrm{E}-24$ & $1.75 \mathrm{E}-31$ & $5.95 \mathrm{E}-27$ & $8.05 \mathrm{E}-29$ \\
\hline 174 & $1.29 \mathrm{E}-26$ & $9.76 \mathrm{E}-25$ & $1.00 \mathrm{E}-24$ & $1.34 \mathrm{E}-24$ & $3.24 \mathrm{E}-31$ & $1.40 \mathrm{E}-27$ & $1.43 \mathrm{E}-28$ \\
\hline 175 & $1.64 \mathrm{E}-26$ & $1.22 \mathrm{E}-24$ & $6.83 \mathrm{E}-25$ & $1.66 \mathrm{E}-24$ & $4.05 \mathrm{E}-31$ & $1.73 \mathrm{E}-27$ & $1.72 \mathrm{E}-28$ \\
\hline 176 & 8.57E-27 & $6.55 \mathrm{E}-25$ & $9.02 \mathrm{E}-25$ & $1.89 \mathrm{E}-24$ & $2.17 \mathrm{E}-31$ & $8.60 \mathrm{E}-27$ & $1.00 \mathrm{E}-28$ \\
\hline 177 & $9.11 \mathrm{E}-27$ & $6.95 \mathrm{E}-25$ & $8.59 \mathrm{E}-25$ & $1.52 \mathrm{E}-24$ & $2.30 \mathrm{E}-31$ & $3.97 \mathrm{E}-27$ & $1.25 \mathrm{E}-28$ \\
\hline 178 & $5.93 \mathrm{E}-26$ & $4.46 \mathrm{E}-24$ & $3.43 \mathrm{E}-24$ & $2.92 \mathrm{E}-24$ & $1.48 \mathrm{E}-30$ & $6.97 \mathrm{E}-28$ & $7.20 \mathrm{E}-28$ \\
\hline 179 & $2.82 \mathrm{E}-26$ & $1.28 \mathrm{E}-24$ & $1.33 \mathrm{E}-24$ & $7.85 \mathrm{E}-25$ & $9.35 \mathrm{E}-31$ & $2.71 \mathrm{E}-28$ & $1.77 \mathrm{E}-28$ \\
\hline 180 & $2.17 \mathrm{E}-26$ & $1.67 \mathrm{E}-24$ & $2.60 \mathrm{E}-24$ & $2.01 \mathrm{E}-24$ & $5.53 \mathrm{E}-31$ & $1.59 \mathrm{E}-27$ & $3.26 \mathrm{E}-28$ \\
\hline 181 & $1.88 \mathrm{E}-26$ & $1.40 \mathrm{E}-24$ & $6.54 \mathrm{E}-25$ & $1.62 \mathrm{E}-24$ & $4.65 \mathrm{E}-31$ & $1.23 \mathrm{E}-27$ & $2.25 \mathrm{E}-28$ \\
\hline 182 & $2.14 \mathrm{E}-26$ & $1.65 \mathrm{E}-24$ & $2.88 \mathrm{E}-24$ & $1.62 \mathrm{E}-24$ & $5.47 \mathrm{E}-31$ & $8.45 \mathrm{E}-28$ & $3.13 \mathrm{E}-28$ \\
\hline 183 & $9.52 \mathrm{E}-26$ & $7.10 \mathrm{E}-24$ & $3.65 \mathrm{E}-24$ & $3.43 \mathrm{E}-24$ & $2.36 \mathrm{E}-30$ & $4.51 \mathrm{E}-28$ & $1.11 \mathrm{E}-27$ \\
\hline 184 & $6.28 \mathrm{E}-26$ & $4.68 \mathrm{E}-24$ & $2.51 \mathrm{E}-24$ & $1.93 \mathrm{E}-24$ & $1.55 \mathrm{E}-30$ & $1.83 \mathrm{E}-28$ & $7.52 \mathrm{E}-28$ \\
\hline 185 & $3.11 \mathrm{E}-26$ & $2.33 \mathrm{E}-24$ & $1.58 \mathrm{E}-24$ & $2.90 \mathrm{E}-24$ & $7.73 \mathrm{E}-31$ & $2.52 \mathrm{E}-27$ & $3.56 \mathrm{E}-28$ \\
\hline 186 & $4.86 \mathrm{E}-26$ & $3.67 \mathrm{E}-24$ & $3.17 \mathrm{E}-24$ & $2.77 \mathrm{E}-24$ & $1.22 \mathrm{E}-30$ & $8.71 \mathrm{E}-28$ & $6.29 \mathrm{E}-28$ \\
\hline 187 & $1.61 \mathrm{E}-26$ & $1.20 \mathrm{E}-24$ & $7.87 \mathrm{E}-25$ & $1.14 \mathrm{E}-24$ & $4.00 \mathrm{E}-31$ & $5.68 \mathrm{E}-28$ & $1.96 \mathrm{E}-28$ \\
\hline 188 & $2.46 \mathrm{E}-26$ & $1.84 \mathrm{E}-24$ & $1.25 \mathrm{E}-24$ & $1.95 \mathrm{E}-24$ & $6.12 \mathrm{E}-31$ & $1.23 \mathrm{E}-27$ & $2.93 \mathrm{E}-28$ \\
\hline 190 & $2.42 \mathrm{E}-26$ & $1.84 \mathrm{E}-24$ & $2.02 \mathrm{E}-24$ & $1.68 \mathrm{E}-24$ & $6.11 \mathrm{E}-31$ & 7.63E-28 & $2.95 \mathrm{E}-28$ \\
\hline 191 & $1.92 \mathrm{E}-26$ & $1.21 \mathrm{E}-24$ & $1.23 \mathrm{E}-24$ & $2.20 \mathrm{E}-24$ & $5.35 \mathrm{E}-31$ & $4.79 \mathrm{E}-27$ & $1.62 \mathrm{E}-28$ \\
\hline 192 & $2.61 \mathrm{E}-26$ & $1.95 \mathrm{E}-24$ & $1.18 \mathrm{E}-24$ & $2.11 \mathrm{E}-24$ & $6.46 \mathrm{E}-31$ & $1.39 \mathrm{E}-27$ & $3.04 \mathrm{E}-28$ \\
\hline 193 & $5.52 \mathrm{E}-26$ & $4.12 \mathrm{E}-24$ & $2.31 \mathrm{E}-24$ & $3.16 \mathrm{E}-24$ & $1.37 \mathrm{E}-30$ & $1.04 \mathrm{E}-27$ & $6.79 \mathrm{E}-28$ \\
\hline 194 & $9.77 \mathrm{E}-26$ & $7.30 \mathrm{E}-24$ & $4.26 \mathrm{E}-24$ & $3.87 \mathrm{E}-24$ & $2.42 \mathrm{E}-30$ & $6.11 \mathrm{E}-28$ & $1.32 \mathrm{E}-27$ \\
\hline 195 & $1.15 \mathrm{E}-26$ & $8.78 \mathrm{E}-25$ & $9.22 \mathrm{E}-25$ & $9.83 \mathrm{E}-25$ & $2.91 \mathrm{E}-31$ & $6.77 \mathrm{E}-28$ & $1.46 \mathrm{E}-28$ \\
\hline 197 & $4.65 \mathrm{E}-27$ & $3.53 \mathrm{E}-25$ & $3.63 \mathrm{E}-25$ & $1.04 \mathrm{E}-24$ & $1.17 \mathrm{E}-31$ & $4.95 \mathrm{E}-27$ & $5.60 \mathrm{E}-29$ \\
\hline 198 & $2.60 \mathrm{E}-26$ & $1.94 \mathrm{E}-24$ & $9.96 \mathrm{E}-25$ & $2.41 \mathrm{E}-24$ & $6.44 \mathrm{E}-31$ & $2.09 \mathrm{E}-27$ & $3.30 \mathrm{E}-28$ \\
\hline 199 & $6.86 \mathrm{E}-26$ & $5.13 \mathrm{E}-24$ & $3.36 \mathrm{E}-24$ & 4.63E-24 & $1.70 \mathrm{E}-30$ & $2.11 \mathrm{E}-27$ & $9.33 \mathrm{E}-28$ \\
\hline 200 & $1.10 \mathrm{E}-26$ & $8.35 \mathrm{E}-25$ & $7.80 \mathrm{E}-25$ & $1.66 \mathrm{E}-24$ & $2.77 \mathrm{E}-31$ & $3.61 \mathrm{E}-27$ & $1.28 \mathrm{E}-28$ \\
\hline 202 & $5.94 \mathrm{E}-26$ & $4.44 \mathrm{E}-24$ & $2.59 \mathrm{E}-24$ & $3.18 \mathrm{E}-24$ & $1.47 \mathrm{E}-30$ & $9.15 \mathrm{E}-28$ & $8.15 \mathrm{E}-28$ \\
\hline 203 & 4.73E-26 & $1.45 \mathrm{E}-24$ & $1.58 \mathrm{E}-24$ & $2.20 \mathrm{E}-24$ & $1.97 \mathrm{E}-30$ & $6.92 \mathrm{E}-27$ & $1.55 \mathrm{E}-28$ \\
\hline 204 & $5.00 \mathrm{E}-26$ & $3.75 \mathrm{E}-24$ & $2.36 \mathrm{E}-24$ & $2.13 \mathrm{E}-24$ & $1.24 \mathrm{E}-30$ & $3.87 \mathrm{E}-28$ & $7.18 \mathrm{E}-28$ \\
\hline 206 & 7.54E-27 & $5.76 \mathrm{E}-25$ & $6.99 \mathrm{E}-25$ & $2.63 \mathrm{E}-24$ & $1.91 \mathrm{E}-31$ & $3.01 \mathrm{E}-26$ & $9.10 \mathrm{E}-29$ \\
\hline 207 & $1.22 \mathrm{E}-25$ & $9.11 \mathrm{E}-24$ & $5.74 \mathrm{E}-24$ & $2.98 \mathrm{E}-24$ & $3.02 \mathrm{E}-30$ & $1.79 \mathrm{E}-28$ & $1.54 \mathrm{E}-27$ \\
\hline 208 & $2.50 \mathrm{E}-26$ & $1.92 \mathrm{E}-24$ & $2.64 \mathrm{E}-24$ & $1.84 \mathrm{E}-24$ & $6.37 \mathrm{E}-31$ & $9.17 \mathrm{E}-28$ & $3.19 \mathrm{E}-28$ \\
\hline 210 & $2.96 \mathrm{E}-26$ & $1.36 \mathrm{E}-24$ & $1.78 \mathrm{E}-24$ & $9.60 \mathrm{E}-25$ & $9.91 \mathrm{E}-31$ & $4.37 \mathrm{E}-28$ & $1.92 \mathrm{E}-28$ \\
\hline 212 & 4.32E-26 & $3.23 \mathrm{E}-24$ & $1.88 \mathrm{E}-24$ & $2.65 \mathrm{E}-24$ & $1.07 \mathrm{E}-30$ & $1.01 \mathrm{E}-27$ & $5.19 \mathrm{E}-28$ \\
\hline 213 & $1.53 \mathrm{E}-26$ & $1.15 \mathrm{E}-24$ & $7.78 \mathrm{E}-25$ & $1.37 \mathrm{E}-24$ & $3.81 \mathrm{E}-31$ & $1.08 \mathrm{E}-27$ & $1.84 \mathrm{E}-28$ \\
\hline
\end{tabular}




\begin{tabular}{|c|c|c|c|c|c|c|c|}
\hline 214 & $6.62 \mathrm{E}-26$ & $4.97 \mathrm{E}-24$ & $3.60 \mathrm{E}-24$ & $1.83 \mathrm{E}-24$ & $1.65 \mathrm{E}-30$ & $1.38 \mathrm{E}-28$ & $8.67 \mathrm{E}-28$ \\
\hline 215 & $1.48 \mathrm{E}-26$ & $1.11 \mathrm{E}-24$ & $8.83 \mathrm{E}-25$ & $1.45 \mathrm{E}-24$ & $3.69 \mathrm{E}-31$ & $1.38 \mathrm{E}-27$ & $1.90 \mathrm{E}-28$ \\
\hline 217 & $1.98 \mathrm{E}-26$ & $1.50 \mathrm{E}-24$ & $1.40 \mathrm{E}-24$ & $1.08 \mathrm{E}-24$ & $4.96 \mathrm{E}-31$ & $3.09 \mathrm{E}-28$ & $2.52 \mathrm{E}-28$ \\
\hline 218 & $4.77 \mathrm{E}-26$ & $2.18 \mathrm{E}-24$ & $2.38 \mathrm{E}-24$ & $1.64 \mathrm{E}-24$ & $1.59 \mathrm{E}-30$ & $8.59 \mathrm{E}-28$ & $2.95 \mathrm{E}-28$ \\
\hline 219 & $4.57 \mathrm{E}-26$ & $2.15 \mathrm{E}-24$ & 4.24E-24 & $1.25 \mathrm{E}-24$ & $1.57 \mathrm{E}-30$ & $3.75 \mathrm{E}-28$ & $3.17 \mathrm{E}-28$ \\
\hline 220 & $1.57 \mathrm{E}-25$ & $2.13 \mathrm{E}-24$ & $1.47 \mathrm{E}-24$ & $8.80 \mathrm{E}-25$ & $9.79 \mathrm{E}-30$ & 4.60E-28 & $1.71 \mathrm{E}-28$ \\
\hline 221 & $3.11 \mathrm{E}-26$ & $2.36 \mathrm{E}-24$ & $2.70 \mathrm{E}-24$ & $1.87 \mathrm{E}-24$ & $7.83 \mathrm{E}-31$ & $6.45 \mathrm{E}-28$ & $3.95 \mathrm{E}-28$ \\
\hline 223 & $4.02 \mathrm{E}-25$ & $3.61 \mathrm{E}-24$ & $4.21 \mathrm{E}-24$ & $4.01 \mathrm{E}-24$ & $3.24 \mathrm{E}-29$ & $2.30 \mathrm{E}-26$ & $2.40 \mathrm{E}-28$ \\
\hline 224 & $6.08 \mathrm{E}-26$ & $4.58 \mathrm{E}-24$ & $3.96 \mathrm{E}-24$ & $3.08 \mathrm{E}-24$ & $1.52 \mathrm{E}-30$ & $7.70 \mathrm{E}-28$ & $8.01 \mathrm{E}-28$ \\
\hline 225 & $1.15 \mathrm{E}-26$ & $3.59 \mathrm{E}-25$ & $6.27 \mathrm{E}-25$ & $9.11 \mathrm{E}-25$ & $4.88 \mathrm{E}-31$ & $7.90 \mathrm{E}-27$ & $4.31 \mathrm{E}-29$ \\
\hline 227 & $9.93 \mathrm{E}-25$ & $5.08 \mathrm{E}-24$ & 4.44E-24 & $4.06 \mathrm{E}-24$ & $1.08 \mathrm{E}-28$ & $2.12 \mathrm{E}-26$ & $2.44 \mathrm{E}-28$ \\
\hline 229 & $1.58 \mathrm{E}-26$ & $1.20 \mathrm{E}-24$ & $1.23 \mathrm{E}-24$ & $1.47 \mathrm{E}-24$ & $3.98 \mathrm{E}-31$ & $1.22 \mathrm{E}-27$ & $2.12 \mathrm{E}-28$ \\
\hline 230 & $1.20 \mathrm{E}-25$ & $9.00 \mathrm{E}-24$ & $6.09 \mathrm{E}-24$ & $5.37 \mathrm{E}-24$ & 2.99E-30 & $1.07 \mathrm{E}-27$ & $1.63 \mathrm{E}-27$ \\
\hline 233 & $1.63 \mathrm{E}-25$ & $1.85 \mathrm{E}-24$ & $3.19 \mathrm{E}-24$ & $2.05 \mathrm{E}-24$ & $1.21 \mathrm{E}-29$ & $9.36 \mathrm{E}-27$ & $1.40 \mathrm{E}-28$ \\
\hline 237 & $3.00 \mathrm{E}-25$ & $2.25 \mathrm{E}-23$ & $1.52 \mathrm{E}-23$ & $3.70 \mathrm{E}-24$ & 7.47E-30 & $5.58 \mathrm{E}-29$ & $3.53 \mathrm{E}-27$ \\
\hline 238 & $1.33 \mathrm{E}-24$ & $7.58 \mathrm{E}-24$ & 7.90E-24 & $1.84 \mathrm{E}-24$ & $1.38 \mathrm{E}-28$ & $8.01 \mathrm{E}-28$ & $3.89 \mathrm{E}-28$ \\
\hline 240 & $6.39 \mathrm{E}-25$ & $4.75 \mathrm{E}-23$ & $2.22 \mathrm{E}-23$ & $5.25 \mathrm{E}-24$ & $1.58 \mathrm{E}-29$ & 3.62E-29 & $8.59 \mathrm{E}-27$ \\
\hline 242 & $1.84 \mathrm{E}-24$ & $1.36 \mathrm{E}-22$ & $5.73 \mathrm{E}-23$ & $4.15 \mathrm{E}-24$ & $4.52 \mathrm{E}-29$ & $2.17 \mathrm{E}-30$ & $2.25 \mathrm{E}-26$ \\
\hline 244 & $2.06 \mathrm{E}-24$ & $1.53 \mathrm{E}-22$ & $7.16 \mathrm{E}-23$ & $5.88 \mathrm{E}-24$ & $5.09 \mathrm{E}-29$ & $4.88 \mathrm{E}-30$ & $2.84 \mathrm{E}-26$ \\
\hline 245 & $2.72 \mathrm{E}-25$ & $2.03 \mathrm{E}-23$ & $1.14 \mathrm{E}-23$ & $3.56 \mathrm{E}-24$ & $6.73 \mathrm{E}-30$ & $6.17 \mathrm{E}-29$ & $2.89 \mathrm{E}-27$ \\
\hline 254 & $1.13 \mathrm{E}-26$ & $8.64 \mathrm{E}-25$ & $1.15 \mathrm{E}-24$ & $2.17 \mathrm{E}-24$ & $2.87 \mathrm{E}-31$ & 7.49E-27 & $1.62 \mathrm{E}-28$ \\
\hline 256 & $5.31 \mathrm{E}-26$ & $2.09 \mathrm{E}-24$ & $2.16 \mathrm{E}-24$ & $2.44 \mathrm{E}-24$ & $1.91 \mathrm{E}-30$ & $3.51 \mathrm{E}-27$ & $2.60 \mathrm{E}-28$ \\
\hline 257 & $4.18 \mathrm{E}-26$ & $3.14 \mathrm{E}-24$ & $2.49 \mathrm{E}-24$ & $6.21 \mathrm{E}-24$ & $1.04 \mathrm{E}-30$ & $1.35 \mathrm{E}-26$ & $5.37 \mathrm{E}-28$ \\
\hline 258 & $1.93 \mathrm{E}-26$ & $1.47 \mathrm{E}-24$ & $1.88 \mathrm{E}-24$ & $2.85 \mathrm{E}-24$ & $4.87 \mathrm{E}-31$ & $5.94 \mathrm{E}-27$ & $2.83 \mathrm{E}-28$ \\
\hline 368 & $6.21 \mathrm{E}-26$ & 4.62E-24 & $2.26 \mathrm{E}-24$ & $3.62 \mathrm{E}-24$ & $1.53 \mathrm{E}-30$ & $1.25 \mathrm{E}-27$ & $8.34 \mathrm{E}-28$ \\
\hline 374 & $4.43 \mathrm{E}-26$ & $3.32 \mathrm{E}-24$ & $2.40 \mathrm{E}-24$ & $2.12 \mathrm{E}-24$ & $1.10 \mathrm{E}-30$ & $4.84 \mathrm{E}-28$ & $5.37 \mathrm{E}-28$ \\
\hline 489 & $4.27 \mathrm{E}-25$ & $1.98 \mathrm{E}-23$ & $3.13 \mathrm{E}-23$ & 4.99E-24 & $1.44 \mathrm{E}-29$ & $2.86 \mathrm{E}-28$ & $2.60 \mathrm{E}-27$ \\
\hline
\end{tabular}

Table A5 Concentrations of $\mathrm{Hg}$ species in surface water of Everglades in spring $2005\left(\left[\mathrm{~S}^{2-}\right]<<\right.$ $3.2 \times 10^{-7} \mathrm{mg} / \mathrm{L}$ )

\begin{tabular}{cccccccc}
\hline Station & $\begin{array}{c}\mathbf{H g} \\
\mathbf{m o l} / \mathbf{L}\end{array}$ & $\begin{array}{c}\mathbf{R S H g}^{(\mathbf{n}-\mathbf{1})-} \\
\mathbf{m o l} / \mathbf{L}\end{array}$ & $\begin{array}{c}\mathbf{H g C l} \mathbf{2} \\
\mathbf{m o l} / \mathbf{L}\end{array}$ & $\begin{array}{c}\mathbf{H g B r C l} \\
\mathbf{m o l} / \mathbf{L}\end{array}$ & $\begin{array}{c}\mathbf{H g C l}_{3}- \\
\mathbf{m o l} / \mathbf{L}\end{array}$ & $\begin{array}{c}\mathbf{H g C l O H} \\
\mathbf{m o l} / \mathbf{L}\end{array}$ & $\begin{array}{c}\mathbf{H g}(\mathbf{O H})_{2} \\
\mathbf{m o l} / \mathbf{L}\end{array}$ \\
\hline $\mathbf{2 8}$ & $3.34 \mathrm{E}-11$ & $3.34 \mathrm{E}-11$ & $2.24 \mathrm{E}-20$ & $5.53 \mathrm{E}-20$ & $2.87 \mathrm{E}-22$ & $1.30 \mathrm{E}-20$ & $6.41 \mathrm{E}-20$ \\
$\mathbf{3 0}$ & $1.50 \mathrm{E}-11$ & $1.50 \mathrm{E}-11$ & $1.67 \mathrm{E}-20$ & $1.33 \mathrm{E}-20$ & $2.22 \mathrm{E}-22$ & $2.37 \mathrm{E}-20$ & $1.23 \mathrm{E}-19$ \\
$\mathbf{3 1}$ & $1.10 \mathrm{E}-11$ & $1.10 \mathrm{E}-11$ & $1.18 \mathrm{E}-20$ & $8.95 \mathrm{E}-21$ & $1.83 \mathrm{E}-22$ & $1.42 \mathrm{E}-20$ & $5.81 \mathrm{E}-20$ \\
$\mathbf{3 3}$ & $1.20 \mathrm{E}-11$ & $1.20 \mathrm{E}-11$ & $7.53 \mathrm{E}-21$ & $5.21 \mathrm{E}-21$ & $1.15 \mathrm{E}-22$ & $1.38 \mathrm{E}-20$ & $1.21 \mathrm{E}-19$ \\
$\mathbf{3 7}$ & $1.25 \mathrm{E}-11$ & $1.25 \mathrm{E}-11$ & $6.42 \mathrm{E}-21$ & $2.18 \mathrm{E}-21$ & $6.94 \mathrm{E}-23$ & $1.99 \mathrm{E}-20$ & $1.63 \mathrm{E}-19$ \\
$\mathbf{4 3}$ & $1.35 \mathrm{E}-11$ & $1.35 \mathrm{E}-11$ & $1.13 \mathrm{E}-20$ & $6.18 \mathrm{E}-21$ & $1.02 \mathrm{E}-22$ & $1.86 \mathrm{E}-20$ & $8.59 \mathrm{E}-20$ \\
$\mathbf{4 5}$ & $1.05 \mathrm{E}-11$ & $1.05 \mathrm{E}-11$ & $1.37 \mathrm{E}-20$ & $7.59 \mathrm{E}-21$ & $1.55 \mathrm{E}-22$ & $9.34 \mathrm{E}-21$ & $5.31 \mathrm{E}-20$ \\
$\mathbf{4 6}$ & $9.47 \mathrm{E}-12$ & $9.47 \mathrm{E}-12$ & $1.65 \mathrm{E}-20$ & $9.47 \mathrm{E}-21$ & $1.78 \mathrm{E}-22$ & $9.74 \mathrm{E}-21$ & $2.75 \mathrm{E}-20$ \\
$\mathbf{4 7}$ & $1.35 \mathrm{E}-11$ & $1.35 \mathrm{E}-11$ & $1.17 \mathrm{E}-20$ & $7.32 \mathrm{E}-21$ & $1.16 \mathrm{E}-22$ & $2.02 \mathrm{E}-20$ & $1.01 \mathrm{E}-19$ \\
$\mathbf{4 9}$ & $1.20 \mathrm{E}-11$ & $1.20 \mathrm{E}-11$ & $1.50 \mathrm{E}-20$ & $9.17 \mathrm{E}-21$ & $2.30 \mathrm{E}-22$ & $1.32 \mathrm{E}-20$ & $6.64 \mathrm{E}-20$ \\
\hline
\end{tabular}




\begin{tabular}{|c|c|c|c|c|c|c|c|}
\hline 51 & $7.48 \mathrm{E}-12$ & $7.48 \mathrm{E}-12$ & $6.17 \mathrm{E}-21$ & $4.26 \mathrm{E}-21$ & $5.56 \mathrm{E}-23$ & $1.03 \mathrm{E}-20$ & $4.89 \mathrm{E}-20$ \\
\hline 52 & $1.10 \mathrm{E}-11$ & $1.10 \mathrm{E}-11$ & $9.69 \mathrm{E}-21$ & $8.63 \mathrm{E}-21$ & $6.76 \mathrm{E}-23$ & $1.29 \mathrm{E}-20$ & $4.61 \mathrm{E}-20$ \\
\hline 53 & $1.10 \mathrm{E}-11$ & $1.10 \mathrm{E}-11$ & $4.62 \mathrm{E}-21$ & $2.78 \mathrm{E}-21$ & $4.79 \mathrm{E}-23$ & $1.09 \mathrm{E}-20$ & $1.33 \mathrm{E}-19$ \\
\hline 54 & $5.98 \mathrm{E}-12$ & $5.98 \mathrm{E}-12$ & $2.72 \mathrm{E}-21$ & $2.68 \mathrm{E}-21$ & $1.71 \mathrm{E}-23$ & $6.33 \mathrm{E}-21$ & $5.23 \mathrm{E}-20$ \\
\hline 55 & $9.47 \mathrm{E}-12$ & $9.47 \mathrm{E}-12$ & $1.39 \mathrm{E}-20$ & $1.04 \mathrm{E}-20$ & $1.16 \mathrm{E}-22$ & $1.26 \mathrm{E}-20$ & $2.68 \mathrm{E}-20$ \\
\hline 56 & $1.50 \mathrm{E}-11$ & $1.50 \mathrm{E}-11$ & $1.01 \mathrm{E}-20$ & $4.80 \mathrm{E}-21$ & $1.60 \mathrm{E}-22$ & $3.01 \mathrm{E}-20$ & $2.55 \mathrm{E}-19$ \\
\hline 57 & $1.75 \mathrm{E}-11$ & $1.75 \mathrm{E}-11$ & $1.43 \mathrm{E}-20$ & $1.04 \mathrm{E}-20$ & $2.10 \mathrm{E}-22$ & $2.22 \mathrm{E}-20$ & $1.26 \mathrm{E}-19$ \\
\hline 59 & $9.47 \mathrm{E}-12$ & $9.47 \mathrm{E}-12$ & $9.75 \mathrm{E}-21$ & $6.73 \mathrm{E}-21$ & $9.66 \mathrm{E}-23$ & $1.64 \mathrm{E}-20$ & $6.71 \mathrm{E}-20$ \\
\hline 61 & $7.48 \mathrm{E}-12$ & $7.48 \mathrm{E}-12$ & $1.08 \mathrm{E}-21$ & $1.03 \mathrm{E}-21$ & $7.08 \mathrm{E}-24$ & $7.53 \mathrm{E}-21$ & $3.55 \mathrm{E}-19$ \\
\hline 62 & $9.97 \mathrm{E}-12$ & $9.97 \mathrm{E}-12$ & 8.29E-21 & $5.86 \mathrm{E}-21$ & $8.03 \mathrm{E}-23$ & $9.13 \mathrm{E}-21$ & $5.96 \mathrm{E}-20$ \\
\hline 63 & $1.30 \mathrm{E}-11$ & $1.30 \mathrm{E}-11$ & $6.83 \mathrm{E}-21$ & $3.56 \mathrm{E}-21$ & $8.15 \mathrm{E}-23$ & $1.27 \mathrm{E}-20$ & $1.64 \mathrm{E}-19$ \\
\hline 66 & $5.48 \mathrm{E}-12$ & $5.48 \mathrm{E}-12$ & $1.04 \mathrm{E}-20$ & $6.33 \mathrm{E}-21$ & $1.59 \mathrm{E}-22$ & $1.84 \mathrm{E}-20$ & $5.54 \mathrm{E}-20$ \\
\hline 67 & $6.48 \mathrm{E}-12$ & $6.48 \mathrm{E}-12$ & $2.81 \mathrm{E}-21$ & $1.65 \mathrm{E}-21$ & $2.97 \mathrm{E}-23$ & $1.14 \mathrm{E}-20$ & $1.62 \mathrm{E}-19$ \\
\hline 68 & $7.48 \mathrm{E}-12$ & $7.48 \mathrm{E}-12$ & $7.57 \mathrm{E}-21$ & $3.67 \mathrm{E}-21$ & $9.72 \mathrm{E}-23$ & $1.30 \mathrm{E}-20$ & $5.19 \mathrm{E}-20$ \\
\hline 69 & $6.98 \mathrm{E}-12$ & $6.98 \mathrm{E}-12$ & $3.52 \mathrm{E}-21$ & $2.78 \mathrm{E}-21$ & $2.78 \mathrm{E}-23$ & 7.17E-21 & $1.15 \mathrm{E}-19$ \\
\hline 70 & $1.50 \mathrm{E}-11$ & $1.50 \mathrm{E}-11$ & $8.84 \mathrm{E}-21$ & $8.72 \mathrm{E}-21$ & $5.57 \mathrm{E}-23$ & $1.75 \mathrm{E}-20$ & $8.60 \mathrm{E}-20$ \\
\hline 73 & $6.48 \mathrm{E}-12$ & $6.48 \mathrm{E}-12$ & $7.16 \mathrm{E}-21$ & $4.00 \mathrm{E}-21$ & $1.35 \mathrm{E}-22$ & $8.47 \mathrm{E}-21$ & 7.94E-20 \\
\hline 75 & $1.25 \mathrm{E}-11$ & $1.25 \mathrm{E}-11$ & $9.68 \mathrm{E}-21$ & $6.69 \mathrm{E}-21$ & $8.72 \mathrm{E}-23$ & $1.80 \mathrm{E}-20$ & $1.11 \mathrm{E}-19$ \\
\hline 77 & $7.48 \mathrm{E}-12$ & $7.48 \mathrm{E}-12$ & $4.52 \mathrm{E}-21$ & $2.08 \mathrm{E}-21$ & $6.10 \mathrm{E}-23$ & 7.97E-21 & $4.92 \mathrm{E}-20$ \\
\hline 80 & $1.05 \mathrm{E}-11$ & $1.05 \mathrm{E}-11$ & $7.68 \mathrm{E}-21$ & $2.87 \mathrm{E}-21$ & $1.28 \mathrm{E}-22$ & $1.39 \mathrm{E}-20$ & $1.26 \mathrm{E}-19$ \\
\hline 81 & $9.97 \mathrm{E}-12$ & $9.97 \mathrm{E}-12$ & $1.03 \mathrm{E}-20$ & $4.66 \mathrm{E}-21$ & $1.55 \mathrm{E}-22$ & 2.02E-20 & $1.02 \mathrm{E}-19$ \\
\hline 82 & $9.97 \mathrm{E}-12$ & $9.97 \mathrm{E}-12$ & $1.41 \mathrm{E}-20$ & $7.03 \mathrm{E}-21$ & $2.28 \mathrm{E}-22$ & $1.79 \mathrm{E}-20$ & $7.03 \mathrm{E}-20$ \\
\hline 83 & $1.30 \mathrm{E}-11$ & $1.30 \mathrm{E}-11$ & $1.51 \mathrm{E}-20$ & $8.51 \mathrm{E}-21$ & $1.67 \mathrm{E}-22$ & 2.05E-20 & $8.83 \mathrm{E}-20$ \\
\hline 84 & $1.05 \mathrm{E}-11$ & $1.05 \mathrm{E}-11$ & $3.40 \mathrm{E}-21$ & $1.51 \mathrm{E}-21$ & 7.67E-23 & $1.38 \mathrm{E}-20$ & $3.72 \mathrm{E}-19$ \\
\hline 85 & $1.05 \mathrm{E}-11$ & $1.05 \mathrm{E}-11$ & $2.24 \mathrm{E}-20$ & $1.40 \mathrm{E}-20$ & $3.13 \mathrm{E}-22$ & $2.48 \mathrm{E}-20$ & $6.87 \mathrm{E}-20$ \\
\hline 88 & $9.47 \mathrm{E}-12$ & $9.47 \mathrm{E}-12$ & 7.40E-21 & $3.53 \mathrm{E}-21$ & $9.67 \mathrm{E}-23$ & $1.30 \mathrm{E}-20$ & $1.07 \mathrm{E}-19$ \\
\hline 89 & $1.50 \mathrm{E}-11$ & $1.50 \mathrm{E}-11$ & $8.99 \mathrm{E}-21$ & $4.14 \mathrm{E}-21$ & $1.94 \mathrm{E}-22$ & $1.74 \mathrm{E}-20$ & $2.45 \mathrm{E}-19$ \\
\hline 90 & $9.47 \mathrm{E}-12$ & $9.47 \mathrm{E}-12$ & $1.01 \mathrm{E}-20$ & $3.88 \mathrm{E}-21$ & $1.64 \mathrm{E}-22$ & $1.54 \mathrm{E}-20$ & $6.34 \mathrm{E}-20$ \\
\hline 91 & $1.60 \mathrm{E}-11$ & $1.60 \mathrm{E}-11$ & $2.46 \mathrm{E}-21$ & $1.17 \mathrm{E}-21$ & $3.21 \mathrm{E}-23$ & $1.52 \mathrm{E}-20$ & $7.47 \mathrm{E}-19$ \\
\hline 93 & $1.20 \mathrm{E}-11$ & $1.20 \mathrm{E}-11$ & $5.10 \mathrm{E}-21$ & $2.31 \mathrm{E}-21$ & $7.00 \mathrm{E}-23$ & $1.18 \mathrm{E}-20$ & $2.23 \mathrm{E}-19$ \\
\hline 94 & $1.15 \mathrm{E}-11$ & $1.15 \mathrm{E}-11$ & $2.61 \mathrm{E}-21$ & $1.39 \mathrm{E}-21$ & $3.06 \mathrm{E}-23$ & $8.77 \mathrm{E}-21$ & $3.25 \mathrm{E}-19$ \\
\hline 95 & $1.10 \mathrm{E}-11$ & $1.10 \mathrm{E}-11$ & $1.79 \mathrm{E}-20$ & $7.71 \mathrm{E}-21$ & $2.57 \mathrm{E}-22$ & $1.82 \mathrm{E}-20$ & $5.89 \mathrm{E}-20$ \\
\hline 99 & $1.20 \mathrm{E}-11$ & $1.20 \mathrm{E}-11$ & $6.08 \mathrm{E}-21$ & $2.67 \mathrm{E}-21$ & $8.63 \mathrm{E}-23$ & $1.16 \mathrm{E}-20$ & $1.30 \mathrm{E}-19$ \\
\hline 101 & $1.84 \mathrm{E}-11$ & $1.84 \mathrm{E}-11$ & $1.93 \mathrm{E}-21$ & $1.40 \mathrm{E}-21$ & $1.65 \mathrm{E}-23$ & $1.26 \mathrm{E}-20$ & $7.48 \mathrm{E}-19$ \\
\hline 105 & $8.48 \mathrm{E}-12$ & $8.48 \mathrm{E}-12$ & $5.18 \mathrm{E}-21$ & $3.00 \mathrm{E}-21$ & 7.23E-23 & 1.09E-20 & $6.90 \mathrm{E}-20$ \\
\hline 106 & $1.20 \mathrm{E}-11$ & $1.20 \mathrm{E}-11$ & $2.16 \mathrm{E}-21$ & $1.53 \mathrm{E}-21$ & $1.90 \mathrm{E}-23$ & $6.59 \mathrm{E}-21$ & $2.19 \mathrm{E}-19$ \\
\hline 107 & $2.34 \mathrm{E}-11$ & $2.34 \mathrm{E}-11$ & $1.24 \mathrm{E}-20$ & $6.11 \mathrm{E}-21$ & $3.90 \mathrm{E}-22$ & $2.83 \mathrm{E}-20$ & $4.90 \mathrm{E}-19$ \\
\hline 114 & $1.40 \mathrm{E}-11$ & $1.40 \mathrm{E}-11$ & $6.45 \mathrm{E}-20$ & $8.10 \mathrm{E}-20$ & $3.20 \mathrm{E}-22$ & $8.13 \mathrm{E}-21$ & $3.32 \mathrm{E}-21$ \\
\hline 119 & $1.30 \mathrm{E}-11$ & $1.30 \mathrm{E}-11$ & $6.29 \mathrm{E}-20$ & $5.43 \mathrm{E}-20$ & $4.53 \mathrm{E}-22$ & $1.29 \mathrm{E}-20$ & $6.74 \mathrm{E}-21$ \\
\hline 351 & $1.50 \mathrm{E}-11$ & $1.50 \mathrm{E}-11$ & $2.25 \mathrm{E}-20$ & $1.96 \mathrm{E}-20$ & $3.70 \mathrm{E}-22$ & $2.72 \mathrm{E}-20$ & $7.24 \mathrm{E}-20$ \\
\hline 365 & $7.98 \mathrm{E}-12$ & $7.98 \mathrm{E}-12$ & $5.52 \mathrm{E}-21$ & $2.99 \mathrm{E}-21$ & $6.34 \mathrm{E}-23$ & $8.59 \mathrm{E}-21$ & $7.86 \mathrm{E}-20$ \\
\hline
\end{tabular}


Table A5 (Cont.)

\begin{tabular}{|c|c|c|c|c|c|c|c|}
\hline Station & $\begin{array}{l}\mathrm{HgBr}_{2} \\
\mathrm{~mol} / \mathrm{L}\end{array}$ & $\begin{array}{c}\mathrm{HgBrOH} \\
\mathrm{mol} / \mathrm{L}\end{array}$ & $\begin{array}{c}\mathrm{HgCl}_{4}{ }^{2-} \\
\mathrm{mol} / \mathrm{L}\end{array}$ & $\begin{array}{c}\mathrm{HgBr}_{3}^{-} \\
\mathrm{mol} / \mathrm{L}\end{array}$ & $\begin{array}{l}\mathrm{HgBr}^{+} \\
\mathrm{mol} / \mathrm{L}\end{array}$ & $\begin{array}{l}\mathrm{HgCl}^{+} \\
\mathrm{mol} / \mathrm{L}\end{array}$ & $\begin{array}{c}\mathrm{HgOH}^{+} \\
\mathrm{mol} / \mathrm{L}\end{array}$ \\
\hline 28 & $3.24 \mathrm{E}-21$ & $1.46 \mathrm{E}-20$ & $1.27 \mathrm{E}-24$ & $8.29 \mathrm{E}-24$ & $2.43 \mathrm{E}-23$ & $6.35 \mathrm{E}-24$ & $3.08 \mathrm{E}-24$ \\
\hline 30 & $7.11 \mathrm{E}-22$ & $5.64 \mathrm{E}-21$ & $1.02 \mathrm{E}-24$ & $2.14 \mathrm{E}-25$ & $5.65 \mathrm{E}-24$ & $4.58 \mathrm{E}-24$ & $3.56 \mathrm{E}-24$ \\
\hline 31 & $5.00 \mathrm{E}-22$ & $3.11 \mathrm{E}-21$ & $9.88 \mathrm{E}-25$ & $1.54 \mathrm{E}-25$ & $3.28 \mathrm{E}-24$ & $2.78 \mathrm{E}-24$ & $1.77 \mathrm{E}-24$ \\
\hline 33 & $1.73 \mathrm{E}-22$ & $3.26 \mathrm{E}-21$ & $6.15 \mathrm{E}-25$ & $7.26 \mathrm{E}-26$ & $1.94 \mathrm{E}-24$ & $1.81 \mathrm{E}-24$ & $2.08 \mathrm{E}-24$ \\
\hline 37 & 7.39E-23 & $1.72 \mathrm{E}-21$ & $2.59 \mathrm{E}-25$ & $5.19 \mathrm{E}-27$ & $1.14 \mathrm{E}-24$ & $2.16 \mathrm{E}-24$ & $3.13 \mathrm{E}-24$ \\
\hline 43 & $3.15 \mathrm{E}-22$ & $2.66 \mathrm{E}-21$ & $3.14 \mathrm{E}-25$ & $3.16 \mathrm{E}-26$ & $3.83 \mathrm{E}-24$ & $4.53 \mathrm{E}-24$ & $3.58 \mathrm{E}-24$ \\
\hline 45 & $1.01 \mathrm{E}-22$ & $2.33 \mathrm{E}-21$ & $5.97 \mathrm{E}-25$ & $4.98 \mathrm{E}-26$ & $3.78 \mathrm{E}-24$ & 4.41E-24 & $2.49 \mathrm{E}-24$ \\
\hline 46 & $2.63 \mathrm{E}-22$ & $1.91 \mathrm{E}-21$ & $6.59 \mathrm{E}-25$ & $6.47 \mathrm{E}-26$ & $4.91 \mathrm{E}-24$ & $5.50 \mathrm{E}-24$ & $2.04 \mathrm{E}-24$ \\
\hline 47 & $4.14 \mathrm{E}-22$ & $3.36 \mathrm{E}-21$ & $3.91 \mathrm{E}-25$ & $5.46 \mathrm{E}-26$ & $4.13 \mathrm{E}-24$ & $4.24 \mathrm{E}-24$ & $3.58 \mathrm{E}-24$ \\
\hline 49 & $2.14 \mathrm{E}-22$ & $3.01 \mathrm{E}-21$ & $1.22 \mathrm{E}-24$ & $9.95 \mathrm{E}-26$ & $3.39 \mathrm{E}-24$ & $3.59 \mathrm{E}-24$ & $2.16 \mathrm{E}-24$ \\
\hline 51 & $2.71 \mathrm{E}-22$ & $1.87 \mathrm{E}-21$ & $1.71 \mathrm{E}-25$ & $3.50 \mathrm{E}-26$ & $2.64 \mathrm{E}-24$ & $2.46 \mathrm{E}-24$ & $1.99 \mathrm{E}-24$ \\
\hline 52 & $7.55 \mathrm{E}-22$ & $2.94 \mathrm{E}-21$ & $1.60 \mathrm{E}-25$ & $9.13 \mathrm{E}-26$ & $6.85 \mathrm{E}-24$ & $4.95 \mathrm{E}-24$ & $3.10 \mathrm{E}-24$ \\
\hline 53 & $7.30 \mathrm{E}-23$ & $2.33 \mathrm{E}-21$ & $1.70 \mathrm{E}-25$ & $1.98 \mathrm{E}-26$ & $1.50 \mathrm{E}-24$ & $1.61 \mathrm{E}-24$ & $2.48 \mathrm{E}-24$ \\
\hline 54 & $1.85 \mathrm{E}-22$ & $1.84 \mathrm{E}-21$ & $3.65 \mathrm{E}-26$ & $3.14 \mathrm{E}-26$ & $2.35 \mathrm{E}-24$ & $1.53 \mathrm{E}-24$ & $1.93 \mathrm{E}-24$ \\
\hline 55 & $8.99 \mathrm{E}-22$ & $2.25 \mathrm{E}-21$ & $3.28 \mathrm{E}-25$ & $9.18 \mathrm{E}-26$ & $6.91 \mathrm{E}-24$ & $5.97 \mathrm{E}-24$ & $2.38 \mathrm{E}-24$ \\
\hline 56 & $2.08 \mathrm{E}-22$ & $3.76 \mathrm{E}-21$ & $8.73 \mathrm{E}-25$ & $3.24 \mathrm{E}-26$ & $1.73 \mathrm{E}-24$ & $2.35 \mathrm{E}-24$ & $3.38 \mathrm{E}-24$ \\
\hline 57 & $5.03 \mathrm{E}-22$ & 4.79E-21 & $1.06 \mathrm{E}-24$ & $1.51 \mathrm{E}-25$ & $4.00 \mathrm{E}-24$ & $3.57 \mathrm{E}-24$ & $3.03 \mathrm{E}-24$ \\
\hline 59 & $5.13 \mathrm{E}-22$ & $2.76 \mathrm{E}-21$ & $3.28 \mathrm{E}-25$ & $6.07 \mathrm{E}-26$ & $3.81 \mathrm{E}-24$ & $3.55 \mathrm{E}-24$ & $2.68 \mathrm{E}-24$ \\
\hline 61 & $3.08 \mathrm{E}-23$ & $2.92 \mathrm{E}-21$ & $1.56 \mathrm{E}-26$ & $1.17 \mathrm{E}-26$ & $8.75 \mathrm{E}-25$ & $5.92 \mathrm{E}-25$ & $3.07 \mathrm{E}-24$ \\
\hline 62 & $1.53 \mathrm{E}-22$ & $2.45 \mathrm{E}-21$ & $2.66 \mathrm{E}-25$ & $5.41 \mathrm{E}-26$ & $3.38 \mathrm{E}-24$ & $3.08 \mathrm{E}-24$ & $2.37 \mathrm{E}-24$ \\
\hline 63 & $5.65 \mathrm{E}-23$ & $2.72 \mathrm{E}-21$ & $3.36 \mathrm{E}-25$ & $2.20 \mathrm{E}-26$ & $1.69 \mathrm{E}-24$ & $2.08 \mathrm{E}-24$ & $2.93 \mathrm{E}-24$ \\
\hline 66 & $6.63 \mathrm{E}-22$ & $2.29 \mathrm{E}-21$ & $8.49 \mathrm{E}-25$ & $6.88 \mathrm{E}-26$ & $2.36 \mathrm{E}-24$ & $2.49 \mathrm{E}-24$ & $1.65 \mathrm{E}-24$ \\
\hline 67 & $6.82 \mathrm{E}-23$ & $1.96 \mathrm{E}-21$ & $1.08 \mathrm{E}-25$ & $1.15 \mathrm{E}-26$ & $8.75 \mathrm{E}-25$ & $9.60 \mathrm{E}-25$ & $2.09 \mathrm{E}-24$ \\
\hline 68 & 2.07E-22 & $1.50 \mathrm{E}-21$ & $4.30 \mathrm{E}-25$ & $2.11 \mathrm{E}-26$ & $1.61 \mathrm{E}-24$ & $2.14 \mathrm{E}-24$ & $1.61 \mathrm{E}-24$ \\
\hline 69 & $5.70 \mathrm{E}-23$ & $2.48 \mathrm{E}-21$ & 7.45E-26 & $2.61 \mathrm{E}-26$ & $1.96 \mathrm{E}-24$ & $1.60 \mathrm{E}-24$ & $2.63 \mathrm{E}-24$ \\
\hline 70 & $9.31 \mathrm{E}-22$ & $4.25 \mathrm{E}-21$ & $1.20 \mathrm{E}-25$ & $1.02 \mathrm{E}-25$ & $7.71 \mathrm{E}-24$ & $5.04 \mathrm{E}-24$ & $4.51 \mathrm{E}-24$ \\
\hline 73 & $5.78 \mathrm{E}-23$ & $2.08 \mathrm{E}-21$ & $8.94 \mathrm{E}-25$ & $4.52 \mathrm{E}-26$ & $1.21 \mathrm{E}-24$ & $1.39 \mathrm{E}-24$ & $1.33 \mathrm{E}-24$ \\
\hline 75 & $3.50 \mathrm{E}-22$ & $3.54 \mathrm{E}-21$ & $2.68 \mathrm{E}-25$ & $5.49 \mathrm{E}-26$ & $4.14 \mathrm{E}-24$ & $3.87 \mathrm{E}-24$ & $3.75 \mathrm{E}-24$ \\
\hline 77 & $6.80 \mathrm{E}-23$ & $1.07 \mathrm{E}-21$ & $2.88 \mathrm{E}-25$ & $1.14 \mathrm{E}-26$ & $8.79 \mathrm{E}-25$ & $1.23 \mathrm{E}-24$ & $1.17 \mathrm{E}-24$ \\
\hline 80 & $4.88 \mathrm{E}-23$ & $1.81 \mathrm{E}-21$ & $7.45 \mathrm{E}-25$ & $1.27 \mathrm{E}-26$ & $9.83 \mathrm{E}-25$ & $1.70 \mathrm{E}-24$ & $1.97 \mathrm{E}-24$ \\
\hline 81 & $2.18 \mathrm{E}-22$ & $2.30 \mathrm{E}-21$ & $8.11 \mathrm{E}-25$ & $2.76 \mathrm{E}-26$ & $1.75 \mathrm{E}-24$ & $2.49 \mathrm{E}-24$ & $2.25 \mathrm{E}-24$ \\
\hline 82 & $2.90 \mathrm{E}-22$ & $2.45 \mathrm{E}-21$ & $1.29 \mathrm{E}-24$ & $5.41 \mathrm{E}-26$ & $2.47 \mathrm{E}-24$ & $3.20 \mathrm{E}-24$ & $2.05 \mathrm{E}-24$ \\
\hline 83 & $3.84 \mathrm{E}-22$ & $3.21 \mathrm{E}-21$ & $6.33 \mathrm{E}-25$ & $5.70 \mathrm{E}-26$ & $4.34 \mathrm{E}-24$ & 4.97E-24 & $3.45 \mathrm{E}-24$ \\
\hline 84 & $2.14 \mathrm{E}-23$ & $2.46 \mathrm{E}-21$ & $6.10 \mathrm{E}-25$ & $1.26 \mathrm{E}-26$ & $3.86 \mathrm{E}-25$ & $5.63 \mathrm{E}-25$ & $1.69 \mathrm{E}-24$ \\
\hline 85 & $9.30 \mathrm{E}-22$ & $3.83 \mathrm{E}-21$ & $1.52 \mathrm{E}-24$ & $1.45 \mathrm{E}-25$ & $5.70 \mathrm{E}-24$ & $5.89 \mathrm{E}-24$ & $2.96 \mathrm{E}-24$ \\
\hline 88 & $8.33 \mathrm{E}-23$ & $2.10 \mathrm{E}-21$ & 4.36E-25 & $1.99 \mathrm{E}-26$ & $1.52 \mathrm{E}-24$ & $2.06 \mathrm{E}-24$ & $2.25 \mathrm{E}-24$ \\
\hline 89 & $5.46 \mathrm{E}-23$ & $3.38 \mathrm{E}-21$ & $1.49 \mathrm{E}-24$ & $3.62 \mathrm{E}-26$ & $1.11 \mathrm{E}-24$ & $1.56 \mathrm{E}-24$ & $2.33 \mathrm{E}-24$ \\
\hline 90 & $1.44 \mathrm{E}-22$ & $1.52 \mathrm{E}-21$ & $9.26 \mathrm{E}-25$ & $1.77 \mathrm{E}-26$ & $1.36 \mathrm{E}-24$ & $2.29 \mathrm{E}-24$ & $1.65 \mathrm{E}-24$ \\
\hline
\end{tabular}




\begin{tabular}{cccccccc}
\hline $\mathbf{9 1}$ & $1.45 \mathrm{E}-23$ & $3.19 \mathrm{E}-21$ & $1.45 \mathrm{E}-25$ & $6.63 \mathrm{E}-27$ & $5.07 \mathrm{E}-25$ & $6.87 \mathrm{E}-25$ & $3.43 \mathrm{E}-24$ \\
$\mathbf{9 3}$ & $2.62 \mathrm{E}-23$ & $2.38 \mathrm{E}-21$ & $3.34 \mathrm{E}-25$ & $1.24 \mathrm{E}-26$ & $9.54 \mathrm{E}-25$ & $1.36 \mathrm{E}-24$ & $2.57 \mathrm{E}-24$ \\
$\mathbf{9 4}$ & $1.26 \mathrm{E}-23$ & $2.42 \mathrm{E}-21$ & $1.23 \mathrm{E}-25$ & $8.75 \mathrm{E}-27$ & $6.67 \mathrm{E}-25$ & $8.10 \mathrm{E}-25$ & $2.59 \mathrm{E}-24$ \\
$\mathbf{9 5}$ & $2.68 \mathrm{E}-22$ & $2.19 \mathrm{E}-21$ & $1.29 \mathrm{E}-24$ & $3.95 \mathrm{E}-26$ & $3.03 \mathrm{E}-24$ & $4.53 \mathrm{E}-24$ & $2.36 \mathrm{E}-24$ \\
$\mathbf{9 9}$ & $4.38 \mathrm{E}-23$ & $1.93 \mathrm{E}-21$ & $4.24 \mathrm{E}-25$ & $1.39 \mathrm{E}-26$ & $1.07 \mathrm{E}-24$ & $1.57 \mathrm{E}-24$ & $2.08 \mathrm{E}-24$ \\
$\mathbf{1 0 1}$ & $2.20 \mathrm{E}-23$ & $4.32 \mathrm{E}-21$ & $4.87 \mathrm{E}-26$ & $1.21 \mathrm{E}-26$ & $9.25 \mathrm{E}-25$ & $8.20 \mathrm{E}-25$ & $4.63 \mathrm{E}-24$ \\
$\mathbf{1 0 5}$ & $1.48 \mathrm{E}-22$ & $1.71 \mathrm{E}-21$ & $3.49 \mathrm{E}-25$ & $2.68 \mathrm{E}-26$ & $1.22 \mathrm{E}-24$ & $1.35 \mathrm{E}-24$ & $1.42 \mathrm{E}-24$ \\
$\mathbf{1 0 6}$ & $1.89 \mathrm{E}-23$ & $2.41 \mathrm{E}-21$ & $5.74 \mathrm{E}-26$ & $1.29 \mathrm{E}-26$ & $9.81 \mathrm{E}-25$ & $8.93 \mathrm{E}-25$ & $2.57 \mathrm{E}-24$ \\
$\mathbf{1 0 7}$ & $8.19 \mathrm{E}-23$ & $6.01 \mathrm{E}-21$ & $4.46 \mathrm{E}-24$ & $8.96 \mathrm{E}-26$ & $1.15 \mathrm{E}-24$ & $1.50 \mathrm{E}-24$ & $2.71 \mathrm{E}-24$ \\
$\mathbf{1 1 4}$ & $7.92 \mathrm{E}-21$ & $2.87 \mathrm{E}-21$ & $5.32 \mathrm{E}-25$ & $1.21 \mathrm{E}-24$ & $8.99 \mathrm{E}-23$ & $4.62 \mathrm{E}-23$ & $3.00 \mathrm{E}-24$ \\
$\mathbf{1 1 9}$ & $4.94 \mathrm{E}-21$ & $2.78 \mathrm{E}-21$ & $1.11 \mathrm{E}-24$ & $5.56 \mathrm{E}-25$ & $4.18 \mathrm{E}-23$ & $3.12 \mathrm{E}-23$ & $2.93 \mathrm{E}-24$ \\
$\mathbf{3 5 1}$ & $2.15 \mathrm{E}-21$ & $5.49 \mathrm{E}-21$ & $2.13 \mathrm{E}-24$ & $4.66 \mathrm{E}-25$ & $6.82 \mathrm{E}-24$ & $5.05 \mathrm{E}-24$ & $2.60 \mathrm{E}-24$ \\
$\mathbf{3 6 5}$ & $6.04 \mathrm{E}-23$ & $1.76 \mathrm{E}-21$ & $2.52 \mathrm{E}-25$ & $1.92 \mathrm{E}-26$ & $1.47 \mathrm{E}-24$ & $1.75 \mathrm{E}-24$ & $1.90 \mathrm{E}-24$ \\
\hline
\end{tabular}

Table A5 (Cont.)

\begin{tabular}{|c|c|c|c|}
\hline Station & $\mathrm{HgBr}_{4}^{2-} \mathrm{mol} / \mathrm{L}$ & $\mathrm{Hg}(\mathrm{OH})_{3}^{-} \mathrm{mol} / \mathrm{L}$ & $\mathrm{Hg}^{2+} \mathrm{mol} / \mathrm{L}$ \\
\hline 28 & $1.07 \mathrm{E}-27$ & $7.03 \mathrm{E}-28$ & $5.62 \mathrm{E}-28$ \\
\hline 30 & $9.21 \mathrm{E}-30$ & $2.24 \mathrm{E}-27$ & $5.67 \mathrm{E}-28$ \\
\hline 31 & $7.46 \mathrm{E}-30$ & $1.01 \mathrm{E}-27$ & $3.09 \mathrm{E}-28$ \\
\hline 33 & $3.16 \mathrm{E}-30$ & $3.77 \mathrm{E}-27$ & $1.76 \mathrm{E}-28$ \\
\hline 37 & $7.76 \mathrm{E}-32$ & $4.51 \mathrm{E}-27$ & $3.81 \mathrm{E}-28$ \\
\hline 43 & $6.27 \mathrm{E}-31$ & $1.08 \mathrm{E}-27$ & $9.16 \mathrm{E}-28$ \\
\hline 45 & $1.25 \mathrm{E}-30$ & $5.95 \mathrm{E}-28$ & $4.44 \mathrm{E}-28$ \\
\hline 46 & $1.63 \mathrm{E}-30$ & $1.94 \mathrm{E}-28$ & $7.36 \mathrm{E}-28$ \\
\hline 47 & $1.37 \mathrm{E}-30$ & $1.49 \mathrm{E}-27$ & $7.71 \mathrm{E}-28$ \\
\hline 49 & $3.80 \mathrm{E}-30$ & $1.08 \mathrm{E}-27$ & $3.19 \mathrm{E}-28$ \\
\hline 51 & $8.75 \mathrm{E}-31$ & $6.26 \mathrm{E}-28$ & $4.93 \mathrm{E}-28$ \\
\hline 52 & $2.27 \mathrm{E}-30$ & $3.54 \mathrm{E}-28$ & $1.29 \mathrm{E}-27$ \\
\hline 53 & $4.98 \mathrm{E}-31$ & $3.74 \mathrm{E}-27$ & $2.17 \mathrm{E}-28$ \\
\hline 54 & 7.79E-31 & $7.31 \mathrm{E}-28$ & $3.91 \mathrm{E}-28$ \\
\hline 55 & 2.29E-30 & $1.57 \mathrm{E}-28$ & $1.40 \mathrm{E}-27$ \\
\hline 56 & $9.90 \mathrm{E}-31$ & $1.02 \mathrm{E}-26$ & $2.77 \mathrm{E}-28$ \\
\hline 57 & $6.52 \mathrm{E}-30$ & $2.76 \mathrm{E}-27$ & $4.04 \mathrm{E}-28$ \\
\hline 59 & $1.68 \mathrm{E}-30$ & $8.83 \mathrm{E}-28$ & $6.98 \mathrm{E}-28$ \\
\hline 61 & $2.90 \mathrm{E}-31$ & $2.12 \mathrm{E}-26$ & $1.09 \mathrm{E}-28$ \\
\hline 62 & $1.49 \mathrm{E}-30$ & $7.82 \mathrm{E}-28$ & $4.16 \mathrm{E}-28$ \\
\hline 63 & $5.59 \mathrm{E}-31$ & $4.84 \mathrm{E}-27$ & $2.18 \mathrm{E}-28$ \\
\hline 66 & $2.64 \mathrm{E}-30$ & $9.92 \mathrm{E}-28$ & $3.84 \mathrm{E}-28$ \\
\hline 67 & $2.90 \mathrm{E}-31$ & $6.59 \mathrm{E}-27$ & $1.50 \mathrm{E}-28$ \\
\hline 68 & $5.35 \mathrm{E}-31$ & $8.81 \mathrm{E}-28$ & $3.35 \mathrm{E}-28$ \\
\hline 69 & $6.51 \mathrm{E}-31$ & $2.62 \mathrm{E}-27$ & $2.32 \mathrm{E}-28$ \\
\hline
\end{tabular}




\begin{tabular}{rlll}
\hline $\mathbf{7 0}$ & $2.56 \mathrm{E}-30$ & $8.55 \mathrm{E}-28$ & $1.53 \mathrm{E}-27$ \\
$\mathbf{7 3}$ & $1.97 \mathrm{E}-30$ & $2.53 \mathrm{E}-27$ & $8.84 \mathrm{E}-29$ \\
$\mathbf{7 5}$ & $1.37 \mathrm{E}-30$ & $1.71 \mathrm{E}-27$ & $7.24 \mathrm{E}-28$ \\
$\mathbf{7 7}$ & $2.92 \mathrm{E}-31$ & $1.11 \mathrm{E}-27$ & $1.57 \mathrm{E}-28$ \\
$\mathbf{8 0}$ & $3.26 \mathrm{E}-31$ & $4.30 \mathrm{E}-27$ & $1.50 \mathrm{E}-28$ \\
$\mathbf{8 1}$ & $7.74 \mathrm{E}-31$ & $2.46 \mathrm{E}-27$ & $3.20 \mathrm{E}-28$ \\
$\mathbf{8 2}$ & $1.80 \mathrm{E}-30$ & $1.29 \mathrm{E}-27$ & $3.58 \mathrm{E}-28$ \\
$\mathbf{8 3}$ & $1.44 \mathrm{E}-30$ & $1.19 \mathrm{E}-27$ & $7.88 \mathrm{E}-28$ \\
$\mathbf{8 4}$ & $5.25 \mathrm{E}-31$ & $4.43 \mathrm{E}-26$ & $3.32 \mathrm{E}-29$ \\
$\mathbf{8 5}$ & $5.19 \mathrm{E}-30$ & $8.49 \mathrm{E}-28$ & $8.33 \mathrm{E}-28$ \\
$\mathbf{8 8}$ & $5.06 \mathrm{E}-31$ & $2.70 \mathrm{E}-27$ & $2.34 \mathrm{E}-28$ \\
$\mathbf{8 9}$ & $1.51 \mathrm{E}-30$ & $1.40 \mathrm{E}-26$ & $9.24 \mathrm{E}-29$ \\
$\mathbf{9 0}$ & $4.53 \mathrm{E}-31$ & $1.30 \mathrm{E}-27$ & $2.71 \mathrm{E}-28$ \\
$\mathbf{9 1}$ & $1.68 \mathrm{E}-31$ & $8.59 \mathrm{E}-26$ & $6.20 \mathrm{E}-29$ \\
$\mathbf{9 3}$ & $3.17 \mathrm{E}-31$ & $1.02 \mathrm{E}-26$ & $1.16 \mathrm{E}-28$ \\
$\mathbf{9 4}$ & $2.21 \mathrm{E}-31$ & $2.15 \mathrm{E}-26$ & $6.96 \mathrm{E}-29$ \\
$\mathbf{9 5}$ & $1.01 \mathrm{E}-30$ & $7.78 \mathrm{E}-28$ & $5.60 \mathrm{E}-28$ \\
$\mathbf{9 9}$ & $3.53 \mathrm{E}-31$ & $4.33 \mathrm{E}-27$ & $1.49 \mathrm{E}-28$ \\
$\mathbf{1 0 1}$ & $3.07 \mathrm{E}-31$ & $6.37 \mathrm{E}-26$ & $1.05 \mathrm{E}-28$ \\
$\mathbf{1 0 5}$ & $8.87 \mathrm{E}-31$ & $1.78 \mathrm{E}-27$ & $1.76 \mathrm{E}-28$ \\
$\mathbf{1 0 6}$ & $3.26 \mathrm{E}-31$ & $9.75 \mathrm{E}-27$ & $1.03 \mathrm{E}-28$ \\
$\mathbf{1 0 7}$ & $5.97 \mathrm{E}-30$ & $4.92 \mathrm{E}-26$ & $6.29 \mathrm{E}-29$ \\
$\mathbf{1 1 4}$ & $2.98 \mathrm{E}-29$ & $1.89 \mathrm{E}-30$ & $1.54 \mathrm{E}-26$ \\
$\mathbf{1 1 9}$ & $1.39 \mathrm{E}-29$ & $8.04 \mathrm{E}-30$ & $8.11 \mathrm{E}-27$ \\
$\mathbf{3 5 1}$ & $2.75 \mathrm{E}-29$ & $1.08 \mathrm{E}-27$ & $6.53 \mathrm{E}-28$ \\
$\mathbf{3 6 5}$ & $4.89 \mathrm{E}-31$ & $1.72 \mathrm{E}-27$ & $2.05 \mathrm{E}-28$ \\
\hline & & & \\
\hline
\end{tabular}

Table A6 Concentrations of $\mathrm{Hg}$ species in surface water of Everglades in fall 2005 ([S $\left.\mathrm{S}^{2-}\right]<<$ $3.2 \times 10^{-7} \mathrm{mg} / \mathrm{L}$ )

\begin{tabular}{|c|c|c|c|c|c|c|c|}
\hline Station & $\mathrm{Hg} \mathrm{mol} / \mathrm{L}$ & $\begin{array}{c}\mathrm{RSHg}^{(\mathrm{n}-1)-} \\
\mathrm{mol} / \mathrm{L}\end{array}$ & $\begin{array}{l}\mathrm{HgCl}_{2} \\
\mathrm{~mol} / \mathrm{L}\end{array}$ & $\begin{array}{c}\mathrm{HgBrCl} \\
\mathrm{mol} / \mathrm{L}\end{array}$ & $\begin{array}{l}\mathrm{HgCl}_{3-} \\
\mathrm{mol} / \mathrm{L}\end{array}$ & $\begin{array}{c}\mathrm{HgClOH} \\
\mathrm{mol} / \mathrm{L}\end{array}$ & $\underset{\mathrm{mol} / \mathrm{L}}{\mathrm{Hg}(\mathrm{OH})_{2}}$ \\
\hline 128 & $8.48 \mathrm{E}-12$ & $8.48 \mathrm{E}-12$ & $4.46 \mathrm{E}-21$ & $3.08 \mathrm{E}-21$ & $4.02 \mathrm{E}-23$ & $2.19 \mathrm{E}-20$ & $2.56 \mathrm{E}-19$ \\
\hline 130 & $1.40 \mathrm{E}-11$ & $1.40 \mathrm{E}-11$ & $5.23 \mathrm{E}-21$ & $4.52 \mathrm{E}-21$ & $3.77 \mathrm{E}-23$ & $2.69 \mathrm{E}-20$ & 8.89E-19 \\
\hline 135 & $5.98 \mathrm{E}-12$ & $5.98 \mathrm{E}-12$ & 2.61E-21 & $2.58 \mathrm{E}-21$ & $1.65 \mathrm{E}-23$ & $1.35 \mathrm{E}-20$ & $2.77 \mathrm{E}-19$ \\
\hline 136 & $7.48 \mathrm{E}-12$ & $7.48 \mathrm{E}-12$ & $4.28 \mathrm{E}-21$ & $5.38 \mathrm{E}-21$ & $2.12 \mathrm{E}-23$ & $1.95 \mathrm{E}-20$ & $2.53 \mathrm{E}-19$ \\
\hline 138 & $5.98 \mathrm{E}-12$ & $5.98 \mathrm{E}-12$ & $1.03 \mathrm{E}-21$ & $9.80 \mathrm{E}-22$ & $6.72 \mathrm{E}-24$ & $9.41 \mathrm{E}-21$ & $5.58 \mathrm{E}-19$ \\
\hline 141 & $1.35 \mathrm{E}-11$ & $1.35 \mathrm{E}-11$ & $1.10 \mathrm{E}-20$ & $5.72 \mathrm{E}-21$ & $1.31 \mathrm{E}-22$ & $2.14 \mathrm{E}-20$ & $1.73 \mathrm{E}-19$ \\
\hline 142 & $5.48 \mathrm{E}-12$ & $5.48 \mathrm{E}-12$ & 3.33E-21 & $2.19 \mathrm{E}-21$ & $3.15 \mathrm{E}-23$ & $1.53 \mathrm{E}-20$ & $1.99 \mathrm{E}-19$ \\
\hline 143 & $8.48 \mathrm{E}-12$ & $8.48 \mathrm{E}-12$ & $4.28 \mathrm{E}-21$ & $2.04 \mathrm{E}-21$ & $5.59 \mathrm{E}-23$ & $1.81 \mathrm{E}-20$ & $3.74 \mathrm{E}-19$ \\
\hline 145 & $1.50 \mathrm{E}-11$ & $1.50 \mathrm{E}-11$ & 8.17E-21 & $4.51 \mathrm{E}-21$ & $9.20 \mathrm{E}-23$ & $3.29 \mathrm{E}-20$ & $4.57 \mathrm{E}-19$ \\
\hline 147 & $7.98 \mathrm{E}-12$ & $7.98 \mathrm{E}-12$ & $1.34 \mathrm{E}-20$ & $5.44 \mathrm{E}-21$ & $2.05 \mathrm{E}-22$ & $1.69 \mathrm{E}-20$ & $7.12 \mathrm{E}-20$ \\
\hline 148 & $1.15 \mathrm{E}-11$ & $1.15 \mathrm{E}-11$ & $4.72 \mathrm{E}-21$ & $2.41 \mathrm{E}-21$ & $5.74 \mathrm{E}-23$ & $1.68 \mathrm{E}-20$ & $3.44 \mathrm{E}-19$ \\
\hline
\end{tabular}




\begin{tabular}{|c|c|c|c|c|c|c|c|}
\hline 149 & $8.97 \mathrm{E}-12$ & $8.97 \mathrm{E}-12$ & $1.69 \mathrm{E}-21$ & $1.66 \mathrm{E}-21$ & $1.06 \mathrm{E}-23$ & $1.28 \mathrm{E}-20$ & $4.69 \mathrm{E}-19$ \\
\hline 151 & $9.97 \mathrm{E}-12$ & $9.97 \mathrm{E}-12$ & 4.15E-21 & $1.64 \mathrm{E}-21$ & $6.54 \mathrm{E}-23$ & $1.74 \mathrm{E}-20$ & $3.80 \mathrm{E}-19$ \\
\hline 152 & $6.98 \mathrm{E}-12$ & $6.98 \mathrm{E}-12$ & $2.48 \mathrm{E}-21$ & $2.85 \mathrm{E}-21$ & $1.34 \mathrm{E}-23$ & 7.62E-21 & $9.35 \mathrm{E}-20$ \\
\hline 153 & $7.98 \mathrm{E}-12$ & $7.98 \mathrm{E}-12$ & $7.28 \mathrm{E}-22$ & $7.74 \mathrm{E}-22$ & $4.26 \mathrm{E}-24$ & $8.83 \mathrm{E}-21$ & $7.09 \mathrm{E}-19$ \\
\hline 154 & $1.30 \mathrm{E}-11$ & $1.30 \mathrm{E}-11$ & $2.77 \mathrm{E}-21$ & $2.25 \mathrm{E}-21$ & $2.12 \mathrm{E}-23$ & $1.92 \mathrm{E}-20$ & $8.32 \mathrm{E}-19$ \\
\hline 156 & $1.05 \mathrm{E}-11$ & $1.05 \mathrm{E}-11$ & 2.02E-20 & $1.03 \mathrm{E}-20$ & $2.46 \mathrm{E}-22$ & $2.07 \mathrm{E}-20$ & $7.72 \mathrm{E}-20$ \\
\hline 157 & $6.98 \mathrm{E}-12$ & $6.98 \mathrm{E}-12$ & $4.08 \mathrm{E}-21$ & $1.73 \mathrm{E}-21$ & $5.97 \mathrm{E}-23$ & $1.03 \mathrm{E}-20$ & $1.31 \mathrm{E}-19$ \\
\hline 158 & $7.98 \mathrm{E}-12$ & $7.98 \mathrm{E}-12$ & $3.08 \mathrm{E}-21$ & $1.85 \mathrm{E}-21$ & $3.19 \mathrm{E}-23$ & $1.08 \mathrm{E}-20$ & $1.86 \mathrm{E}-19$ \\
\hline 159 & $1.15 \mathrm{E}-11$ & $1.15 \mathrm{E}-11$ & $6.63 \mathrm{E}-21$ & $3.10 \mathrm{E}-21$ & $9.71 \mathrm{E}-23$ & $1.62 \mathrm{E}-20$ & $1.95 \mathrm{E}-19$ \\
\hline 160 & $8.48 \mathrm{E}-12$ & $8.48 \mathrm{E}-12$ & 4.23E-21 & 4.03E-21 & $2.76 \mathrm{E}-23$ & $1.38 \mathrm{E}-20$ & $1.82 \mathrm{E}-19$ \\
\hline 161 & $9.47 \mathrm{E}-12$ & $9.47 \mathrm{E}-12$ & $1.34 \mathrm{E}-21$ & $1.42 \mathrm{E}-21$ & $7.84 \mathrm{E}-24$ & $8.95 \mathrm{E}-21$ & $3.13 \mathrm{E}-19$ \\
\hline 162 & $8.97 \mathrm{E}-12$ & $8.97 \mathrm{E}-12$ & $1.05 \mathrm{E}-21$ & $1.12 \mathrm{E}-21$ & $6.15 \mathrm{E}-24$ & $1.09 \mathrm{E}-20$ & $4.26 \mathrm{E}-19$ \\
\hline 163 & $8.97 \mathrm{E}-12$ & $8.97 \mathrm{E}-12$ & $2.66 \mathrm{E}-20$ & $1.62 \mathrm{E}-20$ & $3.54 \mathrm{E}-22$ & $1.83 \mathrm{E}-20$ & $3.91 \mathrm{E}-20$ \\
\hline 165 & 8.97E-12 & 8.97E-12 & $1.01 \mathrm{E}-20$ & 9.92E-21 & $6.34 \mathrm{E}-23$ & $1.45 \mathrm{E}-20$ & $7.04 \mathrm{E}-20$ \\
\hline 166 & $7.48 \mathrm{E}-12$ & $7.48 \mathrm{E}-12$ & $1.37 \mathrm{E}-20$ & $7.75 \mathrm{E}-21$ & $1.52 \mathrm{E}-22$ & $1.59 \mathrm{E}-20$ & $5.54 \mathrm{E}-20$ \\
\hline 167 & $8.48 \mathrm{E}-12$ & $8.48 \mathrm{E}-12$ & $3.32 \mathrm{E}-21$ & $2.48 \mathrm{E}-21$ & $2.77 \mathrm{E}-23$ & $1.08 \mathrm{E}-20$ & $1.70 \mathrm{E}-19$ \\
\hline 169 & $6.98 \mathrm{E}-12$ & $6.98 \mathrm{E}-12$ & $2.80 \mathrm{E}-21$ & $2.35 \mathrm{E}-21$ & $2.08 \mathrm{E}-23$ & $8.37 \mathrm{E}-21$ & $1.29 \mathrm{E}-19$ \\
\hline 170 & $9.47 \mathrm{E}-12$ & $9.47 \mathrm{E}-12$ & $7.40 \mathrm{E}-22$ & $1.28 \mathrm{E}-21$ & $2.67 \mathrm{E}-24$ & $7.20 \mathrm{E}-21$ & $2.60 \mathrm{E}-19$ \\
\hline 171 & $1.84 \mathrm{E}-11$ & $1.84 \mathrm{E}-11$ & $3.06 \mathrm{E}-20$ & $1.69 \mathrm{E}-20$ & $4.48 \mathrm{E}-22$ & $2.93 \mathrm{E}-20$ & $9.86 \mathrm{E}-20$ \\
\hline 173 & $7.98 \mathrm{E}-12$ & $7.98 \mathrm{E}-12$ & $9.42 \mathrm{E}-22$ & $1.08 \mathrm{E}-21$ & $5.09 \mathrm{E}-24$ & $7.75 \mathrm{E}-21$ & $2.70 \mathrm{E}-19$ \\
\hline 174 & $7.98 \mathrm{E}-12$ & $7.98 \mathrm{E}-12$ & $5.30 \mathrm{E}-21$ & $3.33 \mathrm{E}-21$ & $5.25 \mathrm{E}-23$ & $1.11 \mathrm{E}-20$ & $1.15 \mathrm{E}-19$ \\
\hline 175 & $7.98 \mathrm{E}-12$ & $7.98 \mathrm{E}-12$ & $2.05 \mathrm{E}-21$ & $2.36 \mathrm{E}-21$ & $1.11 \mathrm{E}-23$ & 7.73E-21 & $1.48 \mathrm{E}-19$ \\
\hline 176 & $1.10 \mathrm{E}-11$ & $1.10 \mathrm{E}-11$ & $5.40 \mathrm{E}-21$ & $2.53 \mathrm{E}-21$ & $7.17 \mathrm{E}-23$ & $1.81 \mathrm{E}-20$ & $2.88 \mathrm{E}-19$ \\
\hline 177 & $9.47 \mathrm{E}-12$ & $9.47 \mathrm{E}-12$ & $4.98 \mathrm{E}-21$ & $2.60 \mathrm{E}-21$ & $5.95 \mathrm{E}-23$ & $1.71 \mathrm{E}-20$ & $1.89 \mathrm{E}-19$ \\
\hline 178 & $1.15 \mathrm{E}-11$ & $1.15 \mathrm{E}-11$ & $1.06 \mathrm{E}-20$ & $8.84 \mathrm{E}-21$ & $7.84 \mathrm{E}-23$ & $1.59 \mathrm{E}-20$ & $9.27 \mathrm{E}-20$ \\
\hline 179 & $5.98 \mathrm{E}-12$ & $5.98 \mathrm{E}-12$ & $9.64 \mathrm{E}-21$ & $5.97 \mathrm{E}-21$ & $1.26 \mathrm{E}-22$ & $1.08 \mathrm{E}-20$ & $4.06 \mathrm{E}-20$ \\
\hline 180 & $1.15 \mathrm{E}-11$ & $1.15 \mathrm{E}-11$ & $1.63 \mathrm{E}-20$ & $6.73 \mathrm{E}-21$ & $2.46 \mathrm{E}-22$ & $2.64 \mathrm{E}-20$ & $1.18 \mathrm{E}-19$ \\
\hline 181 & $8.48 \mathrm{E}-12$ & $8.48 \mathrm{E}-12$ & $1.51 \mathrm{E}-21$ & 2.09E-21 & $6.81 \mathrm{E}-24$ & $6.76 \mathrm{E}-21$ & $1.13 \mathrm{E}-19$ \\
\hline 182 & $1.05 \mathrm{E}-11$ & $1.05 \mathrm{E}-11$ & $2.04 \mathrm{E}-20$ & $7.53 \mathrm{E}-21$ & $3.45 \mathrm{E}-22$ & $2.30 \mathrm{E}-20$ & $7.80 \mathrm{E}-20$ \\
\hline 183 & $1.50 \mathrm{E}-11$ & $1.50 \mathrm{E}-11$ & $6.68 \mathrm{E}-21$ & 8.39E-21 & $3.31 \mathrm{E}-23$ & $1.10 \mathrm{E}-20$ & $7.20 \mathrm{E}-20$ \\
\hline 184 & $8.97 \mathrm{E}-12$ & $8.97 \mathrm{E}-12$ & $5.51 \mathrm{E}-21$ & $6.62 \mathrm{E}-21$ & $2.86 \mathrm{E}-23$ & $7.59 \mathrm{E}-21$ & $3.94 \mathrm{E}-20$ \\
\hline 185 & $1.25 \mathrm{E}-11$ & $1.25 \mathrm{E}-11$ & $4.31 \mathrm{E}-21$ & 4.11E-21 & $2.82 \mathrm{E}-23$ & $1.33 \mathrm{E}-20$ & $1.77 \mathrm{E}-19$ \\
\hline 186 & $1.30 \mathrm{E}-11$ & $1.30 \mathrm{E}-11$ & $1.04 \mathrm{E}-20$ & $7.75 \mathrm{E}-21$ & $8.65 \mathrm{E}-23$ & $1.70 \mathrm{E}-20$ & $9.60 \mathrm{E}-20$ \\
\hline 187 & $6.98 \mathrm{E}-12$ & $6.98 \mathrm{E}-12$ & $2.76 \mathrm{E}-21$ & $2.72 \mathrm{E}-21$ & $1.74 \mathrm{E}-23$ & 7.22E-21 & $7.00 \mathrm{E}-20$ \\
\hline 188 & $9.47 \mathrm{E}-12$ & $9.47 \mathrm{E}-12$ & $3.85 \mathrm{E}-21$ & $3.67 \mathrm{E}-21$ & $2.51 \mathrm{E}-23$ & $1.06 \mathrm{E}-20$ & $1.15 \mathrm{E}-19$ \\
\hline 190 & $9.97 \mathrm{E}-12$ & $9.97 \mathrm{E}-12$ & $9.31 \mathrm{E}-21$ & $5.48 \mathrm{E}-21$ & $9.86 \mathrm{E}-23$ & $1.32 \mathrm{E}-20$ & $7.80 \mathrm{E}-20$ \\
\hline 191 & $1.30 \mathrm{E}-11$ & $1.30 \mathrm{E}-11$ & $5.42 \mathrm{E}-21$ & $3.43 \mathrm{E}-21$ & $5.86 \mathrm{E}-23$ & $1.48 \mathrm{E}-20$ & $2.09 \mathrm{E}-19$ \\
\hline 192 & $9.97 \mathrm{E}-12$ & $9.97 \mathrm{E}-12$ & $3.19 \mathrm{E}-21$ & $3.39 \mathrm{E}-21$ & $1.87 \mathrm{E}-23$ & $9.86 \mathrm{E}-21$ & $1.24 \mathrm{E}-19$ \\
\hline 193 & $1.30 \mathrm{E}-11$ & $1.30 \mathrm{E}-11$ & $5.01 \mathrm{E}-21$ & $5.76 \mathrm{E}-21$ & $2.71 \mathrm{E}-23$ & $1.26 \mathrm{E}-20$ & $1.14 \mathrm{E}-19$ \\
\hline 194 & $1.40 \mathrm{E}-11$ & $1.40 \mathrm{E}-11$ & $9.15 \mathrm{E}-21$ & $1.01 \mathrm{E}-20$ & $5.15 \mathrm{E}-23$ & $1.70 \mathrm{E}-20$ & $9.20 \mathrm{E}-20$ \\
\hline 195 & $6.98 \mathrm{E}-12$ & $6.98 \mathrm{E}-12$ & $5.17 \mathrm{E}-21$ & $3.18 \mathrm{E}-21$ & $5.24 \mathrm{E}-23$ & $9.83 \mathrm{E}-21$ & $7.14 \mathrm{E}-20$ \\
\hline
\end{tabular}




\begin{tabular}{|c|c|c|c|c|c|c|c|}
\hline 197 & $7.98 \mathrm{E}-12$ & $7.98 \mathrm{E}-12$ & $2.03 \mathrm{E}-21$ & $1.27 \mathrm{E}-21$ & $2.01 \mathrm{E}-23$ & $9.86 \mathrm{E}-21$ & $2.02 \mathrm{E}-19$ \\
\hline 198 & $1.10 \mathrm{E}-11$ & $1.10 \mathrm{E}-11$ & $2.20 \mathrm{E}-21$ & $2.76 \mathrm{E}-21$ & $1.09 \mathrm{E}-23$ & $1.02 \mathrm{E}-20$ & $1.57 \mathrm{E}-19$ \\
\hline 199 & $1.74 \mathrm{E}-11$ & $1.74 \mathrm{E}-11$ & 7.77E-21 & 7.66E-21 & $4.90 \mathrm{E}-23$ & $2.19 \mathrm{E}-20$ & $1.80 \mathrm{E}-19$ \\
\hline 200 & $9.97 \mathrm{E}-12$ & $9.97 \mathrm{E}-12$ & $3.31 \mathrm{E}-21$ & $2.29 \mathrm{E}-21$ & $2.98 \mathrm{E}-23$ & $1.16 \mathrm{E}-20$ & $1.82 \mathrm{E}-19$ \\
\hline 202 & $1.30 \mathrm{E}-11$ & $1.30 \mathrm{E}-11$ & $5.80 \mathrm{E}-21$ & $6.41 \mathrm{E}-21$ & $3.26 \mathrm{E}-23$ & $1.47 \mathrm{E}-20$ & $1.06 \mathrm{E}-19$ \\
\hline 203 & $1.55 \mathrm{E}-11$ & $1.55 \mathrm{E}-11$ & $9.89 \mathrm{E}-21$ & $5.83 \mathrm{E}-21$ & $1.67 \mathrm{E}-22$ & $2.37 \mathrm{E}-20$ & $2.32 \mathrm{E}-19$ \\
\hline 204 & $9.97 \mathrm{E}-12$ & $9.97 \mathrm{E}-12$ & $6.07 \mathrm{E}-21$ & $6.22 \mathrm{E}-21$ & $3.69 \mathrm{E}-23$ & $1.19 \mathrm{E}-20$ & $6.03 \mathrm{E}-20$ \\
\hline 206 & $1.50 \mathrm{E}-11$ & $1.50 \mathrm{E}-11$ & $3.21 \mathrm{E}-21$ & $1.71 \mathrm{E}-21$ & $3.76 \mathrm{E}-23$ & $2.02 \mathrm{E}-20$ & $5.53 \mathrm{E}-19$ \\
\hline 207 & $1.10 \mathrm{E}-11$ & $1.10 \mathrm{E}-11$ & $1.36 \mathrm{E}-20$ & $1.39 \mathrm{E}-20$ & $8.24 \mathrm{E}-23$ & $1.32 \mathrm{E}-20$ & $4.45 \mathrm{E}-20$ \\
\hline 208 & $1.15 \mathrm{E}-11$ & $1.15 \mathrm{E}-11$ & $1.43 \mathrm{E}-20$ & $6.69 \mathrm{E}-21$ & $1.90 \mathrm{E}-22$ & $1.74 \mathrm{E}-20$ & $8.37 \mathrm{E}-20$ \\
\hline 210 & $7.98 \mathrm{E}-12$ & $7.98 \mathrm{E}-12$ & $1.35 \mathrm{E}-20$ & $6.66 \mathrm{E}-21$ & $2.22 \mathrm{E}-22$ & $1.40 \mathrm{E}-20$ & $4.78 \mathrm{E}-20$ \\
\hline 212 & $1.15 \mathrm{E}-11$ & $1.15 \mathrm{E}-11$ & $4.48 \mathrm{E}-21$ & $4.95 \mathrm{E}-21$ & $2.52 \mathrm{E}-23$ & $1.13 \mathrm{E}-20$ & $1.08 \mathrm{E}-19$ \\
\hline 213 & $7.98 \mathrm{E}-12$ & $7.98 \mathrm{E}-12$ & $2.68 \mathrm{E}-21$ & $2.55 \mathrm{E}-21$ & $1.75 \mathrm{E}-23$ & 8.32E-21 & $1.01 \mathrm{E}-19$ \\
\hline 214 & $8.48 \mathrm{E}-12$ & $8.48 \mathrm{E}-12$ & $1.05 \mathrm{E}-20$ & $9.34 \mathrm{E}-21$ & 7.32E-23 & $1.03 \mathrm{E}-20$ & $3.30 \mathrm{E}-20$ \\
\hline 215 & $8.97 \mathrm{E}-12$ & $8.97 \mathrm{E}-12$ & $3.28 \mathrm{E}-21$ & $2.67 \mathrm{E}-21$ & $2.51 \mathrm{E}-23$ & $1.02 \mathrm{E}-20$ & $1.08 \mathrm{E}-19$ \\
\hline 217 & $6.98 \mathrm{E}-12$ & $6.98 \mathrm{E}-12$ & $6.40 \mathrm{E}-21$ & 4.42E-21 & $5.77 \mathrm{E}-23$ & $9.08 \mathrm{E}-21$ & $4.63 \mathrm{E}-20$ \\
\hline 218 & $1.10 \mathrm{E}-11$ & $1.10 \mathrm{E}-11$ & $1.34 \mathrm{E}-20$ & 7.91E-21 & $1.85 \mathrm{E}-22$ & $1.71 \mathrm{E}-20$ & $7.76 \mathrm{E}-20$ \\
\hline 219 & $1.05 \mathrm{E}-11$ & $1.05 \mathrm{E}-11$ & 4.05E-20 & $1.32 \mathrm{E}-20$ & $1.00 \mathrm{E}-21$ & $2.27 \mathrm{E}-20$ & $4.26 \mathrm{E}-20$ \\
\hline 220 & $7.98 \mathrm{E}-12$ & $7.98 \mathrm{E}-12$ & $1.08 \mathrm{E}-20$ & $1.01 \mathrm{E}-20$ & $1.72 \mathrm{E}-22$ & $1.27 \mathrm{E}-20$ & 4.67E-20 \\
\hline 221 & $1.15 \mathrm{E}-11$ & $1.15 \mathrm{E}-11$ & $1.20 \mathrm{E}-20$ & $6.77 \mathrm{E}-21$ & $1.33 \mathrm{E}-22$ & $1.50 \mathrm{E}-20$ & $7.00 \mathrm{E}-20$ \\
\hline 223 & $3.29 \mathrm{E}-11$ & $3.29 \mathrm{E}-11$ & 4.27E-20 & $2.36 \mathrm{E}-20$ & $1.44 \mathrm{E}-21$ & 7.74E-20 & 4.70E-19 \\
\hline 224 & $1.40 \mathrm{E}-11$ & $1.40 \mathrm{E}-11$ & $1.26 \mathrm{E}-20$ & $9.38 \mathrm{E}-21$ & $1.05 \mathrm{E}-22$ & $1.88 \mathrm{E}-20$ & $9.22 \mathrm{E}-20$ \\
\hline 225 & $9.97 \mathrm{E}-12$ & $9.97 \mathrm{E}-12$ & 7.61E-21 & $2.80 \mathrm{E}-21$ & $2.06 \mathrm{E}-22$ & $2.09 \mathrm{E}-20$ & $1.95 \mathrm{E}-19$ \\
\hline 227 & $3.69 \mathrm{E}-11$ & $3.69 \mathrm{E}-11$ & $4.38 \mathrm{E}-20$ & $3.23 \mathrm{E}-20$ & $1.48 \mathrm{E}-21$ & $7.12 \mathrm{E}-20$ & $4.45 \mathrm{E}-19$ \\
\hline 229 & $9.97 \mathrm{E}-12$ & $9.97 \mathrm{E}-12$ & $5.44 \mathrm{E}-21$ & $3.42 \mathrm{E}-21$ & $5.39 \mathrm{E}-23$ & $1.24 \mathrm{E}-20$ & $9.43 \mathrm{E}-20$ \\
\hline 230 & $2.29 \mathrm{E}-11$ & $2.29 \mathrm{E}-11$ & $1.35 \mathrm{E}-20$ & $1.28 \mathrm{E}-20$ & 8.79E-23 & $2.41 \mathrm{E}-20$ & $1.27 \mathrm{E}-19$ \\
\hline 233 & $2.34 \mathrm{E}-11$ & $2.34 \mathrm{E}-11$ & $4.46 \mathrm{E}-20$ & $1.67 \mathrm{E}-20$ & $2.01 \mathrm{E}-21$ & $5.33 \mathrm{E}-20$ & $2.25 \mathrm{E}-19$ \\
\hline 237 & $1.55 \mathrm{E}-11$ & $1.55 \mathrm{E}-11$ & $3.29 \mathrm{E}-20$ & $3.13 \mathrm{E}-20$ & $2.15 \mathrm{E}-22$ & $1.38 \mathrm{E}-20$ & $2.36 \mathrm{E}-20$ \\
\hline 238 & $2.04 \mathrm{E}-11$ & $2.04 \mathrm{E}-11$ & $9.41 \mathrm{E}-20$ & $5.82 \mathrm{E}-20$ & $3.60 \mathrm{E}-21$ & $3.93 \mathrm{E}-20$ & $6.22 \mathrm{E}-20$ \\
\hline 240 & $1.94 \mathrm{E}-11$ & $1.94 \mathrm{E}-11$ & $3.15 \mathrm{E}-20$ & 4.35E-20 & $1.42 \mathrm{E}-22$ & $1.54 \mathrm{E}-20$ & $2.15 \mathrm{E}-20$ \\
\hline 242 & $1.79 \mathrm{E}-11$ & $1.79 \mathrm{E}-11$ & $6.77 \mathrm{E}-20$ & $1.04 \mathrm{E}-19$ & $2.74 \mathrm{E}-22$ & $9.19 \mathrm{E}-21$ & $4.31 \mathrm{E}-21$ \\
\hline 244 & $2.29 \mathrm{E}-11$ & $2.29 \mathrm{E}-11$ & $9.44 \mathrm{E}-20$ & $1.30 \mathrm{E}-19$ & 4.25E-22 & $1.65 \mathrm{E}-20$ & $7.75 \mathrm{E}-21$ \\
\hline 245 & $1.74 \mathrm{E}-11$ & $1.74 \mathrm{E}-11$ & $2.01 \mathrm{E}-20$ & 2.32E-20 & $1.09 \mathrm{E}-22$ & $9.87 \mathrm{E}-21$ & $2.41 \mathrm{E}-20$ \\
\hline 254 & $1.20 \mathrm{E}-11$ & $1.20 \mathrm{E}-11$ & 6.32E-21 & $3.06 \mathrm{E}-21$ & $8.11 \mathrm{E}-23$ & $2.42 \mathrm{E}-20$ & $2.73 \mathrm{E}-19$ \\
\hline 256 & $1.50 \mathrm{E}-11$ & $1.50 \mathrm{E}-11$ & $1.14 \mathrm{E}-20$ & $7.10 \mathrm{E}-21$ & $1.59 \mathrm{E}-22$ & $2.32 \mathrm{E}-20$ & $1.75 \mathrm{E}-19$ \\
\hline 257 & $1.10 \mathrm{E}-11$ & $1.10 \mathrm{E}-11$ & $9.05 \mathrm{E}-21$ & 7.36E-21 & $6.93 \mathrm{E}-23$ & 4.27E-20 & 6.84E-19 \\
\hline 258 & $1.05 \mathrm{E}-11$ & $1.05 \mathrm{E}-11$ & $1.09 \mathrm{E}-20$ & $5.47 \mathrm{E}-21$ & $1.35 \mathrm{E}-22$ & $3.47 \mathrm{E}-20$ & $3.04 \mathrm{E}-19$ \\
\hline 368 & $1.99 \mathrm{E}-11$ & $1.99 \mathrm{E}-11$ & $3.76 \mathrm{E}-21$ & 4.95E-21 & $1.78 \mathrm{E}-23$ & $1.24 \mathrm{E}-20$ & $1.17 \mathrm{E}-19$ \\
\hline 374 & $1.20 \mathrm{E}-11$ & $1.20 \mathrm{E}-11$ & $6.65 \mathrm{E}-21$ & $5.92 \mathrm{E}-21$ & 4.64E-23 & $1.05 \mathrm{E}-20$ & $6.31 \mathrm{E}-20$ \\
\hline 489 & $2.99 \mathrm{E}-11$ & $2.99 \mathrm{E}-11$ & $1.87 \mathrm{E}-19$ & $7.64 \mathrm{E}-20$ & $3.71 \mathrm{E}-21$ & $5.12 \mathrm{E}-20$ & $5.79 \mathrm{E}-20$ \\
\hline
\end{tabular}


Table A6 (Cont.)

\begin{tabular}{|c|c|c|c|c|c|c|c|}
\hline Station & $\begin{array}{l}\mathrm{HgBr}_{2} \\
\mathrm{~mol} / \mathrm{L}\end{array}$ & $\begin{array}{c}\mathrm{HgBrOH} \\
\mathrm{mol} / \mathrm{L}\end{array}$ & $\begin{array}{c}\mathrm{HgCl}_{4}{ }^{2-} \\
\mathrm{mol} / \mathrm{L}\end{array}$ & $\begin{array}{l}\mathrm{HgBr}^{-} \\
\mathrm{mol} / \mathrm{L}\end{array}$ & $\begin{array}{l}\mathrm{HgBr}^{+} \\
\mathrm{mol} / \mathrm{L}\end{array}$ & $\begin{array}{l}\mathrm{HgCl}^{+} \\
\mathrm{mol} / \mathrm{L}\end{array}$ & $\begin{array}{c}\mathrm{HgOH}^{+} \\
\mathrm{mol} / \mathrm{L}\end{array}$ \\
\hline 128 & $2.42 \mathrm{E}-22$ & $3.65 \mathrm{E}-21$ & $1.23 \mathrm{E}-25$ & $2.53 \mathrm{E}-26$ & $1.91 \mathrm{E}-24$ & $1.78 \mathrm{E}-24$ & $3.87 \mathrm{E}-24$ \\
\hline 130 & $1.31 \mathrm{E}-22$ & $9.20 \mathrm{E}-21$ & $9.22 \mathrm{E}-26$ & 4.63E-26 & $3.48 \mathrm{E}-24$ & $2.60 \mathrm{E}-24$ & $9.70 \mathrm{E}-24$ \\
\hline 135 & $1.54 \mathrm{E}-22$ & $4.15 \mathrm{E}-21$ & $3.51 \mathrm{E}-26$ & $3.02 \mathrm{E}-26$ & $2.26 \mathrm{E}-24$ & $1.48 \mathrm{E}-24$ & $4.36 \mathrm{E}-24$ \\
\hline 136 & $6.13 \mathrm{E}-22$ & $6.46 \mathrm{E}-21$ & $3.54 \mathrm{E}-26$ & $8.02 \mathrm{E}-26$ & $5.97 \mathrm{E}-24$ & $3.06 \mathrm{E}-24$ & $6.76 \mathrm{E}-24$ \\
\hline 138 & $3.08 \mathrm{E}-23$ & $3.57 \mathrm{E}-21$ & $1.48 \mathrm{E}-26$ & $1.11 \mathrm{E}-26$ & $8.30 \mathrm{E}-25$ & $5.62 \mathrm{E}-25$ & $3.75 \mathrm{E}-24$ \\
\hline 141 & $1.71 \mathrm{E}-22$ & $3.55 \mathrm{E}-21$ & $5.38 \mathrm{E}-25$ & $3.54 \mathrm{E}-26$ & $2.70 \mathrm{E}-24$ & $3.34 \mathrm{E}-24$ & $3.80 \mathrm{E}-24$ \\
\hline 142 & $1.33 \mathrm{E}-22$ & $2.65 \mathrm{E}-21$ & $1.02 \mathrm{E}-25$ & $1.71 \mathrm{E}-26$ & $1.29 \mathrm{E}-24$ & $1.27 \mathrm{E}-24$ & $2.82 \mathrm{E}-24$ \\
\hline 143 & $4.57 \mathrm{E}-23$ & $2.98 \mathrm{E}-21$ & $2.52 \mathrm{E}-25$ & $1.15 \mathrm{E}-26$ & $8.80 \mathrm{E}-25$ & $1.19 \mathrm{E}-24$ & $3.19 \mathrm{E}-24$ \\
\hline 145 & $1.79 \mathrm{E}-22$ & $5.27 \mathrm{E}-21$ & $3.55 \mathrm{E}-25$ & $2.96 \mathrm{E}-26$ & $2.25 \mathrm{E}-24$ & $2.63 \mathrm{E}-24$ & $5.63 \mathrm{E}-24$ \\
\hline 147 & $1.65 \mathrm{E}-22$ & $1.96 \mathrm{E}-21$ & $1.09 \mathrm{E}-24$ & $2.62 \mathrm{E}-26$ & $2.02 \mathrm{E}-24$ & $3.20 \mathrm{E}-24$ & $2.12 \mathrm{E}-24$ \\
\hline 148 & $4.71 \mathrm{E}-23$ & $3.22 \mathrm{E}-21$ & $2.41 \mathrm{E}-25$ & $1.47 \mathrm{E}-26$ & $1.12 \mathrm{E}-24$ & $1.41 \mathrm{E}-24$ & $3.45 \mathrm{E}-24$ \\
\hline 149 & 7.87E-23 & 4.33E-21 & $2.26 \mathrm{E}-26$ & $1.95 \mathrm{E}-26$ & $1.46 \mathrm{E}-24$ & $9.52 \mathrm{E}-25$ & $4.56 \mathrm{E}-24$ \\
\hline 151 & $2.82 \mathrm{E}-23$ & $2.45 \mathrm{E}-21$ & $3.59 \mathrm{E}-25$ & $7.68 \mathrm{E}-27$ & $5.91 \mathrm{E}-25$ & $9.66 \mathrm{E}-25$ & $2.65 \mathrm{E}-24$ \\
\hline 152 & $1.97 \mathrm{E}-22$ & $2.74 \mathrm{E}-21$ & $2.44 \mathrm{E}-26$ & $3.89 \mathrm{E}-26$ & $2.90 \mathrm{E}-24$ & $1.63 \mathrm{E}-24$ & $2.87 \mathrm{E}-24$ \\
\hline 153 & $2.65 \mathrm{E}-23$ & $3.77 \mathrm{E}-21$ & $8.43 \mathrm{E}-27$ & $9.76 \mathrm{E}-27$ & 7.29E-25 & $4.43 \mathrm{E}-25$ & $3.96 \mathrm{E}-24$ \\
\hline 154 & $6.30 \mathrm{E}-23$ & $6.09 \mathrm{E}-21$ & $5.51 \mathrm{E}-26$ & $2.17 \mathrm{E}-26$ & $1.63 \mathrm{E}-24$ & $1.29 \mathrm{E}-24$ & $6.44 \mathrm{E}-24$ \\
\hline 156 & $3.56 \mathrm{E}-22$ & $3.16 \mathrm{E}-21$ & $1.03 \mathrm{E}-24$ & $6.29 \mathrm{E}-26$ & $4.78 \mathrm{E}-24$ & $6.03 \mathrm{E}-24$ & $3.38 \mathrm{E}-24$ \\
\hline 157 & $3.31 \mathrm{E}-23$ & $1.53 \mathrm{E}-21$ & $3.04 \mathrm{E}-25$ & $8.75 \mathrm{E}-27$ & $6.74 \mathrm{E}-25$ & $1.02 \mathrm{E}-24$ & $1.66 \mathrm{E}-24$ \\
\hline 158 & $5.23 \mathrm{E}-23$ & $2.25 \mathrm{E}-21$ & $1.14 \mathrm{E}-25$ & $1.32 \mathrm{E}-26$ & $1.00 \mathrm{E}-24$ & $1.08 \mathrm{E}-24$ & $2.40 \mathrm{E}-24$ \\
\hline 159 & $6.75 \mathrm{E}-23$ & 2.62E-21 & $4.96 \mathrm{E}-25$ & $1.89 \mathrm{E}-26$ & $1.21 \mathrm{E}-24$ & $1.67 \mathrm{E}-24$ & $2.59 \mathrm{E}-24$ \\
\hline 160 & $2.28 \mathrm{E}-22$ & 4.13E-21 & $6.11 \mathrm{E}-26$ & $4.56 \mathrm{E}-26$ & $3.41 \mathrm{E}-24$ & $2.31 \mathrm{E}-24$ & $4.35 \mathrm{E}-24$ \\
\hline 161 & $6.51 \mathrm{E}-23$ & $3.40 \mathrm{E}-21$ & $1.55 \mathrm{E}-26$ & $1.79 \mathrm{E}-26$ & $1.34 \mathrm{E}-24$ & $8.14 \mathrm{E}-25$ & $3.57 \mathrm{E}-24$ \\
\hline 162 & 7.64E-23 & $3.51 \mathrm{E}-21$ & $1.22 \mathrm{E}-26$ & $1.41 \mathrm{E}-26$ & $1.05 \mathrm{E}-24$ & $6.38 \mathrm{E}-25$ & $3.69 \mathrm{E}-24$ \\
\hline 163 & $8.08 \mathrm{E}-22$ & $3.07 \mathrm{E}-21$ & $1.62 \mathrm{E}-24$ & $1.52 \mathrm{E}-25$ & $6.89 \mathrm{E}-24$ & $7.29 \mathrm{E}-24$ & $2.53 \mathrm{E}-24$ \\
\hline 165 & 7.26E-22 & $4.10 \mathrm{E}-21$ & $1.35 \mathrm{E}-25$ & $1.16 \mathrm{E}-25$ & $8.70 \mathrm{E}-24$ & $5.69 \mathrm{E}-24$ & $4.31 \mathrm{E}-24$ \\
\hline 166 & $3.71 \mathrm{E}-22$ & $2.43 \mathrm{E}-21$ & $5.75 \mathrm{E}-25$ & $5.19 \mathrm{E}-26$ & $3.95 \mathrm{E}-24$ & $4.51 \mathrm{E}-24$ & $2.60 \mathrm{E}-24$ \\
\hline 167 & $8.72 \mathrm{E}-23$ & $2.77 \mathrm{E}-21$ & $7.89 \mathrm{E}-26$ & $2.20 \mathrm{E}-26$ & $1.67 \mathrm{E}-24$ & $1.44 \mathrm{E}-24$ & $2.95 \mathrm{E}-24$ \\
\hline 169 & $8.58 \mathrm{E}-23$ & $2.49 \mathrm{E}-21$ & $5.25 \mathrm{E}-26$ & $2.33 \mathrm{E}-26$ & $1.75 \mathrm{E}-24$ & $1.35 \mathrm{E}-24$ & $2.63 \mathrm{E}-24$ \\
\hline 170 & $1.45 \mathrm{E}-22$ & $3.74 \mathrm{E}-21$ & $3.21 \mathrm{E}-27$ & $2.62 \mathrm{E}-26$ & $1.94 \mathrm{E}-24$ & $7.24 \mathrm{E}-25$ & $3.89 \mathrm{E}-24$ \\
\hline 171 & $6.58 \mathrm{E}-22$ & $4.74 \mathrm{E}-21$ & $2.29 \mathrm{E}-24$ & $1.44 \mathrm{E}-25$ & $6.61 \mathrm{E}-24$ & $7.71 \mathrm{E}-24$ & $3.97 \mathrm{E}-24$ \\
\hline 173 & $6.98 \mathrm{E}-23$ & $2.87 \mathrm{E}-21$ & $9.27 \mathrm{E}-27$ & $1.48 \mathrm{E}-26$ & $1.10 \mathrm{E}-24$ & $6.19 \mathrm{E}-25$ & $3.00 \mathrm{E}-24$ \\
\hline 174 & $9.64 \mathrm{E}-23$ & $2.42 \mathrm{E}-21$ & $1.78 \mathrm{E}-25$ & $2.48 \mathrm{E}-26$ & $1.88 \mathrm{E}-24$ & $1.93 \mathrm{E}-24$ & $2.57 \mathrm{E}-24$ \\
\hline 175 & $1.22 \mathrm{E}-22$ & $3.13 \mathrm{E}-21$ & $2.02 \mathrm{E}-26$ & $3.22 \mathrm{E}-26$ & $2.40 \mathrm{E}-24$ & $1.35 \mathrm{E}-24$ & $3.28 \mathrm{E}-24$ \\
\hline 176 & $5.79 \mathrm{E}-23$ & $2.88 \mathrm{E}-21$ & $3.29 \mathrm{E}-25$ & $1.41 \mathrm{E}-26$ & $1.07 \mathrm{E}-24$ & $1.48 \mathrm{E}-24$ & $3.10 \mathrm{E}-24$ \\
\hline 177 & $1.06 \mathrm{E}-22$ & $2.50 \mathrm{E}-21$ & $2.44 \mathrm{E}-25$ & $1.61 \mathrm{E}-26$ & $1.23 \mathrm{E}-24$ & $1.52 \mathrm{E}-24$ & $2.68 \mathrm{E}-24$ \\
\hline 178 & 4.64E-22 & $4.09 \mathrm{E}-21$ & $1.98 \mathrm{E}-25$ & $8.78 \mathrm{E}-26$ & $6.60 \mathrm{E}-24$ & $5.08 \mathrm{E}-24$ & $4.32 \mathrm{E}-24$ \\
\hline 179 & $2.74 \mathrm{E}-22$ & $1.91 \mathrm{E}-21$ & $5.71 \mathrm{E}-25$ & $5.71 \mathrm{E}-26$ & $2.60 \mathrm{E}-24$ & $2.70 \mathrm{E}-24$ & $1.59 \mathrm{E}-24$ \\
\hline 180 & $2.63 \mathrm{E}-22$ & $2.82 \mathrm{E}-21$ & $1.29 \mathrm{E}-24$ & $3.29 \mathrm{E}-26$ & $2.53 \mathrm{E}-24$ & $3.96 \mathrm{E}-24$ & $3.05 \mathrm{E}-24$ \\
\hline
\end{tabular}




\begin{tabular}{|c|c|c|c|c|c|c|c|}
\hline 181 & $1.88 \mathrm{E}-22$ & $2.82 \mathrm{E}-21$ & $1.03 \mathrm{E}-26$ & $3.42 \mathrm{E}-26$ & $2.54 \mathrm{E}-24$ & $1.19 \mathrm{E}-24$ & $2.95 \mathrm{E}-24$ \\
\hline 182 & $2.36 \mathrm{E}-22$ & $2.30 \mathrm{E}-21$ & $2.03 \mathrm{E}-24$ & $3.29 \mathrm{E}-26$ & $2.54 \mathrm{E}-24$ & $4.44 \mathrm{E}-24$ & $2.49 \mathrm{E}-24$ \\
\hline 183 & $6.34 \mathrm{E}-22$ & $4.30 \mathrm{E}-21$ & $5.52 \mathrm{E}-26$ & $1.25 \mathrm{E}-25$ & $9.32 \mathrm{E}-24$ & 4.79E-24 & $4.51 \mathrm{E}-24$ \\
\hline 184 & $5.14 \mathrm{E}-22$ & $2.76 \mathrm{E}-21$ & $4.98 \mathrm{E}-26$ & $9.44 \mathrm{E}-26$ & 7.04E-24 & $3.78 \mathrm{E}-24$ & $2.90 \mathrm{E}-24$ \\
\hline 185 & $2.15 \mathrm{E}-22$ & 4.12E-21 & $6.22 \mathrm{E}-26$ & 4.64E-26 & $3.48 \mathrm{E}-24$ & $2.35 \mathrm{E}-24$ & $4.33 \mathrm{E}-24$ \\
\hline 186 & $4.18 \mathrm{E}-22$ & $3.68 \mathrm{E}-21$ & $2.46 \mathrm{E}-25$ & $6.87 \mathrm{E}-26$ & $5.18 \mathrm{E}-24$ & 4.48E-24 & $3.90 \mathrm{E}-24$ \\
\hline 187 & $1.77 \mathrm{E}-22$ & $2.14 \mathrm{E}-21$ & $3.71 \mathrm{E}-26$ & $3.19 \mathrm{E}-26$ & $2.39 \mathrm{E}-24$ & $1.56 \mathrm{E}-24$ & $2.25 \mathrm{E}-24$ \\
\hline 188 & $2.13 \mathrm{E}-22$ & $3.13 \mathrm{E}-21$ & $5.55 \mathrm{E}-26$ & 4.15E-26 & $3.11 \mathrm{E}-24$ & $2.10 \mathrm{E}-24$ & $3.29 \mathrm{E}-24$ \\
\hline 190 & $1.82 \mathrm{E}-22$ & $2.47 \mathrm{E}-21$ & $3.59 \mathrm{E}-25$ & $3.82 \mathrm{E}-26$ & $2.91 \mathrm{E}-24$ & $3.19 \mathrm{E}-24$ & $2.65 \mathrm{E}-24$ \\
\hline 191 & $9.57 \mathrm{E}-23$ & $3.33 \mathrm{E}-21$ & $2.19 \mathrm{E}-25$ & $2.84 \mathrm{E}-26$ & $1.79 \mathrm{E}-24$ & $1.83 \mathrm{E}-24$ & $3.25 \mathrm{E}-24$ \\
\hline 192 & $2.12 \mathrm{E}-22$ & $3.30 \mathrm{E}-21$ & $3.70 \mathrm{E}-26$ & $4.28 \mathrm{E}-26$ & $3.20 \mathrm{E}-24$ & $1.94 \mathrm{E}-24$ & $3.47 \mathrm{E}-24$ \\
\hline 193 & $4.55 \mathrm{E}-22$ & $4.29 \mathrm{E}-21$ & 4.93E-26 & $7.87 \mathrm{E}-26$ & $5.88 \mathrm{E}-24$ & $3.29 \mathrm{E}-24$ & $4.51 \mathrm{E}-24$ \\
\hline 194 & $9.96 \mathrm{E}-22$ & $5.01 \mathrm{E}-21$ & $9.78 \mathrm{E}-26$ & $1.33 \mathrm{E}-25$ & $9.91 \mathrm{E}-24$ & $5.78 \mathrm{E}-24$ & $5.26 \mathrm{E}-24$ \\
\hline 195 & $1.24 \mathrm{E}-22$ & $1.84 \mathrm{E}-21$ & $1.83 \mathrm{E}-25$ & $2.32 \mathrm{E}-26$ & $1.76 \mathrm{E}-24$ & $1.85 \mathrm{E}-24$ & $1.97 \mathrm{E}-24$ \\
\hline 197 & $4.49 \mathrm{E}-23$ & $1.99 \mathrm{E}-21$ & $6.83 \mathrm{E}-26$ & $9.50 \mathrm{E}-27$ & $7.21 \mathrm{E}-25$ & $7.41 \mathrm{E}-25$ & $2.12 \mathrm{E}-24$ \\
\hline 198 & $2.62 \mathrm{E}-22$ & $3.64 \mathrm{E}-21$ & $1.82 \mathrm{E}-26$ & $4.11 \mathrm{E}-26$ & $3.07 \mathrm{E}-24$ & $1.58 \mathrm{E}-24$ & $3.81 \mathrm{E}-24$ \\
\hline 199 & $6.71 \mathrm{E}-22$ & $5.76 \mathrm{E}-21$ & $1.04 \mathrm{E}-25$ & $8.98 \mathrm{E}-26$ & $6.72 \mathrm{E}-24$ & 4.39E-24 & $6.07 \mathrm{E}-24$ \\
\hline 200 & $8.28 \mathrm{E}-23$ & $2.65 \mathrm{E}-21$ & $9.18 \mathrm{E}-26$ & $1.88 \mathrm{E}-26$ & $1.42 \mathrm{E}-24$ & $1.32 \mathrm{E}-24$ & $2.82 \mathrm{E}-24$ \\
\hline 202 & $6.48 \mathrm{E}-22$ & $4.28 \mathrm{E}-21$ & $6.21 \mathrm{E}-26$ & $8.40 \mathrm{E}-26$ & $6.29 \mathrm{E}-24$ & $3.67 \mathrm{E}-24$ & $4.51 \mathrm{E}-24$ \\
\hline 203 & $2.01 \mathrm{E}-22$ & $4.41 \mathrm{E}-21$ & $9.99 \mathrm{E}-25$ & $6.54 \mathrm{E}-26$ & $2.00 \mathrm{E}-24$ & $2.19 \mathrm{E}-24$ & $3.04 \mathrm{E}-24$ \\
\hline 204 & $6.55 \mathrm{E}-22$ & $3.06 \mathrm{E}-21$ & $7.60 \mathrm{E}-26$ & $7.55 \mathrm{E}-26$ & $5.65 \mathrm{E}-24$ & $3.56 \mathrm{E}-24$ & $3.22 \mathrm{E}-24$ \\
\hline 206 & $4.89 \mathrm{E}-23$ & $3.50 \mathrm{E}-21$ & $1.52 \mathrm{E}-25$ & $1.08 \mathrm{E}-26$ & $8.22 \mathrm{E}-25$ & $9.98 \mathrm{E}-25$ & $3.75 \mathrm{E}-24$ \\
\hline 207 & $1.03 \mathrm{E}-21$ & $3.93 \mathrm{E}-21$ & $1.69 \mathrm{E}-25$ & $1.68 \mathrm{E}-25$ & $1.26 \mathrm{E}-23$ & 7.95E-24 & $4.13 \mathrm{E}-24$ \\
\hline 208 & $1.90 \mathrm{E}-22$ & $2.53 \mathrm{E}-21$ & $8.73 \mathrm{E}-25$ & $3.72 \mathrm{E}-26$ & $2.85 \mathrm{E}-24$ & $3.93 \mathrm{E}-24$ & $2.73 \mathrm{E}-24$ \\
\hline 210 & $2.48 \mathrm{E}-22$ & $1.95 \mathrm{E}-21$ & $1.28 \mathrm{E}-24$ & $5.06 \mathrm{E}-26$ & $2.32 \mathrm{E}-24$ & $3.04 \mathrm{E}-24$ & $1.64 \mathrm{E}-24$ \\
\hline 212 & $3.49 \mathrm{E}-22$ & $3.80 \mathrm{E}-21$ & $4.79 \mathrm{E}-26$ & $6.49 \mathrm{E}-26$ & $4.85 \mathrm{E}-24$ & $2.83 \mathrm{E}-24$ & $3.99 \mathrm{E}-24$ \\
\hline 213 & $1.51 \mathrm{E}-22$ & $2.44 \mathrm{E}-21$ & $3.87 \mathrm{E}-26$ & $2.88 \mathrm{E}-26$ & $2.16 \mathrm{E}-24$ & $1.46 \mathrm{E}-24$ & $2.57 \mathrm{E}-24$ \\
\hline 214 & $6.46 \mathrm{E}-22$ & $2.59 \mathrm{E}-21$ & $1.73 \mathrm{E}-25$ & $9.89 \mathrm{E}-26$ & 7.43E-24 & $5.38 \mathrm{E}-24$ & $2.74 \mathrm{E}-24$ \\
\hline 215 & $1.57 \mathrm{E}-22$ & $2.39 \mathrm{E}-21$ & $6.55 \mathrm{E}-26$ & $2.57 \mathrm{E}-26$ & $1.94 \mathrm{E}-24$ & $1.54 \mathrm{E}-24$ & $2.53 \mathrm{E}-24$ \\
\hline 217 & $2.09 \mathrm{E}-22$ & $1.86 \mathrm{E}-21$ & $1.77 \mathrm{E}-25$ & $3.63 \mathrm{E}-26$ & $2.74 \mathrm{E}-24$ & $2.56 \mathrm{E}-24$ & $1.97 \mathrm{E}-24$ \\
\hline 218 & $3.21 \mathrm{E}-22$ & $2.97 \mathrm{E}-21$ & $8.83 \mathrm{E}-25$ & 7.19E-26 & $3.28 \mathrm{E}-24$ & $3.59 \mathrm{E}-24$ & $2.48 \mathrm{E}-24$ \\
\hline 219 & $3.23 \mathrm{E}-22$ & $2.12 \mathrm{E}-21$ & $8.90 \mathrm{E}-24$ & $6.67 \mathrm{E}-26$ & $3.13 \mathrm{E}-24$ & $6.18 \mathrm{E}-24$ & $1.82 \mathrm{E}-24$ \\
\hline 220 & 7.64E-22 & $3.27 \mathrm{E}-21$ & $9.74 \mathrm{E}-25$ & $2.68 \mathrm{E}-25$ & $3.64 \mathrm{E}-24$ & $2.52 \mathrm{E}-24$ & $1.50 \mathrm{E}-24$ \\
\hline 221 & $2.48 \mathrm{E}-22$ & $2.55 \mathrm{E}-21$ & $5.02 \mathrm{E}-25$ & $4.53 \mathrm{E}-26$ & $3.44 \mathrm{E}-24$ & $3.94 \mathrm{E}-24$ & $2.73 \mathrm{E}-24$ \\
\hline 223 & $9.75 \mathrm{E}-22$ & $1.22 \mathrm{E}-20$ & $1.78 \mathrm{E}-23$ & $4.66 \mathrm{E}-25$ & 4.19E-24 & $4.88 \mathrm{E}-24$ & $4.64 \mathrm{E}-24$ \\
\hline 224 & $5.37 \mathrm{E}-22$ & $3.97 \mathrm{E}-21$ & $2.97 \mathrm{E}-25$ & $8.31 \mathrm{E}-26$ & $6.27 \mathrm{E}-24$ & $5.41 \mathrm{E}-24$ & $4.21 \mathrm{E}-24$ \\
\hline 225 & $7.61 \mathrm{E}-23$ & $2.22 \mathrm{E}-21$ & $2.00 \mathrm{E}-24$ & $1.96 \mathrm{E}-26$ & $6.12 \mathrm{E}-25$ & $1.07 \mathrm{E}-24$ & $1.55 \mathrm{E}-24$ \\
\hline 227 & $1.50 \mathrm{E}-21$ & $1.61 \mathrm{E}-20$ & $1.85 \mathrm{E}-23$ & $1.13 \mathrm{E}-24$ & $5.79 \mathrm{E}-24$ & $5.06 \mathrm{E}-24$ & $4.63 \mathrm{E}-24$ \\
\hline 229 & $1.62 \mathrm{E}-22$ & $2.22 \mathrm{E}-21$ & $1.83 \mathrm{E}-25$ & $2.55 \mathrm{E}-26$ & $1.93 \mathrm{E}-24$ & $1.99 \mathrm{E}-24$ & $2.37 \mathrm{E}-24$ \\
\hline 230 & $1.07 \mathrm{E}-21$ & $6.15 \mathrm{E}-21$ & $1.94 \mathrm{E}-25$ & $1.45 \mathrm{E}-25$ & $1.09 \mathrm{E}-23$ & 7.35E-24 & $6.48 \mathrm{E}-24$ \\
\hline 233 & $4.36 \mathrm{E}-22$ & $5.84 \mathrm{E}-21$ & $3.38 \mathrm{E}-23$ & $2.00 \mathrm{E}-25$ & $2.27 \mathrm{E}-24$ & $3.91 \mathrm{E}-24$ & $2.52 \mathrm{E}-24$ \\
\hline
\end{tabular}




\begin{tabular}{llllllll}
\hline $\mathbf{2 3 7}$ & $1.74 \mathrm{E}-21$ & $4.14 \mathrm{E}-21$ & $4.75 \mathrm{E}-25$ & $3.54 \mathrm{E}-25$ & $2.66 \mathrm{E}-23$ & $1.80 \mathrm{E}-23$ & $4.37 \mathrm{E}-24$ \\
$\mathbf{2 3 8}$ & $2.30 \mathrm{E}-21$ & $7.39 \mathrm{E}-21$ & $5.12 \mathrm{E}-23$ & $1.62 \mathrm{E}-24$ & $9.25 \mathrm{E}-24$ & $9.65 \mathrm{E}-24$ & $2.25 \mathrm{E}-24$ \\
$\mathbf{2 4 0}$ & $5.49 \mathrm{E}-21$ & $5.61 \mathrm{E}-21$ & $2.14 \mathrm{E}-25$ & $7.13 \mathrm{E}-25$ & $5.30 \mathrm{E}-23$ & $2.47 \mathrm{E}-23$ & $5.86 \mathrm{E}-24$ \\
$\mathbf{2 4 2}$ & $1.14 \mathrm{E}-20$ & $4.10 \mathrm{E}-21$ & $3.72 \mathrm{E}-25$ & $1.89 \mathrm{E}-24$ & $1.40 \mathrm{E}-22$ & $5.90 \mathrm{E}-23$ & $4.27 \mathrm{E}-24$ \\
$\mathbf{2 4 4}$ & $1.76 \mathrm{E}-20$ & $5.84 \mathrm{E}-21$ & $6.43 \mathrm{E}-25$ & $2.14 \mathrm{E}-24$ & $1.59 \mathrm{E}-22$ & $7.42 \mathrm{E}-23$ & $6.10 \mathrm{E}-24$ \\
$\mathbf{2 4 5}$ & $1.22 \mathrm{E}-21$ & $3.96 \mathrm{E}-21$ & $1.98 \mathrm{E}-25$ & $3.17 \mathrm{E}-25$ & $2.36 \mathrm{E}-23$ & $1.32 \mathrm{E}-23$ & $4.15 \mathrm{E}-24$ \\
$\mathbf{2 5 4}$ & $1.30 \mathrm{E}-22$ & $3.15 \mathrm{E}-21$ & $3.59 \mathrm{E}-25$ & $1.76 \mathrm{E}-26$ & $1.35 \mathrm{E}-24$ & $1.79 \mathrm{E}-24$ & $3.38 \mathrm{E}-24$ \\
$\mathbf{2 5 6}$ & $2.90 \mathrm{E}-22$ & $4.35 \mathrm{E}-21$ & $7.74 \mathrm{E}-25$ & $7.36 \mathrm{E}-26$ & $2.90 \mathrm{E}-24$ & $3.00 \mathrm{E}-24$ & $3.38 \mathrm{E}-24$ \\
$\mathbf{2 5 7}$ & $4.40 \mathrm{E}-22$ & $9.98 \mathrm{E}-21$ & $1.80 \mathrm{E}-25$ & $7.10 \mathrm{E}-26$ & $5.33 \mathrm{E}-24$ & $4.23 \mathrm{E}-24$ & $1.05 \mathrm{E}-23$ \\
$\mathbf{2 5 8}$ & $2.63 \mathrm{E}-22$ & $4.51 \mathrm{E}-21$ & $5.74 \mathrm{E}-25$ & $3.26 \mathrm{E}-26$ & $2.48 \mathrm{E}-24$ & $3.19 \mathrm{E}-24$ & $4.83 \mathrm{E}-24$ \\
$\mathbf{3 6 8}$ & $5.89 \mathrm{E}-22$ & $4.31 \mathrm{E}-21$ & $2.83 \mathrm{E}-26$ & $7.73 \mathrm{E}-26$ & $5.75 \mathrm{E}-24$ & $2.82 \mathrm{E}-24$ & $4.51 \mathrm{E}-24$ \\
$\mathbf{3 7 4}$ & $3.36 \mathrm{E}-22$ & $2.85 \mathrm{E}-21$ & $1.10 \mathrm{E}-25$ & $6.27 \mathrm{E}-26$ & $4.70 \mathrm{E}-24$ & $3.40 \mathrm{E}-24$ & $3.00 \mathrm{E}-24$ \\
$\mathbf{4 8 9}$ & $1.80 \mathrm{E}-21$ & $6.64 \mathrm{E}-21$ & $2.60 \mathrm{E}-23$ & $4.82 \mathrm{E}-25$ & $2.23 \mathrm{E}-23$ & $3.53 \mathrm{E}-23$ & $5.63 \mathrm{E}-24$ \\
\hline
\end{tabular}

Table A6 (Cont.)

\begin{tabular}{|c|c|c|c|}
\hline Station & $\mathrm{HgBr}_{4}{ }^{2-} \mathrm{mol} / \mathrm{L}$ & $\mathrm{Hg}(\mathrm{OH})_{3}{ }^{-} \mathrm{mol} / \mathrm{L}$ & $\mathrm{Hg}^{2+} \mathrm{mol} / \mathrm{L}$ \\
\hline 128 & $6.33 \mathrm{E}-31$ & $8.83 \mathrm{E}-27$ & $3.84 \mathrm{E}-28$ \\
\hline 130 & $1.15 \mathrm{E}-30$ & $4.22 \mathrm{E}-26$ & $4.47 \mathrm{E}-28$ \\
\hline 135 & $7.50 \mathrm{E}-31$ & $9.08 \mathrm{E}-27$ & $3.57 \mathrm{E}-28$ \\
\hline 136 & $1.98 \mathrm{E}-30$ & $4.88 \mathrm{E}-27$ & $1.08 \mathrm{E}-27$ \\
\hline 138 & $2.76 \mathrm{E}-31$ & $4.30 \mathrm{E}-26$ & $1.06 \mathrm{E}-28$ \\
\hline 141 & 8.95E-31 & $4.15 \mathrm{E}-27$ & $4.34 \mathrm{E}-28$ \\
\hline 142 & $4.29 \mathrm{E}-31$ & $7.38 \mathrm{E}-27$ & $2.44 \mathrm{E}-28$ \\
\hline 143 & 2.92E-31 & $2.30 \mathrm{E}-26$ & $1.32 \mathrm{E}-28$ \\
\hline 145 & $7.47 \mathrm{E}-31$ & $1.95 \mathrm{E}-26$ & $3.90 \mathrm{E}-28$ \\
\hline 147 & $6.70 \mathrm{E}-31$ & $1.27 \mathrm{E}-27$ & $3.64 \mathrm{E}-28$ \\
\hline 148 & $3.71 \mathrm{E}-31$ & $1.81 \mathrm{E}-26$ & $1.56 \mathrm{E}-28$ \\
\hline 149 & $4.83 \mathrm{E}-31$ & $2.49 \mathrm{E}-26$ & $2.12 \mathrm{E}-28$ \\
\hline 151 & $1.96 \mathrm{E}-31$ & $2.89 \mathrm{E}-26$ & $8.81 \mathrm{E}-29$ \\
\hline 152 & $9.64 \mathrm{E}-31$ & $1.57 \mathrm{E}-27$ & $4.55 \mathrm{E}-28$ \\
\hline 153 & $2.42 \mathrm{E}-31$ & $6.55 \mathrm{E}-26$ & $9.17 \mathrm{E}-29$ \\
\hline 154 & $5.41 \mathrm{E}-31$ & $5.59 \mathrm{E}-26$ & $2.13 \mathrm{E}-28$ \\
\hline 156 & $1.59 \mathrm{E}-30$ & $9.27 \mathrm{E}-28$ & $8.14 \mathrm{E}-28$ \\
\hline 157 & $2.24 \mathrm{E}-31$ & $5.48 \mathrm{E}-27$ & $1.01 \mathrm{E}-28$ \\
\hline 158 & 3.33E-31 & $7.57 \mathrm{E}-27$ & $1.50 \mathrm{E}-28$ \\
\hline 159 & $5.34 \mathrm{E}-31$ & $7.79 \mathrm{E}-27$ & $1.69 \mathrm{E}-28$ \\
\hline 160 & $1.13 \mathrm{E}-30$ & $3.95 \mathrm{E}-27$ & $5.37 \mathrm{E}-28$ \\
\hline 161 & $4.45 \mathrm{E}-31$ & $1.41 \mathrm{E}-26$ & $1.87 \mathrm{E}-28$ \\
\hline 162 & $3.49 \mathrm{E}-31$ & $2.54 \mathrm{E}-26$ & $1.69 \mathrm{E}-28$ \\
\hline 163 & $5.02 \mathrm{E}-30$ & $3.18 \mathrm{E}-28$ & $9.75 \mathrm{E}-28$ \\
\hline 165 & $2.89 \mathrm{E}-30$ & 5.93E-28 & $1.48 \mathrm{E}-27$ \\
\hline
\end{tabular}




\begin{tabular}{|c|c|c|c|}
\hline 166 & $1.31 \mathrm{E}-30$ & $6.21 \mathrm{E}-28$ & $7.28 \mathrm{E}-28$ \\
\hline 167 & $5.53 \mathrm{E}-31$ & $5.10 \mathrm{E}-27$ & $2.46 \mathrm{E}-28$ \\
\hline 169 & $5.82 \mathrm{E}-31$ & $3.30 \mathrm{E}-27$ & $2.48 \mathrm{E}-28$ \\
\hline 170 & $6.43 \mathrm{E}-31$ & $8.88 \mathrm{E}-27$ & $3.09 \mathrm{E}-28$ \\
\hline 171 & $4.82 \mathrm{E}-30$ & $1.31 \mathrm{E}-27$ & $9.07 \mathrm{E}-28$ \\
\hline 173 & 3.67E-31 & $1.25 \mathrm{E}-26$ & $1.69 \mathrm{E}-28$ \\
\hline 174 & $6.22 \mathrm{E}-31$ & $2.69 \mathrm{E}-27$ & $2.75 \mathrm{E}-28$ \\
\hline 175 & $7.98 \mathrm{E}-31$ & $3.42 \mathrm{E}-27$ & $3.39 \mathrm{E}-28$ \\
\hline 176 & $3.57 \mathrm{E}-31$ & $1.41 \mathrm{E}-26$ & $1.64 \mathrm{E}-28$ \\
\hline 177 & 4.07E-31 & $7.01 \mathrm{E}-27$ & $2.20 \mathrm{E}-28$ \\
\hline 178 & $2.19 \mathrm{E}-30$ & $1.03 \mathrm{E}-27$ & $1.06 \mathrm{E}-27$ \\
\hline 179 & $1.89 \mathrm{E}-30$ & $5.49 \mathrm{E}-28$ & $3.58 \mathrm{E}-28$ \\
\hline 180 & $8.40 \mathrm{E}-31$ & $2.41 \mathrm{E}-27$ & $4.95 \mathrm{E}-28$ \\
\hline 181 & $8.44 \mathrm{E}-31$ & $2.23 \mathrm{E}-27$ & $4.08 \mathrm{E}-28$ \\
\hline 182 & $8.42 \mathrm{E}-31$ & $1.30 \mathrm{E}-27$ & $4.82 \mathrm{E}-28$ \\
\hline 183 & $3.09 \mathrm{E}-30$ & $5.92 \mathrm{E}-28$ & $1.46 \mathrm{E}-27$ \\
\hline 184 & $2.34 \mathrm{E}-30$ & $2.76 \mathrm{E}-28$ & $1.13 \mathrm{E}-27$ \\
\hline 185 & $1.15 \mathrm{E}-30$ & $3.76 \mathrm{E}-27$ & $5.32 \mathrm{E}-28$ \\
\hline 186 & $1.72 \mathrm{E}-30$ & $1.23 \mathrm{E}-27$ & 8.88E-28 \\
\hline 187 & 7.92E-31 & $1.12 \mathrm{E}-27$ & $3.89 \mathrm{E}-28$ \\
\hline 188 & $1.03 \mathrm{E}-30$ & $2.07 \mathrm{E}-27$ & 4.93E-28 \\
\hline 190 & $9.66 \mathrm{E}-31$ & $1.21 \mathrm{E}-27$ & $4.66 \mathrm{E}-28$ \\
\hline 191 & $7.93 \mathrm{E}-31$ & 7.09E-27 & $2.40 \mathrm{E}-28$ \\
\hline 192 & $1.06 \mathrm{E}-30$ & $2.28 \mathrm{E}-27$ & $4.99 \mathrm{E}-28$ \\
\hline 193 & $1.95 \mathrm{E}-30$ & $1.49 \mathrm{E}-27$ & $9.67 \mathrm{E}-28$ \\
\hline 194 & $3.29 \mathrm{E}-30$ & $8.30 \mathrm{E}-28$ & $1.79 \mathrm{E}-27$ \\
\hline 195 & $5.85 \mathrm{E}-31$ & $1.36 \mathrm{E}-27$ & $2.93 \mathrm{E}-28$ \\
\hline 197 & $2.39 \mathrm{E}-31$ & $1.01 \mathrm{E}-26$ & $1.14 \mathrm{E}-28$ \\
\hline 198 & $1.02 \mathrm{E}-30$ & $3.31 \mathrm{E}-27$ & $5.22 \mathrm{E}-28$ \\
\hline 199 & $2.23 \mathrm{E}-30$ & $2.76 \mathrm{E}-27$ & $1.22 \mathrm{E}-27$ \\
\hline 200 & $4.71 \mathrm{E}-31$ & $6.14 \mathrm{E}-27$ & $2.18 \mathrm{E}-28$ \\
\hline 202 & $2.09 \mathrm{E}-30$ & $1.29 \mathrm{E}-27$ & $1.15 \mathrm{E}-27$ \\
\hline 203 & $2.72 \mathrm{E}-30$ & $9.56 \mathrm{E}-27$ & $2.14 \mathrm{E}-28$ \\
\hline 204 & $1.88 \mathrm{E}-30$ & $5.83 \mathrm{E}-28$ & $1.08 \mathrm{E}-27$ \\
\hline 206 & $2.73 \mathrm{E}-31$ & $4.29 \mathrm{E}-26$ & $1.30 \mathrm{E}-28$ \\
\hline 207 & $4.18 \mathrm{E}-30$ & $2.48 \mathrm{E}-28$ & $2.13 \mathrm{E}-27$ \\
\hline 208 & $9.46 \mathrm{E}-31$ & $1.36 \mathrm{E}-27$ & $4.74 \mathrm{E}-28$ \\
\hline 210 & $1.69 \mathrm{E}-30$ & 7.46E-28 & $3.28 \mathrm{E}-28$ \\
\hline 212 & $1.61 \mathrm{E}-30$ & $1.51 \mathrm{E}-27$ & $7.79 \mathrm{E}-28$ \\
\hline 213 & $7.18 \mathrm{E}-31$ & $2.04 \mathrm{E}-27$ & $3.47 \mathrm{E}-28$ \\
\hline 214 & $2.47 \mathrm{E}-30$ & $2.07 \mathrm{E}-28$ & $1.30 \mathrm{E}-27$ \\
\hline
\end{tabular}




\begin{tabular}{llll}
\hline $\mathbf{2 1 5}$ & $6.43 \mathrm{E}-31$ & $2.41 \mathrm{E}-27$ & $3.31 \mathrm{E}-28$ \\
$\mathbf{2 1 7}$ & $9.09 \mathrm{E}-31$ & $5.66 \mathrm{E}-28$ & $4.61 \mathrm{E}-28$ \\
$\mathbf{2 1 8}$ & $2.39 \mathrm{E}-30$ & $1.30 \mathrm{E}-27$ & $4.45 \mathrm{E}-28$ \\
$\mathbf{2 1 9}$ & $2.28 \mathrm{E}-30$ & $5.47 \mathrm{E}-28$ & $4.62 \mathrm{E}-28$ \\
$\mathbf{2 2 0}$ & $1.67 \mathrm{E}-29$ & $7.85 \mathrm{E}-28$ & $2.93 \mathrm{E}-28$ \\
$\mathbf{2 2 1}$ & $1.14 \mathrm{E}-30$ & $9.42 \mathrm{E}-28$ & $5.76 \mathrm{E}-28$ \\
$\mathbf{2 2 3}$ & $3.75 \mathrm{E}-29$ & $2.66 \mathrm{E}-26$ & $2.78 \mathrm{E}-28$ \\
$\mathbf{2 2 4}$ & $2.08 \mathrm{E}-30$ & $1.05 \mathrm{E}-27$ & $1.09 \mathrm{E}-27$ \\
$\mathbf{2 2 5}$ & $8.31 \mathrm{E}-31$ & $1.35 \mathrm{E}-26$ & $7.35 \mathrm{E}-29$ \\
$\mathbf{2 2 7}$ & $1.23 \mathrm{E}-28$ & $2.42 \mathrm{E}-26$ & $2.78 \mathrm{E}-28$ \\
$\mathbf{2 2 9}$ & $6.42 \mathrm{E}-31$ & $1.97 \mathrm{E}-27$ & $3.41 \mathrm{E}-28$ \\
$\mathbf{2 3 0}$ & $3.60 \mathrm{E}-30$ & $1.29 \mathrm{E}-27$ & $1.97 \mathrm{E}-27$ \\
$\mathbf{2 3 3}$ & $1.48 \mathrm{E}-29$ & $1.15 \mathrm{E}-26$ & $1.71 \mathrm{E}-28$ \\
$\mathbf{2 3 7}$ & $8.82 \mathrm{E}-30$ & $6.58 \mathrm{E}-29$ & $4.16 \mathrm{E}-27$ \\
$\mathbf{2 3 8}$ & $1.69 \mathrm{E}-28$ & $9.79 \mathrm{E}-28$ & $4.75 \mathrm{E}-28$ \\
$\mathbf{2 4 0}$ & $1.76 \mathrm{E}-29$ & $4.04 \mathrm{E}-29$ & $9.58 \mathrm{E}-27$ \\
$\mathbf{2 4 2}$ & $4.66 \mathrm{E}-29$ & $2.23 \mathrm{E}-30$ & $2.32 \mathrm{E}-26$ \\
$\mathbf{2 4 4}$ & $5.28 \mathrm{E}-29$ & $5.05 \mathrm{E}-30$ & $2.95 \mathrm{E}-26$ \\
$\mathbf{2 4 5}$ & $7.84 \mathrm{E}-30$ & $7.19 \mathrm{E}-29$ & $3.36 \mathrm{E}-27$ \\
$\mathbf{2 5 4}$ & $4.47 \mathrm{E}-31$ & $1.17 \mathrm{E}-26$ & $2.53 \mathrm{E}-28$ \\
$\mathbf{2 5 6}$ & $2.64 \mathrm{E}-30$ & $4.87 \mathrm{E}-27$ & $3.60 \mathrm{E}-28$ \\
$\mathbf{2 5 7}$ & $1.77 \mathrm{E}-30$ & $2.30 \mathrm{E}-26$ & $9.12 \mathrm{E}-28$ \\
$\mathbf{2 5 8}$ & $8.24 \mathrm{E}-31$ & $1.00 \mathrm{E}-26$ & $4.79 \mathrm{E}-28$ \\
$\mathbf{3 6 8}$ & $1.91 \mathrm{E}-30$ & $1.56 \mathrm{E}-27$ & $1.04 \mathrm{E}-27$ \\
$\mathbf{3 7 4}$ & $1.56 \mathrm{E}-30$ & $6.86 \mathrm{E}-28$ & $7.60 \mathrm{E}-28$ \\
$\mathbf{4 8 9}$ & $1.63 \mathrm{E}-29$ & $3.23 \mathrm{E}-28$ & $2.93 \mathrm{E}-27$ \\
\hline
\end{tabular}


VITA

PING JIANG

Born, Qingdao, Shandong, China

2003 - 2007 B.S., in Chemistry

Qingdao University of Science and Technology

Qingdao, Shandong, China

2007 - 2009 M.S., in Biochemistry and molecular biology

Beijing Institute of Technology

Beijing, China

2011 - 2016 Ph.D. candidate in Chemistry

Florida International University

Miami, FL, USA.

Teaching Assistant

Florida International University

Miami, FL, USA.

\section{PUBLICATIONS AND PRESENTATIONS}

1. Jiang, P., Li, Y., Liu, G., et al. (2016) Evaluating the role of re-adsorption of dissolved $\mathrm{Hg}^{2+}$ during cinnabar dissolution using isotope tracer technique, Journal of Hazardous Materials 317, 466-475.

2. Ping Jiang, Yanbin Li, Guangliang Liu, et al. Isotope tracer studies on re-adsorption of dissolved $\mathrm{Hg}^{2+}$ during cinnabar dissolution. Florida Annual Meeting and Exposition (FAME). Tampa, FL USA; May 5-7, 2016

3. Wenbin Cui, Guangliang Liu, Ping Jiang, et al. Methylmercury in food webs in the Everglades: temporal variations over the last two decades. the Greater Everglades Ecosystem Restoration (GEER) Science Conference. Coral Springs, FL USA; April 21-23, 2015

4. Guangliang Liu, Yong Cai, Ping Jiang, et al. Distribution of Mercury in Ecosystem Components in the Everglades: A Mass Budget Perspective the Greater Everglades Ecosystem Restoration (GEER) Science Conference. Coral Springs, FL USA; April 21-23, 2015

5. Ping Jiang, Guangliang Liu, and Yong Cai. Adsorption of $\mathrm{Hg}(\mathrm{II})$ on cinnabar and its role during cinnabar dissolution. The Annual Visitation Day poster presentation. Chemistry department, Fiu; March 7, 2014. 
6. Guidi Yang, Yanbin Li, Ping Jiang, and Yong Cai. Dissolution mechanism of cinnabar in aquatic environments, $9^{\text {th }}$ International Conference on Persistent toxic Substances. Miami, FL; October 23-27, 2012.

7. JIANG Ping, WU Li-Qing, RENA Baktur, LI Qin, HU Xiao-Ming, DAI Rong-Ji, GENG Li-Na, DENG Yu-Lin. Study of Interaction of Fluorescein Sodium and Bovine Serum Albumin by Capillary Electrophoresis / Frontal Analysis and Molecular Modeling Technology[J]. Analytical Chemistry (Chinese), 2011, 39(5): 680-684.

8. Ping Jiang, Liang Hong, Rena Baktur, et al. Fundamental establishment of chip electrophoresis frontal analysis of fluorescein sodium for its interaction with bovine serum albumin. Beijing Conference and Exhibition on Instrumental Analysis (BCEIA). Beijing, China, November 25-28, 2009.

9. Geng Lina, Jiang Ping, Xu Jiandong, et al. Applications of Nanotechnology in Capillary Electrophoresis and Microfluidic Chip Electrophoresis for Biomolecular Separations. PROGRESS IN CHEMISTRY. 2009, 21(9):1905-1921.

10. Jiang Ping, Qu Feng, Tan Xin, et al. The Application of Microfluidic Chip Electrophoresis in Biomolecular Interaction Research. PROGRESS IN CHEMISTRY. 2009, 21(9):1895-1904. 